NUREG-0452

Revision 2

\title{
STANDARD TECHNICAL SPECIFICATIONS FOR WESTINGHOUSE PRESSURIZED WATER REACTORS
}

July 1979

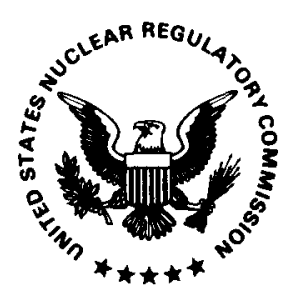

Office of Nuclear Reactor Regulation U. S. Nuclear Regulatory Commission 


\section{DISCLAIMER}

This report was prepared as an account of work sponsored by an agency of the United States Government. Neither the United States Government nor any agency Thereof, nor any of their employees, makes any warranty, express or implied, or assumes any legal liability or responsibility for the accuracy, completeness, or usefulness of any information, apparatus, product, or process disclosed, or represents that its use would not infringe privately owned rights. Reference herein to any specific commercial product, process, or service by trade name, trademark, manufacturer, or otherwise does not necessarily constitute or imply its endorsement, recommendation, or favoring by the United States Government or any agency thereof. The views and opinions of authors expressed herein do not necessarily state or reflect those of the United States Government or any agency thereof. 


\section{DISCLAIMER}

Portions of this document may be illegible in electronic image products. Images are produced from the best available original document. 


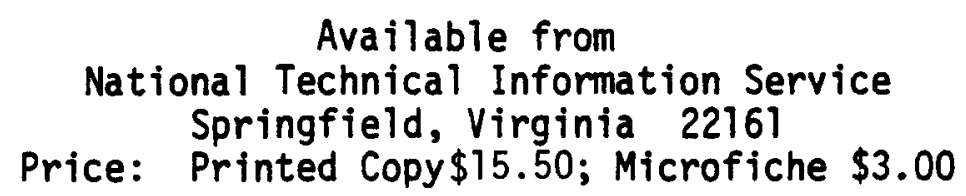




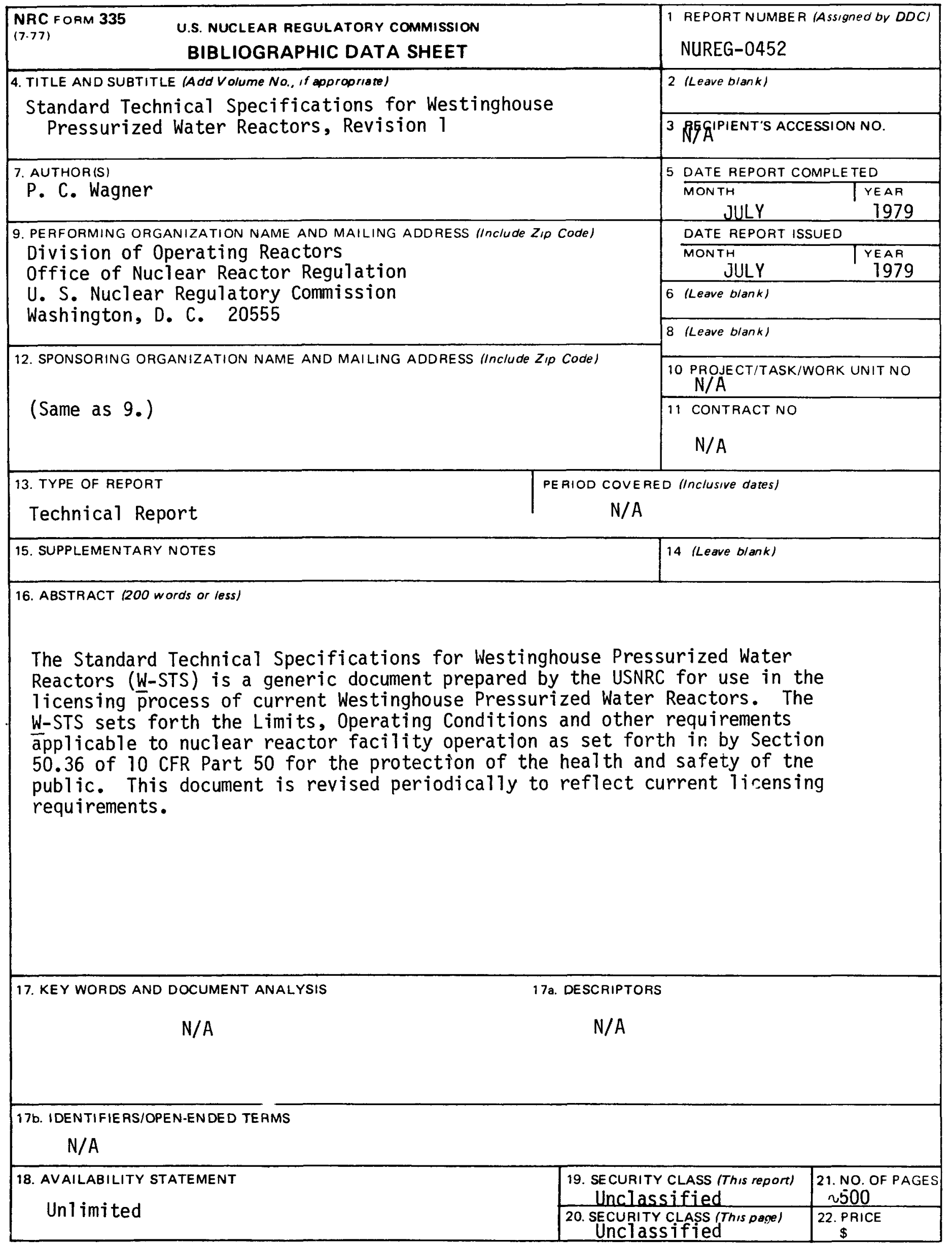




\title{
STANDARD TECHNICAL SPECIFICATIONS FOR WESTINGHOUSE PRESSURIZED WATER REACTORS
}

\author{
Revision of July 1979 \\ Supersedes NUREG-0452, Revision 1
}

Date Published: July 1979

Division of Operating Reactors Office of Nuclear Reactor Regulation U. S. Nuclear Regulatory Commission Washington, D.C. 20555 
STANDARD TECHNICAL SPECIFICATIONS

FOR

WESTINGHOUSE PRESSURIZED WATER REACTORS 
FOREWORD

The following paragraphs briefly describe the applicability, format and implementation of the Westinghouse Standard Technical Specification package.

\section{APPLICABILITY}

This standard Technical Specification (STS) has been structured for the broadest possible use on Westinghouse plants currently being reviewed for an Operating License. Accordingly, the document contains specifications applicable.to.plants with 1) either 3 or 4 loops and 2) with and without loop stop valves. In addition, four separate and discrete containment specification sections are provided for each of the following containment types; Atmospheric, Ice Condenser, Sub-Atmospheric, and Dual. Optional specifications are provided for those features and systems which may be included in individual plant designs but are not generic in their scope of application. Alternate specifications are provided in a limited number of cases to cover situations where alternate specification requirements are necessary on a generic basis because of design differences. This revision of the STS does not typically include requirements which may be added or revised as a result of the NRC staff's further review of the Three Mile Island incident.

\section{FORMAT}

The format of the STS addresses the categories required by 10 CFR and consists of six sections covering the areas of: Definitions, Safety Limits and Limiting Safety System Settings, Limiting Conditions for Operation, Surveillance Requirements, Design Features, and Administrative Controls. The Limiting Conditions for Operation and Surveillance Requirements (Sections 3 \&4) are presented in a combined format with each LCO appearing at the top of the page followed immediately by the applicable Surveillance Requirements. The. combined Section $3 / 4$ is further subdivided into ten subsections covering the areas of:

1. Reactivity Control,

2. Power Distribution,

3. Instrumentation,

4. Reactor coolant System,

5. Emergency Core Cooling System,

6. containment Systems,

7. Plant Systems, 


\section{Electrical}

9. Refueling Operations, and

10. Special Test Exceptions.

The values of those parameters and variables which may vary because of plant design appear as either blanks or parenthesized numbers throughout the STS. The actual value for each parameter will be provided by individual applicants as appropriate for their plants. The values in parentheses are for illustration only.

\section{IMPLEMENTATION}

The implementation of the STS on an individual license application will proceed in three phases. The major steps within each phase are indicated below.

\section{Phase I}

The applicant should:

1. Obtain copies of the STS from the NRC.

2. Select the appropriate containment specification section and set aside the non-applicable containment sections and related bases.

3. Identify and mark those specifications not required because of plant design or other factors. Specifications within this category should be retained in position within the document package for later review and discussion.

4. Identify those areas where specifications are required but are not provided in the STS.

5. Provide the applicable values of the parameters and variables identified by blanks or parentheses in the STS. This information must be consistent with the SAR and other supporting documents.

6. Provide the figures, graphs and other information required to complete the STS document package.

\section{Phase II}

1. The Commission staff will review the information provided in the marked up STS document package resulting from the Phase I preparation. 
2. Applicant/staff meeting will be held to resolve noted differences of position and other related comments from the applicant, vendor and A.E.

Phase III

1. The Commission will provide a Proof and Review edition of the technical specification for final review by all parties based upon the resolution of comments and positions in Phase II.

2. Final comments and corrections will be incorporated into the document as received.

3. The Technical Specifications will be issued by the Commission as Appendix " $\mathrm{A}$ " of the Operating License. 
-
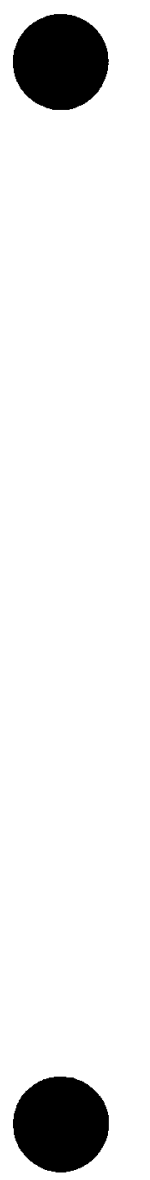
SECTION PAGE

\subsection{DEFINITIONS}

Defined Terms.................................... $1-1$

Thermal Power....................................... $1-1$

Rated Thermal Power................................. $1-1$

Operational Mode.................................. $1-1$

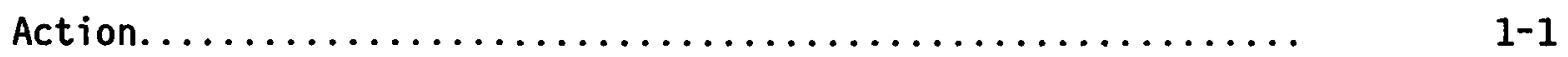

Operable - Operability............................. $1-1$

Reportable Occurrence.............................. 1-2

Containment Integrity.................................

Channel Calibration................................ $1-2$

Channel Check...................................... 1-2

Channel Functional Test............................. $1-3$

Core Alteration................................ 1-3

Shutdown Margin...................................

Identified Leakage.................................. $\quad 1-3$

Unidentified Leakage.............................. $1-4$

Pressure Boundary Leakage............................ 1-4

Controlled Leakage................................. 1-4

Quadrant Power Tilt Ratio............................ $1-4$

Dose Equivalent I-131............................ $1-4$

Staggered Test Basis.................................

Frequency Notation.............................. 1-5

Reactor Trip System Response Time..................... 1-5

Engineered Safety Features Response Time................ 1-5

Axial Flux Difference............................... $1-5$

Physics Tests....................................... $1-5$

E-Average Disintegration Energy...................... $1-5$

Shield Building Integrity........................... 1-6 
2.1 SAFETY LIMITS

2.1.1 REACTOR CORE.................................... 2-1

2.1.2 REACTOR COOLANT SYSTEM PRESSURE.................... $2-1$

\subsection{LIMITING SAFETY SYSTEM SETTINGS}

2.2.1 REACTOR TRIP SYSTEM INSTRUMENTATION SETPOINTS............ 2-4

\subsection{SAFETY LIMITS}

2.1.1 REACTOR CORE................................... B 2 -1

2.1.2 REACTOR COOLANT SYSTEM PRESSURE..................... B 2 .2

\subsection{LIMITING SAFETY SYSTEM SETTINGS}

2.2.1 REACTOR TRIP SYSTEM INSTRUMENTATION SETPOINTS............. B 2-3 


\section{INDEX}

LIMITING CONDITIONS FOR OPERATION AND SURVEILLANCE REQUIREMENTS

SECTION

PAGE

3/4.0 APPLICABILITY.

$3 / 4 \quad 0-1$

3/4.1 REACTIVITY CONTROL SYSTEMS

3/4.1.1 BORATION CONTROL

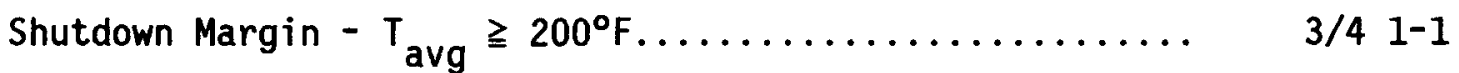

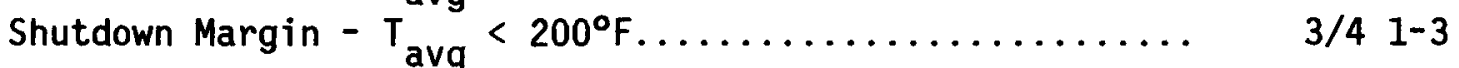

Moderator Temperature Coefficient................. $3 / 4$ 1-4

Minimum Temperature for Criticality................ $3 / 4$ 1-6

3/4.1.2 BORATION SYSTEMS

Flow Paths - Shutdown.......................... $3 / 41-7$

Flow Paths - Operating.......................... $3 / 4$ 1-8

Charging Pump - Shutdown........................ 3/4 1-9

Charging Pumps - Operating...................... $3 / 4$ 1-10

Borated Water Sources - Shutdown.................. 3/4 1-11

Borated Water Sources - Operating................. 3/4 1-12

3/4.1.3 MOVABLE CONTROL ASSEMBLIES

Group Height.............................. $3 / 4$ 1-14

Position Indication Systems - Operating............. 3/4 1-17

Position Indication Systems - Shutdown............. 3/4 1-18

Rod Drop Time.............................. 3/4 1-19

Shutdown Rod Insertion Limit................... $3 / 4$ 1-20

Control Rod Insertion Limits...................... 3/4 1-21

Part Length Rod Insertion Limits.................. 3/4 1-24

Part Length Rod Insertion Limits (Alternate)......... 3/4 1-25 
SECTION

PAGE

3/4.2 POWER DISTRIBUTION LIMITS

3/4.2.1 AXIAL FLUX DIfFERENCE......................... $3 / 4$

3/4.2.2 HEAT FLUX HOT CHANNEL FACTOR.................... $3 / 4$ 2-4

3/4.2.3 RCS FLOW RATE AND R.............................. $3 / 4$ 2-8

3/4.2.4 QUADRANT POWER TILT RATIO...................... $3 / 4$ 2-12

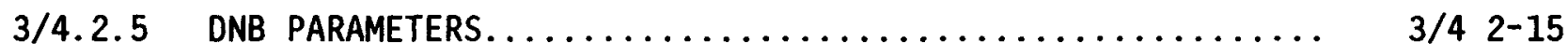

$3 / 4.3$ INSTRUMENTATION

3/4.3.1 REACTOR TRIP SYSTEM INSTRUMENTATION................ $3 / 4$ 3-1

3/4.3.2 ENGINEERED SAFETY FEATURE ACTUATION SYSTEM

INSTRUMENTATION. ............................ $3 / 4,3-16$

3/4.3.3 MONITORING INSTRUMENTATION

Radiation Monitoring......................... 3/4 3-44

Movable Incore Detectors...................... 3/4 3-48

Seismic Instrumentation....................... 3/4 3-49

Meteorological Instrumentation.................... 3/4 3-52

Remote Shutdown Instrumentation.................. 3/4 3-55

Post-Accident Instrumentation................... 3/4 3-58

Chlorine Detection Systems...................... 3/4 3-61

Fire Detection Instrumentation.................. 3/4 3-62

$3 / 4.3 .4$ TURBINE OVERSPEED PROTECTION.................... 3/4 3-64 
SECTION

PAGE

$3 / 4.4$ REACTOR COOLANT SYSTEM

3/4.4.1 REACTOR COOLANT LOOPS

Normal Operation............................. $3 / 4$ 4-1

Isolated Loop................................. $3 / 4$ 4-4

Isolated Loop Startup....................... $3 / 4$ 4-5

3/4.4.2 SAFETY VALVES - SHUTDOWN...................... 3/4 4-6

3/4.4.3 SAFETY VALVES - OPERATING.................... $3 / 4$ 4-7

$3 / 4.4 .4 \quad$ PRESSURIZER................................ $3 / 4$ 4-8

$3 / 4.4 .5 \quad$ STEAM GENERATORS............................. $3 / 4$ 4-9

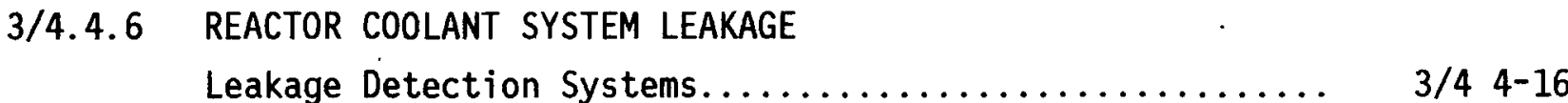

Operational Leakage........................ $3 / 4$ 4-17

$3 / 4.4 .7$ CHEMISTRY................................ 3/4 4-19

3/4.4.8 SPECIFIC ACTIVITY........................... $3 / 4$ 4-22

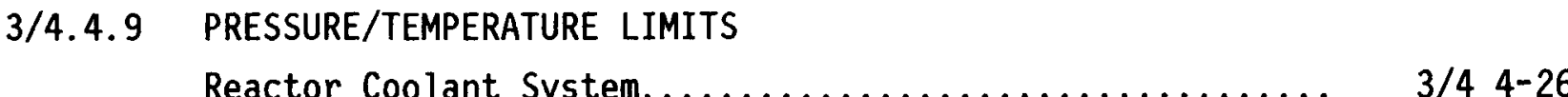

Pressurizer................................ $3 / 4$ 4-29

Overpressure Protection Systems................. 3/4 4-30

3/4.4.10 STRUCTURAL INTEGRITY

ASME Code Class 1,2 and 3 Components............. 3/4 4-32 


\section{INDEX}

SECTION

PAGE

3/4.5 EMERGENCY CORE COOLING SYSTEMS (ECCS)

3/4.5.1 ACCUMULATORS............................... $3 / 4$ 5-1

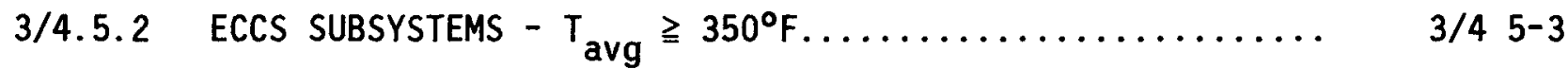

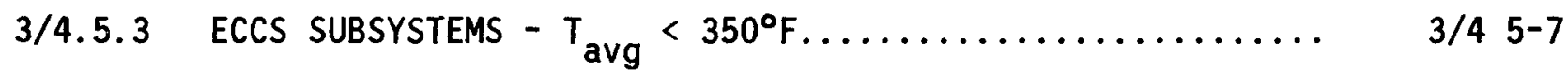

3/4.5.4 BORON INJECTION SYSTEM

Boron Injection Tank........................... 3/4 5-9

Heat Tracing................................. $3 / 4$ 5-10

3/4.5.5 REFUELING WATER STORAGE TANK...................... 3/4 5-11 


\section{INDEX}

SECTION

W - ATMOSPHERIC TYPE CONTAINMENT

$3 / 4.6$ CONTAINMENT SYSTEMS

3/4.6.1 PRIMARY CONTAINMENT

Containment Integrity..................... 3/4 6-1A

Containment Leakage........................ 3/4 6-2A

Containment Air Locks........................ 3/4 6-5A

Containment Isolation Valve and Channel Weld

Pressurization Systems..................... 3/4 6-7A

Internat Pressure......................... 3/4 6-8A

Air Temperature............................... 3/4 6-9A

Containment Structural Integrity................ 3/4 6-10A

Containment Ventilation System................. 3/4 6-17A

3/4.6.2 DEPRESSURIZATION AND COOLING SYSTEMS

Containment Spray System....................... 3/4 6-18A

Spray Additive System....................... 3/4 6-21A

Containment Cooling System................... 3/4 6-22A

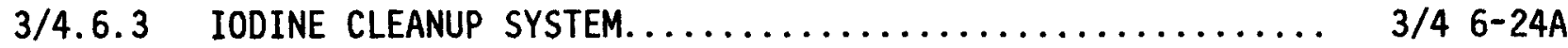

$3 / 4.6 .4$ CONTAINMENT ISOLATION VALVES $\ldots \ldots \ldots \ldots \ldots \ldots \ldots \ldots \ldots \ldots \ldots$ 3/4 6-26A

3/4.6.5 COMBUSTIBLE GAS CONTROL

Hydrogen Analyzers........................ 3/4 6-29A

Electric Hydrogen Recombiners................. 3/4 6-30A

Hydrogen Purge System...................... 3/4 6-31A

Hydrogen Mixing System.................... 3/4 6-33A

3/4.6.6 PENETRATION ROOM EXHAUST AIR CLEANUP SYSTEM.......... $3 / 4$ 6-34A

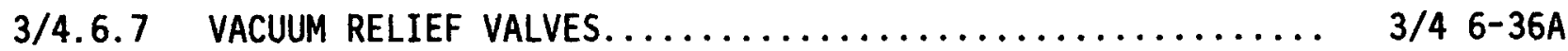


SECTION

3/4.6 CONTAINMENT SYSTEMS

3/4.6.1 PRIMARY CONTAINMENT

Containment Integrity.......................... $3 / 46-1 B$

Containment Leakage........................... 3/4 6-2B

Containment Air Locks........................... 3/4 6-6B

Containment Isolation Valve and Channel Weld

Pressurization Systems......................... $3 / 4$ 6-8B

Internal Pressure.............................. $3 / 4$ 6-9B

Air Temperature.............................. $3 / 4$ 6-10B

Containment Vessel Structural Integrity............. $3 / 4$ 6-11B

Shield Building Structural Integrity............... $3 / 4$ 6-12B

Air Cleanup System........................... $3 / 4$ 6-138

Containment Ventilation System................. $3 / 4$ 6-15B

3/4.6.2 DEPRESSURIZATION AND COOLING SYSTEMS

Containment Spray System....................... $3 / 4$ 6-16B

Spray Additive System......................... $3 / 4$ 6-19B

Containment Cooling System..................... 3/4 6-20B

3/4.6.3 IODINE CLEANUP SYSTEM......................... $3 / 4$ 6-23B

3/4.6.4 CONTAINMENT ISOLATION VALVES.................... $3 / 4$ 6-25B

3/4.6.5 COMBUSTIBLE GAS CONTROL

Hydrogen Analyzers.......................... $3 / 4$ 6-28B

Electric Hydrogen Recombiners................... $3 / 4$ 6-29B

Hydrogen Purge Cleanup System................... $3 / 4$ 6-30B

Hydrogen Mixing System........................ $3 / 4$ 6-32B 


\section{INDEX}

SECTION

PAGE

3/4.6.6 PENETRATION ROOM EXHAUST AIR CLEANUP SYSTEM........... $3 / 4$ 6-33B

3/4.6.7 ICE CONDENSER

Ice Bed................................... $3 / 46-35 B$

Ice Bed Temperature Monitoring System.............. $3 / 4$ 6-37B

Ice Condenser Doors........................... 3/4 6-38B

Inlet Door Position Monitoring System.............. $3 / 4$ 6-40B

Divider Barrier Personne1 Access Doors and

Equipment Hatches........................... $3 / 4 \quad 6-41 B$

Containment Air Recirculation Systems.............. 3/4 6-42B

Floor Drains................................ $3 / 4$ 6-43B

Refueling Canal Drains......................... 3/4 6-44B

Divider Barrier Seal.......................... $3 / 4$ 6-45B

3/4.6.8 VACUUM RELIEF VALVES......................... $3 / 4$ 6-47B 
$\underline{w}$ - SUBATMOSPHERIC TYPE CONTAINMENT

\section{$3 / 4.6$ CONTAINMENT SYSTEMS}

3/4.6.1 PRIMARY CONTAINMENT

Containment Integrity......................... $3 / 4$ 6-1C

Containment Leakage........................... $3 / 4$ 6-2C

Containment Air Locks.......................... $3 / 4$ 6-5C

Containment Isolation Valve and Channel Weld

Pressurization Systems........................ 3/4 6-7C

Internal Pressure............................. $3 / 4$ 6-8C

Air Temperature............................. $3 / 46-10 \mathrm{C}$

Containment Structural Integrity................. $3 / 4$ 6-12C

Containment Ventilation System................... $3 / 4$ 6-19C

3/4.6.2 DEPRESSURIZATION AND COOLING SYSTEMS

Containment Quench Spray System.................. $3 / 4$ 6-20C

Containment Recirculation Spray System............. $3 / 4$ 6-21C

Spray Additive System........................ $3 / 4 \quad 6-22 C$

3/4.6.3 CONTAINMENT ISOLATION VALVES.................... $3 / 46$ 6-23C

3/4.6.4 COMBUSTIBLE GAS CONTROL

Hydrogen Analyzers........................... $3 / 4$ 6-26C

Electric Hydrogen Recombiners................... $3 / 4$ 6-27C

Hydrogen Purge Cleanup System................... $3 / 4$ 6-28C

Hydrogen Mixing System........................ $3 / 4$ 6-30C

3/4.6.5 SUBATMOSPHERIC PRESSURE CONTROL SYSTEM

Steam Jet Air Ejector........................ $3 / 4$ 6-31C

Mechanical Vacuum Pumps........................ $3 / 4$ 6-32C

$3 / 4.6 .6$ VACUUM RELIEF VALVES......................... $3 / 46-33 C$ 


\section{INDEX}

LIMITING CONDITIONS FOR OPERATION AND SURVEILLANCE REQUIREMENTS

SECTION

PAGE

W - DUAL TYPE CONTAINMENT

$3 / 4.6$ CONTAINMENT SYSTEMS

3/4.6.1 PRIMARY CONTAINMENT

Containment Integrity.......................... $3 / 4$ 6-10

Containment Leakage............................ $3 / 4$ 6-20

Containment Air Locks........................... 3/4 6-6D

Containment Isolation Valve and Channel Weld

Pressurization Systems........................ $3 / 4$ 6-8D

Internal Pressure............................. $3 / 4$ 6-9D

Air Temperature.............................. $3 / 4$ 6-10D

Containment Vessel Structural Integrity............. 3/4 6-110

Containment Ventilation System.................. $3 / 4$ 6-12D

3/4.6.2 DEPRESSURIZATION AND COOLING SYSTEMS

Containment Spray System....................... $3 / 4$ 6-130

Spray Additive System......................... $3 / 4$ 6-160

Containment Cooling System.................... 3/4 6-170

$3 / 4.6 .3$ IODINE CLEANUP SYSTEM........................ $3 / 4$ 6-19D

$3 / 4.6 .4$ CONTAINMENT ISOLATION VALVES.................... $3 / 4$ 6-21D

3/4.6.5 COMBUSTIBLE GAS CONTROL

Hydrogen Analyzers........................... 3/4 6-24D

Electric Hydrogen Recombiners................... $3 / 4$ 6-25D

Hydrogen Purge Cleanup System.................... $3 / 4$ 6-260

Hydrogen Mixing System........................ $3 / 4$ 6-28D

3/4.6.6 PENETRATION ROOM EXHAUST AIR CLEANUP SYSTEM........... 3/4 6-29D

$3 / 4.6 .7$ VACUUM RELIEF VALVES...................... 
3/4.6.8 SECONDARY CONTAINMENT

Shield Building Air Cleanup System................. 3/4 6-32D

Shield Building Integrity...................... 3/4 6-34D

Shield Building Structural Integrity.............. 3/4 6-350 


\section{INDEX}

SECTION

PAGE

$3 / 4.7$ PLANT SYSTEMS

3/4.7.1 TURBINE CYCLE

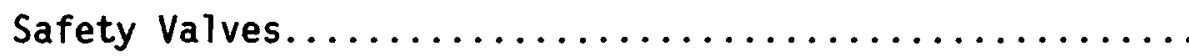

$3 / 47-1$

Auxiliary Feedwater System................... 3/4 7-4

Condensate Storage Tank..................... 3/4 7-6

Activity................................... 3/4 7-7

Main Steam Line Isolation Valves................ 3/4 7-9

3/4.7.2 STEAM GENERATOR PRESSURE/TEMPERATURE LIMITATION....... 3/4 7-10

3/4.7.3 COMPONENT COOLING WATER SYSTEM................ 3/4 7-11

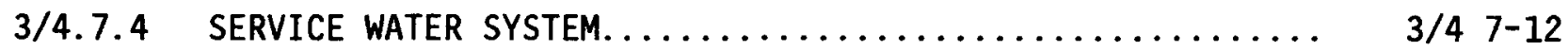

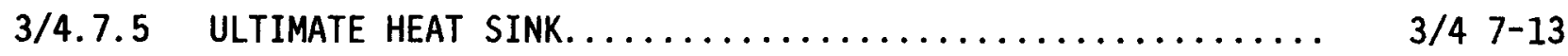

3/4.7.6 FLOOD PROTECTION......................... 3/4 7-14

3/4.7.7 CONTROL ROOM EMERGENCY AIR CLEANUP SYSTEM........... 3/4 7-15

3/4.7.8 ECCS PUMP ROOM EXHAUST AIR CLEANUP SYSTEM........... 3/4 7-17

$3 / 4.7 .9 \quad$ HYDRAULIC SNUBbERS....................... 3/4 7-19

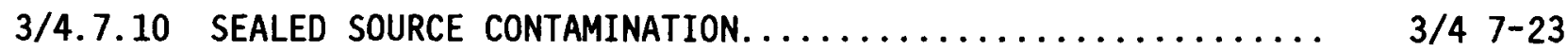


3/4.7.11 FIRE SUPPRESSION SYSTEMS

Fire Suppression Water System.................. $3 / 4 \quad 7-25$

Spray and/or Sprinkler Systems................. 3/4 7-28

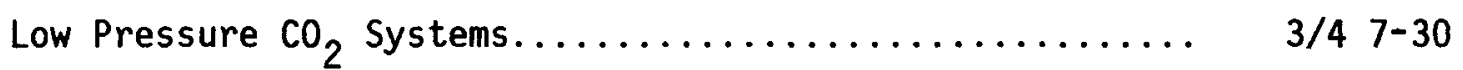

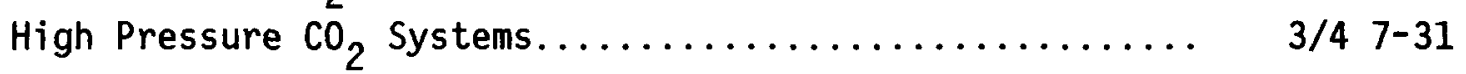

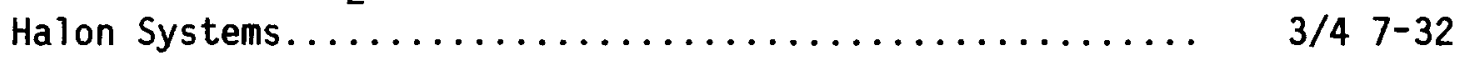

Fire Hose Stations........................... $3 / 4$ 7-33

Yard Fire Hydrants and Hydrant Hose Houses......... 3/4 7-35

3/4.7.12 Fire BARRIER PENETRATIONS...................... 3/4 7-37

$3 / 4.7 .13$ AREA TEMPERATURE MONITORING................... $3 / 4$ 7-38

3/4.8 ELECTRICAL POWER SYSTEMS

3/4.8.1 A.C. SOURCES

Operating................................ $3 / 48$

Shutdown.............................. $3 / 48$

3/4.8.2 ONSITE POWER DISTRIBUTION SYSTEMS

A.C. Distribution - Operating.................. $3 / 4$ 8-9

A.C. Distribution - Shutdown................... $3 / 4$ 8-10

D.C. Distribution - Operating................... $3 / 48-11$

D.C. Distribution - Shutdown................... $3 / 48-13$

3/4.8.3 ELECTRICAL EQUIPMENT PROTECTION DEVICES

Containment Penetration Conductor Overcurrent Protective Devices........................... $3 / 4$ 8-14

Motor-Operated Valves Thermal Overload Protection and/or Bypass Devices.......................... $\quad 3 / 4$ 8-17 


\section{INDEX}

LIMITING CONDITIONS FOR OPERATION AND SURVEILLANCE REQUIREMENTS

SECTION

PAGE

3/4.9 REFUELING OPERATIONS

3/4.9.1 BORON CONCENTRATION........................... 3/4 9-1

3/4.9.2 INSTRUMENTATION.............................. $3 / 4$ 9-2

3/4.9.3 DECAY TIME................................ $3 / 4$ 9-3

3/4.9.4 CONTAinMENT Building Penetrations.................. $3 / 4$ 9-4

3/4.9.5 COMMUNICATIONS............................... 3/4 9-5

3/4.9.6 MANIPULATOR CRANE OPERABILITY..................... 3/4 9-6

3/4.9.7 CRANE TRAVEL - SPENT FUEL STORAGE POOL BUILDING........ $3 / 4$ 9-7

3/4.9.8 COOLANT CIRCULATION............................ 3/4 9-8

3/4.9.9 CONTAINMENT PURGE AND EXHAUST ISOLATION SYSTEM.......... $3 / 4$ 9-9

3/4.9.10 WATER LEVEL - REACTOR VESSEL..................... 3/4 9-10

3/4.9.11 WATER LEVEL - STORAGE POOL ..................... 3/4 9-11

3/4.9.12 STORAGE POOL AIR CLEANUP SYSTEM................... $3 / 4$ 9-12

\section{3/4.10 SPECIAL TEST EXCEPTIONS}

3/4.10.1 SHUTDOWN MARGIN................................ $3 / 4$ 10-1

3/4.10.2 GROUP HEIGHT, INSERTION AND POWER DISTRIBUTION LIMITS.... $3 / 4$ 10-2

$3 / 4.10 .3$ PHYSICS TESTS................................ $3 / 4$ 10-3

$3 / 4.10 .4$ REACTOR COOLANT LOOPS......................... $3 / 4$ 10-4

3/4.10.5 POSITION INDICATOR SYSTEMS - SHUTDOWN.............. $3 / 4$ 10-5

W-STS XI 
3/4.1 REACTIVITY CONTROL SYSTEMS

3/4.1.1 BORATION CONTROL........................... B $3 / 41-1$

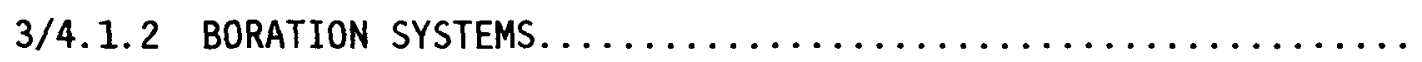

B $3 / 4 \quad 1-2$

3/4.1.3 MOVABLE CONTROL ASSEMBLIES.

B $3 / 4 \quad 1-3$

$3 / 4.2$ POWER DISTRIBUTION LIMITS

$3 / 4.2 .1$ AXIAL FLUX DifferenCE......................... B 3/4 2-1

3/4.2.2 and 3/4.2.3 HEAT FLUX HOT CHANNEL FACTOR, RCS FLOW RATE AND NUCLEAR ENTHALPY RISE HOT CHANNEL FACTOR........... B $3 / 4$ 2-2

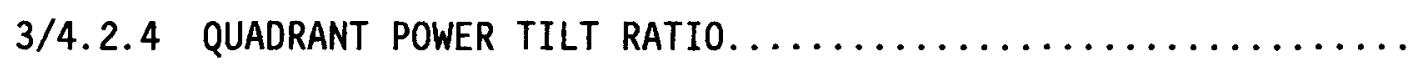

B $3 / 4 \quad 2-5$

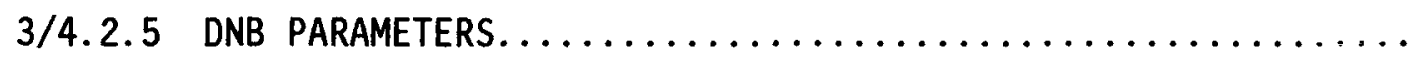

B $3 / 4 \quad 2-5$

3/4. 3 INSTRUMENTATION

3/4.3.1 and 3/4.3.2 REACTOR TRIP AND ENGINEERED SAFETY FEATURE

(ESF) SYSTEMS INSTRUMENTATION.

B $3 / 4$ 3-1

3/4.3.3 MONITORING INSI RUUMENTATION.

B $3 / 4 \quad 3-2$

3/4.3.4 TURBINE OVERSPEED PROTECTION.

B $3 / 4 \quad 3-4$

3/4.4 REACTOR COOLANT SYSTEM

3/4.4.1 REACTOR COOLANT LOOPS...................... B $3 / 4$ 4-1

$3 / 4.4 .2$ and $3 / 4.4 .3$ SAFETY VALVES...................... B $3 / 4$ 4-2

3/4.4.4 PRESSURIZER.......................... B $3 / 4$ 4-2 
SECTION

$\underline{\text { PAGE }}$

3/4.4.5 StEAM GENERATORS............................... B $3 / 4$ 4-3

3/4.4.6 REACTOR COOLANT SYSTEM LEAKAGE.................. B 3/4 4-4

3/4.4.7 CHEMISTRY................................ B $3 / 4$ 4-5

3/4.4.8 SPECIFIC ACTIVITY........................... B $3 / 4$ 4-5

3/4.4.9 PRESSURE/TEMPERATURE LIMITS.................... B 3/4 4-6

$3 / 4.4 .10$ STRUCTURAL INTEGRITY.......................... B $3 / 4$ 4-16

3/4.5 EMERGENCY CORE COOLING SYSTEMS (ECCS)

$3 / 4.5 .1$ ACCUMULATORS................................ B $3 / 4$ 5-1

$3 / 4.5 .2$ and $3 / 4.5 .3$ ECCS SUBSYSTEMS $\ldots \ldots \ldots \ldots \ldots \ldots \ldots \ldots \ldots \ldots \ldots \ldots \ldots \ldots \ldots$ B $3 / 4$ 5-1

3/4.5.4 BORON INJECTION SYSTEM...................... B $3 / 4$ 5-2

3/4.5.5 REFUELING WATER STORAGE TANK (RWST) $\ldots \ldots \ldots \ldots \ldots \ldots \ldots \ldots$ B $3 / 45-2$ 
SECTION

\section{$\underline{W}$ - ATMOSPHERIC TYPE CONTAINMENT}

\section{$3 / 4.6$ CONTAINMENT SYSTEMS}

3/4.6.1 PRIMARY CONTAINMENT.............................. B 3/4 6-1A

3/4.6.2 DEPRESSURIZATION AND COOLING SYSTEMS................ B $3 / 4$ 6-3A

3/4.6.3 IODINE CLEANUP SYSTEM......................... B 3/4 6-4A

$3 / 4.6 .4$ CONTAINMENT ISOLATION VALVES.................... B $3 / 4$ 6-5A

3/4.6.5 COMBUSTIBLE GAS CONTROL......................... B 3/4 6-5A

3/4.6.6 PENETRATION ROOM EXHAUST AIR FILTRATION SYSTEM.......... B $3 / 4$ 6-6A

3/4.6.7 VACUUM RELIEF VALVES........................ B $3 / 4$ 6-6A 
$\underline{\text { INDEX }}$

SECTION

PAGE

$\underline{W}$ - ICE CONDENSER TYPE CONTAINMENT

\section{$3 / 4.6$ CONTAINMENT SYSTEMS}

3/4.6.1 PRIMARY CONTAINMENT........................... B $3 / 4$ 6-1B

3/4.6.2 DEPRESSURIZATION AND COOLING SYSTEMS............... B 3/4 6-3B

3/4.6.3 IODINE CLEANUP SYSTEM.......................... B 3/4 6-5B

3/4.6.4 CONTAINMENT ISOLATION VALVES.................... B $3 / 4$ 6-5B

3/4.6.5 COMBUSTIBLE GAS CONTROL....................... B $3 / 4$ 6-5B

3/4.6.6 PENETRATION ROOM EXHAUST AIR FILTRATION SYSTEM.......... B $3 / 4$ 6-5B

3/4.6.7 ICE CONDENSER............................. B $3 / 4$ 6-6B

$3 / 4.6 .8$ VACUUM RELIEF VALVES......................... B $3 / 4$ 6-7B 
INDEX

SECTION

PAGE

$\underline{W}$ - SUBATMOSPHERIC TYPE CONTAINMENT

$3 / 4.6$ CONTAINMENT SYSTEMS

3/4.6.1 PRIMARY CONTAINMENT.......................... B $3 / 4$ 6-1C

3/4.6.2 DEPRESSURIZATION AND COOLING SYSTEMS............... B $3 / 46$ 6-3C

3/4.6.3 CONTAINMENT ISOLATION VALVES.................... B $3 / 4$ 6-3C

3/4.6.4 COMBUSTIBLE GAS CONTROL....................... B 3/4 6-4C

3/4.6.5 SUBATMOSPHERIC PRESSURE CONTROL SYSTEM................ B $3 / 4$ 6-4C

$3 / 4.6 .6$ VACUUM RELIEF VALVES......................... B $3 / 46$ 6-4C 
SECTION

$$
\text { W - DUAL TYPE CONTAINMENT }
$$

\section{3/4.6 CONTAINMENT SYSTEMS}

3/4.6.1 PRIMARY CONTAINMENT........................... B 3/4 6-1D

3/4.6.2 DEPRESSURIZATION AND COOLING SYSTEMS............... B 3/4 6-3D

$3 / 4.6 .3$ IODINE REMOVAL SYSTEMS....................... B $3 / 4$ 6-4D

3/4.6.4 CONTAINMENT ISOLATION VALVES.................... B $3 / 4$ 6-4D

$3 / 4.6 .5$ COMBUSTIBLE GAS CONTROL....................... B 3/4 6-50

3/4.6.6 PENETRATION ROOM EXHAUST AIR FILTRATION SYSTEM.......... B 3/4 6-5D

$3 / 4.6 .7$ VACUUM RELIEF VALVES......................... $3 / 4$ 6-5D

3/4.6.8 SECONDARY CONTAINMENT......................... B 3/4 6-50 


\section{$3 / 4.7$ PLANT SYSTEMS}

3/4.7.1 TURBINE CYCLE........................... B 3/4 7-1

3/4.7.2 STEAM GENERATOR PRESSURE/TEMPERATURE LIMITATION........ B 3/4 7-3

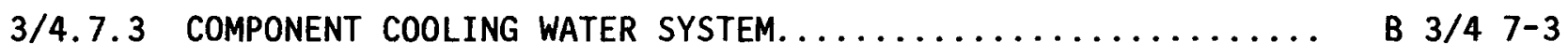

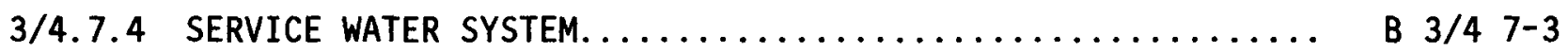

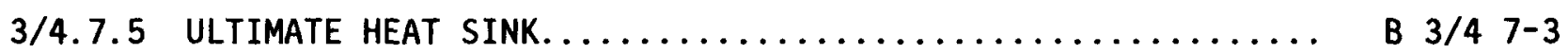

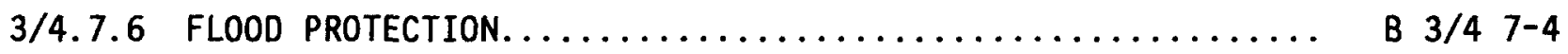

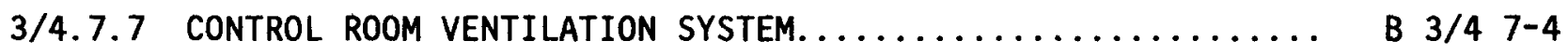

3/4.7.8 ECCS PUMP ROOM EXHAUST AIR FILTRATION SYSTEM.......... B 3/4 7-4

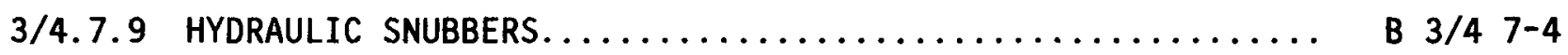

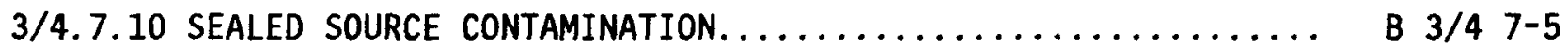

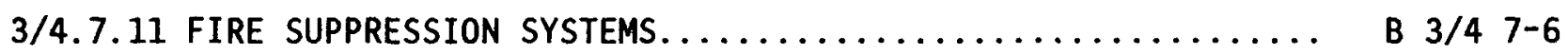

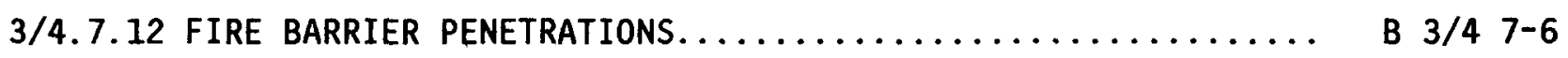

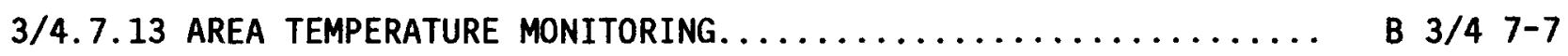

\section{3/4.8 ELECTRICAL POWER SYSTEMS}

3/4.8.1 and 3/4.8.2 A.C. SOURCES AND ONSITE POWER

DISTRIBUTION SYSTEMS....................... B $3 / 4$ 8-1

3/4.8.3 ELECTRICAL EqUIPMENT PROTECTION DEVICES............. B 3/4 8-1 
INDEX

BASES

SECTION

PAGE

3/4.9 REFUELING OPERATIONS

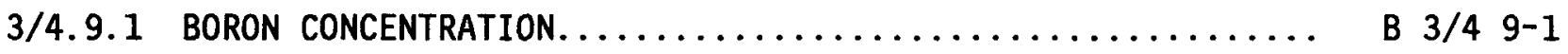

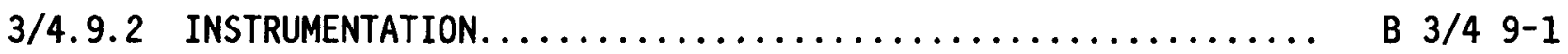

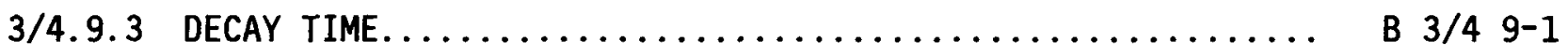

3/4.9.4 CONTAINMENT BUILDING PENETRATIONS................. B 3/4 9-1

$3 / 4.9 .5$ COMMUNICATIONS.......................... B 3/4 9-1

3/4.9.6 MANIPULATOR CRANE OPERABILITY.................. B 3/4 9-1

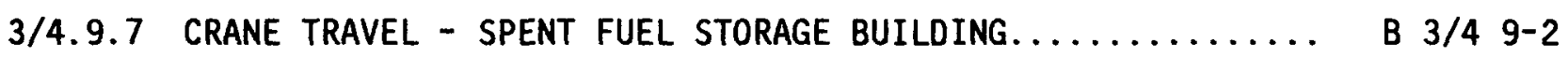

$3 / 4.9 .8$ COOLANT CIRCULATION......................... B $3 / 49-2$

3/4.9.9 CONTAINMENT PURGE AND EXHAUST ISOLATION SYSTEM.......... B 3/4 9-2

3/4.9.10 and 3/4.9.11 WATER LEVEL - REACTOR VESSEL AND STORAGE POOL............................. B $3 / 4$ 9-2

3/4.9.12 STORAGE POOL VENTILATION SYSTEM................. B 3/4 9-2

3/4.10 SPECIAL TEST EXCEPTIONS

$3 / 4.10 .1$ SHUTDOWN MARGIN......................... B 3/4 10-1

3/4.10.2 GROUP HEIGHT, INSERTION AND POWER DISTRIBUTION LIMITS.... B 3/4 10-1

$3 / 4.10 .3$ PHYSICS TESTS........................... B 3/4 10-1

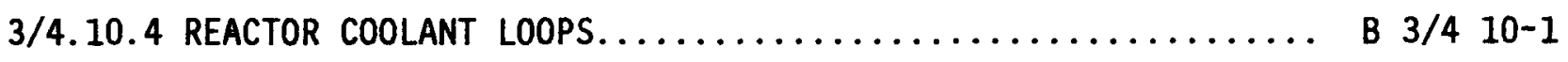

3/4.10.5 POSITION INDICATION SYSTEM - SHUTDOWN............. B 3/4 10-1

W-STS XVI 


\section{INDEX}

SECTION

PAGE

$\underline{5.1 \quad \text { SITE }}$

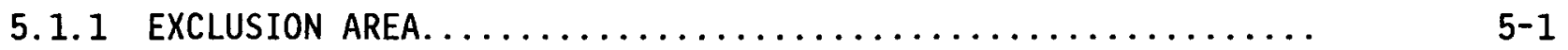

5.1 .2 LOW POPULATION ZONE............................. $5-1$

5.2 CONTAINMENT

5.2 .1 CONFIGURATION..................................

5.2 .2 DESIGN PRESSURE AND TEMPERATURE..................... 5 .1

5.3 REACTOR CORE

5.3.1 FUEL ASSEMBLIES..............................

5.3 .2 CONTROL ROD ASSEMBLIES.......................... $5-4$

5.4 REACTOR COOLANT SYSTEM

5.4.1 DESIGN PRESSURE AND TEMPERATURE.................... 5 .4

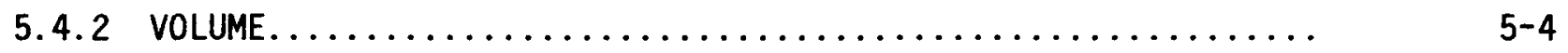

5.5 METEOROLOGICAL TOWER LOCATION.........................

5.6 FUEL STORAGE

5.6 .1 CRITICALITY..................................... $5-5$

5.6 .2 DRAINAGE....................................

5.6 .3 CAPACITY.................................... $5-5$

5.7 COMPONENT CYCLIC OR TRANSIENT LIMIT $\ldots \ldots \ldots \ldots \ldots \ldots \ldots \ldots \ldots \ldots$ 
SECTION

PAGE

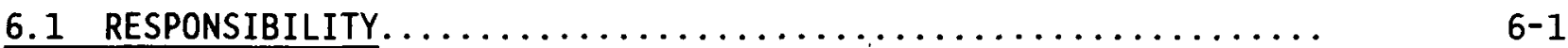

6.2 ORGANIZATION

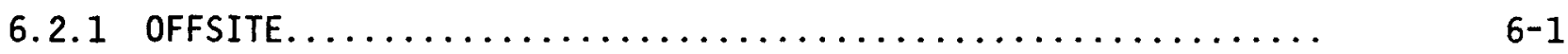

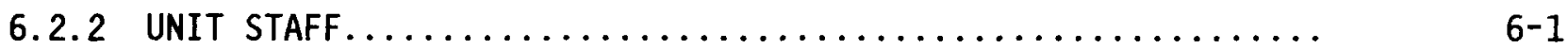

6.3 UNIT STAFF QUALIFICATIONS. . . . . .

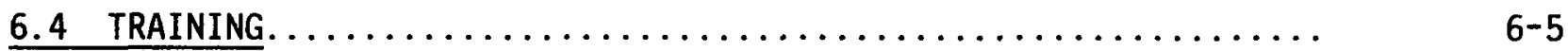

6.5 REVIEW AND AUDIT

6.5.1 UNIT REVIEW GROUP

Function.................................

Composition..................................... $6-6$

Alternates.................................. 6

Meeting Frequency............................ 6

Quorum.................................

Responsibilities.............................. 6-6

Authority..................................

Records......................................

6.5.2 COMPANY NUCLEAR REVIEW AND AUDIT GROUP

Function....................................

Composition.................................... $6-8$

Alternates...................................

Consultants...................................

Meeting Frequency............................ 6

Quorum.................................. 6 


\section{INDEX}

SECTION

PAGE

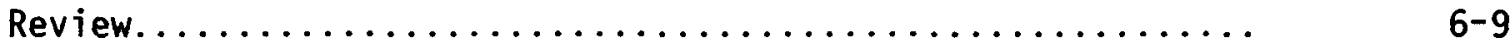

Audits.................................. $6-10$

Authority.............................. 6-10

Records................................. 6 6.11

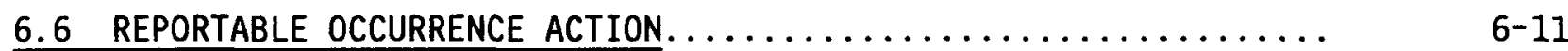

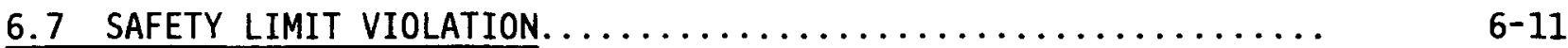

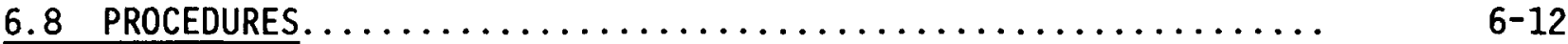

\subsection{REPORTING REQUIREMENTS}

6.9.1 ROUTINE REPORTS AND REPORTABLE OCCURRENCES

Startup Report........................... 6-12

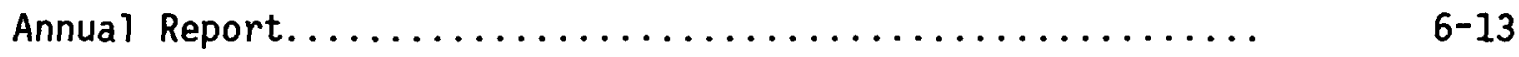

Monthly Operating Report...................... 6-14

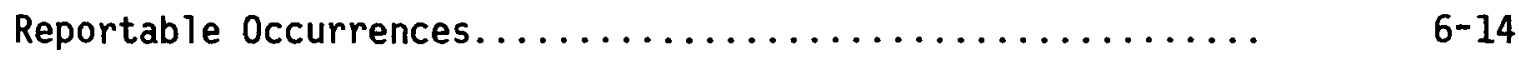

Prompt Notification With Written Followup............. 6-14

Thirty Day Written Reports....................... 6-15

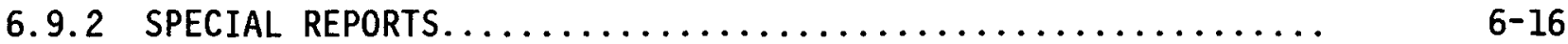

6.10 RECORD RETENTION. ...........................

6.11 RADIATION PROTECTION PROGRAM......................

6.12 HIGH RADIATION AREA. ........................ 
SECTION 1.0

DEF INITIONS 


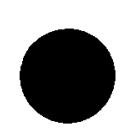

-

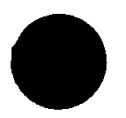


DEFINED TERMS

1.1 The DEFINED TERMS of this section appear in capitalized type and are applicable throughout these Technical Specifications.

\section{THERMAL POWER}

1.2 THERMAL POWER shall be the total reactor core heat transfer rate to the reactor coolant.

RATED THERMAL POWER

1.3 RATED THERMAL POWER shall be a total reactor core heat transfer rate to the reactor coolant of MWt.

\section{OPERATIONAL MODE - MODE}

1.4 An OPERATIONAL MODE (i.e., MODE) shall correspond to any one inclusive combination of core reactivity condition, power level and average reactor coolant temperature specified in Table 1.1 .

\section{$\underline{\text { ACTION }}$}

1.5 ACTION shall be those additional requirements specified as corollary statements to each specification and shall be part of the specifications.

\section{OPERABLE - OPERABILITY}

1.6 A system, subsystem, train, component or device shall be OPERABLE or have OPERABILITY when it is capable of performing its specified function(s).

Implicit in this definition shall be the assumption that all necessary attendant instrumentation, controls, normal and emergency electrical power sources, cooling or seal water, lubrication or other auxiliary equipment that are required for the system, subsystem, train, component or device to perform its function(s) are also capable of performing their related support function(s). 


\section{REPORTABLE OCCURRENCE}

1.7 A REPORTABLE OCCURRENCE shall be any of those conditions specified in Specifications 6.9.1.8 and 6.9.1.9.

\section{CONTAINMENT INTEGRITY}

\subsection{CONTAINMENT INTEGRITY shall exist when:}

a. All penetrations required to be closed during accident conditions are either:

1) Capable of being closed by an OPERABLE containment automatic isolation valve system, or

2) Closed by manual valves, blind flanges, or deactivated automatic valves secured in their closed positions, except as provided in Table (3.6-1) of Specification (3.6.4.1).

b. All equipment hatches are closed and sealed,

c. Each air lock is OPERABLE pursuant to Specification (3.6.1.3),

d. The containment leakage rates are within the limits of Specification (3.6.1.2), and

e. The sealing mechanism associated with each penetration (e.g., welds, bellows or 0-rings) is OPERABLE.

\section{CHANNEL CALIBRATION}

1.9 A CHANNEL CALIBRATION shall be the adjustment, as necessary, of the channel output such that it responds with the necessary range and accuracy to known values of the parameter which the channel monitors. The CHANNEL CALIBRATION shall encompass the entire channel including the sensor and alarm and/or trip functions, and shall include the CHANNEL FUNCTIONAL TEST. The CHANNEL CALIBRATION may be performed by any series of sequential, overlapping or total channel steps such that the entire channel is calibrated.

\section{CHANNEL CHECK}

1.10 A CHANNEL CHECK shall be the qualitative assessment of channel behavior during operation by observation. This determination shall include, where possible, comparison of the channel indication and/or status with other indications and/or status derived from independent instrument channels measuring the same parameter. 
CHANNEL FUNCTIONAL TEST

\subsection{A CHANNEL FUNCTIONAL TEST shal1 be:}

a. Analog channels - the injection of a simulated signal into the channel as close to the sensor as practicable to verify OPERABILITY including alarm and/or trip functions.

b. Bistable channels - the injection of a simulated signal into the sensor to verify OPERABILITY including alarm and/or trip functions.

\section{CORE ALTERATION}

1.12 CORE ALTERATION shall be the movement or manipulation of any component within the reactor pressure vessel with the vessel head removed and fuel in the vessel. Suspension of CORE ALTERATION shall not preclude completion of movement of a component to a safe conservative position.

\section{SHUTDOWN MARGIN}

1.13 SHUTDOWN MARGIN shall be the instantaneous amount of reactivity by which the reactor is subcritical or would be subcritical from its present condition assuming:

a. No change in part length rod position, and

b. All full length rod cluster assemblies (shutdown and control) are fully inserted except for the single rod cluster assembly of highest reactivity worth which is assumed to be fully withdrawn.

\section{IDENTIFIED LEAKAGE}

1.14 IDENTIFIED LEAKAGE shal1 be:

a. Leakage (except CONTROLLED LEAKAGE) into closed systems, such as pump seal or valve packing leaks that are captured and conducted to a sump or collecting tank, or

b. Leakage into the containment atmosphere from sources that are both specifically located and known either not to interfere with the operation of leakage detection systems or not to be PRESSURE BOUNDARY LEAKAGE, or

c. Reactor coolant system leakage through a steam generator to the secondary system. 


\section{UNIDENTIFIED LEAKAGE}

1.15 UNIDENTIFIED LEAKAGE shall be al1 leakage which is not IDENTIFIED LEAKAGE or CONTROLLED LEAKAGE.

\section{PRESSURE BOUNDARY LEAKAGE}

1.16 PRESSURE BOUNDARY LEAKAGE shall be leakage (except steam generator tube leakage) through a non-isolable fault in a Reactor Coolant System component body, pipe wall or vessel wall.

\section{CONTROLLED LEAKAGE}

1.17 CONTROLLED LEAKAGE shall be that seal water flow supplied to the reactor coolant pump seals.

\section{QUADRANT POWER TILT RATIO}

1. 18 QUADRANT POWER TILT RATIO shal1 be the ratio of the maximum upper excore detector calibrated output to the average of the upper excore detector calibrated outputs, or the ratio of the maximum lower excore detector calibrated output to the average of the lower excore detector calibrated outputs, whichever is greater. With one excore detector inoperable, the remaining three detectors shall be used for computing the average.

\section{DOSE EQUIVALENT I-131}

1.19 DOSE EQUIVALENT I-131 shall be that concentration of I-131 (microcurie/ gram) which alone would produce the same thyroid dose as the quantity and isotopic mixture of I-131, I-132, I-133, I-134, and I-135 actually present. The thyroid dose conversion factors used for this calculation shall be those listed in Table III of TID-14844, "Calculation of Distance Factors for Power and Test Reactor Sites."

\section{STAGGERED TEST BASIS}

\subsection{A STAGGERED TEST BASIS shall consist of:}

a. A test schedule for $n$ systems, subsystems, trains or other designated components obtained by dividing the specified test interval into $n$ equal subintervals,

b. The testing of one system, subsystem, train or other designated component at the beginning of each subinterval. 
FREQUENCY NOTATION

1.21 The FREQUENCY NOTATION specified for the performance of Surveillance Requirements shall correspond to the intervals defined in Table 1.2.

\section{REACTOR TRIP SYSTEM RESPONSE TIME}

1.22 The REACTOR TRIP SYSTEM RESPONSE TIME shall be the time interval from when the monitored parameter exceeds its trip setpoint at the channel sensor until loss of stationary gripper coil voltage.

\section{ENGINEERED SAFETY FEATURE RESPONSE TIME}

1.23 The ENGINEERED SAFETY FEATURE RESPONSE TIME shall be that time interval from when the monitored parameter exceeds its ESF actuation setpoint at the channel sensor until the ESF equipment is capable of performing its safety function (i.e., the valves travel to their required positions, pump discharge pressures reach their required values, etc.). Times shall include diesel generator starting and sequence loading delays where applicable.

\section{AXIAL FLUX DIFFERENCE}

1.24 AXIAL FLUX DIFFERENCE shall be the difference in normalized flux signals between the top and bottom halves of a two section excore neutron detector.

\section{PHYSICS TESTS}

1.25 PHYSICS TESTS shall be those tests performed to measure the fundamental nuclear characteristics of the reactor core and related instrumentation and 1) described in Chapter (14.0) of the FSAR, 2) authorized under the provisions of 10 CFR 50.59, or 3) otherwise approved by the Commission.

\section{$\bar{E}$ - AVERAGE DISINTEGRATION ENERGY}

$1.26 \bar{E}$ shall be the average (weighted in proportion to the concentration of each radionuclide in the reactor coolant at the time of sampling) of the sum of the average beta and gamma energies per disintegration (in MeV) for isotopes, other than iodines, with half lives greater than 15 minutes, making up at least $95 \%$ of the total non-iodine activity in the coolant. 


\subsection{SHIELD BUILDING INTEGRITY shall exist when:}

a. Each door in each access opening is closed except when the access opening is being used for normal transit entry and exit, then at least one door shall be closed,

b. The shield building filtration system is OPERABLE, and

c. The sealing mechanism associated with each penetration (e.g., welds, bellows or 0-rings) is OPERABLE. 


\section{TABLE 1.1}

OPERATIONAL MODES

MODE

1. POWER OPERATION

2. STARTUP

3. HOT STANDBY

4. HOT SHUTDOWN

5. COLD SHUTDOWN

6. REFUELING**
REACTIVITY CONDITION, $K_{\text {eff }}$

$\geq 0.99$

$\geq 0.99$

$<0.99$

$<0.99$

$<0.99$

$\leq 0.95$
$\%$ RATED

THERMAL POWER*

$>5 \%$

$\leq 5 \%$

0

0

0

0
AVERAGE COOLANT TEMPERATURE

$\geq 350^{\circ} \mathrm{F}$

$\geq 350^{\circ} \mathrm{F}$

$\geq 350^{\circ} \mathrm{F}$

$350^{\circ} \mathrm{F}>\mathrm{T}_{\text {avg }}$
$>200^{\circ} \mathrm{F}$

$\leq 200^{\circ} \mathrm{F}$

$\leq 140^{\circ} \mathrm{F}$

* Excluding decay heat.

** Reactor vessel head unbolted or removed and fuel in the vessel. 
TABLE 1.2

\section{FREQUENCY NOTATION}

NOTATION

$\mathrm{S}$

D

$W$

$M$

Q

SA

$\mathbf{R}$

$\mathrm{S} / \mathrm{U}$

N.A.

\section{FREQUENCY}

At least once per 12 hours.

At least once per 24 hours.

At least once per 7 days.

At least once per 31 days

At least once per 92 days.

At least once per 184 days.

At least once per 18 months.

Prior to each reactor startup.

Not applicable. 
SECTION 2.0

SAFETY LIMITS

AND

LIMITING SAFETY SYSTEM SETTINGS 
○

-

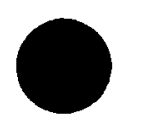




\section{1 SAFETY LIMITS}

\section{REACTOR CORE}

2.1.1 The combination of THERMAL POWER, pressurizer pressure, and the highest operating loop coolant temperature ( $T_{\text {ayg }}$ ) shall not exceed the limits shown in Figures 2.1-1 and 2.1-2 for $n$ and $n-1$ aygop operation, respectively.

APPLICABILITY: MODES 1 and 2.

ACTION:

Whenever the point defined by the combination of the highest operating loop average temperature and THERMAL POWER has exceeded the appropriate pressurizer pressure line, be in HOT STANDBY within 1 hour.

\section{REACTOR COOLANT SYSTEM PRESSURE}

2.1.2 The Reactor Coolant System pressure shall not exceed 2735 psig.

APPLICABILITY: MODES $1,2,3,4$ and 5.

ACTION:

MODES 1 and 2

Whenever the Reactor Coolant System pressure has exceeded 2735 psig, be in HOT STANDBY with the Reactor Coolant System pressure within its limit within 1 hour.

MODES 3,4 and 5

Whenever the Reactor Coolant System pressure has exceeded 2735 psig, reduce the Reactor Coolant System pressure to within its limit within 5 minutes. 


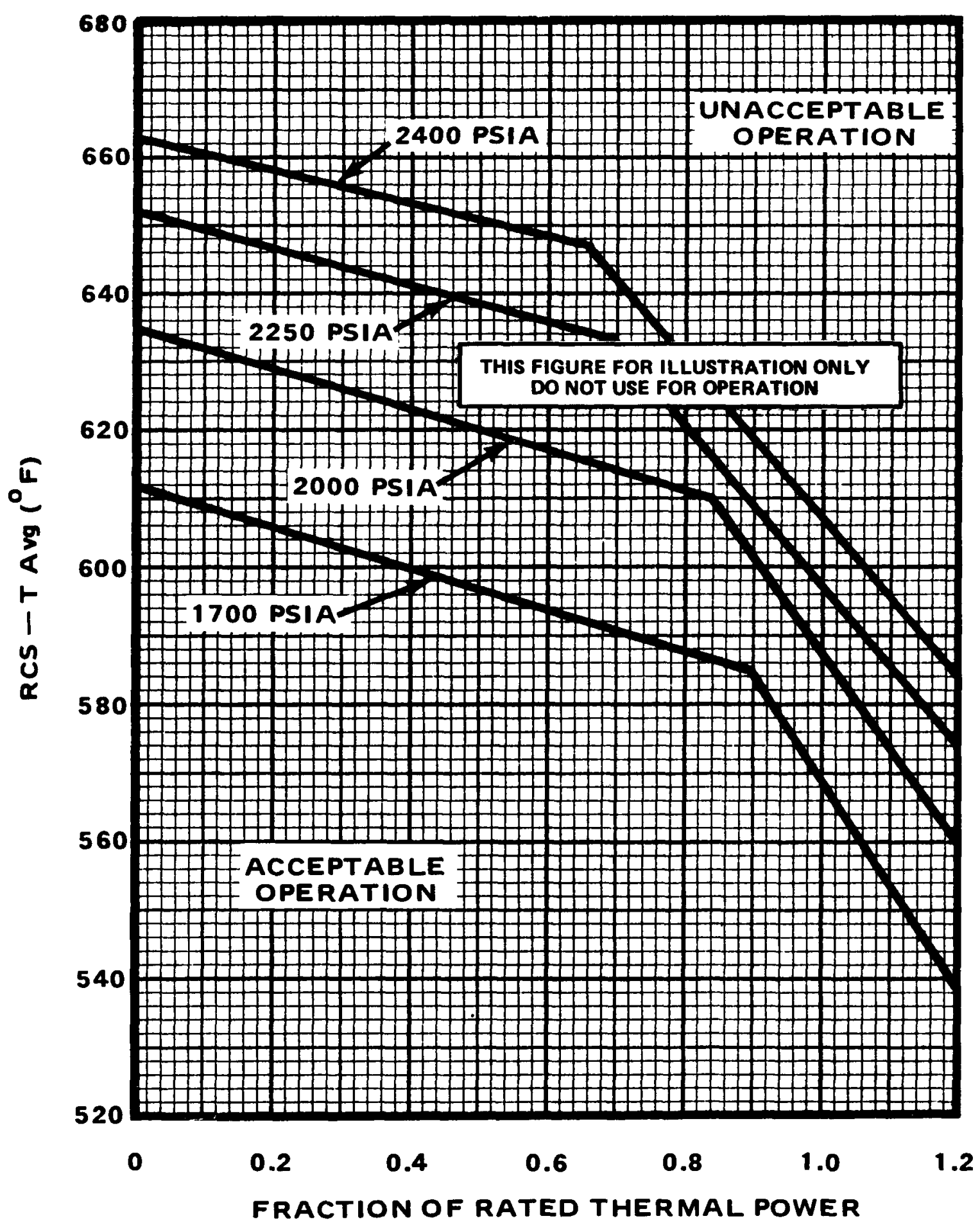

FIGURE 2.1-1

REACTOR CORE SAFETY LIMIT - FOUR LOOPS IN OPERATION 


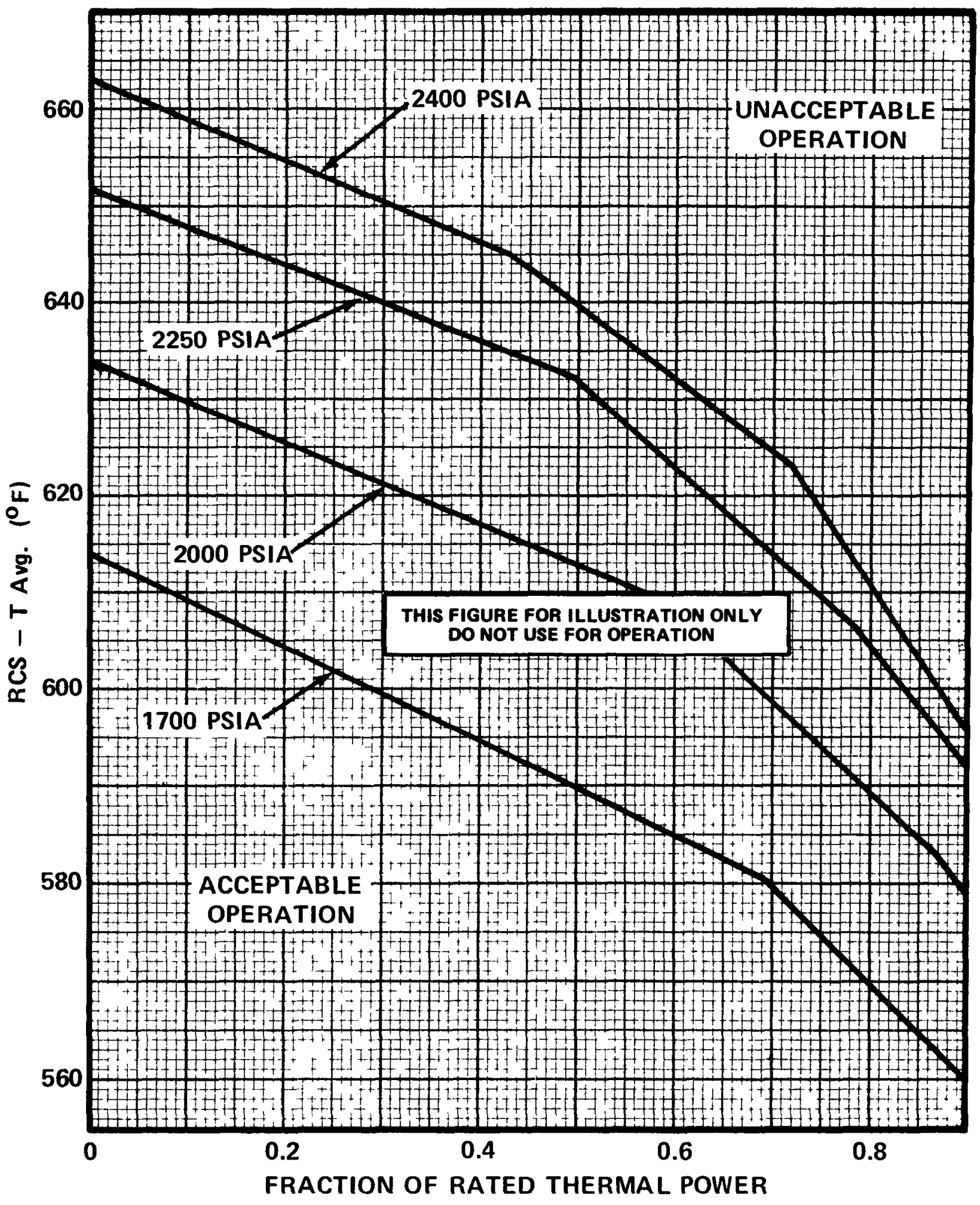

FIGURE 2.1-2

REACTOR CORE SAFETY LIMIT - THREE LOOPS IN OPERATION 


\subsection{LIMITING SAFETY SYSTEM SETTINGS}

\section{REACTOR TRIP SYSTEM INSTRUMENTATION SETPOINTS}

2.2.1 The reactor trip system instrumentation and interlocks setpoints shall be set consistent with the Trip Setpoint values shown in Table 2.2-1.

APPLICABILITY: As shown for each channel in Table 3.3-1.

ACTION:

With a reactor trip system instrumentation or interlock setpoint less conservative than the value shown in the Allowable Values column of Table 2.2-1, declare the channel inoperable and apply the applicable ACTION statement requirement of Specification 3.3.1.1 until the channe 7 is restored to OPERABLE status with its trip setpoint adjusted consistent with the Trip Setpoint value. 


\section{REACTOR TRIP SYSTEM INSTRUMENTATION TRIP SETPOINTS}

\section{FUNCTIONAL UNIT}

1. Manual Reactor Trip

2. Power Range, Neutron Flux

- Power Range, Neutron Flux, High Positive Rate

4. Power Range, Neutron Flux, High Negative Rate

ĩ

5. Intermediate Range, Neutron Flux

6. Source Range, Neutron Flux

7. Overtemperature $\Delta T$

8. Overpower $\Delta \mathrm{T}$

9. Pressurizer Pressure--Low

10. Pressurizer Pressure--High

11. Pressurizer Water Leve1--High

12. Loss of Flow

*Design flow is ( ) gpm per loop.

\section{TRIP SETPOINT}

Not Applicable

Low Setpoint - $\leq(25) \%$ of RATED THERMAL POWER

High Setpoint - $\leq(109) \%$ of RATED THERMAL POWER

$\leq$ (5)\% of RATED THERMAL POWER with a time constant $\geq$ ( 1 ) seconds

$\leq(3) \%$ of RATED THERMAL POWER with a time constant $\geq$ (1) seconds

$\leq(25) \%$ of RATED THERMAL POWER

$\leq\left(10^{5}\right)$ counts per second

See Note 1

See Note 2

$\geq(1865)$ psig

$\leq$ (2385) psig

$\leq(92) \%$ of instrument span

$\geq(90) \%$ of design flow per 10op*

\section{ALLOWABLE VALUES}

Not Applicable

Low Setpoint - $\leq(26) \%$ of RATED THERMAL POWER

High Setpoint - $\leq(110) \%$ of RATED THERMAL POWER

< (5.5)\% of RATED THERMAL POWER with a time constant $\geq$ (1) seconds

( 3.5$) \%$ of RATED THERMAL POWER with a time constant $\geq$ (1) seconds

$\leq(30) \%$ of RATED THERMAL POWER

$\leq\left(1.3 \times 10^{5}\right)$ counts per second

See Note 3

See Note 3

$\geq(1855) \mathrm{psig}$

$\leq$ (2395) psig

$\leq(93) \%$ of instrument span

$\geq(89) \%$ of design flow per loop* 
TABLE 2.2-1 (Continued)

$\underset{\substack{n \\ \text { s }}}{i}$

\section{FUNCTIONAL UNIT}

13. Steam Generator Water Leve1--Low-Low

14. Steam/Feedwater Flow Mismatch and Low Steam Generator Water Level

15. Undervoltage-Reactor Coolant Pumps

16. Underfrequency-Reactor Coolant Pumps

ó

17. Turbine Trip

A. Low Trip System

Pressure

B. Turbine Stop Valve Closure

18. Safety Injection Input from ESF

19. Reactor Coolant Pump Breaker Position Trip

\section{REACTOR TRIP SYSTEM INSTRUMENTATION TRIP SETPOINTS}

\section{TRIP SETPOINT}

$\geq(10 \%)$ of narrow range instrument span-each steam generator

$\leq$ (40\%) of full steam flow at RATED THERMAL POWER coincident with steam generator water level $\geq(25 \%)$ of narrow range instrument span--each steam generator

$\geq(2750)$ volts-each bus

$\geq(57.5) \mathrm{Hz}$ - each bus

$\geq(900)$ psig

$\geq(1 \%)$ open

Not Applicable

Not Applicable

\section{ALLOWABLE VALUES}

$>$ (9\%) of narrow range instrument span-each steam generator

$\leq$ (42.5\%) of full steam flow at RATED THERMAL POWER coincident with steam generator water leve 1 $\geq(24 \%)$ of narrow range instrument span--each steam generator

$\geq(2710)$ volts-each bus

$\geq(57.4) \mathrm{Hz}$ - each bus

$\geq(800)$ psig

$\geq(1 \%)$ open

Not Applicable

Not Applicable 
TABLE 2.2-1 (Continued)

\section{REACTOR TRIP SYSTEM INSTRUMENTATION TRIP SETPOINTS}

FUNCTIONAL UNIT

20. Reactor Trip System Interlocks

A. Intermediate Range Neutron Flux, P-6

B. Low Power Reactor Trips Block, P-7

P-10 Input

$\geq\left(1 \times 10^{-10}\right)$ amps

$<$ (10\%) of RATED

THERMAL POWER

P-13 Input $\leq(10 \%)$ Turbine Impulse Pressure Equivalent

$\leq(30 \%)$ of RATED THERMAL POWER

$\geq(10 \%)$ of RATED THERMAL POWER

E. Turbine Impulse Chamber, $P-73$
< (10\%) Turbine Impulse Pressure Equivalent

\section{ALLOWABLE VALUES}

$\geq\left(6 \times 10^{-11}\right)$ amps

$<$ (11\%) of RATED THERMAL POWER

$\leq$ (11\%) Turbine Impulse Pressure Equivalent

$\leq$ (31\%) of RATED THERMAL POWER

$>$ (9\%) of RATED THERMAL POWER

$<$ (11\%) Turbine Impulse Pressure Equivalent 


\section{REACTOR TRIP SYSTEM INSTRUMENTATION TRIP SETPOINTS}

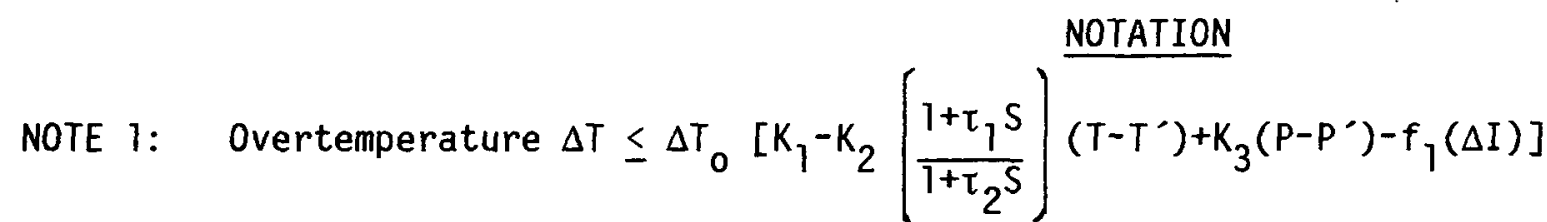

where: $\Delta \mathrm{T}_{0}=$ Indicated $\triangle \mathrm{T}$ at RATED THERMAL POWER

$\mathrm{T}=$ Average temperature, ${ }^{\circ} \mathrm{F}$

$T^{\prime} \leq(576.3)^{\circ} \mathrm{F}$ (Nominal $\mathrm{T}_{\mathrm{avg}}$ at RATED THERMAL POWER)

$\mathrm{P} \quad=$ Pressurizer pressure, $\mathrm{psig}$

$P^{\prime}=(2235)$ psig (Nominal RCS operating pressure)

$\stackrel{1}{1}$

$\frac{1+\tau 1_{1} S}{1+\tau_{2} S}=$ The function generated by the lead-lag controller for $T_{\text {avg }}$ dynamic compensation $\begin{aligned} & \tau_{1} \& \tau_{2}= \text { Time constants utilized in the lead-lag controller for } T_{\text {avg }} \tau_{1}=\text { (33) secs, } \\ & \tau_{2}=(4) \text { secs. }\end{aligned}$ $S=$ Laplace transform operator

Operation with $n$ Loops

$$
\begin{aligned}
& K_{1}=(1.18) \\
& K_{2}=(0.01655) \\
& K_{3}=(0.000801)
\end{aligned}
$$

\section{Operation with $\mathrm{n}-1$ Loops (no loops isolated)}

$$
\begin{aligned}
& K_{1}=(0.99) \\
& K_{2}=(0.01655) \\
& K_{3}=(0.000801)
\end{aligned}
$$

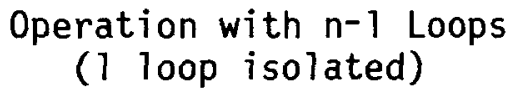

$\mathrm{K}_{1}=(1.1)$

$K_{2}=(0.01655)$

$K_{3}=(0.000801)$

and $f_{1}(\Delta I)$ is a function of the indicated difference between top and bottom detectors of the power-range nuclear ion chambers; with gains to be selected based on measured instrument response during plant startup tests such that: 


\section{REACTOR TRIP SYSTEM INSTRUMENTATION TRIP SETPOINTS}

\section{NOTATION (Continued)}

(i) for $q_{t}-q_{b}$ between $-\left(\right.$ ) percent and $+\left(\right.$ ) percent, $f_{1}(\Delta I)=0$ (where $q_{t}$ and $q_{p}$ are percent RATED THERMAL POWER in the top and bottom halves of the core respectively, and $q_{t}+q_{b}$ is total THERMAL POWER in percent of RATED THERMAL POWER).

(ii) for each percent that the magnitude of $\left(q_{t}-q_{b}\right)$ exceeds $-($ ) percent, the $\Delta \mathrm{T}$ trip setpoint shall be automaticalty reduced by ( ) percent of its value at RATED THERMAL POWER.

(iii) for each percent that the magnitude of $\left(q_{t}-q_{b}\right)$ exceeds +() percent, the $\Delta T$ trip setpoint shall be automaticalty reduced by $($ ) percent of its value at RATED THERMAL POWER.

$\stackrel{\sim}{i}$ Note 2: $\quad$ Overpower $\Delta T \leq \Delta T_{0}\left[K_{4}-K_{5}\left(\frac{\tau_{3} S}{1+\tau_{3} S}\right) T-K_{6}\left(T-T^{\prime \prime}\right)-f_{2}(\Delta I)\right]$

where: $\Delta T_{0}=$ Indicated $\triangle T$ at RATED THERMAL POWER

$\mathrm{T}=$ Average temperature, ${ }^{\circ} \mathrm{F}$

$T^{\prime \prime}=$ Indicated $T_{\text {avg }}$ at RATED THERMAL POWER (Calibration temperature for $\Delta T$ instrumentation, $\leq(576.3)^{\circ} \mathrm{F}$

$K_{4}=(1.07)$

$\mathrm{K}_{5}=\begin{aligned} & \left(0.02 /^{\circ} \mathrm{F}\right) \text { for increasing average temperature and } 0 \text { for decreasing } \\ & \text { average temperature }\end{aligned}$

$K_{6}=\left(0.00128 /^{\circ} \mathrm{F}\right)$ for $T>T^{\prime \prime} ; K_{6}=(0)$ for $T \leq T^{\prime \prime}$

象

$\frac{\tau_{3} S}{1+\tau_{3} S}=$ The function generated by the rate lag controller for $T_{\text {avg }}$ dynamic compensation 
TABLE 2.2-1 (Continued)

\section{REACTOR TRIP SYSTEM INSTRUMENTATION TRIP SETPOINTS}

NOTATION (Continued)

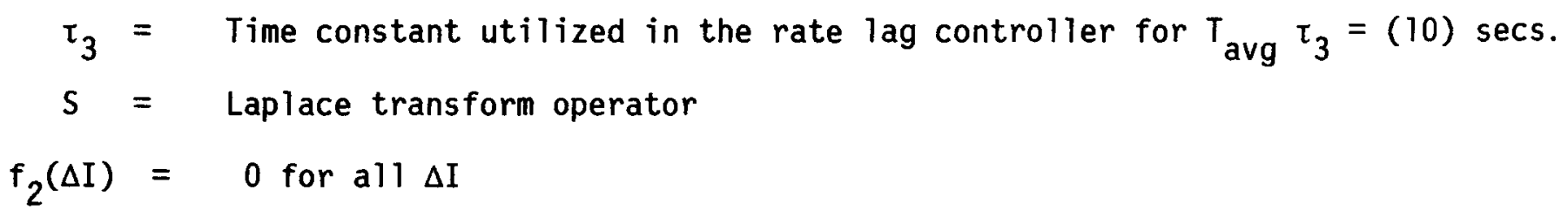

Note 3: The channel's maximum trip point shall not exceed its computed trip point by more than 2 percent.

$\stackrel{\sim}{\stackrel{1}{0}}$

蛋 


\section{BASES}

FOR

SECTION 2.0

SAFETY LIMITS

AND

LIMITING SAFETY SYSTEM SETTINGS 

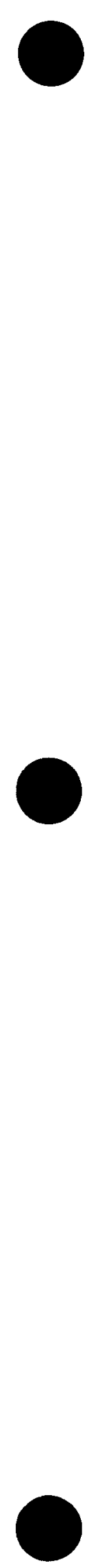
NOTE

The summary statements contained in this section provide the bases for the Specifications of Section 2.0 and are not considered a part of these Technical Specifications as provided in 10 CFR 50.36 . 
-

-

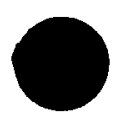




\subsection{SAFETY LIMITS}

BASES

\subsubsection{REACTOR CORE}

The restrictions of this Safety Limit prevent overheating of the fuel and possible cladding perforation which would result in the release of fission products to the reactor coolant. Overheating of the fuel cladding is prevented by restricting fuel operation to within the nucleate boiling regime where the heat transfer coefficient is large and the cladding surface temperature is slightly above the coolant saturation temperature.

Operation above the upper boundary of the nucleate boiling regime could result in excessive cladding temperatures because of the onset of departure from nucleate boiling (DNB) and the resultant sharp reduction in heat transfer coefficient. DNB is not a directly measurable parameter during operation and therefore THERMAL POWER and Reactor Coolant Temperature and Pressure have been related to DNB through the $W-3$ correlation. The $W-3$ DNB correlation has been developed to predict the DNB flux and the location of DNB for axially uniform and non-uniform heat flux distributions. The local DNB heat flux ratio, DNBR, defined as the ratio of the heat flux that would cause DNB at a particular core location to the local heat flux, is indicative of the margin to DNB.

The minimum value of the DNBR during steady state operation, normal operational transients, and anticipated transients is limited to 1.30. This value corresponds to a 95 percent probability at a 95 percent confidence level that DNB will not occur and is chosen as an appropriate margin to ONB for all operating conditions.

The curves of Figures $(2.1-1)$ and $(2.1-2)$ show the loci of points of THERMAL POWER, Reactor Coolant System pressure and average temperature for which the minimum DNBR is no less than 1.30, or the average enthalpy at the vessel exit is equal to the enthalpy of saturated liquid.

These curves are based on an enthalpy hot channel factor, $F_{A H}^{N}$, of 1.55 and a reference cosine with a peak of 1.55 for axial power shape. Ant allowance is included for an increase in $\mathrm{F}_{\Delta H}^{N}$ at reduced power based on the expression:

$$
F_{\Delta H}^{N}=1.55[1+0.2(1-P)]
$$

where $P$ is the fraction of RATED THERMAL POWER

These limiting heat flux conditions are higher than those calculated for the range of all control rods fully withdrawn to the maximum allowable control rod insertion assuming the axial power imbalance is within the limits of the $f_{1}$ (delta I) function of the Overtemperature trip. When the axial power inbalance is not within the tolerance, the axial power imbalance effect on the Overtemperature delta $T$ trips will reduce the setpoints to provide protection consistent with core safety limits. 


\subsubsection{REACTOR COOLANT SYSTEM PRESSURE}

The restriction of this Safety Limit protects the integrity of the Reactor Coolant System from overpressurization and thereby prevents the release of radionuclides contained in the reactor coolant from reaching the containment atmosphere.

The reactor pressure vessel and pressurizer are designed to Section III of the ASME Code for Nuclear Power Plant which permits a maximum transient pressure of $110 \%$ (2735 psig) of design pressure. The Reactor Coolant System piping, valves and fittings, are designed to ANSI B 31.1 Edition,

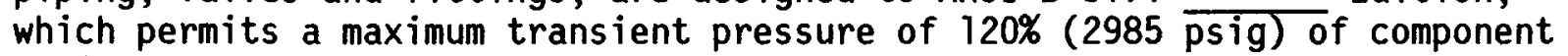
design pressure. The Safety Limit of 2735 psig is therefore consistent with the design criteria and associated code requirements.

The entire Reactor Coolant System is hydrotested at 3107 psig, $125 \%$ of design pressure, to demonstrate integrity prior to initial operation. 


\subsection{LIMITING SAFETY SYSTEM SETTINGS}

BASES

\subsubsection{REACTOR TRIP SYSTEM INSTRUMENTATION SETPOINTS}

The Reactor Trip Setpoint Limits specified in Table 2.2-1 are the values at which the Reactor Trips are set for each functional unit. The Trip Setpoints have been selected to ensure that the reactor core and reactor coolant system are prevented from exceeding their safety limits during normal operation and design basis anticipated operational occurrences and to assist the Engineered Safety Features Actuation System in mitigating the consequences of accidents. Operation with a trip set less conservative than its Trip Setpoint but within its specified Allowable Value is acceptable on the basis that the difference between each Trip Setpoint and the Allowable Value is equal to or less than the drift allowance assumed for each trip in the safety analyses.

\section{Manual Reactor Trip}

The Manual Reactor Trip is a redundant channel to the automatic protective instrumentation channels and provides manual reactor trip capability.

\section{Power Range, Neutron Flux}

The Power Range, Neutron Flux channel high setpoint provides reactor core protection against reactivity excursions which are too rapid to be protected by temperature and pressure protective circuitry. The low set point provides redundant protection in the power range for a power excursion beginning from low power. The trip associated with the low setpoint may be manually bypassed when $\mathrm{p}-10$ is active (two of the four power range channels indicate a power level of above approximately 9 percent of RATED THERMAL POWER) and is automatically reinstated when $P-10$ becomes inactive (three of the four channels indicate a power level below approximately 9 percent of RATED THERMAL POWER).

\section{Power Range, Neutron Flux, High Rates}

The Power Range Positive Rate trip provides protection against rapid flux increases which are characteristic of rod ejection events from any power level. Specifically, this trip complements the Power Range Neutron Flux High and Low trips to ensure that the criteria are met for rod ejection from partial power.

The Power Range Negative Rate trip provides protection to ensure that the minimum DNBR is maintained above 1.30 for control rod drop accidents. At high power a single or multiple rod drop accident could cause local flux peaking which, when in conjunction with nuclear power being maintained equivalent to turbine power by action of the automatic rod control system, could cause an unconservative local DNBR to exist. The Power Range Negative Rate trip will prevent this from occurring by tripping the reactor for all single or multiple dropped rods. 
Intermediate and Source Range, Nučlear Flux

The Intermediate and Source Range, Nuclear Flux trips provide reactor core protection during reactor startup. These trips provide redundant protection to the low setpoint trip of the Power Range, Neutron Flux $+5^{\text {hannels. The }}$ Source Range Channels will initiate a reactor trip at about $10^{+5}$ counts per second unless manually blocked when P- 6 becomes active. The Intermediate Range Channels will initiate a reactor trip at a current level proportional to approximately 25 percent of RATED THERMAL POWER unless manually blocked when p-10 becomes active. No credit was taken for operation of the trips associated with either the Intermediate or Source Range Channels in the accident analyses; however, their functional capability at the specified trip settings is required by this specification to enhance the overall reliability of the Reactor Protection System.

\section{Overtemperature $\Delta T$}

The Overtemperature delta T trip provides core protection to prevent DNB for all combinations of pressure, power, coolant temperature, and axial power distribution, provided that the transient is slow with respect to piping transit delays from the core to the temperature detectors (about 4 seconds), and pressure is within the range between the High and Low Pressure reactor trips. This setpoint includes corrections for changes in density and heat capacity of water with temperature and dynamic compensation for piping delays from the core to the loop temperature detectors. With normal axial power distribution, this reactor trip limit is always below the core safety limit as shown in Figure 2.1-1. If axial peaks are greater than design, as indicated by the difference between top and bottom power range nuclear detectors, the reactor trip is automatically reduced according to the notations in Table 2.2-1.

Operation with a reactor coolant loop out of service below the $(n)$ loop p-8 set point does not require reactor protection system set point modification because the $P-8$ set point and associated trip will prevent DNB during $(n-1)$ loop operation exclusive of the Overtemperature deita T set point. (n-1) loop operation above the $(n)$ loop $P-8$ set point is permissible after resetting the $\mathrm{K} 1, \mathrm{~K} 2$, and $\mathrm{K} 3$ inputs to the Overtemperature delta $\mathrm{T}$ channels and raising the $p-8$ set point to its $(n-1)$ loop value. In this mode of operation, the P-8 interlock and trip functions as a High Neutron Flux trip at the reduced power level. 
LIMITING SAFETY SYSTEM SETTINGS

BASES

Overpower $\Delta T$

The Overpower delta $T$ reactor trip provides assurance of fuel integrity, e.g., no melting, under all possible overpower conditions, limits the required range for Overtemperature delta $T$ protection, and provides a backup to the High Neutron Flux trip. The setpoint includes corrections for axial power distribution, changes in density and heat capacity of water with temperature, and dynamic compensation for piping delays from the core to the loop temperature detectors. No credit was taken for opertion of this trip in the accident analyses; however, its functional capability at the specified trip setting is required by this specification to enhance the overall reliability of the Reactor Protection System.

\section{Pressurizer Pressure}

The Pressurizer High and Low Pressure trips are provided to limit the pressure range in which reactor operation is permitted. The High Pressure trip is backed up by the pressurizer code safety valves for RCS overpressure protection, and is therefore set lower than the set pressure for these valves (2485 psig). The Low Pressure trip provides protection by tripping the reactor in the event of a loss of reactor coolant pressure.

\section{Pressurizer Water Level}

The Pressurizer High Water Level trip ensures protection against Reactor Coolant System overpressurization by limiting the water level to a volume sufficient to retain a steam bubble and prevent water relief through the pressurizer safety valves. No credit was taken for operation of this trip in the accident analyses; however, its functional capability at the specified trip setting is required by this specification to enhance the overall reliability of the Reactor Protection System.

\section{Loss of Flow}

The Loss of Flow trips provide core protection to prevent DNB in the event of a loss of one or more reactor coolant pumps.

Above 11 percent of RATED THERMAL POWER, an automatic reactor trip will occur if the flow in any two loops drop below $89 \%$ of nominal full loop flow. Above (31)\% (P-8) of RATED THERMAL POWER, automatic reactor trip will occur if the flow in any single loop drops below $89 \%$ of nominal full loop flow. This 
latter trip will prevent the minimum value of the DNBR from going below 1.30 during normal operational transients and anticipated transients when $(n-1)$ loops are in operation and the Overtemperature delta $T$ trip set point is adjusted to the value specified for all loops in operation. With the Overtemperature delta $T$ trip set point adjusted to the value specified for $(n-1)$ loop operation, the P-8 trip at (76\%) RATED THERMAL POWER will prevent the minimum value of the DNBR from going below 1.30 during normal operational transients and anticipated transients with (n-1) loops in operation.

\section{Steam Generator Water Level}

The Steam Generator Water Level Low-Low trip provides core protection by preventing operation with the steam generator water level below the minimum volume required for adequate heat removal capacity. The specified setpoint provides allowance that there will be sufficient water inventory in the steam generators at the time of trip to allow for starting delays of the auxiliary feedwater system.

\section{Steam/Feedwater Flow Mismatch and Low Steam Generator Water Level}

The Steam/Feedwater Flow Mismatch in coincidence with a Steam Generator Low Water Level trip is not used in the transient and accident analyses but is included in Table 2.2-1 to ensure the functional capability of the specified trip settings and thereby enhance the overall reliability of the Reactor Protection System. This trip is redundant to the Steam Generator Water Level Low-Low trip. The Steam/Feedwater Flow Mismatch portion of this trip is activated when the steam flow exceeds the feedwater flow by (greater than or equal to $\left(1.42 \times 10^{6}\right)$ 1bs/hour. The Steam Generator Low Water level portion of the trip is activated when the water level drops below (24) percent, as indicated by the narrow range instrument. These trip values include sufficient allowance in excess of normal operating values to preclude spurious trips but will initiate a reactor trip before the steam generators are dry. Therefore, the required capacity and starting time requirements of the auxiliary feedwater pumps are reduced and the resulting thermal transient on the Reactor coolant System and steam generators is minimized.

\section{Undervoltage and Underfrequency - Reactor Coolant Pump Busses}

The Undervoltage and Underfrequency Reactor Coolant Pump bus trips provide reactor core protection against DNB as a result of loss of voltage or underfrequency to more than one reactor coolant pump. The specified set points assure a reactor trip signal is generated before the low flow trip set point 


\section{LIMITING SAFETY SYSTEM SETTINGS}

BASES

is reached. Time delays are incorporated in the underfrequency and undervoltage trips to prevent spurious reactor trips from momentary electrical power transients. For undervoltage, the delay is set so that the time required for a signal to reach the reactor trip breakers following the simultaneous trip of two or more reactor coolant pump bus circuit breakers shall not exceed (0.9) seconds. For underfrequency, the delay is set so that the time required for a signal to reach the reactor trip breakers after the underfrequency trip set point is reached shall not exceed ( 0.3$)$ seconds.

\section{Turbine Trip}

A Turbine Trip causes a direct reactor trip when operating above $\mathrm{P}-7$. Each of the turbine trips provide turbine protection and reduce the severity of the ensuing transient. No credit was taken in the accident analyses for operation of these trips. Their functional capability at the specified trip settings is required to enhance the overall reliability of the Reactor Protection System.

\section{Safety Injection Input from ESF}

If a reactor trip has not already been generated by the reactor protective instrumentation, the ESF automatic actuation logic channels will initiate a reactor trip upon any signal which initiates a safety injection. This trip is provided to protect the core in the event of a LOCA. The ESF instrumentation channels which initiate a safety injection signal are shown in Table 3. 3-3.

\section{Reactor Coolant Pump Breaker Position Trip}

The Reactor Coolant Pump Breaker Position Trips are anticipatory trips which provide reactor core protection against DNB resulting from the opening of any one pump breaker above $\mathrm{P}-8$ or the opening of two or more pump breakers below $\mathrm{P}-8$. These trips are blocked below $\mathrm{P}-7$. The open/close position trips assure a reactor trip signal is generated before the low flow trip set point is reached. No credit was taken in the accident analyses for operation of these trips. Their functional capability at the open/close position settings is required to enhance the overall reliability of the Reactor Protection System. 
Reactor Trip System Interlocks

The Reactor Trip System Interlocks perform the following functions on increasing power:

P-6 Allows the manual block of the source range reactor trip (i.e., prevents premature block of source range trip).

P-7 Defeats the automatic block of reactor trip on: Low flow in more than one primary coolant loop, reactor coolant pump breaker open, undervoltage and underfrequency, turbine trip, pressurizer low pressure, and pressurizer high level.

P-8 Defeats the automatic block of reactor trip on low RCS coolant flow in a single loop.

P-10 Allows the manual block of reactor trip on power range (low setpoint) and intermediate range. Allows manual block of intermediate range rod stops and provides an automatic, backup block for the Source Range. Provides input to $\mathrm{P}-7$.

P-13 Provides input to $P-7$.

On decreasing power the opposite function is performed.

The interlock setpoints are listed in Table 2.2-1. 
SECTIONS 3.0 AND 4.0

LIMITING CONDITIONS FOR OPERATION

AND

SURVEILLANCE REQUIREMENTS 


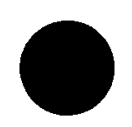

-

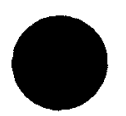




\section{3/4 LIMITING CONDITIONS FOR OPERATION AND SURVEILLANCE REQUIREMENTS}

\section{$3 / 4.0 \quad$ APPLICABILITY}

\section{LIMITING CONDITION FOR OPERATION}

3.0.1 Limiting Conditions for Operation and ACTION requirements shall be applicable during the OPERATIONAL MODES or other conditions specified for each specification.

3.0.2 Adherence to the requirements of the Limiting Condition for Operation and/or associated ACTION within the specified time interval shall constitute compliance with the specification. In the event the Limiting Condition for Operation is restored prior to expiration of the specified time interval, completion of the ACTION statement is not required.

3.0.3 In the event a Limiting Condition for Operation and/or associated ACTION requirements cannot be satisfied because of circumstances in excess of those addressed in the specification, the unit shall be placed in at least HOT STANDBY within 1 hour, in at least HOT SHUTDOWN within the next 6 hours, and in at least COLD SHUTDOWN within the following 24 hours unless corrective measures are completed that permit operation under the permissible ACTION statements for the specified time interval as measured from initial discovery or until the reactor is placed in a MODE in which the specification is not applicable. Exceptions to these requirements shall be stated in the individual specifications.

3.0.4 Entry into an OPERATIONAL MODE or other specified applicability condition shall not be made unless the conditions of the Limiting Condition for Operation are met without reliance on provisions contained in the ACTION statements unless otherwise excepted. This provision shall not prevent passage through OPERATIONAL MODES as required to comply with ACTION statements.

SURVEILLANCE REQUIREMENTS

4.0.1 Surveillance Requirements shall be applicable during the OPERATIONAL MODES or other conditions specified for individual Limiting Conditions for Operation unless otherwise stated in an individual Surveillance Requirement.

4.0.2 Each Surveillance Requirement shall be performed within the specified time interval with:

a. A maximum allowable extension not to exceed $25 \%$ of the surveillance interval, and 
b. A total maximum combined interval time for any 3 consecutive surveillance intervals not to exceed 3.25 times the specified surveillance interval.

4.0.3 Performance of a Surveillance Requirement within the specified time interval shall constitute compliance with OPERABILITY requirements for a Limiting Condition for Operation and associated ACTION statements unless otherwise required by the specification. Surveillance Requirements do not have to be performed on inoperable equipment.

4.0.4 Entry into an OPERATIONAL MODE or other specified applicability condition shall not be made unless the Surveillance Requirement(s) associated with the Limiting Condition for Operation have been performed within the stated surveillance interval or as otherwise specified.

4.0.5 Surveillance Requirements for inservice inspection and testing of ASME Code Class 1, 2 and 3 components shall be applicable as follows:

a. During the time period:

1. From issuance of the Facility Operating License to the start of facility commercial operation, inservice testing of ASME Code Class 1,2 and 3 pumps and vaives shall be performed in accordance with Section XI of the ASME Boiler and Pressure Vessel Code $(*)$ Edition, and Addenda through $(*)$, except where specific written relief has been granted by the Commission.

2. Following start of facility commercial operation, inservice inspection of ASME Code Class 1,2 and 3 components and inservice testing of ASME Code Class 1,2 and 3 pumps and valves shall be performed in accordance with Section XI of the ASME Boiler and Pressure Vessel Code and applicable Addenda as required by 10 CFR 50 , Section $50.55 \mathrm{a}(\mathrm{g})$, except where specific written relief has been granted by the Commission pursuant to 10 CFR 50 , Section $50.55 \mathrm{a}(\mathrm{g})(6)(\mathrm{i})$.

b. Surveillance intervals specified in Section XI of the ASME Boiler and Pressure Vessel Code and applicable Addenda for the inservice inspection and testing activities required by the ASME Boiler and Pressure Vessel Code and applicable Addenda shall be applicable as follows in these Technical Specifications:

₹Specific Code Edition and Addenda are to be specified consistent with 10 CFR $50.55 \mathrm{a}(\mathrm{b})$. 
ASME Boiler and Pressure Vessel

Code and applicable Addenda

terminology for inservice

inspection and testing activities

$$
\text { WeekTy }
$$

Monthly

Quarterly or every 3 months

Semiannually or every 6 months

Every 9 months

Yearly or annually

Required frequencies for
performing inservice
inspection and testing
activities
At least once per 7 days
At least once per 31 days
At least once per 92 days
At least once per 184 days
At least once per 276 days
At least once per 366 days.

Required frequencies for

performing inservice

inspection and testing

activities

At least once per 7 days

At least once per 31 days

At least once per 92 days

At least once per 184 days

At least once per 366 days.

c. The provisions of Specification 4.0.2 are applicable to the above required frequencies for performing inservice inspection and testing activities.

d. Performance of the above inservice inspection and testing activities shall be in addition to other specified Surveillance Requirements.

e. Nothing in the ASME Boiler and Pressure Vessel Code shall be construed to supersede the requirements of any Technical Specification. 
-

-

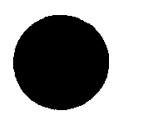




\section{3/4. 1 REACTIVITY CONTROL SYSTEMS}

3/4.1.1 BORATION CONTROL

SHUTDOWN MARGIN - T $\mathrm{avg}>200^{\circ} \mathrm{F}$

3.1.1.1 The SHUTDOWN MARGIN shall be greater than or equal to (1.6\%) delta $k / k$ for $(n)$ loop operation.

APPLICABILITY: MODES $1,2^{\star}, 3$, and 4 .

ACTION:

With the SHUTDOWN MARGIN less than (1.6\%) delta $\mathrm{k} / \mathrm{k}$, immediately initiate and continue boration at greater than or equal to $\mathrm{gpm}$ of $\mathrm{ppm}$ boric acid solution or equivalent until the required SHUTDOWN MARGIN is restored.

\section{SURVEILLANCE REQUIREMENTS}

4.1.1.1.1 The SHUTDOWN MARGIN shall be determined to be greater than or equal to $(1.6 \%)$ delta $\mathrm{k} / \mathrm{k}$ :

a. Within one hour after detection of an inoperable control rod(s) and at least once per 12 hours thereafter while the $\operatorname{rod}(s)$ is inoperable. If the inoperable control rod is immovable or untrippable, the above required SHUTDOWN MARGIN shall be verified acceptable with an increased allowance for the withdrawn worth of the immovable or untrippable control $\operatorname{rod}(s)$.

b. When in MODES 1 or $2^{\#}$, at least once per 12 hours by verifying that control bank withdrawal is within the limits of Specification 3.1.3.6.

c. When in MODE $2^{\# \#}$, within 4 hours prior to achieving reactor criticality by verifying that the predicted critical control rod position is within the limits of Specification 3.1.3.6.

d. Prior to initial operation above 5\% RATED THERMAL POWER after each fuel loading, by consideration of the factors of e below, with the control banks at the maximum insertion limit of Specification 3.1.3.6.

\footnotetext{
*See Special Test Exception 3.10.1

\#With $K_{\text {eff }}$ greater than or equal to 1.0

\#\#ith $K_{\text {eff }}$ less than 1.0 
e. When in MODES 3 or 4 , at least once per 24 hours by consideration of the following factors:

1. Reactor coolant system boron concentration,

2. Control rod position,

3. Reactor coolant system average temperature,

4. Fuel burnup based on gross thermal energy generation,

5. Xenon concentration, and

6. Samarium concentration.

4.1.1.1.2 The overall core reactivity balance shall be compared to predicted values to demonstrate agreement within $\pm 1 \%$ delta $k / k$ at least once per 31 Effective Full Power Days (EFPD). This comparison shall consider at least those factors stated in Specification (4.1.1.1.1.e), above. The predicted reactivity values shall be adjusted (normalized) to correspond to the actual core conditions prior to exceeding a fuel burnup of 60 Effective Ful 1 Power Days after each fuel loading. 
REACTIVITY CONTROL SYSTEMS

SHUTDOWN MARGIN - T avg $<200^{\circ} \mathrm{F}$

LIMITING CONDITION FOR OPERATION

3.1.1.2 The SHUTDOWN MARGIN shall be greater than or equal to $1.0 \%$ de 7 ta $k / k$. APPLICABILITY: MODE 5 .

ACTION:

With the SHUTDOWN MARGIN less than $1.0 \%$ delta $\mathrm{k} / \mathrm{k}$, immediately initiate and continue boration at greater than or equal to gpm of $\mathrm{ppm}$ boric acid solution or equivalent until the required SHUTDOWN MARGIN is restored.

\section{SURVEILLANCE REQUIREMENTS}

4.1.1.2 The SHUTDOWN MARGIN shall be determined to be greater than or equal to $1.0 \%$ delta $\mathrm{k} / \mathrm{k}$ :

a. Within one hour after detection of an inoperable control $\operatorname{rod}(s)$ and at least once per 12 hours thereafter while the rod(s) is inoperable. If the inoperable control rod is immovable or untrippable, the SHUTDOWN MARGIN shall be verified acceptable with an increased allowance for the withdrawn worth of the immovable or untrippable control $\operatorname{rod}(s)$.

b. At least once per 24 hours by consideration of the following factors:

1. Reactor coolant system boron concentration,

2. Control rod position,

3. Reactor coolant system average temperature,

4. Fuel burnup based on gross thermal energy generation,

5. Xenon concentration, and

6. Samarium concentration. 
3.1.1.3 The moderator temperature coefficient (MTC) shall be:

a. Less positive than (0) delta $\mathrm{k} / \mathrm{k} /{ }^{\circ} \mathrm{F}$ for the all rods withdrawn, beginning of cycle life (BOL), hot zero THERMAL POWER condition.

b. Less negative than $-(3.9) \times 10^{-4}$ delta $\mathrm{k} / \mathrm{k} /{ }^{\circ} \mathrm{F}$ for the all rods withdrawn, end of cycle life (EOL), RATED THERMAL POWER condition.

APPLICABILITY: Specification 3.1.1.3.a - MODES 1 and 2* only\# Specification 3.1.1.3.b - MODES 1,2 and 3 on 1y\#

ACTION:

a. With the MTC more positive than the limit of 3.1.1.3.a above, operation in MODES 1 and 2 may proceed provided:

1. Control rod withdrawal limits are established and maintained sufficient to restore the MTC to less positive than 0 delta $\mathrm{k} / \mathrm{k} /{ }^{\circ} \mathrm{F}$ within 24 hours or be in HOT STANDBY within the next 6 hours. These withdrawal limits shall be in addition to the insertion limits of Specification 3.1.3.6.

2. The control rods are maintained within the withdrawal limits established above until a subsequent calculation verifies that the MTC has been restored to within its limit for the all rods withdrawn condition.

3. A Special Report is prepared and submitted to the Commission pursuant to Specification 6.9 .2 within 10 days, describing the value of the measured MTC, the interim control rod withdrawal limits and the predicted average core burnup necessary for restoring the positive MTC to within its 1 imit for the all rods withdrawn condition.

b. With the MTC more negative than the limit of 3.1.1.3.b above, be in HOT SHUTDOWN within 12 hours.

*With $K_{\text {eff }}$ greater than or equal to 1.0

\#See Special Test Exception 3.10.3 
4.1.1.3 The MTC shall be determined to be within its limits during each fuel cycle as follows:

a. The MTC shall be measured and compared to the BOL limit of Specification 3.1.1.3.a, above, prior to initial operation above $5 \%$ of RATED THERMAL POWER, after each fuel loading.

b. The MTC shal $]$ be measured at any THERMAL POWER and compared to -(3.0) $\times 10^{-4}$ delta $\mathrm{k} / \mathrm{k} /{ }^{\circ} \mathrm{F}$ (all rods withdrawn, RATED THERMAL POWER condition) within 7 EFPD after reaching an equilibrium boron concentration of $300 \mathrm{ppm}$. In the event this comparison indicates the MTC is more negative than $-(3.0) \times 10^{-4}$ delta $\mathrm{k} / \mathrm{k} /{ }^{\circ} \mathrm{F}$, the MTC shall be remeasured, and compared to the EOL MTC limit of specification 3.1.1.3.b, at least once per 14 EFPD during the remainder of the fuel cycle. 

3.1 .1 .4 The Reactor Coolant System lowest operating loop temperature ( $\mathrm{T}_{\text {avg }}$ )
shail be greater than or equal to $(541)^{\circ} \mathrm{F}$.

APPLICABILITY: MODES 1 and $2^{\#}$.

ACTION:

With a Reactor Coolant System operating loop temperature ( $T_{\text {ayg }}$ ) less than $(541)^{\circ} \mathrm{F}$, restore $T_{\text {ayg }}$ to within its limit within 15 minutes ayg be in HOT STANDBY within the ayext 15 minutes. 4.1.1.4 The Reactor Coolant System temperature ( $T_{\text {avg }}$ ) shall be determined to
be greater than or equal to $(541)^{\circ} \mathrm{F}$ :

a. Within 15 minutes prior to achieving reactor criticality, and

b. At least once per 30 minutes when the reactor is critical and the Reactor Coolant System $T_{\text {avg }}$ is less than $(551)^{\circ} \mathrm{F}$ with the $\mathrm{T}_{\text {avg }}{ }^{-\mathrm{T}_{\text {ref }}}$
Deviation Alarm not resee.

\#With $K_{\text {eff }}$ greater than or equal to 1.0 . 
REACTIVITY CONTROL SYSTEMS

3/4.1.2 BORATION SYSTEMS

FLOW PATHS - SHUTDOWN

LIMITING CONDITION FOR OPERATION

3.1.2.1 As a minimum, one of the following boron injection flow paths shall be OPERABLE:

a. A flow path from the boric acid tanks via either a boric acid transfer pump or a gravity feed connection and a charging pump to the Reactor Coolant System if only the boric acid storage tank in Specification (3.1.2.5a) is OPERABLE, or

b. The flow path from the refueling water storage tank via a charging pump to the Reactor Coolant System if only the refueling water storage tank in Specification (3.1.2.5b) is OPERABLE.

APPLICABILITY: MODES 5 and 6.

ACTION:

With none of the above flow paths OPERABLE, suspend all operations involving CORE ALTERATIONS or positive reactivity changes.

SURVEILLANCE REQUIREMENTS

4.1.2.1 At least one of the above required flow paths shall be demonstrated OPERABLE:

a. At least once per 7 days by verifying that the temperature of the heat traced portion of the flow path is greater than or equal to $(65)^{\circ} \mathrm{F}$ when a flow path from the boric acid tanks is used.

b. At least once per 31 days by verifying that each valve (manual, power operated or automatic) in the flow path that is not locked, sealed, or otherwise secured in position, is in its correct position. 
REACTIVITY CONTROL SYSTEMS

FLOW PATHS - OPERATING

LIMITING CONDITION FOR OPERATION

3.1.2.2 At least two of the following three boron injection flow paths shall be OPERABLE:

a. The flow path from the boric acid tanks via a boric acid transfer pump and a charging pump to the Reactor Coolant System.

b. Two flow paths from the refueling water storage tank via charging pumps to the Reactor Coolant System.

APPLICABILITY: MODES $1,2,3$ and $4^{\#}$.

ACTION:

With only one of the above required boron injection flow paths to the Reactor Coolant System OPERABLE, restore at least two boron injection flow paths to the Reactor Coolant System to OPERABLE status within 72 hours or be in at least HOT STANDBY and borated to a SHUTDOWN MARGIN equivalent to at least $1 \%$ delta $\mathrm{k} / \mathrm{k}$ at $200^{\circ} \mathrm{F}$ within the next 6 hours; restore at least two flow paths to OPERABLE status within the next 7 days or be in COLD SHUTDOWN within the next 30 hours.

4.1.2.2 At least two of the above required flow paths shall be demonstrated OPERABLE:

a. At least once per 7 days by verifying that the temperature of the heat traced portion of the flow path from the boric acid tanks is greater than or equal to $(65)^{\circ} \mathrm{F}$ when it is a required water source.

b. At least once per 31 days by verifying that each valve (manual, power operated or automatic) in the flow path that is not locked, sealed, or otherwise secured in position, is in its correct position.

c. At least once per 18 months during shutdown by verifying that each automatic valve in the flow path actuates to its correct position on a test signal.

\footnotetext{
\#Only one boron injection flow path is required to be OPERABLE whenever the temperature of one or more of the RCS cold legs is less than or equal to $(275)^{\circ} \mathrm{F}$.
} 
REACTIVITY CONTROL SYSTEMS

CHARGING PUMP - SHUTDOWN

LIMITING CONDITION FOR OPERATION

3.1.2.3 One charging pump in the boron injection flow path required by Specification (3.1.2.1) shal1 be OPERABLE and capable of being powered from an OPERABLE emergency bus.

APPLICABILITY: MODES 5 and 6.

ACTION:

With no charging pump OPERABLE, suspend all operations involving CORE ALTERATIONS or positive reactivity changes.

4.1.2.3.1 The above required charging pump shall be demonstrated OPERABLE by verifying, that on recirculation flow, the pump develops a discharge pressure of greater than or equal to psig when tested pursuant to Specification 4.0.5.

4.1.2.3.2 All charging pumps, excluding the above required OPERABLE pump, shall be demonstrated inoperable at least once per 12 hours, except when the reactor vessel head is removed, by verifying that the motor circuit breakers have been removed from their electrical power supply circuits. 
REACTIVITY CONTROL SYSTEMS

CHARGING PUMPS - OPERATING

LIMITING CONDITION FOR OPERATION

3.1.2.4 At least two charging pumps shall be OPERABLE.

APPLICABILITY: MODES $1,2,3$ and $4^{\#}$.

ACTION:

With only one charging pump OPERABLE, restore at least two charging pumps to OPERABLE status within 72 hours or be in at least HOT STANDBY and borated to a SHUTDOWN MARGIN equivalent to at least $1 \%$ delta $\mathrm{k} / \mathrm{k}$ at $200^{\circ} \mathrm{F}$ within the next 6 hours; restore at least two charging pumps to OPERABLE status within the next 7 days or be in COLD SHUTDOWN within the next 30 hours.

SURVEILLANCE REQUIREMENTS

4.1.2.4.1 At least two charging pumps shall be demonstrated OPERABLE by verifying, that on recirculation flow, each pump develops a discharge pressure of greater than or equal to 4.0.5. psig when tested pursuant to Specification

4.1.2.4.2 A11 charging pumps, except the above required OPERABLE pump, shall be demonstrated inoperable at least once per 12 hours whenever the temperature of one or more of the RCS cold legs is less than or equal to $(275)^{\circ} \mathrm{F}$ by verifying that the motor circuit breakers have been removed from their electrical power supply circuits.

\#A maximum of one centrifugal charging pump shall be OPERABLE whenever the temperature of one or more of the RCS cold legs is less than or equal to $(275)^{\circ} \mathrm{F}$. 
REACTIVITY CONTROL SYSTEMS

BORATED WATER SOURCES - SHUTDOWN

LIMITING CONDITION FOR OPERATION

3.1.2.5 As a minimum, one of the following borated water sources shall be OPERABLE:

a. A boric acid storage system and at least one associated heat tracing system with:

1. A minimum contained borated water volume of gallons,

2. Between $(20,000)$ and $(22,500) \mathrm{ppm}$ of boron, and

3. A minimum solution temperature of $(145)^{\circ} \mathrm{F}$.

b. The refueling water storage tank with:

1. A minimum contained borated water volume of gallons,

2. A minimum boron concentration of (2000) ppm, and

3. A minimum solution temperature of $(35)^{\circ} \mathrm{F}$.

APPLICABILITY: MODES 5 and 6.

ACTION:

With no borated water source OPERABLE, suspend all operations involving CORE ALTERATIONS or positive reactivity changes.

SURVEILLANCE REQUIREMENTS

4.1.2.5 The above required borated water source shall be demonstrated OPERABLE:

a. At least once per 7 days by:

1. Verifying the boron concentration of the water,

2. Verifying the contained borated water volume, and

3. Verifying the boric acid storage tank solution temperature when it is the source of borated water.

b. At least once per 24 hours by verifying the RWST temperature when it is the source of borated water and the (outside) air temperature is less than $(35)^{\circ} \mathrm{F}$. 
REACTIVITY CONTROL SYSTEMS

BORATED WATER SOURCES - OPERATING

LIMITING CONDITION FOR OPERATION

3.1.2.6 As a minimum, the following borated water source(s) shall be OPERABLE as required by Specification 3.1.2.2:

a. A boric acid storage system and at least one associated heat tracing system with:

1. A minimum contained borated water volume of gallons,

2. Between $(20,000)$ and $(22,500)$ ppm of boron, and

3. A minimum solution temperature of $(145)^{\circ} \mathrm{F}$.

b. The refueling water storage tank with:

1. A contained borated water volume of between and gallons,

2. Between (2000) and (2100) ppm of boron, and

3. A minimum solution temperature of $(35)^{\circ} \mathrm{F}$.

APPLICABILITY: MODES $1,2,3$ and 4.

ACTION:

a. With the boric acid storage system inoperable and being used as one of the above required borated water sources, restore the storage system to OPERABLE status within 72 hours or be in at least HOT STANDBY within the next 6 hours and borated to a SHUTDOWN MARGIN equivalent to at least $1 \%$ delta $\mathrm{k} / \mathrm{k}$ at $200^{\circ} \mathrm{F}$; restore the boric acid storage system to OPERABLE status within the next 7 days or be in COLD SHUTDOWN within the next 30 hours.

b. With the refueling water storage tank inoperable, restore the tank to OPERABLE status within one hour or be in at least HOT STANDBY within the next 6 hours and in COLD SHUTDOWN within the following 30 hours.

\section{SURVEILLANCE REQUIREMENTS}

4.1.2.6 Each borated water source shall be demonstrated OPERABLE: 
a. At least once per 7 days by:

1. Verifying the boron concentration in the water,

2. Verifying the contained borated water volume of the water source, and

3. Verifying the boric acid storage system solution temperature when it is the source of borated water.

b. At least once per 24 hours by verifying the RWST temperature when the (outside) air temperature is less than $(35)^{\circ} \mathrm{F}$. 
REACTIVITY CONTROL SYSTEMS

\section{3/4.1.3 MOVABLE CONTROL ASSEMBLIES}

GROUP HEIGHT

LIMITING CONDITION FOR OPERATION

3.1.3.1 All full length (shutdown and control) rods, and all part length rods which are inserted in the core, shall be OPERABLE and positioned within \pm 12 steps (indicated position) of their group step counter demand position.

\section{APPLICABILITY: MODES $1^{*}$ and $2^{*}$}

\section{ACTION:}

a. With one or more full length rods inoperable due to being immovable as a result of excessive friction or mechanical interference or known to be untrippable, determine that the SHUTDOWN MARGIN requirement of Specification 3.1.1.1 is satisfied within 1 hour and be in HOT STANDBY within 6 hours.

b. With more than one full or part length rod inoperable or misaligned from the group step counter demand position by more than \pm 12 steps (indicated position), be in HOT STANDBY within 6 hours.

c. With one full or part length rod inoperable due to causes other than addressed by ACTION a, above, or misaligned from its group step counter demand height by more than \pm 12 steps (indicated position), POWER OPERATION may continue provided that within one hour either:

1. The rod is restored to OPERABLE status within the above alignment requirements, or

2. The rod is declared inoperable and the SHUTDOWN MARGIN requirement of Specification 3.1.1.1 is satisfied. POWER OPERATION may then continue provided that:

a) A reevaluation of each accident analysis of Table 3.1-1 is performed within 5 days; this reevaluation shall confirm that the previously analyzed results of these accidents remain valid for the duration of operation under these conditions.

b) The SHUTDOWN MARGIN requirement of Specification 3.1.1.1 is determined at least once per 12 hours.

₹See Special Test Exceptions 3.10.2 and 3.10.3. 
c) A power distribution map is obtajned from the movable incore detectors and $F_{0}(Z)$ and $F_{A H}^{N}$ are verified to be within their limits within 72 hoûrs.

d) Either the THERMAL POWER level is reduced to less than or equal to $75 \%$ of RATED THERMAL POWER within one hour and within the next 4 hours the high neutron flux trip setpoint is reduced to less than or equal to $85 \%$ of RATED THERMAL POWER, or

e) The remainder of the rods in the group with the inoperable rod are aligned to within \pm 12 steps of the inoperable rod within one hour while maintaining the rod sequence and insertion limits of Figures $(3.1-1)$ and $(3.1-2)$; the THERMAL POWER level shall be restricted pursuant to Specification (3.1.3.6) during subsequent operation.

4.1.3.1.1 The position of each full and part length rod shall be determined to be within the group demand limit by verifying the individual rod positions at least once per 12 hours except during time intervals when the Rod Position Deviation Monitor is inoperable, then verify the group positions at least once per 4 hours.

4.1.3.1.2 Each full length rod not fully inserted and each part length rod which is inserted in the core shall be determined to be OPERABLE by movement of at least 10 steps in any one direction at least once per 31 days. 


\section{TABLE $3.1-1$}

\section{ACCIDENT ANALYSES REQUIRING REEVALUATION IN THE EVENT OF AN INOPERABLE FULL OR PART LENGTH ROD}

Rod Cluster Control Assembly Insertion Characteristics

Rod Cluster Control Assembly Misalignment

Loss Of Reactor Coolant From Small Ruptured Pipes Or From Cracks In Large Pipes Which Actuates The Emergency Core Cooling System

Single Rod Cluster Control Assembly Withdrawal At Full Power

Major Reactor Coolant System Pipe Ruptures (Loss of Coolant Accident)

Major Secondary System Pipe Rupture

Rupture of a Control Rod Drive Mechanism Housing (Rod Cluster Control Assembly Ejection) 
REACTIVITY CONTROL SYSTEMS

POSITION INDICATION SYSTEMS-OPERATING

LIMITING CONDITION FOR OPERATION

3.1.3.2 The shutdown, control and part length control rod position indication system and the demand position indication system shall be OPERABLE and capable of determining the control rod positions within \pm 12 steps.

APPLICABILITY: MODES 1 and 2.

ACTION:

a. With a maximum of one rod position indicator per bank inoperable either:

1. Determine the position of the non-indicating $\operatorname{rod}(s)$ indirectly by the movable incore detectors at least once per 8 hours and immediately after any motion of the non-indicating rod which exceeds 24 steps in one direction since the last determination of the rod's position, or

2. Reduce THERMAL POWER TO less than $50 \%$ of RATED THERMAL POWER within 8 hours.

b. With a maximum of one demand position indicator per bank inoperable either:

1. Verify that all rod position indicators for the affected bank are OPERABLE and that the most withdrawn rod and the least withdrawn rod of the bank are within a maximum of 12 steps of each other at least once per 8 hours, or

2. Reduce THERMAL POWER to less than $50 \%$ of RATED THERMAL POWER within 8 hours.

SURVEILLANCE REQUIREMENTS

4.1.3.2 Each rod position indicator shall be determined to be OPERABLE by verifying that the demand position indication system and the rod position indication system agree within 12 steps at least once per 12 hours except during time intervals when the Rod Position Deviation Monitor is inoperable, then compare the demand position indication system and the rod position indication system at least once per 4 hours. 
3.1.3.3 One rod position indicator (excluding demand position indication) shail be OPERABLE and capable of determining the control rod position within \pm 12 steps for each shutdown, control or part length rod not fully inserted.

APPLICABILITY: MODES $3^{*} \#, 4^{*} \#$ and $5^{\star} \#$

ACTION:

With less than the above required position indicator(s) OPERABLE, immediately open the reactor trip system breakers.

4.1.3.3 Each of the above required rod position indicator(s) shall be determined to be OPERABLE by performance of a CHANNEL FUNCTIONAL TEST at least once per 18 months.

*With the reactor trip system breakers in the closed position.

\#See Special Test Exception 3.10.5. 
REACTIVITY CONTROL SYSTEMS

ROD DROP TIME

LIMITING CONDITION FOR OPERATION

3.1.3.4 The individual full length (shutdown and control) rod drop time from the fully withdrawn position shall be less than or equal to (2.2) seconds from beginning of decay of stationary gripper coil voltage to dashpot entry with:

a. $T_{\text {avg }}$ greater than or equal to $(541)^{\circ} \mathrm{F}$, and

b. All reactor coolant pumps operating.

APPLICABILITY: MODES 1 and 2.

ACTION:

a. With the drop time of any ful, length rod determined to exceed the above limit, restore the rod drop time to within the above limit prior to proceeding to MODE 1 or 2.

b. With the rod drop times within limits but determined with $n-1$ reactor coolant pumps operating, operation may proceed provided THERMAL POWER is restricted to:

1. Less than or equal to (66)\% of RATED THERMAL POWER when the reactor coolant stop valves in the nonoperating loop are open, or

2. Less than or equal to (76)\% of RATED THERMAL POWER when the reactor coolant stop valves in the nonoperating loop are closed.

4.1.3.4 The rod drop time of full length rods shall be demonstrated through measurement prior to reactor criticality:

a. For all rods following each removal of the reactor vessel head,

b. For specifically affected individual rods following any maintenance on or modification to the control rod drive system which could affect the drop time of those specific rods, and

c. At least once per 18 months. 
REACTIVITY CONTROL SYSTEMS

SHUTDOWN ROD INSERTION LIMIT

3.1.3.5 All shutdown rods shall be fully withdrawn.

APPLICABILITY: MODES $1^{\star}$ and $2^{\star} \#$

ACTION:

With a maximum of one shutdown rod not fully withdrawn, except for surveillance testing pursuant to Specification (4.1.3.1.2), within one hour either:

a. Fully withdraw the rod, or

b. Declare the rod to be inoperable and apply Specification (3.1.3.1).

4.1.3.5 Each shutdown rod shall be determined to be fully withdrawn:

a. Within 15 minutes prior to withdrawal of any rods in control banks $A, B, C$ or $D$ during an approach to reactor criticality, and

b. At least once per 12 hours thereafter.

*See Special Test Exceptions 3.10.2 and 3.10.3.

\#With $\mathrm{K}_{\text {eff }}$ greater than or equal to 1.0 
REACTIVITY CONTROL SYSTEMS

CONTROL ROD INSERTION LIMITS

LIMITING CONDITION FOR OPERATION

3.1.3.6 The control banks shall be limited in physical insertion as shown in Figures $(3.1-1)$ and $(3.1-2)$.

APPLICABILITY: MODES $1^{*}$ and $2^{*} \#$.

ACTION:

With the control banks inserted beyond the above insertion limits, except for surveillance testing pursuant to Specification (4.1.3.1.2), either:

a. Restore the control banks to within the limits within two hours, or

b. Reduce THERMAL POWER within two hours to less than or equal to that fraction of RATED THERMAL POWER which is allowed by the group position using the above figures, or

c. Be in at least HOT STANDBY within 6 hours.

SURVEILLANCE REQUIREMENTS

4.1.3.6 The position of each control bank shall be determined to be within the insertion limits at least once per 12 hours except during time intervals when the Rod Insertion Limit Monitor is inoperable, then verify the individual rod positions at least once per 4 hours.

*See Special Test Exceptions 3.10.2 and 3.10.3

\#With $K_{\text {eff }}$ greater than or equal to 1.0 . 
(FULLY WITHDRAWN)

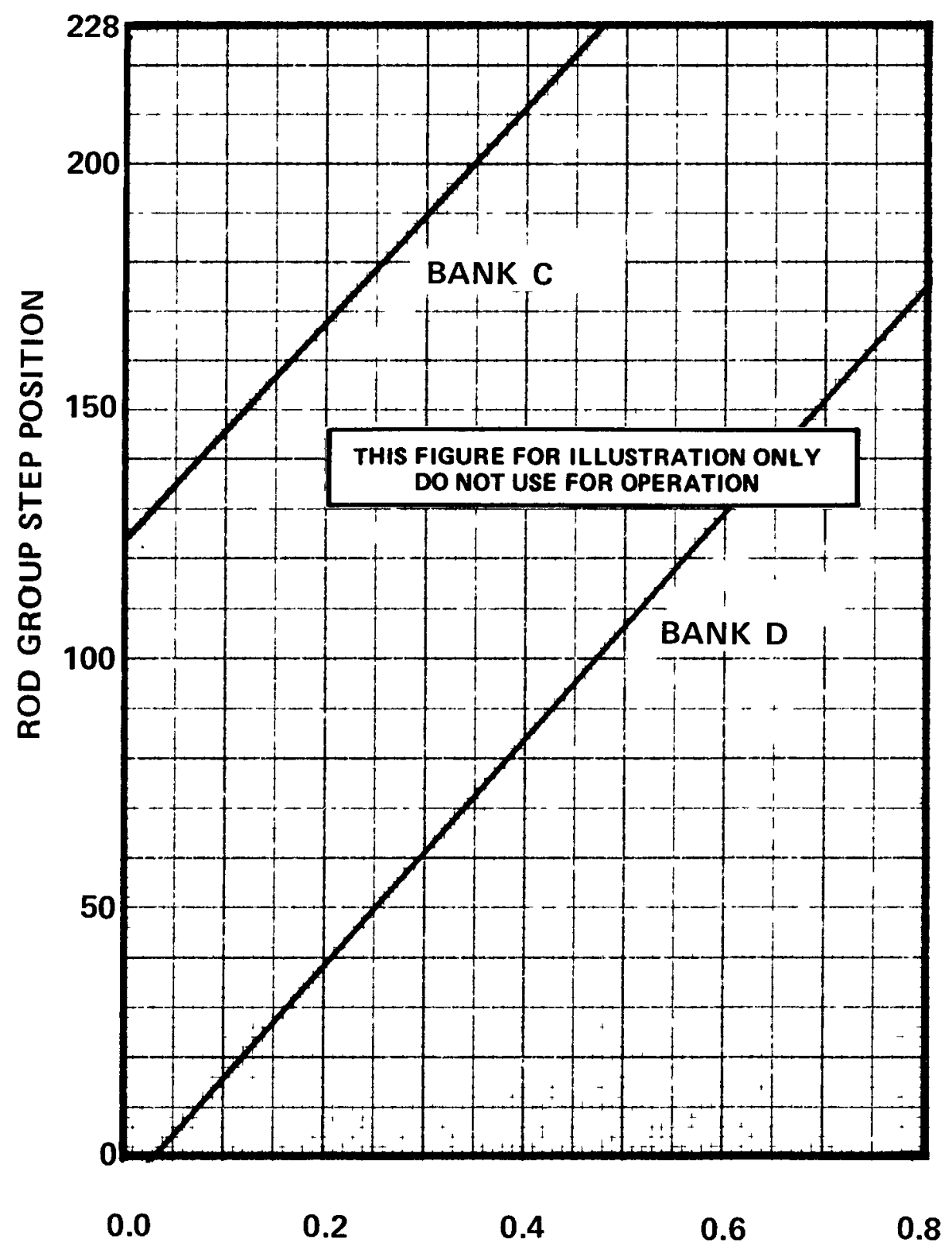

(FULLY INSERTED)

FRACTION OF RATED THERMAL POWER

FIGURE 3.1-1

ROD GROUP INSERTION LIMITS VERSUS THERMAL POWER THREE LOOP OPERATION 
(Fully withdrawn)

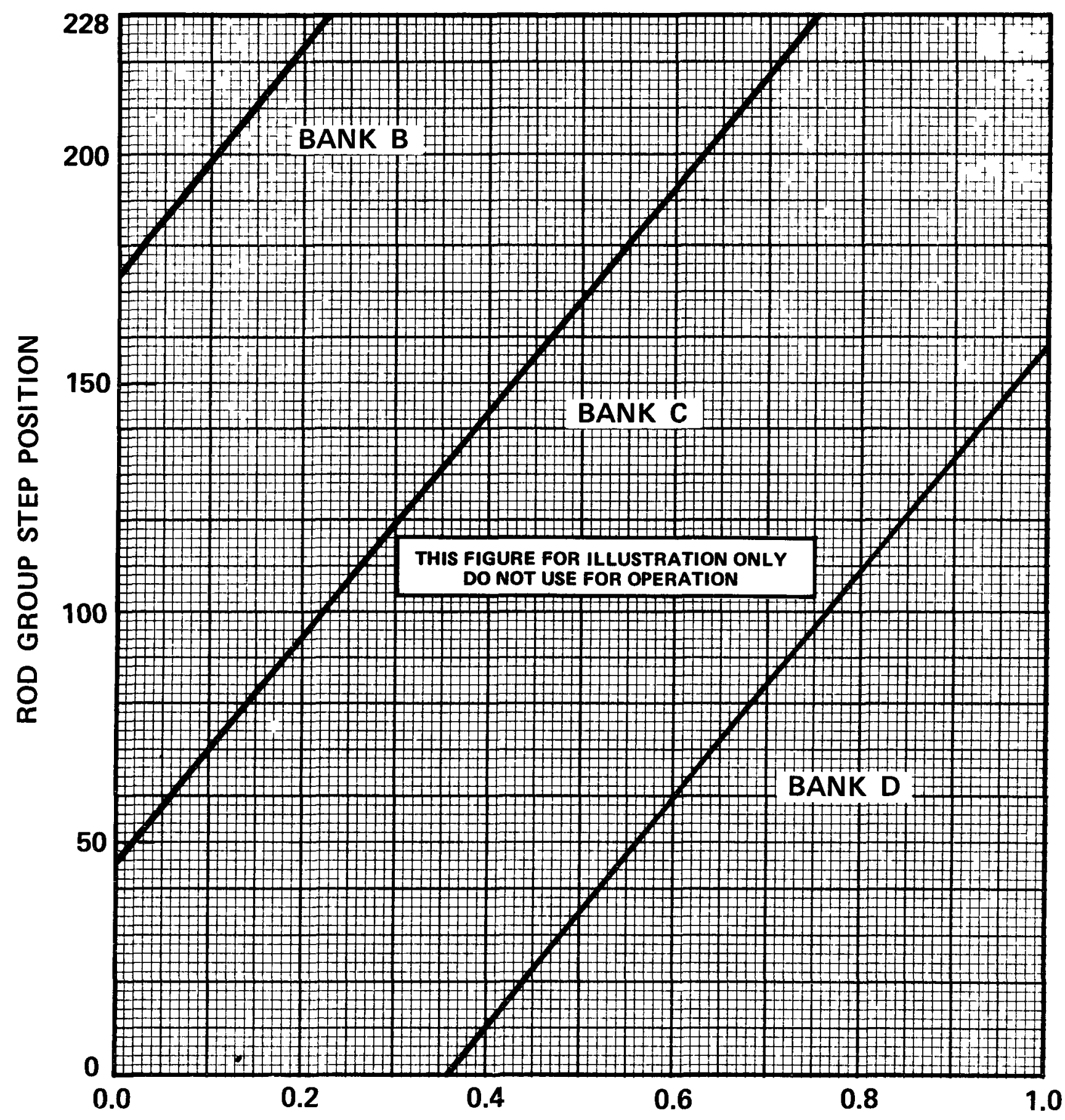

(Fully Inserted)

FRACTION OF RATED THERMAL POWER

Figure 3.1-2 ROD GROUP INSERTION LIMITS VERSUS THERMAL POWER FOUR LOOP OPERATION 
3.1.3.7 The part length control rod bank shall be:

a. Limited in physical insertion as shown on Figure (3.1-3), and

b. Limited from covering any axial segment of the fuel assemblies for a period in excess of (18) out of any 30 Equivalent Full Power Days.

APPLICABILITY: MODES $1^{*}$ and $2^{*}$

ACTION:

a. With the part length control rod bank inserted beyond the insertion limit of Figure (3. $1-3)$, either:

1. Withdraw the part length control rod bank to within the limit within two hours, or

2. Reduce THERMAL POWER within two hours to less than or equal to that fraction of RATED THERMAL POWER which is allowed by the bank position using the above figure, or

3. Be in at least HOT STANDBY within 6 hours.

b. With the neutron absorber section of the part length control rod bank covering any axial segment of the fuel assemblies for a period exceeding 18 out of any 30 consecutive EFPD period, either:

1. Reposition the part length control rod group to satisfy the above limit within 2 hours, or

2. Be in at least HOT STANDBY within the next 6 hours.

4.1.3.7 The position of the part length control rod bank shall be determined at least once per 12 hours.

*See Special Test Exceptions 3.10.2 and 3.10.3. 
REACTIVITY CONTROL SYSTEMS

(ALTERNATE)

PART LENGTH ROD INSERTION LIMITS (if required by DNB considerations)

LIMITING CONDITION FOR OPERATION

3.1.3.7 All part length rods shall be fully withdrawn.

APPLICABILITY: MODES $1^{*}$ and $2^{*}$

ACTION:

With a maximum of one part length rod not fully withdrawn, within one hour either:

a. Fully withdraw the rod, or

b. Be in at least HOT STANDBY within the next 6 hours.

4.1.3.7 Each part length rod shall be determined to be fully withdrawn by:

a. Verifying the position of the part length rod prior to increasing THERMAL POWER above 5\% of RATED THERMAL POWER, and

b. Verifying, at least once per 31 days, that electric power has been disconnected from its drive mechanism by physical removal of a breaker from the circuit.

* See Special Test Exceptions 3.10.2. and 3.10.3. 


\section{PART LENGTH ROD GROUP INSERTION}

LIMIT VERSUS THERMAL POWER

FIGURE 3.1-3 
3/4.2 POWER DISTRIBUTION LIMITS

AXIAL FLUX DIFFERENCE (AFD)

3.2.1 The indicated AXIAL FLUX DIFFERENCE (AFD) shall be maintained within a $\pm(5) \%$ target band (flux difference units) about the target flux difference.

APPLICABILITY: MODE 1 above 50\% of RATED THERMAL POWER*

ACTION:

a. With the indicated AXIAL FLUX DIFFERENCE outside of the $\pm(5) \%$ target band about the target flux difference and with THERMAL POWER:

1. Above $90 \%$ of RATED THERMAL POWER, within 15 minutes:

a) Either restore the indicated AFD to within the target band limits, or

b) Reduce THERMAL POWER to less than $90 \%$ of RATED THERMAL POWER.

2. Between $50 \%$ and $90 \%$ of RATED THERMAL POWER:

a) POWER OPERATION may continue provided:

1) The indicated AFD has not been outside of the $\pm(5) \%$ target band for more than 1 hour penalty deviation cumulative during the previous 24 hours, and

2) The indicated AFD is within the limits shown on Figure (3.2-1). Otherwise, reduce THERMAL POWER to less than $50 \%$ of RATED THERMAL POWER within 30 minutes and reduce the Power Range Neutron Flux-High Trip Setpoints to less than or equal to $55 \%$ of RATED THERMAL POWER within the next 4 hours.

b) Surveillance testing of the Power Range Neutron Flux Channels may be performed pursuant to Specification (4.3.1.1) provided the indicated AFD is maintained within the limits of Figure 3.2-1. A total of 16 hours operation may be accumulated with the AFD outside of the target band during this testing without penalty deviation.

b. THERMAL POWER shal1 not be increased above $90 \%$ of RATED THERMAL POWER unless the indicated AFD is within the $\pm(5) \%$ target band and ACTION a.2.a) 1), above has been satisfied.

Xee Special Test Exception 3.10.2 


\section{POWER DISTRIBUTION LIMITS}

$\underline{\text { ACTION (Continued) }}$

c. THERMAL POWER shall not be increased above $50 \%$ of RATED THERMAL POWER unless the indicated AFD has not been outside of the $\pm(5) \%$ target band for more than 1 hour penalty deviation cumulative during the previous 24 hours.

\section{SURVEILLANCE REQUIREMENTS}

4.2.1.1 The indicated AXIAL FLUX DIFFERENCE shall be determined to be within its iimits during POWER OPERATION above $15 \%$ of RATED THERMAL POWER by:

a. Monitoring the indicated AFD for each OPERABLE excore channel:

1. At least once per 7 days when the AFD Monitor Alarm is OPERABLE, and

2. At least once per hour for the first 24 hours after restoring the AFD Monitor Alarm to OPERABLE status.

b. Monitoring and logging the indicated AXIAL FLUX DIFFERENCE for each OPERABLE excore channel at least once per hour for the first 24 hours and at least once per 30 minutes thereafter, when the AXIAL. FLUX DIFFERENCE Monitor Alarm is inoperable. The logged values of the indicated AXIAL FLUX DIFFERENCE shall be assumed to exist during the interval preceding each logging.

4.2.1.2 The indicated AFD shall be considered outside of its $\pm(5) \%$ target band when at least 2 of 4 or 2 of 3 OPERABLE excore channels are indicating the AFD to be outside the target band. Penalty deviation outside of the $\pm(5) \%$ target band shall be accumulated on a time basis of:

a. One minute penalty deviation for each one minute of POWER OPERATION outside of the target band at THERMAL POWER levels equal to or above $50 \%$ of RATED THERMAL POWER, and

b. One-half minute penalty deviation for each one minute of POWER OPERATION outside of the target band at THERMAL POWER levels between $15 \%$ and $50 \%$ of RATED THERMAL POWER.

4.2.1.3 The target flux difference of each OPERABLE excore channel shall be determined by measurement at least once per 92 Effective Full Power Days with all part length control rods fully withdrawn. The provisions of Specification 4.0.4 are not applicable.

4.2.1.4 The target flux difference shall be updated at least once per 31 Effective Full Power Days by either determining the target flux difference pursuant to 4.2 .1 .3 above or by linear interpolation between the most recently measured value and 0 percent at the end of the cycle life. The provisions of Specification 4.0.4 are not applicable. 


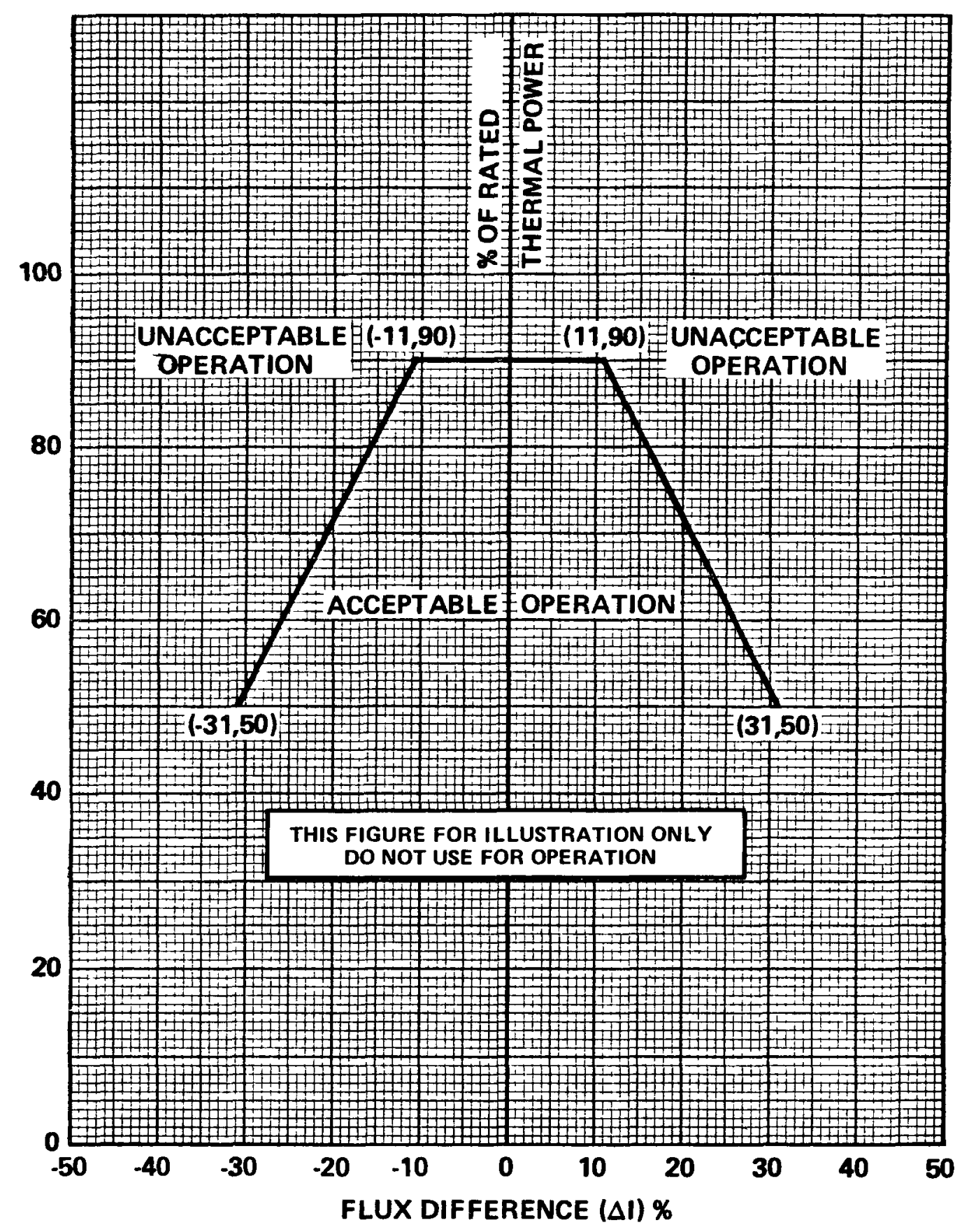

FIGURE 3.2-1 AXIAL FLUX DIFFERENCE LIMITS AS A FUNCTION OF RATED THERMAL POWER 
POWER DISTRIBUTION LIMITS

$\underline{\text { HEAT FLUX HOT CHANNEL FACTOR-F }}{ }_{Q}(Z)$

3.2.2 $F_{Q}(Z)$ shall be limited by the following relationships:

$$
\begin{aligned}
& F_{Q}(Z) \leq \frac{2.32]}{P}[K(Z)] \text { for } P>0.5 \\
& F_{Q}(Z) \leq[(4.64)][K(Z)] \text { for } P \leq 0.5 \\
& \text { where } P=\frac{\text { THERMAL POWER }}{\text { RATED THERMAL POWER }} \\
& \text { and } K(Z) \text { is the function obtained from Figure }(3.2-2) \text { for a } \\
& \text { given core height location. }
\end{aligned}
$$

\section{APPLICABILITY: MODE 1}

\section{ACTION:}

With $F_{Q}(Z)$ exceeding its limit:

a. Comply with either of the following ACTIONS:

1. Reduce THERMAL POWER at least $1 \%$ for each $1 \% \mathrm{~F}_{0}(\mathrm{Z})$ exceeds the limit within 15 minutes and similiarly reduce the Power Range Neutron Flux-High Trip Setpoints within the next 4 hours; POWER OPERATION may proceed for up to a total of 72 hours; subsequent POWER OPERATION may proceed provided the Overpower delta T Trip Setpoints have been reduced at least $1 \%$ for each $1 \% F_{0}(Z)$ exceeds the limit. The Overpower delta $T$ Trip Setpoiht reduction shall be performed with the reactor in at least HOT STANDBY.

2. Reduce THERMAL POWER as necessary to meet the limits of Specification (3.2.6) using the APDMS with the latest incore map and updated $\bar{R}$. (APDMS plants only)

b. Identify and correct the cause of the out of limit condition prior to increasing THERMAL POWER above the reduced limit required by a, above; THERMAL POWER may then be increased provided $F_{0}(Z)$ is demonstrated through incore mapping to be within its limit? 
POWER DISTRIBUTION LIMITS

SURVEILLANCE REQUIREMENTS

4.2.2.1 The provisions of Specification 4.0.4 are not applicable.

4.2.2.2 $F_{x y}$ shall be evaluated to determine if $F_{Q}(Z)$ is within its 1 imit by:

a. Using the movable incore detectors to obtain a power distribution map at any THERMAL POWER greater than $5 \%$ of RATED THERMAL POWER.

b. Increasing the measured $F_{\text {}}$ component of the power distribution map by $3 \%$ to account for manufucturing tolerances and further increasing the value by $5 \%$ to account for measurement uncertainties.

c. Comparing the $F_{x y}$ computed $\left(F_{x y}^{C}\right)$ obtained in $b$, above to:

1. The $F_{x y}$ limits for RATED THERMAL POWER $\left(F_{x y}^{R T P}\right)$ for the appropriate measured core planes given in $e$ and $f$ below, and

2. The relationship:

$$
F_{x y}^{L}=F_{x y}^{R T P}[1+0.2(1-P)]
$$

where $F_{x y}^{L}$ is the limit for fractional THERMAL POWER operation expressed as a function of $F_{X Y}^{R T P}$ and $P$ is the fraction of RATED THERMAL POWER at which $F_{x y}$ was measured.

d. Remeasuring $F_{x y}$ according to the following schedule:

1. When $F_{x y}^{C}$ is greater than the $F_{x y}^{R T P}$ limit for the appropriate measured core $p$ lane but less than the $F_{x y}^{L}$ relationship, additional power distribution maps shall be taken and $F_{x y}^{C}$ compared to $F_{x y}^{R T P}$ and $F_{x y}{ }^{L}$ :

a) Either within 24 hours after exceeding by $20 \%$ of RATED THERMAL POWER or greater, the THERMAL POWER at which $F_{x y}{ }^{C}$ was last determined, or

b) At least once per 31 EFPD, whichever occurs first. 
2. When the $F_{x y}^{C}$ is less than or equal to the $F_{x y}^{R T P}$ limit for the appropriate measured core plane, additional power distribution maps shall be taken and $F_{x y}^{C}$ compared to $F_{x y}^{R T P}$ and $F_{x y}^{L}$ at least once per 31 EFPD.

e. The $F_{x y}$ limits for RATED THERMAL POWER within specific core planes shall be:

1. $F_{x y}^{R T P}$ less than or equal to 1.71 for all core planes containing bank "D" control rods and/or any part length rods, and

2. $F_{x y}^{R T P}$ less than or equal to 1.55 for all unrodded core planes.

f. The $F_{x y}$ limits of e, above, are not applicable in the following core planes regions as measured in percent of core height from the bottom of the fuel:

1. Lower core region from 0 to $15 \%$, inclusive.

2. Upper core region from 85 to $100 \%$, inclusive.

3. Grid plane regions at $17.8 \pm 2 \%, 32.1 \pm 2 \%, 46.4 \pm 2 \%, 60.6$ $\pm 2 \%$ and $74.9 \pm 2 \%$, inclusive. ( $17 \times 17$ fuel elements $)$.

4. Core plane regions within $\pm 2 \%$ of core height ( \pm 2.88 inches) about the bank demand position of the bank "D" or part length control rods.

g. With $F_{x y}^{C}$ exceeding $F_{x y}^{L}$ :

1. The $F_{Q}(Z)$ limit shall be reduced at least $1 \%$ for each $1 \% F_{x y}^{C}$ exceeds $F_{x y}$, and (for plants with $F_{Q}(Z)$ less than 2.32 and using APDMS)

2. The effects or $t_{x y}$ on $F_{Q}(Z)$ shall be evaluated to determine if $F_{Q}(Z)$ is within its limits.

4.2.2.3 When $F_{0}(Z)$ is measurea ror other than $F_{x y}$ determinations, an overall measured $F_{0}(Z)$ shall be obtained from a power distribution map and increased by $3 \%$ to account for manufacturing tolerances and further increased by $5 \%$ to account for measurement uncertainty. 
立

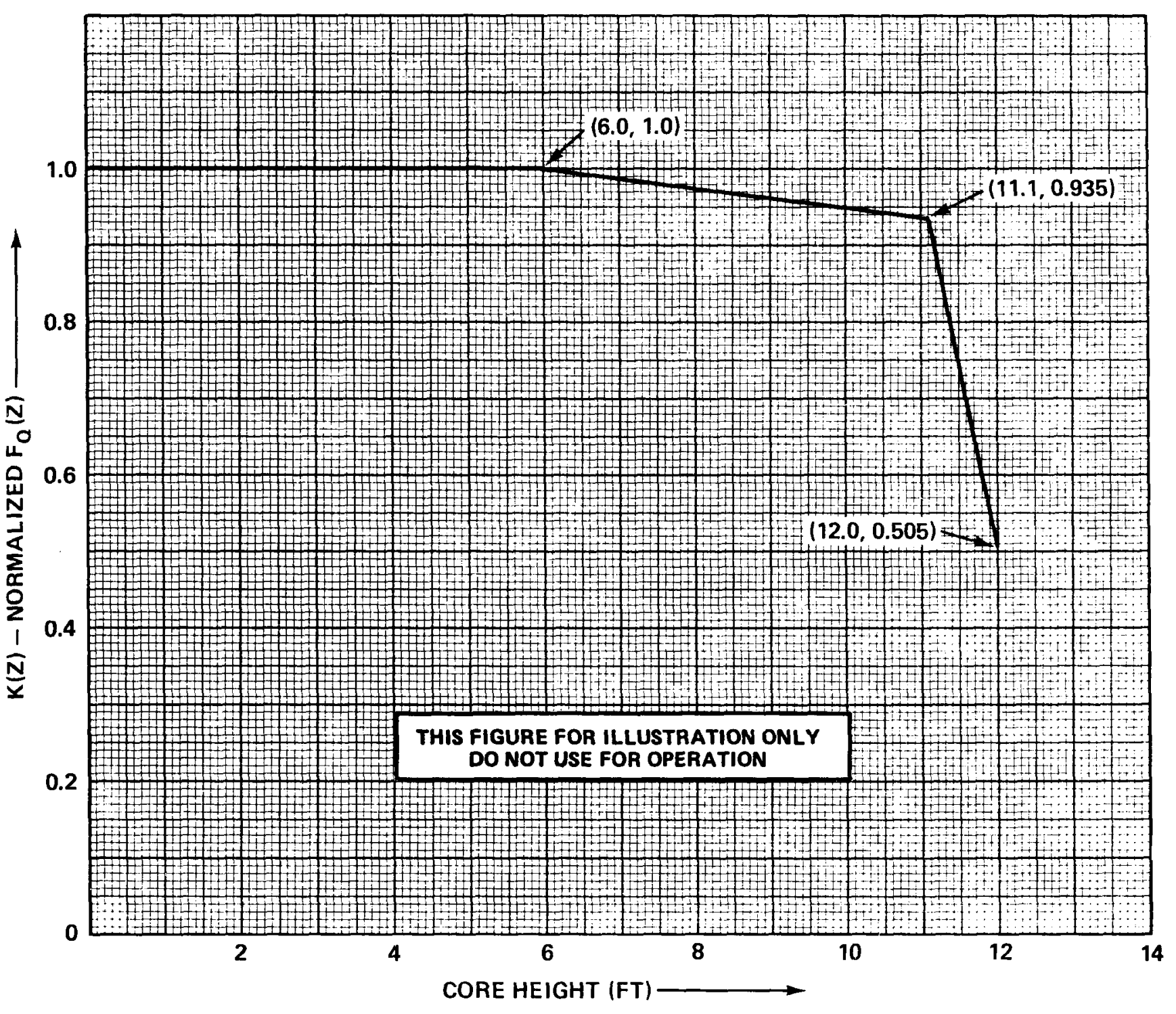

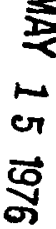

FIGURE 3.2-2 $K(Z)$ - NORMALIZED $F_{Q}(Z)$ AS A FUNCTION OF CORE HEIGHT 
3.2.3 The combination of indicated Reactor Coolant System (RCS) total flow rate and $R_{1}, R_{2}$ shall be maintained within the region of allowable operation shown on Flgure $3.2-3$ for 4 loop operation.

Where:

$$
\begin{aligned}
& \text { a. } \quad R_{1}=\frac{F_{\Delta H}^{N}}{1.49[1.0+0.2(1.0-P)]} \text {, } \\
& \text { b. } \quad R_{2}=\frac{R_{1}}{[1-R B P(B U)]} \text {, } \\
& \text { c. } \quad P=\frac{\text { THERMAL POWER }}{\text { RATED THERMAL POWER }} \text {, } \\
& \text { d. } F_{\Delta H}^{N}=\text { Measured values of } F_{\Delta H}^{N} \text { obtained by using the movable incore }
\end{aligned}
$$

e. $\quad R B P(B U)=$ Rod Bow Penalty as a function of region average burnup as shown in Figure 3.2-4, where a region is defined as those assemblies with the same loading date (reloads) or enrichment (first core).

APPLICABILITY: MODE 1.

\section{ACTION:}

With the combination of RCS total flow rate and $R_{1}, R_{2}$ outside the region of acceptable operation shown on Figure 3.2-3:

a. Within 2 hours:

1. Either restore the combination of RCS total flow rate and $R_{1}$, $\mathrm{R}_{2}$ to within the above limits, or

2. Reduce THERMAL POWER to less than 50\% of RATED THERMAL POWER and reduce the Power Range Neutron Flux - High trip setpoint to less than or equal to 55\% of RATED THERMAL POWER within the next 4 hours. 
POWER DISTRIBUTION LIMITS

ACTION: (Continued)

b. Within 24 hours of initially being outside the above limits, verify through incore flux mapping and RCS total flow rate comparison that the combination of $R_{1}, R_{2}$ and $R C S$ total flow rate are restored to within the above $1 \mathrm{im}$ ts, ${ }^{2}$ or reduce THERMAL POWER to less than $5 \%$ of RATED THERMAL POWER within the next 2 hours.

c. Identify and correct the cause of the out-of-limit condition prior to increasing THERMAL POWER above the reduced THERMAL POWER limit required by ACTION items a.2. and/or b. above; subsequent POWER OPERATION may proceed provided that the combination of $R_{l}, R_{2}$ and indicated RCS total flow rate are demonstrated, through lncore flux mapping and RCS total flow rate comparison, to be within the region of acceptable operation shown on Figure 3.2-3 prior to exceeding the following THERMAL POWER levels:

1. A nominal $50 \%$ of RATED THERMAL POWER,

2. A nominal $75 \%$ of RATED THERMAL POWER, and

3. Within 24 hours of attaining greater than or equal to $95 \%$ of RATED THERMAL POWER.

\section{SURVEILLANCE REQUIREMENTS}

4.2.3.1 The provisions of Specification 4.0.4 are not applicable.

4.2.3.2 The combination of indicated RCS total flow rate and $R_{1}, R_{2}$ shall be determined to be within the region of acceptable operation of Figure 3.2-3:

a. Prior to operation above $75 \%$ of RATED THERMAL POWER after each fue] loading, and

b. At least once per 31 Effective Full Power Days.

4.2.3.3 The indicated RCS total flow rate shall be verified to be within the region of acceptable operation of Figure 3.2-3 at least once per 12 hours when the most recently obtained values of $R_{1}$ and $R_{2}$, obtained per Specification 4.2.3.2, are assumed to exist.

4.2.3.4 The RCS total flow rate indicators shall be subjected to a CHANNEL CALIBRATION at least once per 18 months.

4.2.3.5 The RCS total flow rate shall be determined by measurement at least once per 18 months. 


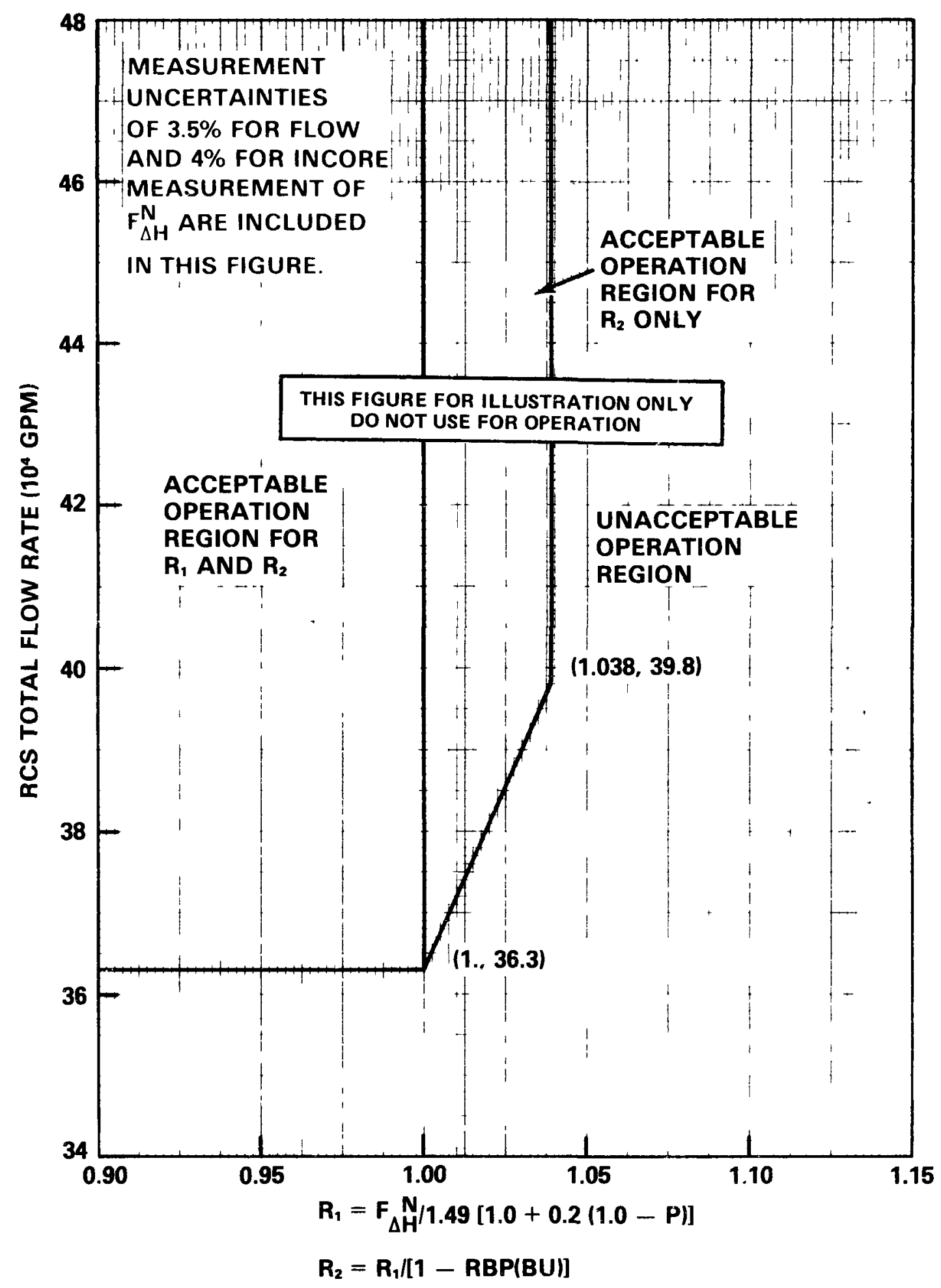

FIGURE 3.2-3 RCS TOTAL FLOWRATE VERSUS R - FOUR LOOPS IN OPERATION 
留

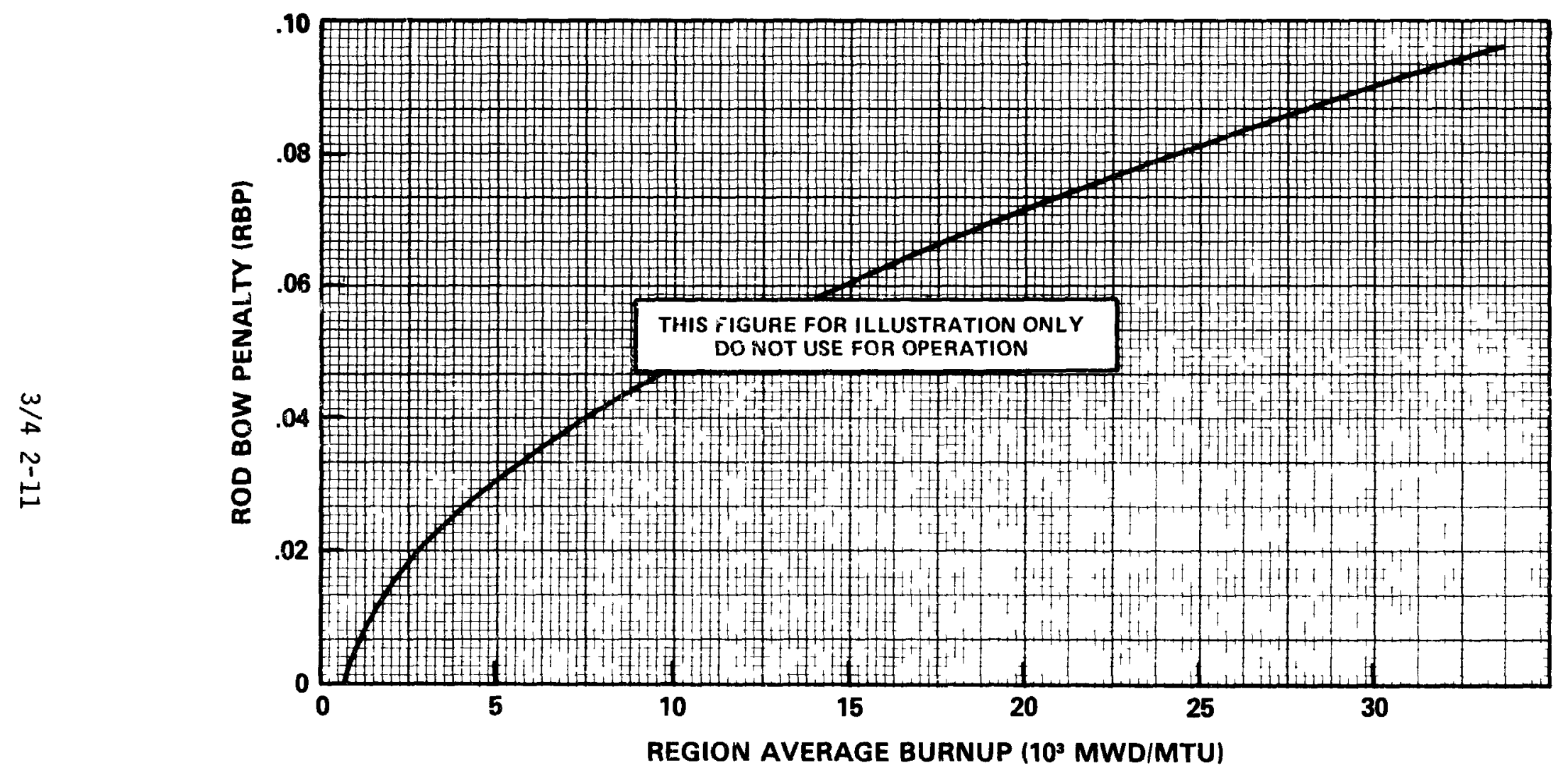

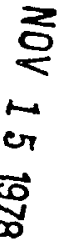

FIGURE 3.2-4

ROD BOW PENALTY AS A FUNCTION OF BURNUP 
POWER DISTRIBUTION LIMITS

QUADRANT POWER TILT RATIO

LIMITING CONDITION FOR OPERATION

3.2.4 THE QUADRANT POWER TILT RATIO shal1 not exceed 1.02 .

APPLICABILITY: MODE 1 above $50 \%$ of RATED THERMAL POWER*

ACTION:

a. With the QUADRANT POWER TILT RATIO determined to exceed 1.02 but

less than or equal to 1.09:

1. Calculate the QUARANT POWER TILT RATIO at least once per hour until:

a) Either the QUADRANT POWER TILT RATIO is reduced to within its limit, or

b) THERMAL POWER is reduced to less than $50 \%$ of RATED THERMAL POWER.

2. Within 2 hours:

a) Either reduce the QUADRANT POWER TILT RATIO to within its limit, or

b) Reduce THERMAL POWER at least 3\% from RATED THERMAL POWER for each $1 \%$ of indicated QUADRANT POWER TILT RATIO in excess of 1.0 and similarly reduce the Power Range Neutron Flux-High Trip Setpoints within the next 4 hours.

3. Verify that the QUADRANT POWER TILT RATIO is within its limit within 24 hours after exceeding the limit or reduce THERMAL POWER to less than 50\% of RATED THERMAL POWER within the next 2 hours and reduce the Power Range Neutron Flux-High Trip setpoints to less than or equal to $55 \%$ of RATED THERMAL POWER within the next 4 hours.

4. Identify and correct the cause of the out of limit condition prior to increasing THERMAL POWER; subsequent POWER OPERATION above $50 \%$ of RATED THERMAL power may proceed provided that the QUADRANT POWER TILT RATIO is verified within its limit at least once per hour for 12 hours or until verified acceptable at $95 \%$ or greater RATED THERMAL POWER.

*See Special Test Exception 3.10.2. 
POWER DISTRIBUTION LIMITS

ACTION: (Continued)

b. With the QUADRANT POWER TILT RATIO determined to exceed 1.09 due to misalignment of either a shutdown, control or part length rod:

1. Calculate the QUADRANT POWER TILT RATIO at least once per hour unti1:

a) Either the QUADRANT POWER TILT RATIO is reduced to within its limit, or

b) THERMAL POWER is reduced to less than 50\% of RATED THERMAL POWER.

2. Reduce THERMAL POWER at least $3 \%$ from RATED THERMAL POWER for each $1 \%$ of indicated QUADRANT POWER TILT RATIO in excess of 1.0 , within 30 minutes.

3. Verify that the QUADRANT POWER TILT RATIO is within its limit within 2 hours after exceeding the limit or reduce THERMAL

POWER to less than 50\% of RATED THERMAL POWER within the next 2 hours and reduce the Power Range Neutron Flux-High trip Setpoints to less than or equal to $55 \%$ of RATED THERMAL POWER within the next 4 hours.

4. Identify and correct the cause of the out of limit condition prior to increasing THERMAL POWER; subsequent POWER OPERATION above $50 \%$ of RATED THERMAL POWER may proceed provided that the QUADRANT POWER TILT RATIO is verified within its limit at least once per hour for 12 hours or until verified acceptable at 95\% or greater RATED THERMAL POWER.

c. With the QUADRANT POWER TILT RATIO determined to exceed 1.09 due to causes other than the misalignment of either a shutdown, control or part length rod:

1. Calculate the QUADRANT POWER TILT RATIO at least once per hour until:
a) Either the QUADRANT POWER TILT RATIO is reduced to within its limit, or
b) THERMAL POWER is reduced to less than $50 \%$ of RATED THERMAL POWER.


ACTION: (Continued)

2. Reduce THERMAL POWER to less than 50\% of RATED THERMAL POWER within 2 hours and reduce the Power Range Neutron Flux-High Trip Setpoints to less than or equal to 55\% of RATED THERMAL POWER within the next 4 hours.

3. Ideritify and correct the cause of the out of limit condition prior to increasing THERMAL POWER; subsequent POWER OPERATION above $50 \%$ of RATED THERMAL POWER may proceed provided that the QUACRANT POWER TILT RATIO is verified within its limit at least once per hour for 12 hours or until verified at $95 \%$ or greater RATED THERMAL POWER.

4.2.4 The QUADRANT POWER TILT RATIO shall be determined to be within the limit above $50 \%$ of RATED THERMAL POWER by:

a. Calculating the ratio at least once per 7 days when the alarm is OPERABLE.

b. Caiculating the ratio at least once per 12 hours during steady state operation when the alarm is inoperable.

c. Using the novabie incore detectors to confirm that the symmetric powar distribution, obtained from the eight symmetric thimble locations, is consistent with the indicated QUADRANT POWER TILT RATIO at least once per 12 hours when one Power Range Channel is inoperable and THERMAL POWER is greater than 75 percent of RATED THERMAL POWER. 


\section{POWER DISTRIBUTION LIMITS}

DNB PARAMETERS

3.2.5 The following DNB related parameters shall be maintained within the limits shown on Table 3.2-1:

a. Reactor Coolant System $\mathrm{T}_{\text {avg }}$.

b. Pressurizer Pressure

\section{APPLICABILITY: MODE 1}

ACTION:

With any of the above parameters exceeding its limit, restore the parameter to within its limit within 2 hours or reduce THERMAL POWER to less than $5 \%$ of RATED THERMAL POWER within the next 4 hours.

4.2.5 Each of the parameters of Table 3.2-1 shall be verified to be within their limits at least once per 12 hours. 


\section{DNB PARAMETERS}

$\begin{array}{llll}\text { PARAMETER } & \begin{array}{l}\text { N Loops In } \\ \text { Operation }\end{array} & \begin{array}{c}\mathrm{N}-1 \text { Loops In Opera- } \\ \text { tion \& Loop Stop } \\ \text { Valves Open }\end{array} & \begin{array}{c}\text { LIMITS } \\ \text { tion \& Loop Stop In Opera- } \\ \text { Valves Closed }\end{array} \\ \text { Reactor Coolant System Tavg } & \leq(581)^{\circ} \mathrm{F} & \leq(569)^{\circ} \mathrm{F} & \leq(570)^{\circ} \mathrm{F} \\ \text { Pressurizer Pressure } & \geq(2220) \text { psia* } & \geq(2220) \text { psia* } & \geq(2220)^{*} \mathrm{psia}\end{array}$

$\omega$
$\stackrel{\omega}{\sigma}$
$\stackrel{\Delta}{\sigma}$

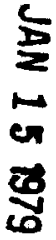

*Limit not applicable during either a THERMAL POWER ramp in excess of (5\%) of RATED THERMAL POWER per minute or a THERMAL POWER step in excess of (10)\% of RATED THERMAL POWER.
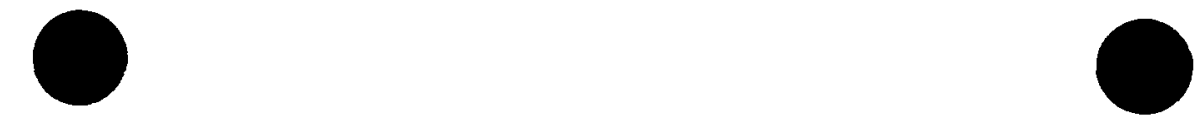
$3 / 4.3$ INSTRUMENTATION

3/4.3.1 REACTOR TRIP SYSTEM INSTRUMENTATION

LIMITING CONDITION FOR OPERATION

3.3.1 As a minimum, the reactor trip system instrumentation channels and interlocks of Table 3.3-1 shall be OPERABLE with RESPONSE TIMES as shown in Table 3.3-2.

APPLICABILITY: As shown in Table 3.3-1.

ACTION:

As shown in Table 3.3-1.

SURVEILLANCE REQUIREMENTS

4.3.1.1 Each reactor trip system instrumentation channel shall be demonstrated OPERABLE by the performance of the CHANNEL CHECK, CHANNEL CALIBRATION and CHANNEL FUNCTIONAL TEST operations for the MODES and at the frequencies shown in Table 4.3-1.

4.3.1.2 The logic for the interlocks shall be demonstrated OPERABLE prior to each reactor startup unless performed during the preceding 92 days. The total interlock function shall be demonstrated OPERABLE at least once per 18 months during CHANNEL CALIBRATION testing of each channel affected by interlock operation.

4.3.1.3 The REACTOR TRIP SYSTEM RESPONSE TIME of each reactor trip function shall be demonstrated to be within its limit at least once per 18 months. Each test shall include at least one logic train such that both logic trains are tested at least once per 36 months and one channel per function such that all channels are tested at least once every $\mathrm{N}$ times 18 months where $\mathrm{N}$ is the total number of redundant channels in a specific reactor trip function as shown in the "Total No. of Channels" column of Table 3.3-1. 
TABLE 3.3-1

\section{FUNCTIONAL UNIT}

1. Manual Reactor Trip

2. Power Range, Neutron Flux

3. Power Range, Neutron Flux High Positive Rate

4. Power Range, Neutron Flux, High Negative Rate

5. Intermediate Range, Neutron Flux

6. Source Range, Neutron Flux
A. Startup

B. Shutdown

7. Overtemperature $\Delta T$

A. Four Loop Plant

Four Loop Operation

Three Loop Operation

B. Three Loop Plant

Three Loop Operation

Two Loop Operation

\section{REACTOR TRIP SYSTEM INSTRUMENTATION}

$$
\begin{aligned}
& \text { TOTAL NO. } \\
& \text { OF CHANNELS } \\
& \hline
\end{aligned}
$$

2

4

4

4

2

2

2

4
4

3

3
MINIMUM

CHANNELS APPLICABLE

OPERABLE

MODES

CHANNELS

1

2

2

2

1

\section{2}

1, 2 and *

3

1,2

3

1,2

3

1,2

21,2 and *

3

2

$2^{\# \#}$ and *

3,4 and 5

4

5

$2^{\#}$

$1 * x$

3

1,2

9

$2 * *$

$\begin{array}{ll}2 & 1,2 \\ 2 & 1,2\end{array}$

蛋
니
형 
Iz
1
$\frac{n}{n}$

\section{FUNCTIONAL UNIT}

8. Overpower $\Delta \mathrm{T}$

A. Four Loop Plant Four Loop Operation Three Loop Operation

B. Three Loop Plant Three Loop Operation Two Loop Operation

9. Pressurizer Pressure-Low

$\underbrace{\omega}_{\omega}$

A. Four Loop Plant

B. Three Loop Plant

$\omega$ w 10. Pressurizer Pressure--High

A. Four Loop Plant

B. Three Loop Plant

11. Pressurizer Water Leve1--High

12. A. Loss of Flow - Single Loop (Above $\mathrm{P}-8$ )

B. Loss of Flow - Two Loops (Above $P-7$ and below $P-8$ )
TABLE 3.3-1 (Continued)

\section{REACTOR TRIP SYSTEM INSTRUMENTATION}

TOTAL NO. CHANNELS MINIMUM

OF CHANNELS TO TRIP

APPLICABLE

MODES

ACTION

4

2

3

1,2

$2^{\#}$

3

2

2
2

1,2
1,2

$2^{\#}$

4

4
3

2

3

1,2

$6^{\#}$

\section{4}

3

3/loop

3/1oop

3

\begin{tabular}{|c|c|c|}
\hline $\begin{array}{l}2 \\
2\end{array}$ & $\begin{array}{l}3 \\
2\end{array}$ & $\begin{array}{l}1,2 \\
1,2\end{array}$ \\
\hline 2 & 2 & 1,2 \\
\hline $\begin{array}{l}2 / 1 \text { oop in } \\
\text { any oper- } \\
\text { ating loop }\end{array}$ & $\begin{array}{l}\text { 2/loop in } \\
\text { each oper- } \\
\text { ating loop }\end{array}$ & 1 \\
\hline $\begin{array}{l}2 / 10 o p \text { in } \\
\text { two oper- } \\
\text { ating loops }\end{array}$ & $\begin{array}{l}2 / 10 o p \\
\text { each oper- } \\
\text { ating loop }\end{array}$ & 1 \\
\hline
\end{tabular}

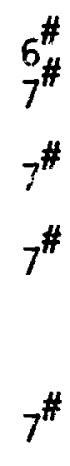

$7^{\#}$ 


\section{REACTOR TRIP SYSTEM INSTRUMENTATION}

\section{FUNCTIONAL UNIT}

13. Steam Generator Water Leve 1--Low-Low

14. Steam/Feedwater Flow Mismatch and Low Steam Generator Water Level

$\underset{D}{\omega}$

15. Undervoltage-Reactor Coolant Pumps
A. Four Loop Plant
B. Three Loop Plant
4-1/bus
$3-1 /$ bus

16. Underfrequency-Reactor Coolant Pumps
A. Four Loop Plant

B. Three Loop Plant

17. Turbine Trip

A. Low Fluid 0 il Pressure 3

톨

B. Turbine Stop Valve Closure 4

4- 1/bus

\begin{tabular}{|c|c|}
\hline $\begin{array}{l}\text { TOTAL NO. } \\
\text { OF CHANNELS } \\
\end{array}$ & $\begin{array}{l}\text { CHANNELS } \\
\text { TO TRIP }\end{array}$ \\
\hline $3 / 10 o p$ & $\begin{array}{l}2 / 10 o p \text { in } \\
\text { any oper- } \\
\text { ating loops }\end{array}$ \\
\hline $\begin{array}{l}2 / 1 \text { oop-leve } 1 \\
\text { and } \\
2 / 100 p-f l o w \\
\text { mismatch in } \\
\text { same loop }\end{array}$ & $\begin{array}{c}\text { 1/loop-level } \\
\text { coincident } \\
\text { with } \\
\text { l/loop-flow } \\
\text { mismatch in } \\
\text { same loop }\end{array}$ \\
\hline
\end{tabular}

$3-1 /$ bus

\section{MINIMUM}

CHANNELS

OPERABLE

2/loop in

each oper-

ating loop

1/loop-level 1, 2 and 2/loop-flow mismatch in same loop or 2/loop-level and

l/loop-flow mismatch in same loop

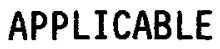


TABLE 3.3-1 (Continued)

\section{REACTOR TRIP SYSTEM INSTRUMENTATION}

\section{FUNCTIONAL UNIT}

18. Safety Injection Input from ESF

19. Reactor Coolant Pump Breaker Position Trip
A. Above P-8
B. Above $\mathrm{P}-7$

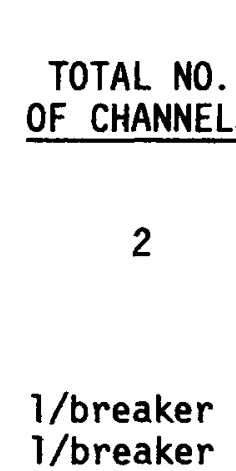

1/breaker
I/breaker

C. Power Range Neutron

Flux, P-8

4

D. Power Range Neutron Flux, $P-10$ (Input to $P-7$ )

4

E. Turbine Impulse Chamber Pressure, $\mathrm{P}-13$

CHANNELS

TO TRIP

1

2

$\begin{array}{ll}\text { 1/breaker } & 1 \\ 1 / \text { breaker } & 1 \\ \text { per oper } & \\ \text { ating loop } & \end{array}$

$21 /$ breaker

ACTION

CHANNELS APPLICABLE

MODES

1,2

12

1

$\stackrel{\omega}{\Phi}$ 
TABLE 3.3-1 (Continued)

$\frac{\bar{c}}{\dot{s}}$

\section{REACTOR TRIP SYSTEM INSTRUMENTATION}

\section{FUNCTIONAL UNIT}

21. Reactor Trip Breakers

22. Automatic Trip Logic
TOTAL NO. OF CHANNELS

2

2
CHANNELS

TO TRIP

1

1

\section{MINIMUM}

CHANNELS OPERABLE

2

2
APPLICABLE MODES

ACTION

1,2 and $* \quad 12$

1,2 and $* 12$

$\underset{\omega}{\omega}$

w

궁
00
0
00
0 


\section{TABLE 3.3-I (Continued)}

\section{TABLE NOTATION}

*

With the reactor trip system breakers in the closed position, the control rod drive system capable of rod withdrawal, and fuel in the $* *$ reactor vesse 1 .

The channel(s) associated with the protective functions derived from the out of service Reactor Coolant Loop shall be placed in the tripped condition.

\#The provisions of Specification 3.0.4 are not applicable.

\#\#igh voltage to detector may be de-energized above $P-6$.

\section{ACTION STATEMENTS}

ACTION 1 - With the number of OPERABLE channels one less than required by the Minimum Channels OPERABLE requirement, restore the inoperable channel to OPERABLE status within 48 hours or be in HOT STANDBY within the next 6 hours and/or open the reactor trip breakers.

ACTION 2 - With the number of OPERABLE channels one less than the Total Number of Channels, STARTUP and/or POWER OPERATION may proceed provided the following conditions are satisfied:

a. The inoperable channel is placed in the tripped condition within 1 hour.

b. The Minimum Channels OPERABLE requirement is met; however, one additional channel may be bypassed for up to 2 hours for surveillance testing per Specification 4.3.1.1.

c. Either, THERMAL POWER is restricted to less than or equal to $75 \%$ of RATED THERMAL POWER and the Power Range, Neutron Flux trip setpoint is reduced to less than or equal to (85)\% of RATED THERMAL POWER within 4 hours; or, the QUADRANT POWER TILT RATIO is monitored at least once per 12 hours.

d. The QUADRANT POWER TILT RATIO, as indicated by the remaining three detectors, is verified consistent with the power distribution obtained by using the movable incore detectors in the eight symmetric thimble locations at least once per 12 hours when THERMAL POWER is greater than $75 \%$ of RATED THERMAL POWER. 
ACTION 3 - With the number of channels OPERABLE one less than required by the Minimum Channels OPERABLE requirement and with the THERMAL POWER level:

a. Below $P-6$, restore the inoperable channel to OPERABLE status prior to increasing THERMAL POWER above the P-6 Setpoint.

b. Above P-6 but below 5\% of RATED THERMAL POWER, restore the inoperable channel to OPERABLE status prior to increasing THERMAL POWER above $5 \%$ of RATED THERMAL POWER.

c. Above 5\% of RATED THERMAL POWER, POWER OPERATION may continue.

ACTION 4 - With the number of OPERABLE channels one less than required by the Minimum Channe Ts OPERABLE requirement and with the THERMAL POWER level:

a. Below $\mathrm{P}-6$, restore the inoperable channel to OPERABLE status prior to increasing THERMAL POWER above the P-6 Setpoint.

b. Above $P-6$, operation may continue.

ACTION 5 - With the number of OPERABLE channels one less than required by the Minimum Channels OPERABLE requirement, verify compliance with the SHUTDOWN MARGIN requirements of Specification 3.1.1.1 or 3.1.1.2, as applicable, within 1 hour and at least once per 12 hours thereafter.

ACTION 6 - With the number of OPERABLE channels one less than the Total Number of Channels, STARTUP and/or POWER OPERATION may proceed provided the following conditions are satisfied:

a. The inoperable channel is placed in the tripped condition within 1 hour.

b. The Minimum Channels OPERABLE requirement is met; however, one additional channel may be bypassed for up to 2 hours for surveillance testing per Specification 4.3.1.1.

ACTION 7 - With the number of OPERABLE channels one less than the Total Number of Channels, STARTUP and/or POWER OPERATION may proceed until performance of the next required CHANNEL FUNCTIONAL TEST provided the inoperable channel is placed in the tripped condition within 1 hour. 


\section{TABLE 3.3-1 (Continued)}

ACTION 8 - With less than the Minimum Number of Channels OPERABLE, declare the interlock inoperable and verify that all affected channels of the functions listed below are OPERABLE or apply the appropriate ACTION statement(s) for those functions. Functions to be evaluated are:

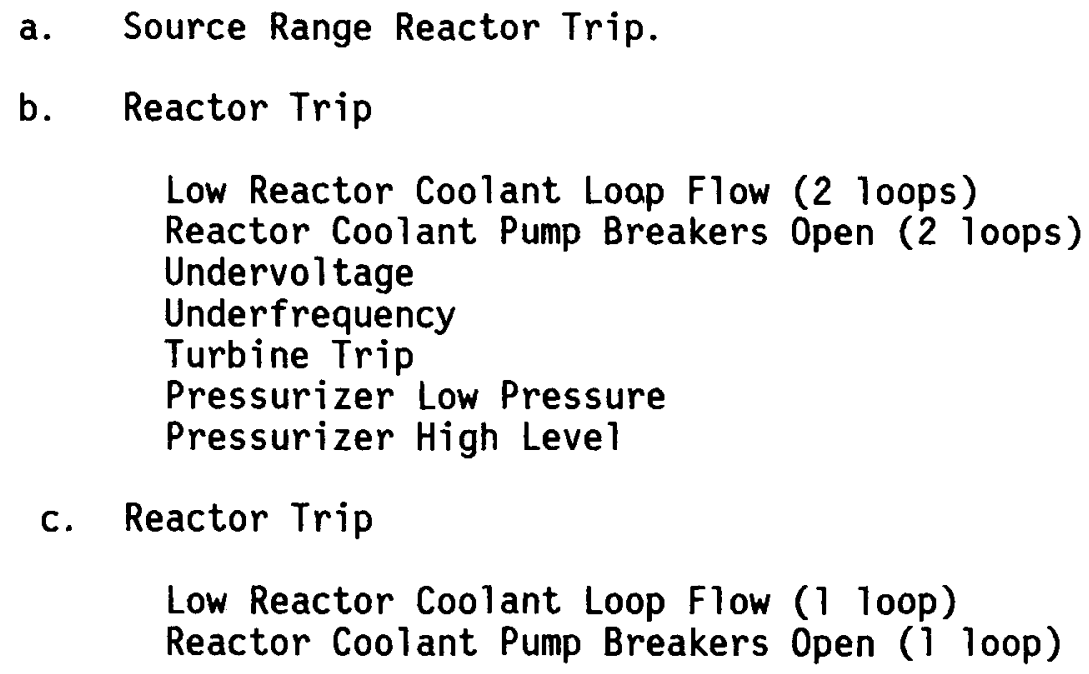

a. Source Range Reactor Trip.

b. Reactor Trip

Low Reactor Coolant Loop Flow (2 loops)

Reactor Coolant Pump Breakers Open (2 loops)

Undervoltage

Underfrequency

Turbine Trip

Pressurizer Low Pressure

Pressurizer High Level

c. Reactor Trip

Low Reactor Coolant Loop Flow (1 loop)

Reactor Coolant Pump Breakers Open (1 1oop)

d. Reactor Trip

Intermediate Range

Low Power Range

Source Range

ACTION 9 - With a channel associated with an operating loop inoperable, restore the inoperable channe] to OPERABLE status within 2 hours or be in HOT STANDBY within the next 6 hours; however, one channel associated with an operating loop may be bypassed for up to 2 hours for surveillance testing per Specification 4.3.1.1.

ACTION 10 - With one channel inoperable, restore the inoperable channel to OPERABLE status within 2 hours or reduce THERMAL POWER to below P-8 within the next 2 hours. Operation below P-8 may continue pursuant to ACTION 11. 


\section{TABLE 3.3-1 (Continued)}

ACTION 11 - With less than the Minimum Number of Channels OPERABLE, operation may continue provided the inoperable channel is placed in the tripped condition within 1 hour.

ACTION 12 - With the number of OPERABLE chanilels one less than required by the Minimum Channels OPERABLE requirement, be in HOT STANDBY within 6 hours; however, one channel may be bypassed for up to 1 hour for surveillance testing per Specification 4.3.1.1 


\section{REACTOR TRIP SYSTEM INSTRUMENTATION RESPONSE TIMES}

\section{FUNCTIONAL UNIT}

1. Manual Reactor Trip

2. Power Range, Neutron Fiux

3. Power Range, Neutron Flux, High Positive Rate

4. Power Range, Neutron Flux, High Negative Rate

5. Intermediate Range, Neutron Fiux

6. Source Range, Neutron Flux

$\omega \quad 7 . \quad$ Overtemperature $\Delta \mathrm{T}$

$\omega$ 8. Overpower $\Delta T$

$\omega$

9. Pressurizer Pressure--Low

10. Pressurizer Pressure--High

11. Pressurizer Water Leve1--High

\section{PESPONSE TIME}

Not Applicable

$\leq(0.5)$ seconds*

Irot Applicable

$\leq(0.5)$ seconds*

Not Applicat: le

Not Applicable

$\leq(2.0)$ seconds*

Not Applicable

$\leq(2.0)$ seconds

$\leq(2.0)$ seconds

Not Applicable

\footnotetext{
m Neutron detectors are exempt from response time testing. Response time of the neutron flux signal portion of the channel shall be measured from detector output or input of first electronic component in channel. (This provision is not applicable to CP's docketed after January 1, 1978. See Regulatory Guide 1.118, November 1977.)
} 


\section{REACTOR TRIP SYSTEM INSTRUMENTATION RESPONSE TIMES}

FUNCTIONAL UNIT

12. A. Loss of Flow - Single Loop (Above P-8)

B. Loss of Flow - Two Loops (Above $\mathrm{P}-7$ and below $\mathrm{P}-8$ )

13. Steam Generator Water Leve1--Low-Low

14. Steam/Feedwater Flow Mismatch and Low Steam Generator Water Level

$\varliminf_{\omega}^{\omega}$

$\omega$

$\stackrel{\bullet}{\sim}$

15. Undervoltage-Reactor Coolant Pumps

16. Underfrequency-Reactor Coolant Pumps

17. Turbine Trip

A. Low Fluid 0il Pressure

B. Turbine Stop Valve

18. Safety Injection Input from ESF

19. Reactor Coolant Pump Breaker Position Trip

20. Reactor Trip System Interlocks

21. Reactor Trip Breakers

22. Automatic Trip Logic

\section{RESPONSE TIME}

$\leq(1.0)$ seconds

$\leq(1.0)$ seconds

$\leq(2.0)$ seconds

Not Applicable

$\leq(1.2)$ seconds

$\leq(0.6)$ seconds

Not Applicable Not Applicable

Not Applicable

Not Applicable

Not Applicable

Not Applicable

Not Applicable

70
00
0
0
0
0 
TABLE 4.3-1

\section{REACTOR TRIP SYSTEM INSTRUMENTATION SURVEILLANCE REQUIREMENTS}

\section{FUNCTIONAL UNIT}

1. Manua 7 Reactor Trip

2. Power Range, Neutron Flux

3. Power Range, Neutron Flux, High Positive Rate

$\omega$
$\omega$
$\frac{\omega}{\omega}$

4. Power Range, Neutron Flux, High Negative Rate

5. Intermediate Range, Neutron Flux

6. Source Range, Neutron Flux

7. Overtemperature $\Delta \mathrm{T}$

8. Overpower $\Delta \mathrm{T}$

9. Pressurizer Pressure--Low

10. Pressurizer Pressure--High

E 11. Pressurizer Water Leve1--High

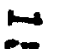

बृ
12. A. Loss of Flow - Single Loop

B. Loss of Flow - Two Loops

\begin{tabular}{|c|c|c|c|}
\hline $\begin{array}{l}\text { CHANNEL } \\
\text { CHECK } \\
\end{array}$ & $\begin{array}{c}\text { CHANNEL } \\
\text { CALIBRATION } \\
\end{array}$ & $\begin{array}{c}\text { CHANNEL } \\
\text { FUNCTIONAL } \\
\text { TEST } \\
\end{array}$ & $\begin{array}{c}\text { MODES IN WHICH } \\
\text { SURVEILLANCE } \\
\text { REQUIRED } \\
\end{array}$ \\
\hline N.A. & N. A. & $S / U(1)$ & N.A. \\
\hline$S$ & $\begin{array}{l}D(2), M(3) \\
\text { and } Q(6)\end{array}$ & M & 1,2 \\
\hline N.A. & $R(6)$ & M & 1,2 \\
\hline N.A. & $R(6)$ & M & 1,2 \\
\hline$S$ & $R(6)$ & $S / U(1)$ & 1,2 and $x$ \\
\hline$s(7)$ & $R(6)$ & $M$ and $S / U(1)$ & $\begin{array}{l}2,3,4, \\
5 \text { and * }\end{array}$ \\
\hline$S$ & $\mathbf{R}$ & $M$ & 1,2 \\
\hline$S$ & $R$ & M & 1,2 \\
\hline$S$ & $\mathbf{R}$ & M & 1,2 \\
\hline $\mathrm{S}$ & R & M & 1,2 \\
\hline$S$ & $R$ & $M$ & 1,2 \\
\hline$S$ & $\mathbf{R}$ & M & 1 \\
\hline$S$ & $\mathbf{R}$ & N.A. & 1 \\
\hline
\end{tabular}


TABLE 4.3-1 (Continued)

\section{REACTOR TRIP SYSTEM INSTRUMENTATION SURVEILLANCE REQUIREMENTS}

\section{FUNCTIONAL UNIT}

13. Steam Generator Water Leve 1-Low-Low

14. Steam/Feedwater Flow Mismatch and Low Steam Generator Water Level

15. Undervoltage - Reactor Coolant Pumps

$\underset{\omega}{\omega}$

16. Underfrequency - Reactor Coolant Pumps

$\stackrel{\omega}{\omega}$ 17. Turbine Trip

A. Low Fluid 0il Pressure

B. Turbine Stop Valve Closure

18. Safety Injection Input from ESF

19. Reactor Coolant Pump Breaker Position Trip

20. Reactor Trip System Interlocks

21. Reactor Trip Breaker

22. Automatic Trip Logic

\begin{tabular}{|c|c|}
\hline $\begin{array}{l}\text { CHANNEL } \\
\text { CHECK } \\
\end{array}$ & $\begin{array}{c}\text { CHANNEL } \\
\text { CALIBRATION }\end{array}$ \\
\hline
\end{tabular}

S

S

N.A.

N.A.

N.A.

N.A.

N.A.

N.A.

N.A.

N. A.

N.A.

\section{R}

R

$\mathbf{R}$

R

N.A.

N.A.

N. A.

N.A.

N.A.

N.A.

N.A.

\section{CHANNEL} FUNCTIONAL

TEST

M

M

$M$

M

1

MODES IN WHICH SURVEILLANCE REQUIRED

1,2

1,2

1,2

1,2

1,2

N.A.

N.A.

$M(5)$ and $S / U(1) \quad 1,2$, and *

$M(5)$ 


\section{TABLE 4.3-1 (Continued)}

\section{TABLE NOTATION}

* - With the reactor trip system breakers closed and the control rod drive system capable of rod withdrawal.

(1) - If not performed in previous 7 days.

(2) - Heat balance only, above 15\% of RATED THERMAL POWER. Adjust channel if absolute difference greater than 2 percent.

(3) - Compare incore to excore axial flux difference above 15\% of RATED THERMAL POWER. Recalibrate if the absolute difference greater than or equal to (2) percent.

(4) - Manual ESF functional input check every 18 months.

(5) - Each train tested every other month.

(6) - Neutron detectors may be excluded from CHANNEL CALIBRATION.

(7) - Below P-6 setpoint. 
3.3.2 The Engineered Safety Feature Actuation System (ESFAS) instrumentation channels and interlocks shown in Table 3.3-3 shall be OPERABLE with their trip setpoints set consistent with the values shown in the Trip Setpoint column of Table 3.3-4 and with RESPONSE TIMES as shown in Table 3.3-5.

APPLICABILITY: As shown in Table 3.3-3.

ACTION:

a. With an ESFAS instrumentation channel or interlock trip setpoint less conservative than the value shown in the Allowable Values column of Table 3.3-4, declare the channel inoperable and apply the applicable ACTION requirement of Table 3.3-3 until the channel is restored to OPERABLE status with the trip setpoint adjusted consistent with the Trip Setpoint value.

b. With an ESFAS instrumentation channel or interlock inoperable, take the ACTION shown in Table 3.3-3.

4.3.2.1 Each ESFAS instrumentation channel shall be demonstrated OPERABLE by the performance of the CHANNEL CHECK, CHANNEL CALIBRATION and CHANNEL FUNCTIONAL TEST operations for the MODES and at the frequencies shown in Table 4.3-2.

4.3.2.2 The logic for the interlocks shall be demonstrated OPERABLE during the automatic actuation logic test. The total interlock function shall be demonstrated OPERABLE at least once per 18 months during CHANNEL CALIBRATION testing of each channel affected by interlock operation.

4.3.2.3 The ENGINEERED SAFETY FEATURES RESPONSE TIME of each ESFAS function shall be demonstrated to be within the limit at least once per 18 months. Each test shall include at least one logic train such that both lagic trains are tested at least once per 36 months and one channel per function such that all channels are tested at least once per $N$ times 18 months where $N$ is the total number of redundant channels in a specific ESFAS function as shown in the "Total No. of Channels" Column of Table 3.3-3. 
TABLE 3.3-3

\section{MINIMUM}

CHANNELS

OPERABLE
TOTAL NO. OF CHANNELS

\section{APPLICABLE}

MODES

\section{ACTION}

1. SAFETY INJECTION, TURBINE

TRIP AND FEEDWATER ISOLATION
a. Manual Initiation
b. Automatic Actuation
Logic
c. Containment Pressure-High
d. Pressurizer
Pressure - Low
e. Differential
Pressure Between
Steam Lines - High

2

$\omega$
$\omega$
$\omega$
$\frac{1}{v}$

i) Four Loop Plant

$\begin{array}{llll}\begin{array}{l}\text { Four Loops } \\ \text { Operating }\end{array} & \text { 3/steam line } & \begin{array}{l}\text { 2/steam line 2/steam line } \\ \text { any steam line }\end{array} \\ \begin{array}{l}\text { Three Loops } \\ \text { Operating }\end{array} & \begin{array}{l}\text { 3/operating } \\ \text { steam line }\end{array} & \begin{array}{l}\text { 1 \#\#\#/steam } \\ \text { line any } \\ \text { operating } \\ \text { steam line }\end{array} & \begin{array}{l}\text { 2/operating } \\ \text { steam line }\end{array}\end{array}$

\section{$14^{\star}$}

졸
0
0
0
0 
TABLE 3.3-3 (Continued)

\section{FUNCTIONAL UNIT}

ii)

Three Loop Plant

Three Loops

Operating

Two Loops

Operating

$\underset{\omega}{\omega}$

롤 f. Steam Flow in Two
Steam Lines-High

i) Four Loop Plant

Four Loops
Operating
Three Loops
Operating

\begin{tabular}{cl} 
TOTAL NO. & CHANNELS \\
OF CHANNELS & TO TRIP \\
\hline
\end{tabular}

$2 /$ steam line twice and $1 / 3$ steam lines

3/operating steam line

$2^{\# \# \# / \text { steam }}$

Iine twice

in either

operating

steam line
MINIMUM

CHANNELS

OPERABLE

APPLICABLE

MODES

ACTION

2/steam line

$14^{\star}$

15

2/operating

steam line

$$
1,2,3^{\# \#}
$$

$\begin{array}{lll}\text { 2/steam line } & \begin{array}{l}\text { 1/steam line } \\ \text { any 2 steam } \\ \text { 1ines }\end{array} & \text { 1/steam line } \\ \text { 2/operating } & \begin{array}{l}\text { 1\#\#\#/any } \\ \text { operating } \\ \text { steam line }\end{array} & \begin{array}{l}\text { 1/operating } \\ \text { steam line }\end{array}\end{array}$




\section{TABLE 3.3-3 (Continued)}

FUNCTIONAL UNIT

ii) Three Loop Plant

Three Loops

Operating

Two Loops

Operating

COINCIDENT WITH

EITHER

$\omega$
$\omega$
$\omega$
$\omega$

$$
T_{\text {avg }}{ }^{--L o w-L o w ~}
$$

i) Four Loop Plant

Four Loops

Operating

Three Loops

Operating

ii) Three Loop Plant

Three Loops

Operating

至
er
总
Two Loops

\begin{tabular}{|c|c|c|}
\hline $\begin{array}{l}\text { TOTAL NO. } \\
\text { OF CHANNELS }\end{array}$ & $\begin{array}{l}\text { CHANNELS } \\
\text { TO TRIP } \\
\end{array}$ & $\begin{array}{l}\text { MINIMUM } \\
\text { CHANNELS } \\
\text { OPERABLE }\end{array}$ \\
\hline $2 /$ steam 7 ine & $\begin{array}{l}\text { 1/steam line } \\
\text { any } 2 \text { steam } \\
\text { lines }\end{array}$ & 1/steam line \\
\hline $\begin{array}{l}\text { 2/operating } \\
\text { steam line }\end{array}$ & $\begin{array}{l}1^{\# \# / \text { /any }} \\
\text { operating } \\
\text { steam Tine }\end{array}$ & $\begin{array}{l}\text { l/operating } \\
\text { steam line }\end{array}$ \\
\hline
\end{tabular}

Operating
APPLICABLE

MODES

$\underline{\text { ACTION }}$

$14^{*}$

15

$1,2,3^{\# \#}$

\begin{tabular}{|c|c|c|}
\hline $1 \mathrm{~T}_{\text {avg }} /$ loop & $\begin{array}{l}2 T_{\text {avg }} \text { any } \\
\text { loops }\end{array}$ & $\begin{array}{l}1 \mathrm{~T}_{\text {avg }} \text { any } \\
3 \text { loops }\end{array}$ \\
\hline $\begin{array}{l}1 T_{\text {avg }}^{\prime} \\
\text { operating } \\
\text { loop }\end{array}$ & $\begin{array}{l}1^{\# \# \#} T_{\text {avg }} \text { in } \\
\text { any operating } \\
\text { loop }\end{array}$ & $\begin{array}{l}1 T_{\text {avg in any }} \\
\text { two operating } \\
\text { loops }\end{array}$ \\
\hline
\end{tabular}

$14^{\star}$

$14^{*}$

$$
\begin{array}{lll}
1 \mathrm{~T}_{\text {avg }} \text { loop } & \begin{array}{l}
2 \mathrm{~T}_{\text {avg }} \\
\text { loops }
\end{array} & \begin{array}{l}
1 \mathrm{~T}_{\text {avg }} \text { any } 2 \\
\text { loops }
\end{array} \\
1 \mathrm{~T}_{\text {avg' }} & \begin{array}{l}
\# \# \mathrm{~T}_{\text {avg }} \text { in } \\
\text { operating loop }
\end{array} & \begin{array}{l}
\text { any operating } \\
\text { loop }
\end{array}
\end{array}
$$


TABLE 3.3-3 (Continued)

FUNCTIONAL UNIT

OR, COINCIDENT WITH

Steam Line Pressure-Low

i) Four Loop Plant Four Loops Operating

Three Loops

Operating

ii) Three Loop Plant

Operating

Two Loops

Operating
Three Loops

1 pressure/
loop
l pressure/
operating
loop
1 pressure/
loop
1 pressure/
loop

2 pressures any loops

\#\#\# ating loop

1 pressure any 3 Toops

MINIMUM

CHANNELS

OPERABLE

1 pressure

in any 2

operating loops

\section{2 pressures 1 pressure} any loops any 2 loops

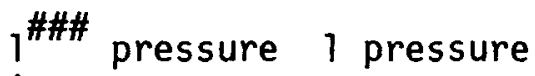
in any oper- any operating ating loop loop in any oper-

\section{APPLICABLE \\ MODES \\ $1,2,3^{\# \#}$ \\ ACTION}

$14^{*}$

15

$14^{*}$

2. CONTAINMENT SPRAY
a. Manual
2
2
(1)
2
2
$1,2,3,4$
b. Automatic Actuation
Logic
c. Containment Pressure--
4
2
3
18
13
16 High-High 
TABLE 3.3-3 (Continued)

\section{ENGINEERED SAFETY FEATURE ACTUATION SYSTEM INSTRUMENTATION}

FUNCTIONAL UNIT

$$
\begin{aligned}
& \text { TOTAL NO. } \\
& \text { OF CHANNELS }
\end{aligned}
$$

CHANNELS
TO TRIP

MINIMUM

CHANNELS

OPERABLE

APPLICABLE

MODES

ACTION

3. CONTAINMENT ISOLATION

a. Phase "A" Isolation

\begin{tabular}{|c|c|c|c|c|}
\hline 1) Manual & 2 & 1 & 2 & $1,2,3,4$ \\
\hline $\begin{array}{l}\text { From Safety Injection } \\
\text { Automatic Actuation }\end{array}$ & 2 & 1 & 2 & $1,2,3,4$ \\
\hline
\end{tabular}

b. Phase "B" Isolation

$\omega$
$\omega$
$\vdots$
$\sim$

\begin{tabular}{|c|c|c|}
\hline 1) & Manual & 2 \\
\hline 2) & $\begin{array}{l}\text { Automatic } \\
\text { Actuation Logic }\end{array}$ & 2 \\
\hline & $\begin{array}{l}\text { Containment } \\
\text { Pressure--High-High }\end{array}$ & 4 \\
\hline
\end{tabular}

c. Purge and Exhaust

Isolation
1) Manual
2) Containment
Radioactivity-High

(4)

(2)

$1,2,3,4$

17

$1,2,3,4$

17

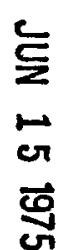


TABLE 3.3-3 (Continued)

TOTAL NO. CHANNELS OF CHANNELS TO TRIP

4. STEAM LINE ISOLATION

a. Manua1

b. Automatic Actuation Logic

c. Containment Pressure-$\mathrm{High}$-High

छூ

2

1

d. Steam Flow in Two

Steam Lines--High

i) Four Loop Plant Four Loops

Operating

Three Loops

Operating

4

2

$2 /$ steam line

lines

2/operating

steam line

ii) Three Loop Plant Three Loops Operating

2/steam line

lines

2/operating

$1^{\# \# \# / a n y ~}$
Two Loops
Operating

steam line
MINIMUM

CHANNELS

OPERABLE

APPLICABLE

MODES

ACTION

1/steam line $1 /$ steam line

1/operating

$1,2,3$

18 steam line

$1,2,3$

13

2

$1,2,3$

16

3

$1,2,3^{\# \#}$

$1 /$ steam line any 2 steam

1/steam line

1 \#\#\#/any

operating

1/operating

steam line

1/steam line any 2 steam

1/steam line operating steam line

1/operating

steam line 
TABLE 3.3-3 (Continued)

$\frac{1}{i}$

\section{ENGINEERED SAFETY FEATURE ACTUATION SYSTEM INSTRUMENTATION}

FUNCTIONAL UNIT

TOTAL NO. CHANNELS CHANNELS

OF CHANNELS TO TRIP OPERABLE MODES ACTION

COINCIDENT WITH EITHER

Tavg ${ }^{--L o w-L o w ~}$

$i, 2,3^{\# \#}$

i) Four Loop Plant

Four Loops

Operating

$1 \mathrm{~T}_{\mathrm{avg}} / 10 \mathrm{pp}$

$2 T_{\text {avg }}$ any

$1 T_{\text {avg }}$ any

$14^{*}$

Three Loops

$\stackrel{\omega}{\omega}$

Operating

$1 \mathrm{~T}_{\text {avg }}$ /oper-

loops

3 loops

ating loop any operating two operating

loop loops

ii) Three Loop Plant

Three Loops

Operating

$1 \mathrm{~T}_{\mathrm{avg}} / 100 \mathrm{p}$

$2 T_{\text {avg }}$ any

2 loops

1 Tavg any

$14^{*}$

Two loops

Operating

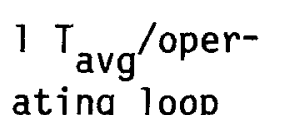

$1^{\# \# \#} \mathrm{~T}_{\text {avg }} 1 \mathrm{~T}_{\text {avg }}$ in any

in any oper- operating loop ating loop 
TABLE 3.3-3 (Continued)

\section{ENGINEERED SAFETY FEATURE ACTUATION SYSTEM INSTRUMENTATION}

FUNCTIONAL UNIT

\begin{tabular}{cll} 
TOTAL NO. & CHANNELS & $\begin{array}{l}\text { MINIMUM } \\
\text { CHANNELS }\end{array}$ \\
OF CHANNELS & TO TRIP & OPERABLE \\
\hline
\end{tabular}

APPLICABLE

MODES

$\underline{\text { ACTION }}$

OR, COINCIDENT WITH

Steam Line PressureLow

$1,2,3^{\# \#}$

i) Four Loop Plant

Four Loops

Operating

Three Loops

Operating

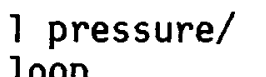

2 pressures any loops

1 pressure

$14^{*}$

1 pressure/

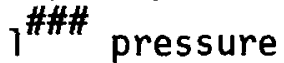

any 3 loops

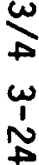

operating loop in any oper-

ating loop ating loops

ii) Three Loop Plant

\section{Three Loops Operating}

Two Loops Operating

5. TURBINE TRIP \& FEEDWATER ISOLATION

a. Steam Generator Water Leve1-High-High
3/1 oop

2/loop in any operating loop

2/loop in

$1,2,3$

each oper-

ating loop any operating loop 
TABLE 3.3-3 (Continued)

\section{ENGINEERED SAFETY FEATURE ACTUATION SYSTEM INSTRUMENTATION}

FUNCTIONAL UNIT

6. AUXILIARY FEEDWATER

a. Stm. Gen. Water Leve]-Low-Low

i. Start Motor Driven Pumps

ii. Start TurbineDriven Pumps

b. Undervoltage-RCP

Start Turbine-

Driven Pump

(4) $-1 /$ bus

2

3

1

19

c. S.I.

Start Motor-

Driven Pumps

d. Station Blackout

Start Motor-Driven

Pumps

(2)

(2)

(2)

$1,2,3,4$

18

e. Trip of Main

Feedwater Pumps

Start Motor-

Driven Pumps

(2/pump)

(1/pump)

(1/pump)

1,2 
TABLE 3.3-3 (Continued)

\section{ENGINEERED SAFETY FEATURE ACTUATION SYSTEM INSTRUMENTATION}

FUNCTIONAL UNIT

7. LOSS OF POWER

a. $4 \mathrm{kv}$ Bus

8. ENGINEERED SAFETY FEATURE Loss of Voltage

b. Grid Degraded Vołtage ACTUATION SYSTEM INTERLOCKS
a. Pressurizer Pressure, P-11
b. Low-Low $\mathrm{T}_{\text {avg }}, \mathrm{P}-12$
(See 5.a above) Leve1, P-14

\section{TOTAL NO. \\ CHANNELS \\ CHANNELS}

TO TRIP

\section{MINIMUM}

OPERABLE

APPLICABLE MODES

ACTION
(3/Bus)

$1,2,3$

$19^{*}$

(3/Bus)

$1,2,3$

$19 *$

吾
당
$\overrightarrow{0}$
$\overrightarrow{0}$ 
TABLE 3.3-3 (Continued)

TABLE NOTATIDN

\#Trip function may be bypassed in this MODE below $\mathrm{P}-11$.

\#\# Trip function may be bypassed in this MODE below $\mathrm{P}-12$.

\#\#\# The channel(s) associated with the protective functions derived from the out of service Reactor Coolant Loop shall be placed in the tripped mode.

*The provisions of Specification 3.0.4 are not applicable.

\section{ACTION STATEMENTS}

ACTION 13 - With the number of OPERABLE channels one less than the Total Number of Channels, be in HOT STANDBY within 6 hours and in COLD SHUTDOWN within the following 30 hours; however, one channel may be bypassed for up to 1 hour for surveillance testing per Specification 4.3.2.1.

ACTION 14 - With the number of OPERABLE channels one less than the Total Number of Channels, operation may proceed until performance of the next required CHANNEL FUNCTIONAL TEST provided the inoperable channel is placed on the tripped condition within 1 hour.

ACTION 15 - With a channel associated with an operating loop inoperable, restore the inoperable channel to OPERABLE status within 2 hours or be in at least HOT STANDBY within the next 6 hours and in at least HOT SHUTDOWN within the following 6 hours; however, one channel associated with an operating loop may be bypassed for up to 2 hours for surveillance testing per Specification 4.3.2.1.

ACTION 16 - With the number of OPERABLE channels one less than the Total Number of Channels, operation may proceed provided the inoperable channel is placed in the bypassed condition and the Minimum Channels OPERABLE requirement is demonstrated within 1 hour; one additional channel may be bypassed for up to 2 hours for surveillance testing per Specification 4.3.2.1.

ACTION 17 - With less than the Minimun Channels OPERABLE, operation may continue provided the containment purge and exhaust valves are maintained closed.

ACTION 18 - With the number of OPERABLE Channels one less than the Total Number of Channels, restore the inoperable channel to OPERABLE status within 48 hours or be in at least HOT STANDBY within the next 6 hours and in COLD SHUTDOWN within the following 30 hours. 


\section{TABLE 3.3-3 (Continued)}

ACTION 19 - With the number of OPERABLE Channels one less than the Total Number of Channels, STARTUP and/or POWER OPERATION may proceed provided the following conditions are satisfied:

a. The inoperable channel is placed in the tripped condition within 1 hour.

b. The Minimum Channels OPERABLE requirements is met; however, one additional channel may be bypassed for up to 2 hours for surveillance testing per Specification 4.3.2.1.

ACTION 20 - With less than the Minimum Number of Channels OPERABLE, declare the interlock inoperable and verify that all affected channels of the functions listed below are OPERABLE or apply the appropriate ACTION statement(s) for those functions. Functions to be evaluated are:

a. Safety Injection

Pressurizer Pressure

b. Safety Injection

High Steam Line Flow

Low-Low Tavg

Low Steam line Pressure

Steam Line Isolation

High Steam Line Flow

Low-Low Tavg

Low Steamline Pressure

Steam Dump 
TABLE 3.3-4

\section{ENGINEERED SAFETY FEATURE ACTUATION SYSTEM INSTRUMENTATION TRIP SETPOINTS}

FUNCTIONAL UNIT

1. SAFETY INJECTION, TURBINE TRIP AND FEEDWATER ISOLATION

a. Manual Initiation

b. Automatic Actuation Logic

c. Containment Pressure--High

d. Pressurizer Pressure--Low

e. Differential Pressure Between Steam Lines--High

$\omega$ f. Steam Flow in Two Steam Lines-High, Coincident with

$T_{\text {avg }}{ }^{- \text {-Low-Low or }}$

Steam Line Pressure--Low

\section{TRIP SETPOINT}

Not Applicable

Not Applicable

$\leq 5$ psig

$\geq 1765$ psig

$\leq 100 \mathrm{psi}$

$<$ A function defined as follows: A $\Delta p$ corresponding to $40 \%$ of full steam flow between $0 \%$ and $20 \%$ load and then a $\Delta p$ in- $^{-}$ creasing linearly to a $\Delta p$ corresponding to $110 \%$ of full steam flow at full load with

$\mathrm{T}_{\text {avg }} \geq(541)^{\circ} \mathrm{F}$, or Steam Line Pressure $\geq(600)$ psig

\section{ALLOWABLE VALUES}

Not Applicable

Not Applicable

$\leq 5.5 \mathrm{psig}$

$\geq 1755$ psig

$\leq 112 \mathrm{psi}$

$<$ A function defined as follows: A $\Delta p$ corresponding to $44 \%$ of full steam flow between $0 \%$ and $20 \%$ load and then a $\Delta p$ increasing linearly to a $\Delta p$ corresponding to

$111.5 \%$ of full steam flow at full load with

$\mathrm{T}_{\text {avg }} \geq(539)^{\circ} \mathrm{F}$, or

Steam Line Pressure

$\geq(580)$ psig 
TABLE 3.3-4 (Continued)

$\underset{\substack{n \\ \text { ind }}}{1}$

ENGINEERED SAFETY FEATURE ACTUATION SYSTEM INSTRUMENTATION TRIP SETPOINTS

FUNCTIONAL UNIT

TRIP SETPOINT

ALLOWABLE VALUES

2. CONTAINMENT SPRAY

a. Manual Initiation

Not Applicable

Not Applicable

b. Automatic Actuation Logic

Not Applicable

Not Applicable

c. Containment Pressure--High-High

$\leq$ (20) psig

$\leq$ (22) psig

3. CONTAINMENT ISOLATION

a. Phase "A" Isolation

$\stackrel{\omega}{\infty}$

1. Manual

Not Applicable

Not Applicable

2. From Safety Injection Automatic Actuation logic

Not Applicable

Not Applicable

b. Phase " $B$ " Isolation

1. Manual

Not Applicable

Not Applicable

2. Automatic Artuation Logic

Not Applicable

Not Applicable

3. Containment Pressure--.High-High

< (20) psig

$\leq$ (22) psig

c. Purge and Exhaust Isolation

둥
항

1. Manual

2. Containment Radioactivity--High
Not Applicable

( $\leq 2 \times$ background)
Not Applicable

( $\leq 2 \times$ background) 
TABLF 3.3-4 (Continued)

FUNCTIONAL UNIT

4. STEAM LINE ISOLATION

a. Manual

b. Automatic Actuation Logic

c. Containment Pressure--High-High

d. Steam Flow in Two Steam Lines-: High, Coincident with Tavg - -Low-Low, or

$\underset{\omega}{\omega}$

w

5. TURBINE TRIP AND FEED WATER ISOLATION
a. Steam Generator Water leve]--- High-High

TRIP SETPOINT

Not Applicable

Not Applicable

$\leq$ (20) psig

$<$ A function defined as follows: A $\Delta p$ corresponding to $40 \%$ of full steam flow between $0 \%$ and $20 \%$

load and then a $\Delta p$ increasing linearly to a $\Delta \mathrm{p}$ corresponding to $110 \%$ of full steam flow at full load with

$\mathrm{T}_{\text {avg }} \geq(541)^{\circ} \mathrm{F}$, or

Steam Line Pressure

$\geq$ (600) psig

$\leq(67) \%$ of narrow range instrument span each steam generator

\section{ALLOWABLE VALUES}

Not Applicable

Not Applicable

$\leq$ (22) psig

$<$ A function defined as follows: A $\Delta p$ corresponding to $44 \%$ of full steam flow between $0 \%$ and $20 \%$ load and then a $\Delta p$ increasing linearly to a $\Delta p$ corresponding to $111.5 \%$ of full steam flow at full load with

$\mathrm{T}_{\text {avg }} \geq(539)^{\circ} \mathrm{F}$, or Steam Line Pressure $\geq(580)$ psig

$\leq(68) \%$ of narrow range instrument span each steam generator

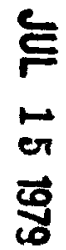




\section{TRIP SETPOINT}

6. AUXILIARY FEEDWATER
a. Steam Generator Water Level-10w-10w

b. Undervoltage - RCP

c. S.I.

d. Station Blackout

e. Trip of Main Feedwater

$\stackrel{\omega}{\omega}$

w

7. LOSS OF POWER
a. 4.16 kv Emergency Bus Undervoltage (Loss of Voltage)
b. $\quad 4.16 \mathrm{kv}$ Emergency Bus Undervoltage (Degraded Voltage)

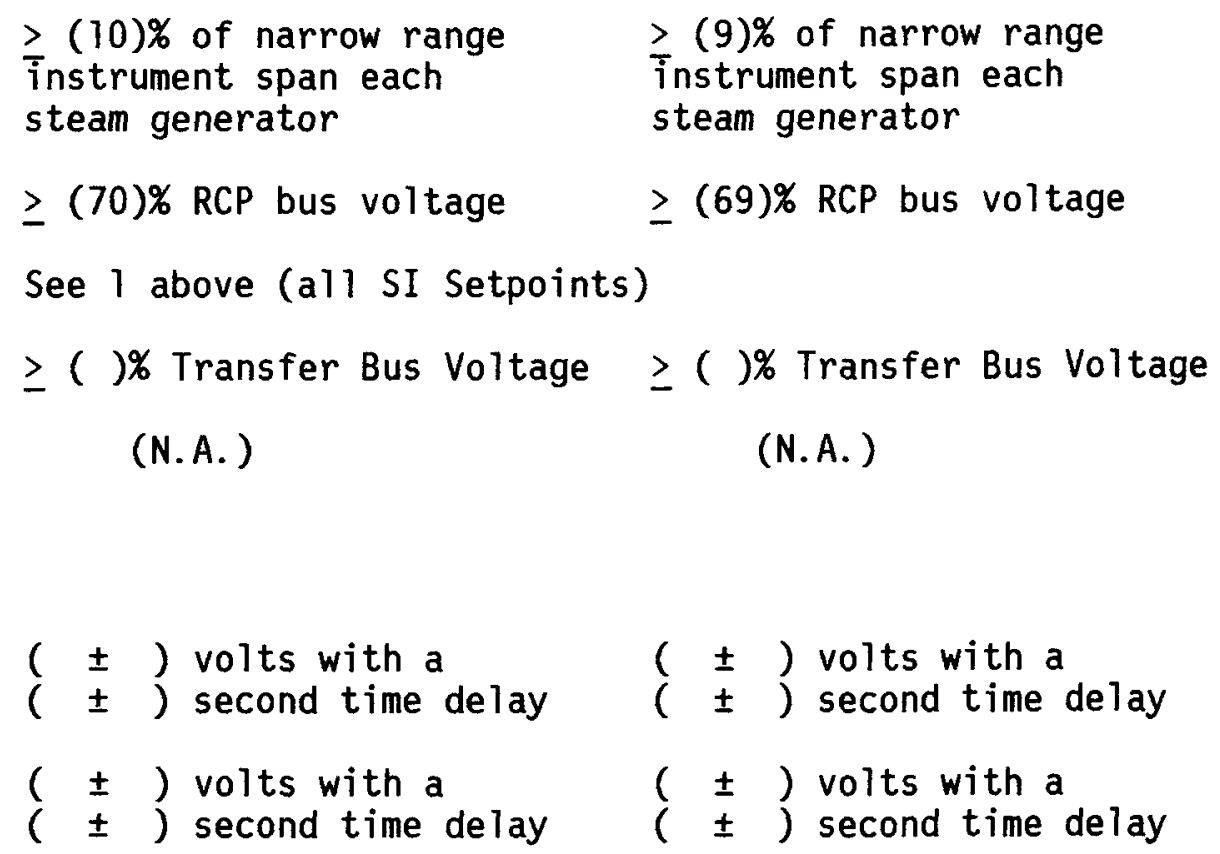


TABLE 3.3-4 (Continued)

is

\section{ENGINEERED SAFETY FEATURE ACTUATION SYSTEM INSTRUMENTATION TRIP SETPOINTS}

FUNCTIONAL UNIT

8. ENGINEERED SAFETY FEATURE ACTUATION SYSTEM INTERLOCKS
a. Pressurizer Pressure, $P-11$
b. Low-Low $T_{\text {avg }}$, P-12 $\begin{aligned} & \text { (Increasing) } \\ & \text { (Decreasing) }\end{aligned}$
c. Steam Generator Leve1, P-14

TRIP SETPOINT

$\leq(2000)$ psig

$(543)^{\circ} \mathrm{F}$

$(543)^{\circ} \mathrm{F}$

(See 5. above)
ALLOWABLE VALUES

$\leq(2010)$ psig

$\leq(545)^{\circ} \mathrm{F}$
$\geq(541)^{\circ} \mathrm{F}$

$\omega$
$\stackrel{\omega}{\omega}$
$\vdots$
$\omega$
$\omega$ 


\section{ENGINEERED SAFETY FEATURES RESPONSE TIMES}

\section{INITIATING SIGNAL AND FUNCTION}

1. Manual
a. Safety Injection (ECCS)
Feedwater Isolation
Reactor Trip (SI)
Containment Isolation-Phase "A"
Containment Vent and Purge Isolation
Auxiliary Feedwater Pumps
Essential Service Water System
Containment Air Recirculation Fan
b. Containment Spray
Containment Isolation-Phase " $B$ "
Containment Vent and Purge Isolation
c. Containment Isolation-Phase " $A$ "
Containment Vent and Purge Isolation
d. Steam Line Isolation

2. Containment Pressure-High
a. Safety Injection (ECCS)
b. Reactor Trip (from SI)
c. Feedwater Isolation
d. Containment Isolation-Phase " $A$ "
e. Containment Vent and Purge Isolation
f. Auxiliary Feedwater Pumps
g. Essential Service Water System

RESPONSE TIME IN SECONDS

\begin{abstract}
Not Applicable
Not Applicable

Not Applicable

Not Applicable

Not Applicable

Not Applicable

Not Applicable

Not Applicable

Not Applicable

Not Applicable

Not Applicable

Not Applicable

Not Applicable

Not Applicable
\end{abstract}




\section{TABLE 3.3-5 (Continued)}

\section{ENGINEERED SAFETY FEATURES RESPONSE TIMES}

INITIATING SIGNAL AND FUNCTION

3. Pressurizer Pressure-Low

a. Safety Injection (ECCS)

b. Reactor Trip (from SI)

c. Feedwater Isolation

d. Cantainment Isolation-Phase "A"

e. Containment Vent and Purge Isolation

f. Auxiliary Feedwater Pumps

g. Essential Service Water System
RESPONSE TIME IN SECONDS

$\leq(27.0)^{*} /(12.0) \#$

$\leq(2.0)$

$\leq(7.0)$

$\leq(17.0) \#$

Not Applicable

Not Applicable

$\leq(47.0) * /(12.0) \#$

4. Differential Pressure Between Steam Lines-High
a. Safety Injection (ECCS)
$\leq(11.0) \# /(22.0) \# \#$
b. Reactor Trip (from SI)
$\leq(2.0)$
c. Feedwater Isolation
$\leq(7.0)$
d. Containment Isolation-Phase "A"
$\leq(17.0) \# /(27.0) \# \#$
e. Containment Vent and Purge Isolation
Not Applicable
f. Auxiliary Feedwater Pumps
Not Applicable
g. Essential Service Water System
$\leq(12.0) \# /(47.0) \# \#$

5. Steam Flow in Two Steam Lines - High Coincident with

Iavg- - Low-Low

a. Safety Injection (ECCS)

b. Reactor Trip (from SI)

c. Feedwater Isolation

d. Containment Isolation-Phase "A"

e. Containment Vent and Purge Isolation

f. Auxiliary Feedwater Pumps

g. Essential Service Water System

h. Steam Line Isolation $\leq(14.0) \# /(24.0) \# \#$

$\leq(4.0)$

$\leq(9.0)$

$\leq(19.0) \# /(29.0) \# \#$

Not Applicable

Not Applicable

$\leq(14.0) \# /(49.0) \# \#$

$\leq(9.0)$ 


\section{ENGINEERED SAFETY FEATURES RESPONSE TIMES}

INITIATING SIGNAL AND FUNCTION

RESPONSE TIME IN SECONDS

6. Steam Flow in Two Steam Lines-High Coincident with Steam Line Pressure-Low
a. Safety Injection (ECCS)
$\leq(12.0) \# /(22.0) \# \#$
b. Reactor Trip (from SI)
$\leq(2.0)$
c. Feedwater Isolation
$\leq(7.0)$
d. Containment Isolation-Phase "A"
$\leq(17.0) \# /(27.0) \#$
e. Containment Vent and Purge Isolation
Not Applicable
f. Auxiliary Feedwater Pumps
Not Applicable
g. Essential Service Water System
$\leq(12.0) \# /(47.0) \# \#$
h. Steam Line Isolation
$\leq(7.0)$

7. Containment Pressure--High-High
a. Containment Spray
$\leq(45.0)$
b. Containment Isolation-Phase "B"
Not Applicable
c. Steam Line Isolation
$\leq(7.0)$
d. Containment Air Recirculation Fan
$\leq(600.0)$

8. Steam Generator Water Level--High-High
a. Turbine Trip
$\leq(2.5)$
b. Feedwater Isolation
$\leq(11.0)$

9. Steam Generator Water Level - Low-Low
a. Motor-driven Auxiliary

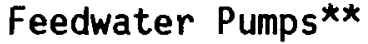
$\leq(60.0)$
b. Turbine-driven Auxiliary

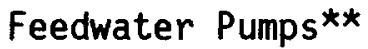
$\leq(60.0)$ 
TABLE 3.3-5 (Continued)

\section{ENGINEERED SAFETY FEATURES RESPONSE TIMES}

INITIATING SIGNAL AND FUNCTION

10. Undervoltage RCP

a. Turbine-driven Auxiliary Feedwater Pumps

11. Station Blackout

a. Motor-driven Auxiliary Feedwater Pumps

12. Trip of Main Feedwater Pumps

a. Motor-driven Auxiliary

Feedwater Pumps

13. Loss of Power

a. $\quad 4.16 \mathrm{kv}$ Emergency Bus Undervoltage (Loss of Voltage)

b. $\quad 4.16 \mathrm{kv}$ Emergency Bus Undervoltage (Degraded Voltage)

Note: Response time for Motordriven Auxiliary Feedwater Pumps on all S.I. signal starts
RESPONSE TIME IN SECONDS

$\leq(60.0)$

$\leq(60.0)$

$\leq(60.0)$

$\leq(\quad)$

$\leq(\quad)$

$\leq(60.0)$ 
TABLE 3.3-5 (Continued)

TABLE NOTATION

* Diesel generator starting and sequence loading delays included. Response time limit includes opening of valves to establish SI path and attainment of discharge pressure for centrifugal charging pumps, SI (4 loop only) and RHR pumps.

** On $2 / 3$ any Steam Generator

*** on $2 / 3$ in $2 / 4$ Steam Generators (4 loop plant)

*** on $2 / 3$ in $2 / 3$ Steam Generators ( 3 loop plant)

\# Diesel generator starting and sequence loading delay not included. Offsite power available. Response time limit includes opening of valves to establish SI path and attainment of discharge pressure for centrifigal charging pumps.

\#\# Diesel generator starting and sequence loading delays included. Response time limit includes opening of valves to establish SI path and attainment of discharge pressure for centrifugal charging pumps. 
TABLE 4.3-2

\section{ENGINEERED SAFETY FEATURE ACTUATION SYSTEM INSTRUMENTATION} SURVEILLANCE REQUIREMENTS

FUNCTIONAL UNIT

CHANNEL
CHECK CALIBRATION

CHANNEL

1. SAFETY INJECTION, TURBINE TRIP AND FEEDWATER ISOLATION
a. Manual Initiation
N.A.
N.A.
N.A.
N.A.
b. Automatic Actuation Logic
S
R
$S$
d. Pressurizer Pressure--Low
e. Differential Pressure Between Steam Lines--High
S
f. Steam Flow in Two Steam
Lines--High Coincident with $\mathrm{T}_{\text {avg }}{ }^{- \text {Low-Low or }}$ Steam Line Pressure--Low

M(1)

$M(2)$

$M(3)$

2. CONTAINMENT SPRAY
a. Manual Initiation
N. A.
N.A.
$M(1)$
$1,2,3,4$
b. Automatic Actuation Logic
N.A.
N.A.
M(2)
$1,2,3,4$
c. Containment Pressure--High-
$\mathrm{S}$
$\mathbf{R}$
$M(3)$
$1,2,3$

MODES IN WHICH SURVEILLANCE REQUIRED 
TABLE 4.3-2 (Continued)

ENGINEERED SAFETY FEATURE ACTUATION SYSTEM INSTRUMENTATION SURVEILLANCE REQUIREMENTS

FUNCTIONAL UNIT

CHANNEL CHANNEL FUNCTIONAL

CHECK CALIBRATION

TEST

MODES IN WHICH SURVEILLANCE REQUIRED

3. CONTAINMENT ISOLATION

a. Phase "A" Isolation
1) Manua 1
2) From Safety Injection Automatic Actuation Logic

N.A.

N. A.

$M(1)$

$1,2,3,4$

N. A.

N.A.

$M(2)$

$1,2,3,4$

$\omega$
$\omega$
1
$t$
0

b. Phase "B" Isolation
1) Manual
N. A.
N.A.
$M(1)$
$1,2,3,4$
2) Automatic Actuation
N.A.
N.A.
$M(2)$
$1,2,3,4$
3) Containment Pressure--
$S$
R
$M(3)$
$1,2,3$

c. Purge and Exhaust Isolation
1) Manual
N.A.
N. A.
$M(1)$
$1,2,3,4$
2) Containment Radio-
S
$\mathrm{R}$
M
$1,2,3,4$

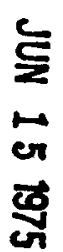


TABLE 4.3-2 (Continued)

ENGINEERED SAFETY FEATURE ACTUATION SYSTEM INSTRUMENTATION SURVEILLANCE REQUIREMENTS

FUNCTIONAL UNIT

\begin{tabular}{ccc} 
CHANNEL & CHANNEL \\
CHECK & CHANNEL & $\begin{array}{c}\text { FUNCTIONAL } \\
\text { CALIBRATION }\end{array}$ \\
\hline
\end{tabular}

MODES IN WHICH

SURVEILLANCE REQUIRED

4. STEAM LINE ISOLATION

$\underset{\omega}{\omega}$

$\omega$
1
\pm

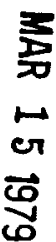

a. Manual

b. Automatic Actuation Logic

c. Containment Pressure-High-High

d. Steam Flow in Two Steam Lines--High Coincident with $\mathrm{T}_{\text {avg }^{--L o w} \text {-Low or Steam Line }}$ Pressure--Low

5. TURBINE TRIP AND FEEDWATER ISOLATION

a. Steam Generator Water Level--High-High
N. A.

N.A.

S

N.A.

N.A.

R

S

$\mathbf{R}$

$M(1)$

$1,2,3$

$1,2,3$

$1,2,3$

$M(3)$

M

$1,2,3$

M

$1,2,3$ 
TABLE 4.3-2 (Continued)

\section{ENGINEERED SAFETY FEATURE ACTUATION SYSTEM INSTRUMENTATION} SURVEILLANCE REQUIREMENTS

FUNCTIONAL UNIT

6. AUXILIARY FEEDWATER

a. Steam Generator Water Leve 1--Low-Low

b. Undervoltage - RCP

c. S.I.

d. Station Blackout

e. Trip of Main Feedwater Pumps

7. LOSS OF FOWER

a. $4.16 \mathrm{kv}$ Emergency Bus Undervoltage (Loss of Voltage)

b. $4.16 \mathrm{kv}$ Emergency Bus Undervoltage (Degraded Voltage)

8. Engineered Safety Feature Actuation System Interlocks

\section{CHANNEL CHECK \\ CHANNEL \\ CALIBRATION}

\begin{tabular}{c} 
CHANNEL \\
FUNCTIONAL. \\
TEST \\
\hline
\end{tabular}

$\mathrm{S}$

$\mathbf{R}$

M

$1,2,3,4$

$S$

R

M

1,2 SURVEILLANCE REQUIRED

$\begin{array}{llll}\text { N.A. } & R & \text { N.A. } & 1,2,3,4\end{array}$

N.A.

N.A.

1,2

S

S

N.A.

N. A 


\section{TABLE 4.3-2 (Continued)}

\section{TABLE NOTATION}

(1) Manual actuation switches shall be tested at least once per 18 months during shutdown. Ali other circuitry associated with manual safeguards actuation shal1 receive a CHANNEL FUNCTIONAL TEST at least once per 31 days.

(2) Each train or logic channel shall be tested at least every other 31 days.

(3) The CHANNEL FUNCTIONAL TEST shall include exercising the transmitter by applying either a vacuum or pressure to the appropriate side of the transmitter. 


\section{3/4.3.3 MONITORING INSTRUMENTATION}

RADIATION MONITORING INSTRUMENTATION

3.3.3.1 The radiation monitoring instrumentation channels shown in Table 3.3-6 shall be OPERABLE with their alarm/trip setpoints within the specified limits.

APPLICABILITY: As shown in Table 3.3-6.

ACTION:

a. With a radiation monitoring channel alarm/trip setpoint exceeding the value shown in Table 3.3-6, adjust the setpoint to within the limit within 4 hours or declare the channel inoperable.

b. With one or more radiation monitoring channels inoperable, take the ACTION shown in Table 3.3-6.

c. The provisions of Specifications 3.0.3 and 3.0.4 are not applicable.

\section{SURVEILLANCE REQUIREMENTS}

4.3.3.1 Each radiation monitoring instrumentation channel shall be demonstrated OPERABLE by the performance of the CHANNEL CHECK, CHANNEL CALIBRATION and CHANNEL FUNCTIONAL TEST operations for the MODES and at the frequencies shown in Table 4.3-3. 


\section{INSTRUMENT}

MINIMUM

CHANNELS

OPERABLE

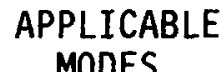

ALARM/TRIP

MEASUREMENT

1. AREA MONITORS

a. Fue l Storage Pool Area
i. Criticality Monitor
ii. Ventilation System Isolation

b. Containment - Purge \&

c. Control Room Isolation Exhaust Isolation
2. PROCESS MONITORS a. Fuel Storage Pool Area Ventilation System Isolation

i. Gaseous Activity

ii. Particulate Activity
**

$\star \star$

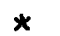

$* *$

6

A11 MODES b. Containment

i. Gaseous Activity
a)Purge \& Exhaust
Isolation

b) RCS Leakage Detection(1)

6

$1,2,3 \& 4$

ii. Particulate Activity

a)Purge \& Exhaust

$$
\text { Isolation }
$$

b) RCS Leakage Detection(1)

$1,2,3 \& 4$

* With fuel in the storage pool or building

or ** With irradiated fuel in the storage pool

( $\leq 2 \times$ background $)$

$\left(1-10_{5}^{5}\right) \mathrm{cpm}$

( $\leq 2 \times$ background $)$ N/A 


\section{TABLE 3.3-6 (Continued)}

TABLE NOTATION

ACTION 21 - With the number of channels OPERABLE less than required by the Minimum Channels OPERABLE requirement, perform area surveys of the monitored area with portable monitoring instrumentation at least once per 24 hours.

ACTION 22 - With the number of channels OPERABLE less than required by the Minimum Channels OPERABLE requirement, comply with the ACTION requirements of Specification (3.4.6.1).

ACTION 23 - With the number of channels OPERABLE less than required by the Minimum Channels OPERABLE requirement, comply with the ACTION requirements of Specification (3.9.12).

ACTION 24 - With the number of channels OPERABLE less than required by the Minimum Channels OPERABLE requirement, comply with the ACTION requirements of Specification (3.9.9).

ACTION 25 - With the number of channe 1s OPERABLE less than required by the Minimum Channels OPERABLE requirement, within 1 hour initiate and maintain operation of the control room emergency ventilation system in the recirculation mode of operation. 
TABLE 4.3-3

\section{INSTRUMENT}

\section{AREA MONITORS}

\begin{tabular}{|c|c|c|c|}
\hline $\begin{array}{l}\text { CHANNEL } \\
\text { CHECK }\end{array}$ & $\begin{array}{c}\text { CHANNEL } \\
\text { CALIBRATION }\end{array}$ & $\begin{array}{c}\text { CHANNEL } \\
\text { FUNCTIONAL } \\
\text { TEST }\end{array}$ & $\begin{array}{l}\text { MODES IN WHICH } \\
\text { SURVEILLANCE } \\
\text { REQUIRED }\end{array}$ \\
\hline
\end{tabular}
a. Fuel Storage Pool Area
i. Criticality Monitor
ii. Ventilation System Isolation

b. Containment - Purge \& Exhaust Isolation

C. Control Room Isolation

2. PROCESS MONITORS
a. Fuel Storage Pool Area - Ven-

tilation System Isolation

i. Gaseous Activity

ii. Particulate Activity

b. Containment

i. Gaseous Activity
a)Purge \& Exhaust

Isolation

b) RCS Leakage Detection

ii. Particulate Activity
a)Purge \& Exhaust
Isolation
b) RCS Leakage Detection

\section{$S$}

$S$

$S$

$S$

$S$

$S$

$S$

$S$
CALIBRATION

TES 


\section{INSTRUMENTATION}

MOVABLE INCORE DETECTORS

3.3.3.2 The movable incore detection system shall be OPERABLE with:

a. At 1east $75 \%$ of the detector thimbles,

b. A minimum of 2 detector thimbles per core quadrant, and

c. Sufficient movable detectors, drive, and readout equipment to map these thimbles.

APPLICABILITY: When the movable incore detection system is used for:

a. Recalibration of the excore neutron flux detection system,

b. Monitoring the QUADRANT POWER TILT RATIO, or

c. Measurement of $F_{\Delta H}^{N}, F_{Q}(Z)$ and $F_{x y}$

ACTION:

With the movable incore detection system inoperable, do not use the system for the above applicable monitoring or calibration functions. The provisions of Specifications 3.0 .3 and 3.0 .4 are not applicable.

4.3.3.2 The movable incore detection system shall be demonstrated OPERABLE by normalizing each detector output when required for:

a. Recalibration of the excore neutron flux detection system, or

b. Monitoring the QUADRANT POWER TILT RATIO, or

c. Measurement of $F_{\Delta H}^{N}, F_{Q}(Z)$, and $F_{x y}$. 
INSTRUMENTATION

SEISMIC INSTRUMENTATION*

LIMITING CONDITION FOR OPERATION

3.3.3.3 The seismic monitoring instrumentation shown in Table 3.3-7 shall be OPERABLE.

APPLICABILITY: At all times.

ACTION:

a. With one or more seismic monitoring instruments inoperable for more than 30 days, prepare and submit a Special Report to the Commission pursuant to Specification 6.9.2 within the next 10 days outlining the cause of the malfunction and the plans for restoring the instrument(s) to OPERABLE status.

b. The provisions of Specifications 3.0.3 and 3.0.4 are not applicable.

4.3.3.3.1 Each of the above seismic monitoring instruments shall be demonstrated OPERABLE by the performance of the CHANNEL CHECK, CHANNEL CALIBRATION and CHANNEL FUNCTIONAL TEST operations at the frequencies shown in Table 4. 3-4.

4.3.3.3.2 Each of the above seismic monitoring instruments actuated during a seismic event shall be restored to OPERABLE status within 24 hours and a CHANNEL CALIBRATION performed within 5 days following the seismic event. Data shall be retrieved from actuated instruments and analyzed to determine the magnitude of the vibratory ground motion. A Special Report shall be prepared and submitted to the Commission pursuant to Specification 6.9.2 within 10 days describing the magnitude, frequency spectrum and resultant effect upon facility features important to safety.

ॠThis specification not required for additional units at a common site provided at least one unit has seismic instrumentation and corresponding technical specifications meeting the recommendations of Regulatory Guide 1.12, Apri1 1974. 
TABLE 3.3-7

SEISMIC MONITORING INSTRUMENTATION

\section{INSTRUMENTS AND SENSOR LOCATIONS}

\section{MEASUREMENT}

RANGE

MINIMUM

INSTRUMENTS

OPERABLE

1. Triaxial Time-History Accelerographs
a.
b.
c.
d.

2. Triaxial Peak Accelerographs
a.
b.
c.
d.
e.

3. Triaxial Seismic Switches
a.
b.
c.
d.

4. Triaxial Response-Spectrum Recorders
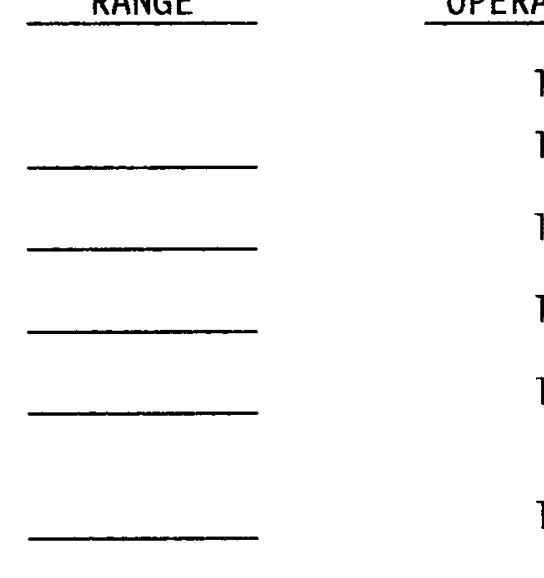

\section{1}

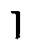

a.

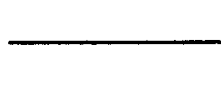

b.

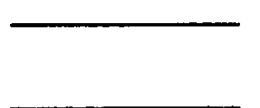

c.

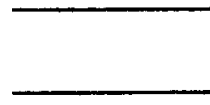

d.

e.

f.

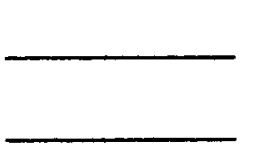

*With reactor control room indication 
TABLE 4.3-4

SEISMIC MONITORING INSTRUMENTATION SURVEILLANCE REQUIREMENTS

INSTRUMENTS AND SENSOR LOCATIONS

1. Triaxial Time-History Accelerographs

a.

b.

c.

d.

2. Triaxial Peak Accelerographs

a.

b.

c.

d.

e.

3. Triaxial Seismic Switches

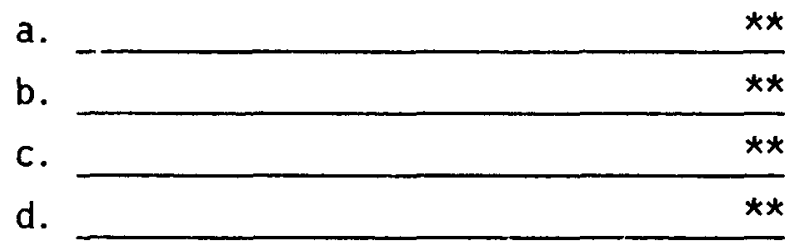

4. Triaxial Response-Spectrum Recorders

a.

**

b.

c.

d.

e.

$f$.

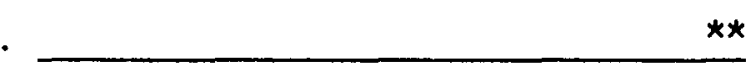

.

.

.

f.

f.

${ }^{*}$ Except seismic trigger

**With reactor control room indications.
CHANNEL CHANNEL CHECK CALIBRATION

$\begin{array}{lll}M^{*} & R & S A \\ M^{*} & R & S A \\ M^{*} & R & S A \\ M^{*} & R & S A\end{array}$

NA

NA

NA

$N A$

NA

$R$
NA

NA

NA

NA

NA

CHANNEL

FUNCTIONAL

TEST

\section{$S A$ \\ $S A$ \\ $S A$}

$S A$

A

SA

SA

$S A$

SA 
3.3.3.4 The meteorological monitoring instrumentation channels shown in Table 3.3-8 shall be OPERABLE.

\section{APPLICABILITY: At all times.}

ACTION:

a. With one or more required meteorological monitoring channels inoperable for more than 7 days, prepare and submit a Special Report to the Commission pursuant to Specification 6.9 .2 within the next 10 days outlining the cause of the malfunction and the plans for restoring the channel(s) to OPERABLE status.

b. The provisions of Specifications 3.0.3 and 3.0.4 are not applicable.

4.3.3.4 Each of the above meteorological monitoring instrumentation channels shall be demonstrated OPERABLE by the performance of the CHANNEL CHECK and CHANNEL CALIBRATION operations at the frequencies shown in Table 4.3-5.

*This Specification not required for additional units at a Common Site provided at least one unit has meteorological instrumentation and the corresponding technical Specifications and that the same meteorological data is appliicable to the additional units. 
TABLE 3.3-8

METEOROLOGICAL MONITORING INSTRUMENTATION

INSTRUMENT

LOCATION

MINIMUM

OPERABLE

1. WIND SPEED

a.

Nominal Elev.

1

b.

Nominal Elev.

2. WIND DIRECTION

a.

b.

3. AIR TEMPERATURE - DELTA T

a.

b.

(n)
Nominal Elev.

Nominal Elev.

Nominal Elev.

Nominal Elev.
1

1 


\section{TABLE 4.3-5}

METEOROLOGICAL MONITORING INSTRUMENTATION

SURVEILLANCE REQUIREMENTS

INSTRUMENT

1. WIND SPEED
CHANNEL CHECK

D

D

CHANNEL

CALIBRATION

2. WIND DIRECTION
a. Nominal Elev.
D
SA
b. Nominal Elev.
D
SA

3. AIR TEMPERATURE - DELTA T
a. Nominal Elev.
D
SA
b. Nominal Elev.
D
SA 
3.3.3.5 The remote shutdown monitoring instrumentation channels shown in Table 3.3-9 shall be OPERABLE with readouts displayed external to the control room.

APPLICABILITY: MODES 1,2 and 3.

ACTION:

a. With the number of OPERABLE remote shutdown monitoring channels less than required by Table 3.3-9, either restore the inoperable channel to OPERABLE status within 30 days, or be in HOT SHUTDOWN within the next 12 hours.

b. The provisions of Specification 3.0.4 are not applicable.

4.3.3.5 Each remote shutdown monitoring instrumentation channel shall be demonstrated OPERABLE by performance of the CHANNEL CHECK and CHANNEL CALIBRATION operations at the frequencies shown in Table 4.3-6. 
TABLE 3.3-9

REMOTE SHUTDOWN MONITORING INSTRUMENTATION

\section{INSTRUMENT}

1. Power Range Nuclear Flux

2. Intermediate Range Nuclear Flux

3. Source Range Nuclear Flux

4. Reactor Trip Breaker Indication

5. Reactor Coolant Temperature Average

6. Reactor Coolant Flow Rate

崩 7. Pressurizer Pressure

8. Pressurizer Level

9. Steam Generator Pressure

10. Steam Generator Leve1

11. Control Rod Position Limit Switches

12. RHR Flow Rate

13. RHR Temperature

窝

14. Auxiliary Feedwater Flow Rate
MEASUREMENT

READOUT

LOCATION

\section{MINIMUM}

CHANNELS

OPERABLE

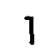

1

1

OPEN-CLOSE

I/trip breaker

1

1

1

1

$1 /$ steam generator

1/steam generator

1 insertion limit switch/rod 
TABLE 4.3-6

REMOTE SHUTDOWN MONITORING INSTRUMENTATION SURVEILLANCE REQUIREMENTS

\section{INSTRUMENT}

1. Power Range Nuclear Flux

2. Intermediate Range Nuclear Flux

3. Source Range Nuclear Flux

4. Reactor Trip Breaker Indication

5. Reactor Coolant Temperature - Average

6. Reactor Coolant Flow Rate

$\omega$ 7. Pressurizer Pressure

w

8. Pressurizer Level

9. Steam Generator Pressure

10. Steam Generator Leve1

11. Control Rod Position Limit Switches

12. RHR Flow Rate

13. RHR Temperature

14. Auxiliary Feedwater Flow Rate

\begin{abstract}
CHANNEL
CHECK
\end{abstract}

M

M

M

M

M

M

M

M

M

M

M

M

M

M
CHANNEL

CALIBRATION

Q

N. A.

N. A.

N. A.

R

R

R

R

R

R

R

R

R

R

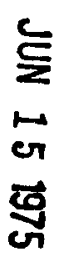


3.3.3.6 The post-accident monitoring instrumentation channels shown in Table 3.3-10 shall be OPERABLE.

APPLICABILITY: MODES 1,2 and 3.

ACTION:

a. With the number of OPERABLE post-accident monitoring channels less than required by Table 3.3-10, either restore the inoperable channel to OPERABLE status within 30 days, or be in HOT SHUTDOWN within the next 12 hours.

b. The provisions of Specification 3.0.4 are not applicable.

4.3.3.6 Each post-accident monitoring instrumentation channel shall be demonstrated OPERABLE by performance of the CHANNEL CHECK and CHANNEL CALIBRATION operations at the frequencies shown in Table 4.3-7. 


\section{POST-ACCIDENT MONITORING INSTRUMENTATION}

INSTRUMENT (Illustrational Only)

1. Containment Pressure

2. Reactor Coolant Outlet Temperature - $T_{\text {HOT }}$ (Wide Range)

3. Reactor Coolant Inlet Temperature - TCOLD (Wide Range)

4. Reactor Coolant Pressure - Wide Range

5. Pressurizer Water Leve1

$\omega \quad$ 6. Steam Line Pressure

J

8. Steam Generator Water Level - Wide Range

9. Refueling Water Storage Tank Water Level

10. Boric Acid Tank Solution Level
MINIMUM

CHANNELS

OPERABLE

2

2

2

2

2

$2 /$ steam generator

1/steam generator

1/steam generator

2

S
ले
कु 


\section{POST-ACCIDENT MONITORING INSTRUMENTATION SURVEILLANCE REQUIREMENTS}

INSTRUMENT (Illustrational Only)

1. Containment Pressure

2. Reactor Coolant Outlet Temperature - $T_{H O T}$ (Wide Range)

3. Reactor Coolant Inlet Temperature - $T_{\text {COLD }}$ (Wide Range)

4. Reactor Coolant Pressure - Wide Range

5. Pressurizer Water Level

6. Steam Line Pressure

7. Steam Generator Water Level - Narrow Range

8. Steam Generator Water Leve] - Wide Range

9. RWST Water Leve1

10. Boric Acid Tank Solution Level
CHANNEL

CHECK

M

M

M

M

M

M

M

$M$

M

M
CHANNEL

CALIBRATION

R

R

R

$\mathbf{R}$

R

$\mathbf{R}$

$\mathbf{R}$

R

R

R 
3.3.3.7 Two independent chlorine detection systems, with their alarm/trip setpoints adjusted to actuate at a chlorine concentration of less than or equal to $5 \mathrm{ppm}$, shall be OPERABLE.

APPLICABILITY: MODES 1,2, 3, and 4 .

ACTION:

a. With one chlorine detection system inoperable, restore the inoperable detection system to OPERABLE status within 7 days or within the next 6 hours initiate and maintain operation of the control room emergency ventilation system in the recirculation mode of operation.

b. With no chlorine detection system OPERABLE, within 1 hour initiate and maintain operation of the control room emergency ventilation system in the recirculation mode of operation.

c. The provisions of Specification 3.0.4 are not applicable.

4.3.3.7 Each chlorine detection system shall be demonstrated OPERABLE by performance of a CHANNEL CHECK at least once per 12 hours, a CHANNEL FUNCTION TEST at least once per 31 days and a CHANNEL CALIBRATION at least once per 18 months. 
INSTRUMENTATION

FIRE DETECTION INSTRUMENTATION

LIMITING CONDITION FOR OPERATION

3.3.3.8 As a minimum, the fire detection instrumentation for each fire detection zone shown in Table 3.3-11 shal1 be OPERABLE.

APPLICABILITY: Whenever equipment in that fire detection zone is required to be OPERABLE.

ACTION:

With one or more of the fire detection instrument(s) shown in Table $3.3-11$ inoperable:

a. Within 1 hour establish a fire watch patrol to inspect the zone(s) with the inoperable instrument(s) at least once per hour, unless the instrument(s) is located inside the containment, then inspect the containment at least once per 8 hours or (monitor the containment air temperature at least once per hour at the locations listed in Specification 4.6.1.6).

b. Restore the inoperable instrument(s) to OPERABLE status within 14 days, or in lieu of any other report required by Specification 6.9.1, prepare and submit a Special Report to the Commission pursuant to Specification 6.9.2 within the next 30 days outlining the action taken, the cause of the inoperability and the plans and schedule for restoring the instrument(s) to OPERABLE status.

c. The provisions of Specifications 3.0 .3 and 3.0.4 are not applicable.

4.3.3.8.1 Each of the above required fire detection instruments which are accessible during plant operation shall be demonstrated OPERABLE at least once per 6 months by performance of a CHANNEL FUNCTIONAL TEST. Fire detectors which are not accessible during plant operation shall be demonstrated OPERABLE by the performance of a CHANNEL FUNCTIONAL TEST during each COLD SHUTDOWN exceeding 24 hours unless performed in the previous 6 months.

4.3.3.8.2 The NFPA Standard 72D supervised circuits supervision associated with the detector alarms of each of the above required fire detection instruments shall be demonstrated OPERABLE at least once per 6 months.

4.3.3.8.3 The non-supervised circuits, associated with detector alarms, between the instrument and the control room shall be demonstrated OPERABLE at least once per 31 days. 
FIRE DETECTION INSTRUMENTS

INSTRUMENT LOCATION (I1lustrative**)

1. Containment

Zone 1 Elevation

Zone 2 Elevation

2. Control Room

3. Cable Spreading

Zone 1 Elevation

Zone 2 Elevation

4. Computer Room

5. Switchgear Room

6. Remote Shutdown Panels

7. Station Battery Rooms

Zone 1 Elevation

Zone 2 Elevation

8. Turbine

Zone 1 Elevation

Zone 2 Elevation

9. Diesel Generator

Zone 1 Elevation

Zone 2 Elevation

10. Diesel Fuel Storage

11. Safety Related Pumps

Zone 1 Elevation

Zone 2 Elevation

12. Fuel Storage

Zone 1 Elevation

Zone 2 Elevation
MINIMUM INSTRUMENTS OPERABLE*

HEAT FLAME SMOKE




\section{3/4.3.4 TURBINE OVERSPEED PROTECTION}

3.3.4 At least one turbine overspeed protection system shall be OPERABLE. APPICABILITY: MODES 1, 2 and 3.

ACTION:

a. With one stop valve or one control valve per high pressure turbine steam lead inoperable or with one reheat stop valve or one reheat intercept valve per low pressure turbine steam lead inoperable, operation may continue for up to 72 hours provided the inoperable valve(s) is restored to OPERABLE status or at least one valve in the affected steam lead is closed; otherwise, isolate the turbine from the steam supply within the next 6 hours.

b. With the above required turbine overspeed protection system otherwise inoperable, within 6 hours either restore the system to OPERABLE status or isolate the turbine from the steam supply.

4.3.4.1 The provisions of Specification 4.0.4 are not applicable.

4.3.4.2 The above required turbine overspeed protection system shall be demonstrated OPERABLE:

a. At least once per 7 days by cycling each of the following valves through at least one complete cycle from the running position.

1. (Four) high pressure turbine stop valves.

2. (Four) high pressure turbine control valves.

3. (Four) low pressure turbine reheat stop valves.

4. (Four) low pressure turbine reheat intercept valves. 
b. At least once per 31 days by direct observation of the movement of each of the above valves through one complete cycle from the running position.

c. At least once per 18 months by performance of a CHANNEL CALIBRATION on the turbine overspeed protection systems.

d. At least once per 40 months by disassembling at least one of each of the above valves and performing a visual and surface inspection of valve seats, disks and stems and verifying no unacceptable flaws or corrosion. 
-

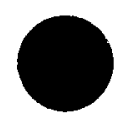

• 
$3 / 4.4$ REACTOR COOLANT SYSTEM

3/4.4.1 REACTOR COOLANT LOOPS

NORMAL OPERATION

LIMITING CONDITION FOR OPERATION

3.4.1.1 All reactor coolant loops shall be in operation.

APPLICABILITY: As noted below, but excluding MODE 6.*

ACTION:

Above P-7, comply with either of the following ACTIONS:

a. With one reactor coolant loop and associated pump not in operation, STARTUP and/or continued POWER OPERATION may proceed provided THERMAL POWER is restricted to less than (31)\% of RATED THERMAL POWER and the following ESF. instrumentation channels associated with the loop not in operation, are placed in their tripped condition within 1 hour:

1. Tum -- Low-Low channel used in the coincidence circuit with Stegm Flow - High for Safety Injection.

2. Steam Line Pressure - Low channel used in the coincidence circuit with Steam Flow - High for Safety Injection.

3. Steam Flow-High Channel used for Safety Injection.

4. Differential Pressure Between Steam Lines - High channel used for Safety Injection (trip all bistables which indicate low active loop steam pressure with respect to the idle loop steam pressure).

b. With one reactor coolant loop and associated pump not in operation, subsequent STARTUP and POWER OPERATION above (31)\% of RATED THERMAL POWER may proceed provided:

1. The following actions have been completed with the reactor in at least HOT STANDBY:

a) Reduce the overtemperature de1ta $T$ trip setpoint to the value specified in Specification (2.2.1) for $(n-1)$ loop operation.

ॠSee Special Test Exception 3.10.4. 
ACTION: (Continued)

b) Place the following reactor trip system and ESF instrumentation channels, associated with the loop not in operation, in their tripped conditions:

1) Overpower delta T channel.

2) Overtemperature delta $T$ channel.

3) $T_{\text {avg }}$-- Low-Low channel used in the coincidence circuit with Steam Flow - High for Safety Injection.

4) Steam Line Pressure - Low channel used in the coincidence circuit with Steam Flow - High for Safety Injection.

5) Steam Flow-High channel used for Safety Injection.

6) Differential Pressure Between Steam Lines - High channel used for Safety Injection (trip all bistables which indicate low active loop steam pressure with respect to the idle loop steam pressure).

c) Change the P-8 interlock setpoint from the value specified in Table 3.3-1 to:

1) Less than or equal to (76)\% of RATED THERMAL POWER when the reactor coolant stop valves in the nonoperating loop are closed, or

2) Less than or equal to (66)\% of RATED THERMAL POWER when the reactor coolant stop valves in the nonoperating loop are open.

2. THERMAL POWER is restricted to:

a) Less than or equal to (71)\% of RATED THERMAL POWER when the reactor coolant stop valves in the nonoperating loop are closed, or

b) Less than or equal to (61)\% of RATED THERMAL POWER when the reactor coolant stop valves in the nonoperating loop are open. 
ACTION (Continued)

Below P-7\#:

a. With $K_{\text {eff }}$ greater than or equal to 1.0 , operation may proceed provided aff least two reactor coolant loops and associated pumps are in operation.

b. With $K_{\text {eff }}$ less than to 1.0 , operation may proceed provided at least one reaffor coolant loop is in operation with an associated reactor coolant or residual heat removal pump.*

c. The provisions of Specifications 3.0 .3 and 3.0.4 are not applicable.

4.4.1.1 With one reactor coolant loop and associated pump not in operation, at least once per 31 days determine that:

a. The applicable reactor trip system and/or ESF actuation system instrumentation channels specified in the ACTION statements above have been placed in their tripped conditions, and

b. The P-8 interlock setpoint is within the following limits if the P-8 interlock was reset for $(n-1)$ loop operation:

1. Less than or equal to (76)\% of RATED THERMAL POWER when the reactor coolant stop valves in the nonoperating loop are closed, or

2. Less than or equal to (66)\% of RATED THERMAL POWER when the reactor coolant stop valves in the nonoperating loop are open.

\footnotetext{
${ }^{*} \bar{A} 11$ reactor coolant pumps and residual heat removal pumps may be de-energized for up to 1 hour, provided no operations are permitted which could cause dilution of the reactor coolant system boron concentration.

\#A reactor coolant pump shall not be started with one or more of the RCS cold leg temperatures less than or equal to $(275)^{\circ} \mathrm{F}$ unless 1) the pressurizer water volume is less than _ cubic feet or 2) the secondary water temperature of each steam generator is less than ${ }^{\circ} \mathrm{F}$ above each of the RCS cold leg temperatures.
} 
REACTOR COOLANT SYSTEM

ISOLATED LOOP (OPTIONAL)

LIMITING CONDITION FOR OPERATION

3.4.1.2 The boron concentration of an isolated loop shall be maintained greater than or equal to the boron concentration of the operating loops.

APPLICABILITY: MODES $1,2,3,4$ and 5.

ACTION:

With the requirements of the above specification not satisfied, do not open the isolated loop's stop valves; either increase the boron concentration of the isolated loop to within the limits within 4 hours or be in at least HOT STANDBY within the next 6 hours with the unisolated portion of the RCS borated to a SHUTDOWN MARGIN equivalent to at least $1 \%$ delta $\mathrm{k} / \mathrm{k}$ at $200^{\circ} \mathrm{F}$.

4.4.1.2 The boron concentration of an isolated loop shall be determined to be greater than or equal to the boron concentration of the operating loops at least once per 24 hours and within 30 minutes prior to opening either the hot leg or cold leg stop valves of an isolated loop. 
3.4.1.3 A reactor coolant loop shall remain isolated until:

a. The isolated loop has been operating on a recirculation flow of greater than or equal to gpm for at least 90 minutes and the temperature at the cold leg of the isolated loop is within $20^{\circ} \mathrm{F}$ of the highest cold leg temperature of the operating loops.

b. The reactor is subcritical by at least 1 percent delta $k / k$.

\section{APPLICABILITY: ALL MODES.}

ACTION:

With the requirements of the above specification not satisfied, suspend startup of the isolated 1oop.

\section{SURVEILLANCE REQUIREMENTS}

4.4.1.3.1 The isolated loop cold leg temperature shall be determined to be within $20^{\circ} \mathrm{F}$ of the highest cold leg temperature of the operating loops within 30 minutes prior to opening the cold leg stop valve.

4.4.1.3.2 The reactor shall be determined to be subcritical by at least 1 percent delta $\mathrm{k} / \mathrm{k}$ within 30 minutes prior to opening the cold leg stop valve. 
REACTOR COOLANT SYSTEM

3/4.4.2 SAFETY VALVES - SHUTDOWN

LIMITING CONDITION FOR OPERATION

3.4.2 A minimum of one pressurizer code safety valve shall be OPERABLE with a lift setting of 2485 PSIG $\pm 1 \%$ * $^{*}$

APPLICABILITY: MODES 4 and 5.

ACTION:

With no pressurizer code safety valve OPERABLE, immediately suspend all operations involving positive reactivity changes and place an OPERABLE RHR loop into operation in the shutdown cooling mode.

4.4.2 No additional Surveillance Requirements other than those required by Specification 4.0.5.

*The lift setting pressure shall correspond to ambient conditions of the valve at nominal operating temperature and pressure. 
REACTOR COOLANT SYSTEM

$3 / 4.4 .3$ SAFETY VALVES - OPERATING

LIMITING CONDITION FOR OPERATION

3.4.3 All pressurizer code safety valves shall be OPERABLE with a lift setting of 2485 PSIG $\pm 1 \%$.*

APPLICABILITY: MODES 1,2 and 3.

\section{ACTION:}

With one pressurizer code safety valve inoperable, either restore the inoperable valve to OPERABLE status within 15 minutes or be in at least HOT STANDBY within 6 hours and in at least HOT SHUTDOWN within the following 6 hours.

4.4.3 No additional Surveillance Requirements other than those required by Specification 4.0.5.

*The lift setting pressure shall correspond to ambient conditions of the valve at nominal operating temperature and pressure. 
REACTOR COOLANT SYSTEM

3/4.4.4 PRESSURIZER

LIMITING CONDITION FOR OPERATION

3.4.4 The pressurizer shall be OPERABLE with a water volume of less than or equal to cubic feet.

APPLICABILITY: MODES 1,2 and 3

ACTION:

With the pressurizer inoperable, be in at least HOT STANDBY with the reactor trip breakers open within 6 hours and in HOT SHUTDOWN within the following 6 hours.

4.4.4 The pressurizer water volume shall be determined to be within its limit at least once per 12 hours. 
REACTOR COOLANT SYSTEM

3/4.4.5 STEAM GENERATORS

LIMITING CONDITION FOR OPERATION

3.4.5 Each steam generator sha11 be OPERABLE.

APPLICABILITY: MODES $1,2,3$ and 4.

ACTION:

With one or more steam generators inoperable, restore the inoperable generator(s) to OPERABLE status prior to increasing $T_{\text {avg }}$ above $200^{\circ} \mathrm{F}$.

SURVEILLANCE REQUIREMENTS

4.4.5.0 Each steam generator shall be demonstrated OPERABLE by performance of the following augmented inservice inspection program and the requirements of Specification 4.0.5.

4.4.5.1 Steam Generator Sample Selection and Inspection - Each steam generator shall be determined OPERABLE during shutdown by selecting and inspecting at least the minimum number of steam generators specified in Table 4.4-1.

4.4.5.2 Steam Generator Tube Sample Selection and Inspection - The steam generator tube minimum sample size, inspection result classification, and the corresponding action required shall be as specified in Table 4.4-2. The inservice inspection of steam generator tubes shall be performed at the frequencies specified in Specification 4.4.5.3 and the inspected tubes shall be verified acceptable per the acceptance criteria of Specification 4.4.5.4. The tubes selected for each inservice inspection shall include at least $3 \%$ of the total number of tubes in all steam generators; the tubes selected for these inspections shall be selected on a random basis except:

a. Where experience in similar plants with similar water chemistry indicates critical areas to be inspected, then at least $50 \%$ of the tubes inspected shall be from these critical areas.

b. The first sample of tubes selected for each inservice inspection (subsequent to the preservice inspection) of each steam generator shall include: 
1. All nonplugged tubes that previously had detectable wall penetrations (greater than 20\%).

2. Tubes in those areas where experience has indicated potential problems.

3. A tube inspection (pursuant to Specification 4.4.5.4.a.8) shall be performed on each selected tube. If any selected tube does not permit the passage of the eddy current probe for a tube inspection, this shall be recorded and an adjacent tube shall be selected and subjected to a tube inspection.

c. The tubes selected as the second and third samples (if required by Table 4.4-2) during each inservice inspection may be subjected to a partial tube inspection provided:

1. The tubes selected for these samples include the tubes from those areas of the tube sheet array where tubes with imperfections were previously found.

2. The inspections include those portions of the tubes where imperfections were previously found.

The results of each sample inspection shall be classified into one of the following three categories:

Category

$\mathrm{C}-1$

$c-2$

$c-3$

\section{Inspection Results}

Less than $5 \%$ of the total tubes inspected are degraded tubes and none of the inspected tubes are defective.

One or more tubes, but not more than $1 \%$ of the total tubes inspected are defective, or between $5 \%$ and $10 \%$ of the total tubes inspected are degraded tubes.

More than $10 \%$ of the total tubes inspected are degraded tubes or more than $1 \%$ of the inspected tubes are defective.

Note: In all inspections, previously degraded tubes must exhibit significant (greater than 10\%) further wall penetrations to be included in the above percentage calculations. 
REACTOR COOLANT SYSTEM

SURVEILLANCE REQUIREMENTS (Continued)

4.4.5.3 Inspection Frequencies - The above required inservice inspections of steam generator tubes shall be performed at the following frequencies:

a. The first inservice inspection shall be performed after 6 Effective Full Power Months but within 24 calendar months of initial criticality. Subsequent inservice inspections shall be performed at intervals of not less than 12 nor more than 24 calendar months after the previous inspection. If two consecutive inspections following service under AVT conditions, not including the preservice inspection, result in all inspection results falling into the $c-1$ category or if two consecutive inspections demonstrate that previously observed degradation has not continued and no additional degradation has occurred, the inspection interval may be extended to a maximum of once per 40 months.

b. If the results of the inservice inspection of a steam generator conducted in accordance with Table 4.4-2 at 40 month intervals fall in Category $\mathrm{C}-3$, the inspection frequency shall be increased to at least once per 20 months. The increase in inspection frequency shall apply until the subsequent inspections satisfy the criteria of Specification 4.4.5.3.a; the interval may then be extended to a maximum of once per 40 months.

c. Additional, unscheduled inservice inspections shall be performed on each steam generator in accordance with the first sample inspection specified in Table 4.4-2 during the shutdown subsequent to any of the following conditions:

1. Primary-to-secondary tubes leaks (not including leaks originating from tube-to-tube sheet welds) in excess of the limits of Specification 3.4.6.2.

2. A seismic occurrence greater than the Operating Basis Earthquake.

3. A loss-of-coolant accident requiring actuation of the engineered safeguards.

4. A main steam line or feedwater line break. 


\subsubsection{Acceptance Criteria}

a. As used in this Specification:

1. Imperfection means an exception to the dimensions, finish or contour of a tube from that required by fabrication drawings or specifications. Eddy-current testing indications below $20 \%$ of the nominal tube wall thickness, if detectable, may be considered as imperfections.

2. Degradation means a service-induced cracking, wastage, wear or general corrosion occurring on either inside or outside of a tube.

3. Degraded Tube means a tube containing imperfections greater than or equal to $20 \%$ of the nominal wall thickness caused by degradation.

4. \% Degradation means the percentage of the tube wall thickness affected or removed by degradation.

5. Defect means an imperfection of such severity that it exceeds the plugging limit. A tube containing a defect is defective.

6. Plugging Limit means the imperfection depth at or beyond which the tube shall be removed from service because it may become unserviceable prior to the next inspection and is equal to $(40) \%$ of the nominal tube wall thickness.

7. Unserviceable describes the condition of a tube if it leaks or contains a defect large enough to affect its structural integrity in the event of an Operating Basis Earthquake, a loss-ofcoolant accident, or a steam line or feedwater line break as specified in 4.4.5.3.c, above.

8. Tube Inspection means an inspection of the steam generator tube from the point of entry (hot leg side) completely around the U-bend to the top support of the cold leg.

*Value to be determined in accordance with the recommendations of Regulatory Guide 1.121, August 1976. 
REACTOR COOLANT SYSTEM

SURVEILLANCE REQUIREMENTS (Continued)

9. Preservice Inspection means an inspection of the full length of each tube in each steam generator performed by eddy current techniques prior to service establish a baseline condition of the tubing. This inspection shall be performed after the field hydrostatic test and prior to initial POWER OPERATION using the equipment and techniques expected to be used during subsequent inservice inspections.

b. The steam generator shall be determined OPERABLE after completing the corresponding actions (plug all tubes exceeding the plugging limit and a 11 tubes containing through-wa11 cracks) required by Table 4.4-2.

\subsubsection{Reports}

a. Following each inservice inspection of steam generator tubes, the number of tubes plugged in each steam generator shall be reported to the Commission within 15 days.

b. The complete results of the steam generator tube inservice inspection shall be submitted to the Commission in a Special Report pursuant to Specification 6.9.2 within 12 months following the completion of the inspection. This Special Report shall include:

1. Number and extent of tubes inspected.

2. Location and percent of wal1-thickness penetration for each indication of an imperfection.

3. Identification of tubes plugged.

c. Results of steam generator tube inspections which fall into Category C- 3 and require prompt notification of the Commission shall be reported pursuant to Specification 6.9.1 prior to resumption of plant operation. The written followup of this report shall provide a description of investigations conducted to determine cause of the tube degradation and corrective measures taken to prevent recurrence. 
TABLE 4.4-1

MINIMUM NUMBER OF STEAM GENERATORS TO BE

INSPECTED DURING INSERVICE INSPECTION

\begin{tabular}{|c|c|c|c|c|c|c|}
\hline Preservice Inspection & \multicolumn{3}{|c|}{ No } & \multicolumn{3}{|c|}{ Yes } \\
\hline No. of Steam Generators per Unit & Two & Three & Four & Two & Three & Four \\
\hline First Inservice Inspection & \multicolumn{3}{|c|}{ All } & One & Two & Two \\
\hline Second \& Subsequent Inservice Inspections & \multicolumn{3}{|c|}{ One ${ }^{1}$} & One ${ }^{1}$ & $\mathrm{One}^{2}$ & One $\mathrm{e}^{3}$ \\
\hline
\end{tabular}

Table Notation:

1. The inservice inspection may be limited to one steam generator on a rotating schedule encompassing $3 \mathrm{~N} \%$ of the tubes (where $\mathrm{N}$ is the number of steam generators in the plant) if the results of the first or previous inspections indicate that all steam generators are performing in a like manner. Note that under some circumstances, the operating conditions in one or more steam generators may be found to be more severe than those in other steam generators. Under such circumstances the sample sequence shall be modified to inspect the most severe conditions.

2. The other steam generator not inspected during the first inservice inspection shall be inspected. The third and subsequent inspections should follow the instructions described in 1 above.

3. Each of the other two steam generators not inspected during the first inservice inspections shall be inspected during the second and third inspections. The fourth and subsequent inspections shall follow the instructions described in 1 above. 
TABLE 4.4-2

STEAM GENERATOR TUBE INSPECTION

\begin{tabular}{|c|c|c|c|c|c|c|}
\hline \multicolumn{3}{|c|}{ 1ST SAMPLE INSPECTION } & \multicolumn{2}{|c|}{ 2ND SAMPLE INSPECTION } & \multicolumn{2}{|c|}{ 3RD SAMPLE INSPECTION } \\
\hline Sample Size & Result & Action Required & Result & Action Required & Result & Action Required \\
\hline \multirow{9}{*}{$\begin{array}{l}\text { A minimum of } \\
S \text { Tubes per } \\
\text { S. G. }\end{array}$} & $C-1$ & None & N/A & N/A & N/A & N/A \\
\hline & \multirow[t]{5}{*}{$\mathrm{C}-2$} & \multirow{5}{*}{$\begin{array}{l}\text { Plug defective tubes } \\
\text { and inspect additional } \\
2 S \text { tubes in this S. G. }\end{array}$} & $\mathrm{C}-1$ & None & N/A & N/A \\
\hline & & & \multirow{3}{*}{$\mathrm{C}-2$} & \multirow{3}{*}{$\begin{array}{l}\text { Plug defective tubes } \\
\text { and inspect additional } \\
4 S \text { tubes in this } S . G \text {. }\end{array}$} & $\mathrm{C}-1$ & None \\
\hline & & & & & $\mathrm{C}-2$ & Plug defective tubes \\
\hline & & & & & $\mathrm{C}-3$ & $\begin{array}{l}\text { Perform action for } \\
\mathrm{C}-3 \text { result of first } \\
\text { sample }\end{array}$ \\
\hline & & & $\mathrm{C}-3$ & $\begin{array}{l}\text { Perform action for } \\
\text { C-3 result of first } \\
\text { sample }\end{array}$ & N/A & N/A \\
\hline & \multirow[t]{3}{*}{$\mathrm{C}-\mathbf{3}$} & \multirow{3}{*}{$\begin{array}{l}\text { Inspect all tubes in } \\
\text { this S. G., plug de- } \\
\text { fective tubes and } \\
\text { inspect } 2 \text { S tubes in } \\
\text { each other S. G. } \\
\\
\text { Prompt notification } \\
\text { to NRC pursuant } \\
\text { to specification } \\
6.9 .1\end{array}$} & $\begin{array}{l}\text { All other } \\
\text { S. G.S are } \\
\text { C-1 }\end{array}$ & None & $N / A$ & N/A \\
\hline & & & $\begin{array}{l}\text { Some S. G.s } \\
\text { C-2 but no } \\
\text { additional } \\
\text { S. G. are } \\
\text { C-3 }\end{array}$ & $\begin{array}{l}\text { Perform action for } \\
\mathrm{C}-2 \text { result of second } \\
\text { sample }\end{array}$ & N/A & N/A \\
\hline & & & \begin{tabular}{|l} 
Additional \\
$\mathrm{S}$. $\mathrm{G}$. is $\mathrm{C}-3$
\end{tabular} & $\begin{array}{l}\text { Inspect all tubes in } \\
\text { each S. G. and plug } \\
\text { defective tubes. } \\
\text { Prompt notification } \\
\text { to NRC pursuant } \\
\text { to specification } \\
6.9 .1\end{array}$ & $N / A$ & N/A \\
\hline
\end{tabular}


REACTOR COOLANT SYSTEM

3/4.4.6 REACTOR COOLANT SYSTEM LEAKAGE

LEAKAGE DETECTION SYSTEMS

3.4.6.1 The following Reactor Coolant System leakage detection systems shall be OPERABLE:

a. The containment atmosphere (gaseous or particulate) radioactivity monitoring system,

b. The containment sump level and flow monitoring system, and

c. Either the (containment air cooler condensate flow rate) or a containment atmosphere (gaseous or particulate) radioactivity monitoring system.

APPLICABILITY: MODES $1,2,3$ and 4.

ACTION:

With only two of the above required leakage detection systems OPERABLE, operation may continue for up to 30 days provided grab samples of the containment atmosphere are obtained and analyzed at least once per 24 hours when the required gaseous or particulate radioactive monitoring system is inoperable; otherwise, be in at least HOT STANDBY within the next 6 hours and in COLD SHUTDOWN within the following 30 hours.

\section{SURVEILLANCE REQUIREMENTS}

4.4.6.1 The leakage detection systems shall be demonstrated OPERABLE by:

a. Containment atmosphere (gaseous and/or particulate) monitoring system-performance of CHANNEL CHECK, CHANNEL CALIBRATION and CHANNEL FUNCTIONAL TEST at the frequencies specified in Table 4.3-3,

b. Containment sump level and flow monitoring system-performance of CHANNEL CALIBRATION at least once per 18 months,

c. (Specify appropriate surveillance tests depending upon the type of leakage detection system selected.) 
3.4.6.2 Reactor Coolant System leakage shall be limited to:

a. No PRESSURE BOUNDARY LEAKAGE,

b. 1 GPM UNIDENTIFIED LEAKAGE,

c. 1 GPM total primary-to-secondary leakage through all steam generator not isolated from the Reactor Coolant System and (500) gallons per day through any one steani generator not isolated from the Reactor Coolant System,

d. 10 GPM IDENTIFIED LEAKAGE from the Reactor Coolant System, and

e. GPM CONTROLLED LEAKAGE at a Reactor Coolant System pressure of $\overline{2235} \pm 20$ psig.

\section{APPLICABILITY: MODES $1,2,3$ and 4}

\section{ACTION:}

a. With any PRESSURE BOUNDARY LEAKAGE, be in at least HOT STANDBY within 6 hours and in COLD SHUTDOWN within the following 30 hours.

b. With any Reactor Coolant System leakage greater than any one of the above limits, excluding PRESSURE BOUNDARY LEAKAGE, reduce the leakage rate to within limits within 4 hours or be in at least HOT STANDBY within the next 6 hours and in COLD SHUTDOWN within the following 30 hours.

\section{SURVEILLANCE REQUIREMENTS}

4.4.6.2 Reactor Coolant System leakages shall be demonstrated to be within each of the above limits by;

a. Monitoring the containment atmosphere (gaseous or particulate) radioactivity monitor at least once per 12 hours.

b. Monitoring the containment sump inventory and discharge at least once per 12 hours. 
c. Measurement of the CONTROLLED LEAKAGE to the reactor coolant pump seals when the Reactor Coolant System pressure is $2235 \pm 20$ psig at least once per 31 days with the modulating valve fully open,

d. Performance of a Reactor Coolant System water inventory balance at least once per 72 hours during steady state operation, and

e. Monitoring the reactor head flange leakoff system at least once per 24 hours. 
REACTOR COOLANT SYSTEM

\section{3/4.4.7 CHEMISTRY}

\section{LIMITING CONDITION FOR OPERATION}

3.4.7 The Reactor Coolant System chemistry shall be maintained within the limits specified in Table 3.4-1.

APPLICABILITY: At all times.

ACTION:

MODES $1,2,3$ and 4 :

a. With any one or more chemistry parameter in excess of its Steady State Limit but within its Transient Limit, restore the Parameter to within its Steady State Limit within 24 hours or be in at least HOT STANDBY within the next 6 hours and in COLD SHUTDOWN within the following 30 hours.

b. With any one or more chemistry parameter in excess of its Transient Limit, be in at least HOT STANDBY within 6 hours and in COLD SHUTDOWN within the following 30 hours.

At All Other Times:

With the concentration of either chloride or fluoride in the Reactor Coolant System in excess of its Steady State Limit for more than 24 hours or in excess of its Transient Limit, reduce the pressurizer pressure to less than or equal to $500 \mathrm{psig}$, if applicable, and perform an engineering evaluation to determine the effects of the out-of-limit condition on the structural integrity of the Reactor Coolant System; determine that the Reactor Coolant System remains acceptable for continued operation prior to increasing the pressurizer pressure above 500 psig or prior to proceeding to MODE 4.

\section{SURVEILLANCE REQUIREMENTS}

4.4.7 The Reactor Coolant System chemistry shall be determined to be within the limits by analysis of those parameters at the frequencies specified in Table 4.4-3. 
TABLE $3.4-1$

\section{REACTOR COOLANT SYSTEM}

\section{CHEMISTRY LIMITS}

PARAMETER

DISSOLVED OXYGEN*

CHLORIDE

FLUORIDE
STEADY STATE

LIMIT

$\leq 0.10 \mathrm{ppm}$

$\leq 0.15 \mathrm{ppm}$

$\leq 0.15 \mathrm{ppm}$
TRANSIENT

LIMIT

$\leq 1.00 \mathrm{ppm}$

$\leq 1.50 \mathrm{ppm}$

$\leq 1.50 \mathrm{ppm}$

*imit not applicable with Tavg $\leq 250^{\circ} \mathrm{F}$. 


\section{TABLE $4.4-3$}

\section{REACTOR COOLANT SYSTEM}

CHEMISTRY LIMITS SURVEILLANCE REQUIREMENTS

PARAMETER

DISSOLVED OXYGEN*

CHLORIDE

FLUORIDE
SAMPLE AND

ANALYSIS FREQUENCY

At least once per 72 hours

At least once per 72 hours

At least once per 72 hours

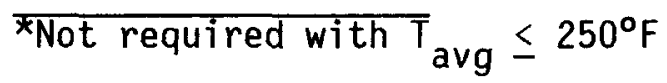


3.4.8 The specific activity of the primary coolant shall be 1 imited to:

a. Less than or equal to 1.0 microcurie per gram DOSE EQUIVALENT I-131, and

b. Less than or equal to $100 / \bar{E}$ microcuries per gram.

APPLICABILITY: MODES $1,2,3,4$ and 5 .

ACTION:

MODES 1,2 and $3^{*}$ :

a. With the specific activity of the primary coolant greater than 1.0 microcurie per gram DOSE EQUIVALENT I-131 but within the allowable limit (below and to the left of the line) shown on Figure 3.4-1, operation may continue for up to 48 hours provided that the cumulative operating time under these circumstances does not exceed 800 hours in any consecutive 12 month period. With the total cumulative operating time at a primary coolant specific activity greater than 1.0 microcurie per gram DOSE EQUIVALENT I- 131 exceeding 500 hours in any consecutive 6 month period, prepare and submit a Special Report to the Commission pursuant to Specification 6.9 .2 within 30 days indicating the number of hours above this limit. The provisions of Specification 3.0.4 are not applicable.

b. With the specific activity of the primary coolant greater than 1.0 microcurie per gram DOSE EQUIVALENT I-131 for more than 48 hours during one continuous time interval or exceeding the limit line shown on Figure $3.4-1$, be in at least HOT STANDBY with Tavg less than $500^{\circ} \mathrm{F}$ within 6 hours.

c. With the specific activity of the primary coolant greater than $100 / \bar{E}$ microcurie per gram, be in at least HOT STANDBY with $T_{\text {avg }}$ less than $500^{\circ} \mathrm{F}$ within 6 hours.

* With $\mathrm{T}_{\text {avg }}$ greater than or equal to $500^{\circ} \mathrm{F}$. 


\section{REACTOR COOLANT SYSTEM}

ACTION: (Continued)

MODES $1,2,3,4$ and 5 :

a. With the specific activity of the primary coolant greater than 1.0 microcurie per gram DOSE EQUIVALENT I-131 or greater than $100 / \bar{E}$ microcuries per gram, perform the sampling and analysis requirements of item 4a of Table 4.4-4 until the specific activity of the primary coolant is restored to within its limits. A REPORTABLE OCCURRENCE shall be prepared and submitted to the Commission pursuant to Specification 6.9.1. This report shall contain the results of the specific activity analyses together with the following information:

1. Reactor power history starting 48 hours prior to the first sample in which the limit was exceeded,

2. Fuel burnup by core region,

3. Clean-up flow history starting 48 hours prior to the first sample in which the limit was exceeded,

4. History of de-gassing operations, if any, starting 48 hours prior to the first sample in which the limit was exceeded, and

5. The time duration when the specific activity of the primary coolant exceeded 1.0 microcurie per gram DOSE EQUIVALENT I-131.

4.4.8 The specific activity of the primary coolant shall be determined to be within the limits by performance of the sampling and analysis program of Table 4. 4-4. 
TYPE OF MEASUREMENT

AND ANALYSIS

1. Gross Activity Determination

2. Isotopic Analysis for DOSE EQUIVALENT I-131 Concentration

3. Radiochemical for $\bar{E}$ Determination

4. Isotopic Analys is for Iodine Including $\mathrm{I}-131, \mathrm{I}-133$, and $\mathrm{I}-135$

$\underset{⿱ 亠 䒑}{\stackrel{\omega}{p}}$
SAMPLE AND ANALYSIS

FREQUENCY

At least once per 72 hours

1 per 14 days

1 per 6 months*

a) Once per 4 hours, whenever the specific activity exceeds 1.0

$\mu \mathrm{Ci}$ /gram DOSE

EQUIVALENT I-131

or $100 / \mathrm{E} \mu \mathrm{Ci} / \mathrm{gram}$, and

b) One sample between 2 and 6 hours following

a THERMAL POWER change exceeding

15 percent of the

RATED THERMAL

POWER within a one hour period.
MODES IN WHICH SAMPLE AND ANALYSIS REQUIRED

$1,2,3,4$

1

1

$1^{\#}, 2^{\#}, 3^{\#}, 4^{\#}, 5^{\#}$

$1,2,3$

\#Until the specific activity of the primary coolant system is restored within its limits.

* Sample to be taken after a minimum of 2 EFPD and 20 days of POWER OPERATION have elapsed since reactor was last subcritical for 48 hours or longer. 


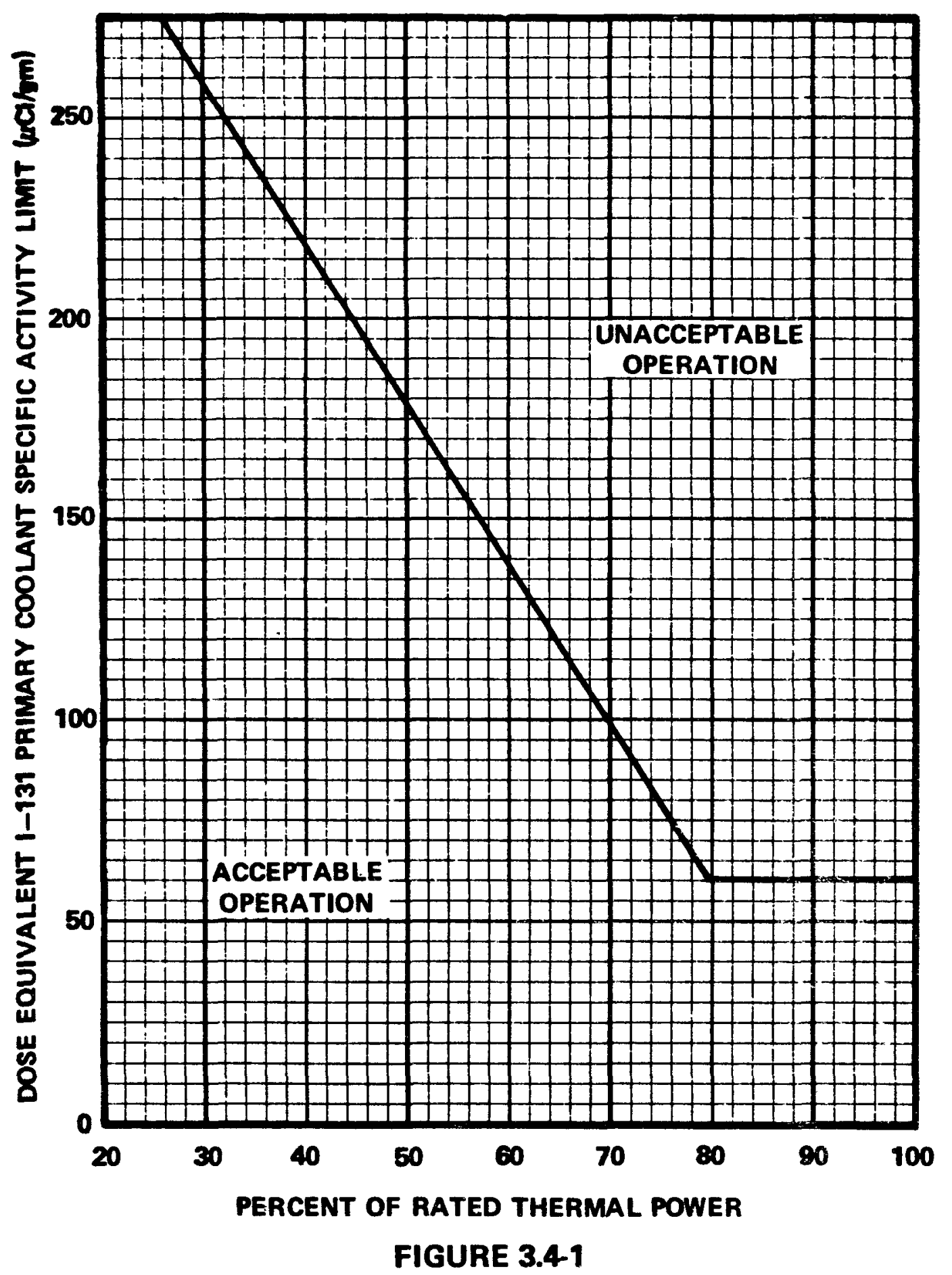

DOSE EQUIVALENT I-131 Primary Coolant Specific Activity Limit Versus Percent of RATED THERMAL POWER with the Primary Coolant Specific Activity $>1.0 \mu \mathrm{Ci} /$ gram Dose Equivalent 1.131 
3.4.9.1 The Reactor Coolant System (except the pressurizer) temperature and pressure shall be limited in accordance with the limit lines shown on Figures 3.4-2 and 3.4-3 during heatup, cooldown, criticality, and inservice leak and hydrostatic testing with:

a. A maximum heatup of $100^{\circ} \mathrm{F}$ in any one hour period.

b. A maximum cooldown of $100^{\circ} \mathrm{F}$ in any one hour period.

c. A maximum temperature change of less than or equal to $(10)^{\circ} \mathrm{F}$ in any one hour period during inservice hydrostatic and leak testing operations above the heatup and cooldown limit curves.

\section{APPLICABILITY: At all times.}

\section{ACTION:}

With any of the above limits exceeded, restore the temperature and/or pressure to within the limit within 30 minutes; perform an engineering evaluation to determine the effects of the out-of-limit condition on the fracture toughness properties of the Reactor Coolant System; determine that the Reactor Coolant System remains acceptable for continued operation or be in at least HOT STANDBY within the next 6 hours and reduce the RCS $T_{\text {ayg }}$ and pressure to less than $200^{\circ} \mathrm{F}$ and $500 \mathrm{psig}$, respectively, within the afollowing 30 hours.

\section{SURVEILLANCE REQUIREMENTS}

4.4.9.1.1 The Reactor Coolant System temperature and pressure shall be determined to be within the limits at least once per 30 minutes during system heatup, cooldown, and inservice leak and hydrostatic testing operations.

\subsection{The reactor vessel material irradiation surveillance specimens} shall be removed and examined, to determine changes in material properties, at the intervals required by 10 CFR 50 , Appendix $H$. The results of these examinations shall be used to update Figures $3.4-2$ and 3.4-3. 
$\frac{1}{1}$

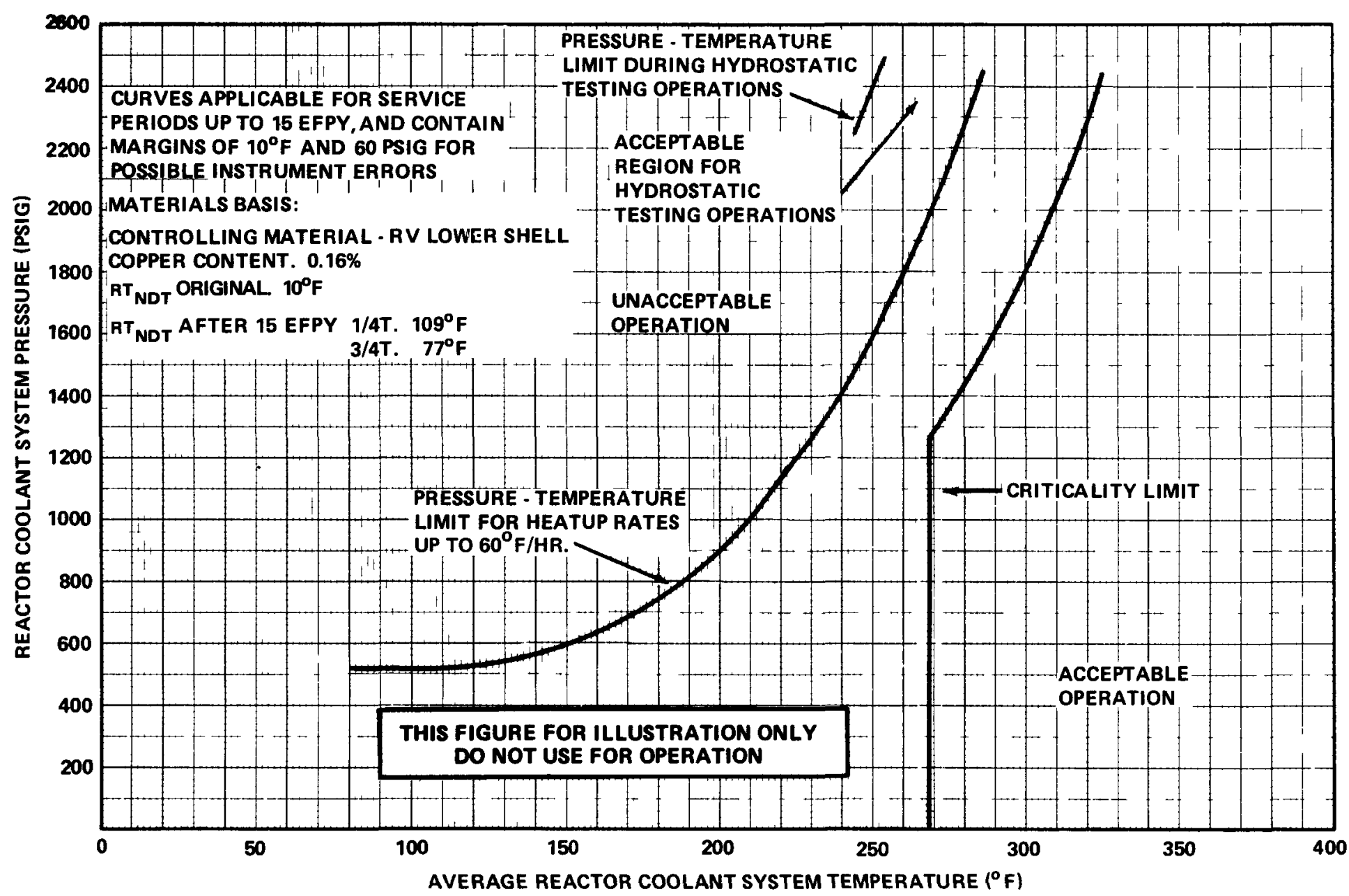

옥

FIGURE 3.4-2

REACTOR COOLANT SYSTEM PRESSURE - TEMPERATURE LIMITS VERSUS $60^{\circ} \mathrm{F} /$ HOUR HEATUP RATE CRITICALITY LIMIT AND HYDROSTATIC TEST LIMIT 


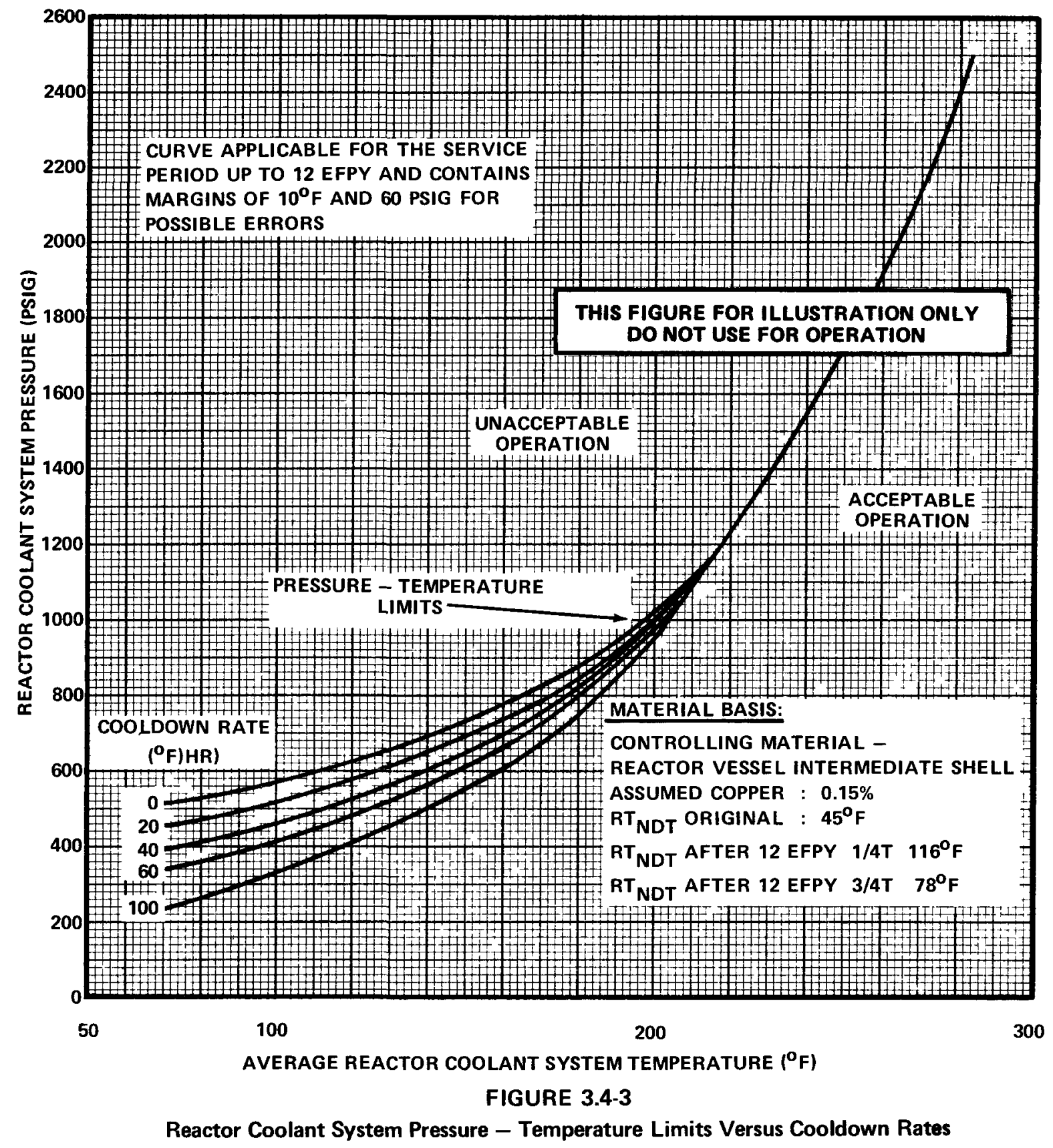


REACTOR COOLANT SYSTEM

PRESSURIZER

LIMITING CONDITION FOR OPERATION

3.4.9.2 The pressurizer temperature shall be limited to:

a. A maximum heatup of $100^{\circ} \mathrm{F}$ in any one hour period,

b. A maximum cooldown of $200^{\circ} \mathrm{F}$ in any one hour period, and

c. A maximum spray water temperature differential of $320^{\circ} \mathrm{F}$.

APPLICABILITY: At all times.

ACTION:

With the pressurizer temperature limits in excess of any of the above 1 imits, restore the temperature to within the limits within 30 minutes; perform an engineering evaluation to determine the effects of the out-of-limit condition on the fracture toughness properties of the pressurizer; determine that the pressurizer remains acceptable for continued operation or be in at least HOT STANDBY within the next 6 hours and reduce the pressurizer pressure to less than 500 psig within the following 30 hours.

4.4.9.2 The pressurizer temperatures shall be determined to be within the limits at least once per 30 minutes during system heatup or cooldown. The spray water temperature differential shall be determined to be within the limit at least once per 12 hours during auxiliary spray operation. 
REACTOR COOLANT SYSTEM

OVERPRESSURE PROTECTION SYSTEMS

3.4.9.3 At least one of the following overpressure protection systems shall be OPERABLE:

a. Two power operated relief valves (PORVs) with a lift setting of less than or equal to (450) psig, or

b. A reactor coolant system vent of greater than or equal to ( ) square inches.

APPLICABILITY: When the temperature of one or more of the RCS cold legs is less than or equal to $(275)^{\circ} \mathrm{F}$, except when the reactor vessel head is removed.

ACTION:

a. With one PORV inoperable, either restore the inoperable PORV to OPERABLE status within 7 days or depressurize and vent the RCS through a ( ) square inch vent(s) within the next 8 hours; maintain the RCS in a vented condition until both PORVs have been restored to OPERABLE status.

b. With both PORVs inoperable, depressurize and vent the RCS through a ( ) square inch vent(s) within 8 hours; maintain the RCS in a vented condition until both PORVs have been restored to OPERABLE status.

c. In the event either the PORVs or the RCS vent(s) are used to mitigate a RCS pressure transient, a Special Report shall be prepared and submitted to the Commission pursuant to Specification 6.9.2 within 30 days. The report shall describe the circumstances initiating the transient, the effect of the PORVs or vent(s) on the transient and any corrective action necessary to prevent recurrence.

d. The provisions of Specification 3.0.4 are not applicable. 
4.4.9.3.1 Each PORV shall be demonstrated OPERABLE by:

a. Performance of a CHANNEL FUNCTIONAL TEST on the PORV actuation channe1, but excluding valve operation, within 31 days prior to entering a condition in which the PORV is required OPERABLE and at least once per 31 days thereafter when the PORV is required OPERABLE.

b. Performance of a CHANNEL CALIBRATION on the PORV actuation channel at least once per 18 months.

c. Verifying the PORV isolation valve is open at least once per 72 hours when the PORV is being used for overpressure protection.

d. Testing in accordance with the inservice test requirements for ASME Category $C$ valves pursuant to Specification 4.0 .5 .

4.4.9.3.2 The RCS vent(s) shall be verified to be open at least once per 12 hours* when the vent(s) is being used for overpressure protection.

*Except when the vent pathway is provided with a valve which is locked, sealed, or otherwise secured in the open position, then verify these valves open at least once per 31 days. 
REACTOR COOLANT SYSTEM

3/4.4.10 STRUCTURAL INTEGRITY

ASME CODE CLASS 1,2 and 3 COMPONENTS

LIMITING CONDITION FOR OPERATION

3.4.10 The structural integrity of ASME Code Class 1, 2 and 3 components shall be maintained in accordance with Specification 4.4.10.

\section{APPLICABILITY: A11 MODES}

ACTION:

a. With the structural integrity of any ASME Code Class 1 component(s) not conforming to the above requirements, restore the structural integrity of the affected component(s) to within its limit or isolate the affected component(s) prior to increasing the Reactor Coolant System temperature more than $50^{\circ} \mathrm{F}$ above the minimum temperature required by NDT considerations.

b. With the structural integrity of any ASME Code Class 2 component(s) not conforming to the above requirements, restore the structural integrity of the affected component(s) to within its limit or isolate the affected component(s) prior to increasing the Reactor Coolant System temperature above $200^{\circ} \mathrm{F}$.

c. With the structural integrity of any ASME Code Class 3 component(s) not conforming to the above requirements, restore the structural integrity of the affected component(s) to within its limit or isolate the affected component(s) from service.

d. The provisions of Specification 3.0.4 are not applicable.

SURVEILLANCE REQUIREMENTS

4.4.10 In addition to the requirements of Specification 4.0.5, each reactor coolant pump flywheel shall be inspected per the recommendations of Regulatory Position C.4.b of Regulatory Guide 1.14, Revision 1, August 1975. 


\section{3/4.5 EMERGENCY CORE COOLING SYSTEMS (ECCS)}

3/4.5.1 ACCUMULATORS

LIMITING CONDITION FOR OPERATION

3.5.1 Each reactor coolant system accumulator shall be OPERABLE with:

a. The isolation valve open,

b. A contained borated water volume of between

and gallons,

c. A boron concentration of between (1900) and (2100) ppm, and

d. A nitrogen cover-pressure of between and psig.

APPLICABILITY: MODES 1,2 and $3 .^{*}$

\section{ACTION:}

a. With one accumulator inoperable, except as a result of a closed isolation valve, restore the inoperable accumulator to OPERABLE status within one hour or be in at least HOT STANDBY within the next 6 hours and in HOT SHUTDOWN within the following 6 hours.

b. With one accumulator inoperable due to the isolation valve being closed, either immediately open the isolation valve or be in at least HOT STANDBY within one hour and in HOT SHUTDOWN within the following 12 hours.

\section{SURVEILLANCE REQUIREMENTS}

4.5.1.1 Each accumulator shall be demonstrated OPERABLE:

a. At least once per 12 hours by:

1. Verifying, by the absence of alarms, the contained borated water volume and nitrogen cover-pressure in the tanks, and

2. Verifying that each accumulator isolation valve is open.

*Pressurizer Pressure above 1000 psig. 
b. At least once per 31 days and within 6 hours after each solution volume increase of greater than or equal to ( $1 \%$ of tank volume) by verifying the boron concentration of the accumulator solution.

c. At least once per 31 days when the RCS pressure is above 2000 psig by verifying that power to the isolation valve operator is disconnected by removal of the breaker from the circuit.

d. At least once per 18 months by verifying that each accumulator isolation valve opens automatically under each of the following conditions:

1. When the RCS pressure exceeds the P-11 setpoint,

2. Upon receipt of a safety injection test signal.

4.5.1.2 Each accumulator water level and pressure channel shall be demonstrated OPERABLE:

a. At least once per 31 days by the performance of a CHANNEL FUNCTIONAL TEST.

b. At least once per 18 months by the performance of a CHANNEL CALIBRATION. 


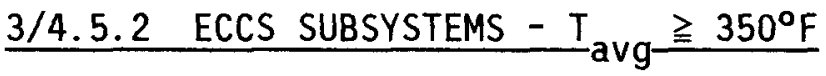

3.5.2 Two independent ECCS subsystems shall be OPERABLE with each subsystem comprised of:

a. One OPERABLE centrifugal charging pump,

b. One OPERABLE safety injection pump (four loop plants only),

c. One OPERABLE residual heat removal heat exchanger,

d. One OPERABLE residual heat removal pump, and

e. An OPERABLE flow path capable of taking suction from the refueling water storage tank on a safety injection signal and transferring suction to the containment sump during the recirculation phase of operation.

APPLICABILITY: MODES 1, 2 and 3.

\section{ACTION:}

a. With one ECCS subsystem inoperable, restore the inoperable subsystem to OPERABLE status within 72 hours or be in at least HOT STANDBY within the next 6 hours and in HOT SHUTDOWN within the following 6 hours.

b. In the event the ECCS is actuated and injects water into the Reactor Coolant System, a Special Report shall be prepared and submitted to the Commission pursuant to Specification 6.9.2 within 90 days describing the circumstances of the actuation and the total accumulated actuation cycles to date. 
4.5.2 Each ECCS subsystem shall be demonstrated OPERABLE:

a. At least once per 12 hours by verifying that the following valves are in the indicated positions with power to the valve operators removed:

Valve Number Valve Function Valve Position
a.
b.
a.
b.
c.
a.
b.
c.

b. At least once per 31 days by verifying that each valve (manual, power operated or automatic) in the flow path that is not locked, sealed, or otherwise secured in position, is in its correct position.

c. By a visual inspection which verifies that no loose debris (rags, trash, clothing, etc.) is present in the containment which could be transported to the containment sump and cause restriction of the pump suctions during LOCA conditions. This visual inspection shall be performed:

1. For all accessible areas of the containment prior to establishing CONTAINMENT INTEGRITY, and

2. Of the areas affected within containment at the completion of each containment entry when CONTAINMENT INTEGRITY is established.

d. At least once per 18 months by:

1. Verifying automatic isolation and interlock action of the RHR system from the Reactor Coolant System when the Reactor Coolant System pressure is above psig.

2. A visual inspection of the containment sump and verifying that the subsystem suction inlets are not restricted by debris and that the sump components (trash racks, screens, etc.) show no evidence of structural distress or corrosion. 
e. At least once per 18 months, during shutdown, by:

1. Verifying that each automatic valve in the flow path actuates to its correct position on a test signal.

2. Verifying that each of the following pumps start automatically upon receipt of a safety injection test signal:
a) Centrifugal charging pump
b) Safety injection pump
c) Residual heat removal pump

f. By verifying that each of the following pumps develops the indicated discharge pressure on recirculation flow when tested pursuant to Specification 4.0.5:

1. Centrifugal charging pump

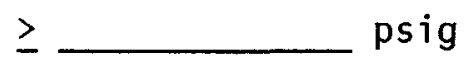

2. Safety Injection pump

$\geq$ psig

3. Residual heat removal pump

$\geq$ psig

g. By verifying the correct position of each electrical and/or mechanical position stop for the following ECCS throttle valves:

1. Within 4 hours following completion of each valve stroking operation or maintenance on the valve when the ECCS subsystems are required to be OPERABLE.

2. At least once per 18 months.

HPSI System

Valve Number

a.

b.

c.

d.
LPSI System Valve Number

a.

b.

c.

d. 
h. By performing a flow balance test, during shutdown, following completion of modifications to the ECCS subsystems that alter the subsystem flow characteristics and verifying the following flow rates:

HPSI System - Single Pump

$\begin{array}{ll}\text { a. } & \text { Injection Leg } 1, \geq-\mathrm{gpm} \\ \text { b. } & \text { Injection Leg } 2, \geq-\mathrm{gpm} \\ \text { c. } & \text { Injection Leg } 3, \geq-\mathrm{gpm} \\ \text { d. } & \text { Injection Leg } 4, \geq \square \mathrm{gpm}\end{array}$

\section{LPSI System - Single Pump}

a. Injection Leg $1, \geq \ldots \mathrm{gpm}$

b. Injection Leg 2, $\geq-\mathrm{gpm}$

c. Injection Leg $3,>-\mathrm{gpm}$

d. Injection Leg $4, \Sigma-\mathrm{gpm}$ 


\section{$3 / 4.5 .3$ ECCS SUBSYSTEMS - T avg $<350^{\circ} \mathrm{F}$}

\section{LIMITING CONDITION FOR OPERATION}

3.5.3 As a minimum, one ECCS subsystem comprised of the following shall be OPERABLE:

a. One OPERABLE centrifugal charging pump, \#

b. One OPERABLE residual heat removal heat exchanger,

c. One OPERABLE residual heat removal pump, and

d. An OPERABLE flow path capable of taking suction from the refueling water storage tank upon being manually realigned and transferring suction to the containment sump during the recirculation phase of operation.

APPLICABILITY: MODE 4 ,

ACTION:

a. With no ECCS subsystem OPERABLE because of the inoperability of either the centrifugal charging pump or the flow path from the refueling water storage tank, restore at least one ECCS subsystem to OPERABLE status within 1 hour or be in COLD SHUTDOWN within the next 20 hours.

b. With no ECCS subsystem OPERABLE because of the inoperability of either the residual heat removal heat exchanger or residual heat removal pump, restore at least one ECCS subsystem to OPERABLE status or maintain the Reactor Coolant System $\mathrm{T}_{\text {avg }}$ less than $350^{\circ} \mathrm{F}$ by use
of alternate heat removal methods.

c. In the event the ECCS is actuated and injects water into the Reactor Coolant System, a Special Report shall be prepared and submitted to the Commission pursuant to Specification 6.9.2 within 90 days describing the circumstances of the actuation and the total accumulated actuation cycles to date.

\#A maximum of one centrifugal charging pump and one safety injection pump shall be OPERABLE whenever the temperature of one or more of the RCS cold legs is less than or equal to $(275)^{\circ} \mathrm{F}$. 
4.5.3.1 The ECCS subsystem shall be demonstrated OPERABLE per the applicable Surveillance Requirements of 4.5.2.

4.5.3.2 All charging pumps and safety injection pumps, except the above required OPERABLE pumps, shall be demonstrated inoperable at least once per 12 hours whenever the temperature of one or more of the RCS cold legs is less than or equal to $(275)^{\circ} \mathrm{F}$ by verifying that the motor circuit breakers have been removed from their electrical power supply circuits. 
EMERGENCY CORE COOLING SYSTEMS

3/4.5.4 BORON INJECTION SYSTEM

BORON INJECTION TANK

LIMITING CONDITION FOR OPERATION

3.5.4.1 The boron injection tank shal1 be OPERABLE with:

a. A contained borated water volume of between gallons, and

b. A boron concentration of between 20,000 and $22,500 \mathrm{ppm}$, and

c. A minimum solution temperature of $145^{\circ} \mathrm{F}$.

APPLICABILITY: MODES 1, 2 and 3.

ACTION:

With the boron injection tank inoperable, restore the tank to OPERABLE status within 1 hour or be in HOT STANDBY and borated to a SHUTDOWN MARGIN equivalent to $1 \%$ delta $\mathrm{k} / \mathrm{k}$ at $200^{\circ} \mathrm{F}$ within the next 6 hours; restore the tank to OPERABLE status within the next 7 days or be in HOT SHUTDOWN within the next 12 hours.

SURVEILLANCE REQUIREMENTS

4.5.4.1 The boron injection tank shall be demonstrated OPERABLE by:

a. Verifying the contained borated water volume at least once per 7 days,

b. Verifying the boron concentration of the water in the tank at least once per 7 days, and

c. Verifying the water temperature at least once per 24 hours. 
HEAT TRACING

3.5.4.2 At least two independent channels of heat tracing shall be OPERABLE for the boron injection tank and for the heat traced portions of the associated flow paths.

APPLICABILITY: MODES 1,2 and 3.

ACTION:

With only one channel of heat tracing on either the boron injection tank or on the heat traced portion of an associated flow path OPERABLE, operation may continue for up to 30 days provided the tank and flow path temperatures are verified to be greater than or equal to $(145)^{\circ} \mathrm{F}$ at least once per 8 hours; otherwise, be in at least HOT STANDBY within 6 hours and in HOT SHUTDOWN within the following 6 hours.

\section{SURVEILLANCE REQUIREMENTS}

4.5.4.2 Each heat tracing channel for the boron injection tank and associated flow path shall be demonstrated OPERABLE:

a. At least once per 31 days by energizing each heat tracing channel, and

b. At least once per 24 hours by verifying the tank and flow path temperatures to be greater than or equal to $(145)^{\circ} \mathrm{F}$. The tank temperature shall be determined by measurement. The flow path temperature shall be determined by either measurement or recirculation flow until establishment of equilibrium temperatures within the tank. 
3.5.5 The refueling water storage tank (RWST) shall be OPERABLE with:

a. A contained borated water volume of between and gallons,

b. A boron concentration of between (2000) and (2100) ppm of boron, and c. A minimum water temperature of $(35)^{\circ} \mathrm{F}$.

APPLICABILITY: MODES 1, 2, 3 and 4.

ACTION:

With the refueling water storage tank inoperable, restore the tank to OPERABLE status within 1 hour or be in at least HOT STANDBY within 6 hours and in COLD SHUTDOWN within the following 30 hours.

\section{SURVEILLANCE REQUIREMENTS}

\subsubsection{The RWST shall be demonstrated OPERABLE:}

a. At least once per 7 days by:

1. Verifying the contained borated water volume in the tank, and

2. Verifying the boron concentration of the water.

b. At least once per 24 hours by verifying the RWST temperature when the (outside) air temperature is less than $35^{\circ} \mathrm{F}$. 

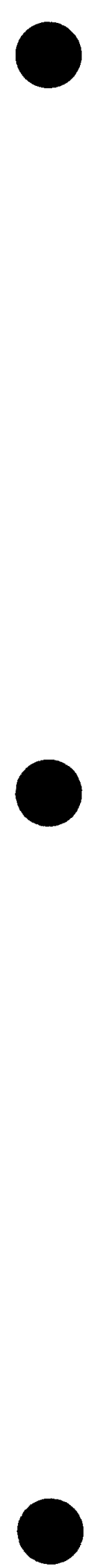
SECTION $3 / 4.6 \mathrm{~A}$

CONTAINMENT SYSTEMS SPECIFICATIONS

FOR

WEST INGHOUSE

ATMOSPHERIC TYPE CONTAINMENT 

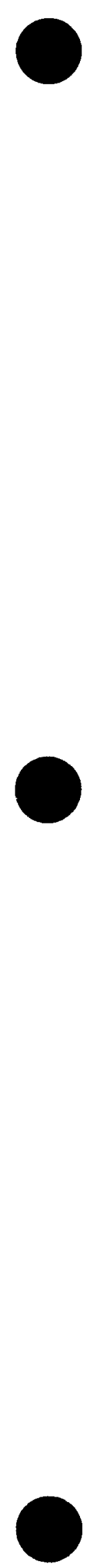


\section{3/4.6 CONTAINMENT SYSTEMS}

3/4.6.1 PRIMARY CONTAINMENT

CONTAINMENT INTEGRITY

LIMITING CONDITION FOR OPERATION

3.6.1.1 Primary CONTAINMENT INTEGRITY shall be maintained.

APPLICABILITY: MODES $1,2,3$ and 4.

ACTION:

Without primary CONTAINMENT INTEGRITY, restore CONTAINMENT INTEGRITY within one hour or be in at least HOT STANDBY within the next 6 hours and in COLD SHUTDOWN within the following 30 hours.

\section{SURVEILLANCE REQUIREMENTS}

4.6.1.1 Primary CONTAINMENT INTEGRITY shal1 be demonstrated:

a. At least once per 31 days by verifying that all penetrations* not capable of being closed by OPERABLE containment automatic isolation valves and required to be closed during accident conditions are closed by valves, blind flanges, or deactivated automatic valves secured in their positions, except as provided in Table 3.6-1 of Specification 3.6.4.1.

b. By verifying that each containment air lock is OPERABLE per Specification 3.6.1.3.

c. After each closing of the equipment hatch, by leak rate testing the equipment hatch seals with gas at $P_{\text {, }}$ (50 psig) and verifying that when the measured leakage rate for these seals is added to the leakage rates determined pursuant to Specification 4.6.1.2.d for all other Type $B$ and $C$ penetrations, the combined leakage rate is less than or equal to $0.60 \mathrm{~L}_{\mathrm{a}}$.

*Except valves, blind flanges, and deactivated automatic valves which are located inside the containment and are locked, sealed or otherwise secured in the closed position. These penetrations shall be verified closed during each COLD SHUTDOWN except that such verification need not be performed more often than once per 92 days. 
3.6.1.2 Containment leakage rates shall be limited to:

a. An overall integrated leakage rate of:

1. Less than or equal to $L_{a},(0.20)$ percent by weight of the containment air per 24 hours at $P_{a}$, (50 psig), or

2. Less than or equal to $L_{t},(0.10)$ percent by weight of the containment air per 24 hours at a reduced pressure of $P_{t},(25$ psig).

b. A combined leakage rate of less than or equal to $0.60 \mathrm{~L}$ for all penetrations and valves subject to Type $B$ and $C$ tests, when pressurized to $\mathrm{P}_{\mathrm{a}}$.

APPLICABILITY: MODES $1,2,3$ and 4.

ACTION:

With either (a) the measured overall integrated containment leakage rate exceeding $0.75 \mathrm{~L}$ or $0.75 \mathrm{~L}_{t}$, as applicable, or (b) with the measured combined leakage rate for $a 11$ penetrations and valves subject to Types $B$ and $C$ tests exceeding $0.60 \mathrm{~L}$, restore the overall integrated leakage rate to less than or equal to $0.75 \mathrm{~L}^{a}$ or less than or equal to $0.75 \mathrm{~L}_{t}$, as applicable, and the combined leakage rate for all penetrations subject to Type $B$ and $C$ tests to less than or equal to $0.60 \mathrm{~L}_{\mathrm{a}}$ prior to increasing the Reactor Coolant System temperature above $200^{\circ} \mathrm{F}$.

4.6.1.2 The containment leakage rates shall be demonstrated at the following test schedule and shall be determined in conformance with the criteria specified in Appendix $J$ of 10 CFR 50 using the methods and provisions of ANSI N45. 4-(1972):

a. Three Type A tests (Overall Integrated Containment Leakage Rate) shall be conducted at $40 \pm 10$ month intervals during shutdown at either $P_{a}$ ( 50 psig) or at $P_{t}$ (25 psig) during each 10-year service period. The third test of exach set shall be conducted during the shutdown for the 10-year plant inservice inspection. 
b. If any periodic Type $A$ test fails to meet either $0.75 L_{\text {or }} 0.75 \mathrm{~L}_{t}$, the test schedule for subsequent Type $A$ tests shall be reviewed and approved by the Commission. If two consecutive Type $A$ tests fail to meet either $0.75 \mathrm{~L}$ or $0.75 \mathrm{~L}_{t}$, a Type $A$ test shall be performed at least every 18 months until two consecutive Type $A$ tests meet either $0.75 \mathrm{~L}_{\mathrm{a}}$ or $0.75 \mathrm{~L}_{t}$ at which time the above test schedule may be resumed.

c. The accuracy of each Type A test shall be verified by a supplemental test which:

1. Confirms the accuracy of the Type A test by verifying that the difference between supplemental and Type $A$ test data is within $0.25 \mathrm{~L}_{\mathrm{a}}$, or $0.25 \mathrm{~L}_{\mathrm{t}}$.

2. Has a duration sufficient to establish accurately the change in leakage rate between the Type $A$ test and the supplemental test.

3. Requires the quantity of gas injected into the containment or bled from the containment during the supplemental test to be equivalent to at least 25 percent of the total measured leakage at $P_{a}\left(50\right.$ psig) or $P_{t}(25$ psig. $)$

d. Type $B$ and $C$ tests shall be conducted with gas at $P$ (50 psig) at intervals no greater than 24 months except for tests involving:

1. Air locks,

2. Penetrations using continuous leakage monitoring systems, and

3. Valves pressurized with fluid from a seal system.

e. Air locks shall be tested and demonstrated OPERABLE per Surveillance Requirement 4.6.1.3.

f. Type B periodic tests are not required for penetrations continuously monitored by the Containment Isolation Valve and Channel Weld Pressurization Systems provided the systems are OPERABLE per Surveillance Requirement 4.6.1.4. 
g. Leakage from isolation valves that are sealed with fluid from a seal system may be excluded, subject to the provisions of Appendix $J$, Section III.C.3, when determining the combined leakage rate provided the seal system and valves are pressurized to at least $1.10 \mathrm{P}$ ( 55 psig) and the seal system capacity is adequate to maintain system pressure for at least 30 days.

h. Type B tests for penetrations employing a continuous leakage monitoring system shall be conducted at $P_{a}(50$ psig) at intervals no greater than once per 3 years.

i. All test leakage rates shall be calculated using observed data converted to absolute values. Error analyses shall be performed to select a balanced integrated leakage measurement system.

j. The provisions of Specification 4.0.2 are not applicable. 
3.6.1.3 Each containment air lock shall be OPERABLE with:

a. Both doors closed except when the air lock is being used for normal transit entry and exit through the containment, then at least one air lock door shall be closed, and

b. An overall air lock leakage rate of less than or equal to $0.05 \mathrm{~L}_{a}$ at $\mathrm{P}_{\mathrm{a}}$, (50) psig.

APPLICABILITY: MODES $1,2,3$ and 4.

ACTION:

a. With one containment air lock door inoperable:

1. Maintain at least the OPERABLE air lock door closed and either restore the inoperable air lock door to OPERABLE status within 24 hours or lock the OPERABLE air lock door closed.

2. Operation may then continue until performance of the next required overall air lock leakage test provided that the OPERABLE air lock door is verified to be locked closed at least once per 31 days.

3. Otherwise, be in at least HOT STANDBY within the next six hours and in COLD SHUTDOWN within the following 30 hours.

4. The provisions of Specification 3.0.4 are not applicable.

b. With the containment air lock inoperable, except as the result of an inoperable air lock door, maintain at least one air lock door closed; restore the inoperable air lock to OPERABLE status within 24 hours or be in at least HOT STANDBY within the next six hours and in COLD SHUTDOWN within the following 30 hours. 
4.6.1.3 Each containment air lock shall be demonstrated OPERABLE:

a. *After each opening, except when the air lock is being used for multiple entries, then at least once per 72 hours, by verifying no detectable seal leakage by pressure decay when the volume between the door seals is pressurized to greater than or equal to $\mathrm{P}_{\mathrm{a}}$ (50 psig) for at least 15 minutes.

b. At least once per six months by conducting an overall air lock leakage test at $P_{2}(50 \mathrm{psig})$ and by verifying that the overall air lock leakage rate ${ }^{a}$ is within its 1 imit\#, and

c. At least once per six months by verifying that only one door in each air lock can be opened at a time.

*Exemption to Appendix "J" of 10 CFR 50.

\# The provisions of Specification 4.0.2 are not applicable. 
3.6.1.4 The containment isolation valve and channel weld pressurization systems shall be OPERABLE.

APPLICABILITY: MODES 1, 2, 3 and 4 .

ACTION:

With the containment isolation valve or channel weld pressurization system inoperable, restore the inoperable system to OPERABLE status within 7 days or be in at least HOT STANDBY within the next 6 hours and in COLD SHUTDOWN within the following 30 hours.

4.6.1.4.1 The containment isolation valve pressurization system shall be demonstrated OPERABLE at least once per 31 days by verifying that the system is pressurized to greater than or equal to $1.10 \mathrm{P}$ ( $55 \mathrm{psig}$ ) and has adequate capacity to maintain system pressure for at least ${ }^{2} 30$ days.

4.6.1.4.2 The containment channel weld pressurization system shall be demonstrated OPERABLE at least once per 31 days by verifying that the system is pressurized to greater than or equal to $P$ ( $50 \mathrm{psig}$ ) and has adequate capacity to maintain system pressure for at least 30 days. 
3.6.1.5 Primary containment internal pressure shall be maintained between and psig.

APPLICABILITY: MODES $1,2,3$ and 4.

ACTION:

With the containment internal pressure outside of the limits above, restore the internal pressure to within the limits within 1 hour or be in at least HOT STANDBY within the next 6 hours and in COLD SHUTDOWN within the following 30 hours.

4.6.1.5 The primary containment internal pressure shall be determined to be within the limits at least once per 12 hours. 
3.6.1.6 Primary containment average air temperature shall not exceed ${ }^{\circ} \mathrm{F}$. APPLICABILITY: MODES $1,2,3$ and 4.

ACTION:

With the containment average air temperature greater than ${ }^{\circ} \mathrm{F}$, reduce the average air temperature to within the limit within 8 hours, or be in at least HOT STANDBY within the next 6 hours and in COLD SHUTDOWN within the following 30 hours.

4.6.1.6 The primary containment average air temperature shall be the arithmetical average of the temperatures at the following locations and shall be determined at least once per 24 hours:

Location

a.

b.

c.

d.

e. 
CONTAINMENT STRUCTURAL INTEGRITY (Prestressed concrete containment with ungrouted tendons and typical dome. )

3.6.1.7 The structural integrity of the containment shall be maintained at a level consistent with the acceptance criteria in Specification 4.6.1.7.

APPLICABILITY: MODES $1,2,3$, and 4 .

ACTION:

With the structural integrity of the containment not conforming to the above requirements, restore the structural integrity to within the limits within 24 hours or be in at least HOT STANDBY within the next 6 hours and in COLD SHUTDOWN within the following 30 hours.

4.6.1.7.1 Containment Tendons. The containment tendons' structural integrity shall be demonstrated at the end of one, three and five years following the initial containment structural integrity test and at five year intervals thereafter. The tendons' structural integrity shall be demonstrated by:

a. Determining that a representative sample* of at least 21 tendons (6 dome, 5 vertical, and 10 hoop) each have a 1 ift off force of between (minimum) and (maximum) pounds at the first year inspection.

$\overline{\text { For }}$ subsequent inspections, the maximum allowable lift off force shall be decreased from the value determined at the first year inspection by the amount: $\quad \log t$ and the minimum allowable lift off force shall be decreased from the value determined at the first year inspection by the amount: $\log t$ where $t$ is the time interval in years from initial tensioning of the tendon to the current testing date. This test shall include an unloading cycle in which each of these tendons is detensioned to determined if any wires or strands are broken or damaged. Tendons found acceptable during this test shall be retensioned to their observed lift off

*For each inspection, the tendons shall be selected on a random but representative basis so that the sample group will change somewhat for each inspection; however, to develop a history of tendon performance and to correlate the observed data, one tendon from each group (dome, vertical, and hoop) may be kept unchanged after the initial selection. 
force, $\pm 3 \%$. During retensioning of these tendons, the change in load and elongation shall be measured simultaneously. If the lift off force of any one tendon in the total sample population is out of the predicted bounds (less than minimum or greater than maximum), an adjacent tendon on each side of the defective tendon shall also be checked for 1 ift off force. If both of these adjacent tendons are found acceptable, the surveillance program may proceed considering the single deficiency as unique and acceptable. This single tendon shall be restored to the required level of integrity. More than one defective tendon out of the original sample population is evidence of abnormal degradation of the containment structure. Unless there is evidence of abnormal degradation of the containment tendons during the first three tests of the tendons, the number of tendons checked for $1 \mathrm{ift}$ off force and change in elongation during subsequent tests may be reduced to a representative sample of at least 9 tendons (3 dome, 3 vertical and 3 hoop).

b. Removing one wire or strand from each of a dome, vertical and hoop tendon checked for a $1 \mathrm{ift}$ off force and determining that over the entire length of the removed wire or strand that:

1. The tendon wires or strands are free of corrosion, cracks and damage.

2. There are no changes in the presence or physical appearance of the sheathing filler grease.

3. A minimum tensile strength value of psi (guaranteed ultimate strength of the tendon material) for $\overline{a t}$ least three wire or strand samples (one from each end and one at mid-length) cut from each removed wire or strand. Failure of any one of the wire or strand samples to meet the minimum tensile strength test is evidence of abnormal degradation of the containment structure. 
4.6.1.7.2 End Anchorages and Adjacent Concrete Surfaces The structural integrity of the end anchorages of all tendons inspected pursuant to Specification 4.6.1.7.1 and the adjacent concrete surfaces shall be demonstrated by determining through inspection that no apparent changes have occurred in the visual appearance of the end anchorage or the concrete crack patterns adjacent to the end anchorages. Inspections of the concrete shall be performed during the Type A containment leakage rate tests (reference Specification 4.6.1.2) while the containment is at its maximum test pressure.

4.6.1.7.3 Containment Surfaces The structural integrity of the exposed accessible interior and exterior surfaces of the containment, including the liner plate, shall be determined during the shutdown for each Type A containment leakage rate test (reference Specification 4.6.1.2) by a visual inspection of these surfaces. This inspection shall be performed prior to the Type A containment leakage rate test to verify no apparent changes in appearance or other abnormal degradation.

4.6.1.7.4 Reports Any abnormal degradation of the containment structure detected during the above required tests and inspections shall be reported to the Commission pursuant to Specification 6.9.1. This report shall include a description of the tendon condition, the condition of the concrete (especially at tendon anchorages), the inspection procedure, the tolerances on cracking, and the corrective actions taken. 
CONTAINMENT STRUCTURAL INTEGRITY (Prestressed concrete containment with ungrouted

- tendons and hemispherical dome.)

3.6.1.7 The structural integrity of the containment shall be maintained at a level consistent with the acceptance criteria in Specification 4.6.1.7.

APPLICABILITY: MODES 1, 2, 3, and 4.

ACTION:

With the structural integrity of the containment not conforming to the above requirements, restore the structural integrity to within the limits within 24 hours or be in at least HOT STANDBY within the next 6 hours and in COLD SHUTDOWN within the following 30 hours.

4.6.1.7.1 Containment Tendons. The containment tendons' structural integrity shall be demonstrated at the end of one, three and five years following the initial containment structural integrity test and at five year intervals thereafter. The tendons' structural integrity shall be demonstrated by:

a. Determining that a representative sample* of at least $4 \%$ but no 1 ess than 4 , of the $U$ tendons each have a lift off force of between (minimum) and (maximum) pounds at the first year inspection and that a representative sample* of at least $4 \%$, but no less than 9 , of the hoop tendons each have a lift off force of between (minimum) and (maximum) pounds at the first year inspection. For subsequent inspections, the maximum allowable lift off forces shall be decreased from the value determined at the first year inspection by the amount: $\quad \log t$ and the minimum allowable lift off force shall be decreased from the value determined at the first year inspection by the amount: log $t$ where $t$ is the time interval in years from initial tensioning of the tendon to the current testing date. This test shall include an unloading cycle in ' which each of these tendons is detensioned to determined if any wires or strands are broken or damaged. Tendons found acceptable during this test shall be retensioned to their observed lift off

*For each inspection, the tendons shall be selected on a random but representative basis so that the sample group will change somewhat for each inspection; however, to develop a history of tendon performance and to correlate the observed data, one tendon from each group ( $U$ and hoop) may be kept unchanged after the initial selection. 
force, $\pm 3 \%$. During retensioning of these tendons, the change in load and elongation shall be measured simultaneously. If the lift off force of any one tendon in the total sample population is out of the predicted bounds (less than minimum or greater than maximum), an adjacent tendon on each side of the defective tendon shall also be checked for lift off force. If both of these adjacent tendons are found acceptable, the surveillance program may proceed considering the single deficiency as unique and acceptable. This single tendon shall be restored to the required level of integrity. More than one defective tendon out of the original sample population is evidence of abnormal degradation of the containment structure. Unless there is evidence of abnormal degradation of the containment tendons during the first three tests of the tendons, the number of tendons checked for 1 ift off force and change in elongation during subsequent tests may be reduced to a representative sample of at least $2 \%$, but no less than 2, of the $U$ tendons and a representative sample of at least $2 \%$, but no less than 3 , of the hoop tendons.

b. Removing one wire or strand from one $U$ tendon and one hoop tendon checked for lift off force and determining that over the entire length of the removed wire or strand that:

1. The tendon wires or strands are free of corrosion, cracks and damage.

2. There are not changes in the presence or physical appearance of the sheathing filler grease.

3. A minimum tensile strength value of __ psi (guaranteed ultimate strength of the tendon material) for at least three wire or strand samples (one from each end and one at mid-length) cut from each removed wire or strand. Failure of any one of the wire or strand samples to meet the minimum tensile strength test is evidence of abnormal degradation of the containment structure. 
4.6.1.7.2 End Anchorages and Adjacent Concrete Surfaces The structural integrity of the end anchorages of all tendons inspected pursuant to Specification 4.6.1.7.1 and the adjacent concrete surfaces shall be demonstrated by determining through inspection that no apparent changes have occurred in the visual appearance of the end anchorage or the concrete crack patterns adjacent to the end anchorages. Inspections of the concrete shall be performed during the Type A containment leakage rate tests (reference Specification 4.6.1.2) while the containment is at its maximum test pressure.

4.6.1.7.3 Containment Surfaces The structural integrity of the exposed accessible interior and exterior surfaces of the containment, including the liner plate, shall be determined during the shutdown for each Type A containment leakage rate test (reference Specification 4.6 .1 .2 ) by a visual inspection of these surfaces. This inspection shall be performed prior to the Type A containment leakage rate test to verify no apparent changes in appearance or other abnormal degradation.

4.6.1.7.4 Reports Any abnormal degradation of the containment structure detected during the above required tests and inspections shall be reported to the Commission pursuant to Specification 6.9.1. This report shall include a description of the tendon condition, the condition of the concrete (especially at tendon anchorages), the inspection procedure, the tolerances on cracking, and the corrective actions taken. 
CONTAINMENT STRUCTURAL INTEGRITY (Reinforced concrete containment)

3.6.1.7 The structural integrity of the containment shall be maintained at a level consistent with the acceptance criteria in Specification 4.6.1.7.

APPLICABILITY: MODES $1,2,3$ and 4.

ACTION:

With the structural integrity of the containment not conforming to the above requirements, restore the structural integrity to within the limits within 24 hours or be in at least HOT STANDBY within the next 6 hours and in COLD SHUTDOWN within the following 30 hours.

SURVEILLANCE REQUIREMENTS

4.6.1.7.1 Containment Surfaces The structural integrity of the exposed accessible interior and exterior surfaces of the containment, including the liner plate, shall be determined during the shutdown for each Type A containment leakage rate test (reference Specification 4.6 .1 .2 ) by a visual inspection of these surfaces. This inspection shall be performed prior to the Type A containment leakage rate test to verify no apparent changes in appearance or other abnormal degradation.

4.6.1.7.2 Reports Any abnormal degradation of the containment structure detected during the above required inspections shall be reported to the Commission pursuant to Specification 6.9.1. This report shall include a description of the condition of the concrete, the inspection procedure, the tolerances on cracking, and the corrective actions taken. 
3.6.1.8 The containment purge supply and exhaust isolation valves shall be closed.

APPLICABILITY: MODES $1,2,3$, and 4.

ACTION:

With one containment purge supply and/or one exhaust isolation valve open, close the open valve(s) within one hour or be in at least HOT STANDBY within the next 6 hours and in COLD SHUTDOWN within the following 30 hours.

\section{SURVEILLANCE REQUIREMENTS}

4.6.1.8 The containment purge supply and exhaust isolation valves shall be determined closed at least once per 31 days.

${ }^{\star}$ This specification may be modified if the facility design conforms to Branch Technical Position CSB 6-4 of the Standard Review Plan. 
3.6.2.1 Two independent containment spray systems shall be OPERABLE with each spray system capable of taking suction from the RWST and transferring suction to the containment sump.

APPLICABILITY: MODES $1,2,3$ and 4.

ACTION:

With one containment spray system inoperable, restore the inoperable spray system to OPERABLE status within 72 hours or be in at least HOT STANDBY within the next 6 hours; restore the inoperable spray system to OPERABLE status within the next 48 hours or be in COLD SHUTDOWN within the following 30 hours.

\section{SURVEILLANCE REQUIREMENTS}

4.6.2.1 Each containment spray system shall be demonstrated OPERABLE:

a. At least once per 31 days by verifying that each valve (manual, power operated or automatic) in the flow path that is not locked, sealed, or otherwise secured in position, is in its correct position.

b. By verifying, that on recirculation flow, each pump develops a discharge pressure of greater than or equal to tested pursuant to Specification 4.0.5. psig when

c. At least once per 18 months during shutdown, by:

1. Verifying that each automatic valve in the flow path actuates to its correct position on a test signal.

2. Verifying that each spray pump starts automatically on a test signal.

d. At least once per 5 years by performing an air or smoke flow test through each spray header and verifying each spray nozzle is unobstructed. 
CONTAINMENT SYSTEMS

3/4.6.2 DEPRESSURIZATION AND COOLING SYSTEMS

CONTAINMENT SPRAY SYSTEM (No credit taken for iodine removal)

LIMITING CONDITION FOR OPERATION

3.6.2.1 Two independent containment spray systems shall be OPERABLE with each spray system capable of taking suction from the RWST and transferring suction to the containment sump.

APPLICABILITY: MODES $1,2,3$ and 4 .

ACTION:

a. With one containment spray system inoperable and at least (four) containment cooling fans OPERABLE, restore the inoperable spray system to OPERABLE status within 7 days or be in at least HOT STANDBY within the next 6 hours and in COLD SHUTDOWN within the following 30 hours.

b. With two containment spray systems inoperable and at least (four) containment cooling fans OPERABLE, restore at least one spray system to OPERABLE status within 72 hours or be in at least HOT STANDBY within the next 6 hours and in COLD SHUTDOWN within the following 30 hours. Restore both spray systems to OPERABLE status within 7 days of initial loss or be in at least HOT STANDBY within the next 6 hours and in COLD SHUTDOWN within the following 30 hours.

c. With one containment spray system inoperable and one group of required containment cooling fans inoperable, restore either the inoperable spray system or the inoperable group of cooling fans to OPERABLE status within 72 hours or be in at least HOT STANDBY within the next 6 hours and in COLD SHUTDOWN within the folloiwng 30 hours. Restore both the inoperable spray system and the inoperable group of cooling fans to OPERABLE status within 7 days of initial loss or be in at least HOT STANDBY within the next 6 hours and in COLD SHUTDOWN within the following 30 hours. 
4.6.2.1 Each containment spray system shall be demonstrated OPERABLE:

a. At least once per 31 days by verifying that each valve (manual, power operated or automatic) in the flow path that is not locked, sealed or otherwise secured in position, is in its correct position.

b. By verifying, that on recirculation flow, each pump develops a discharge pressure of greater than or equal to pursuant to Specification 4.0.5.

c. At least once per 18 months, during shutdown, by:

1. Verifying that each automatic valve in the flow path actuates to its correct position on a test signa?

2. Verifying that each spray pump starts automatically on a test signal.

d. At least once per 5 year by performing an air or smoke flow test through each spray header and verifying each spray nozzle is unobstructed. 
SPRAY ADDITIVE SYSTEM (OPTIONAL)

LIMITING CONDITION FOR OPERATION

3.6.2.2 The spray additive system shall be OPERABLE with:

a. A spray additive tank containing a volume of between and solution, and gallons of between and percent by weight $\mathrm{NaOH}$

b. Two spray additive eductors each capable of adding $\mathrm{NaOH}$ solution from the chemical additive tank to a containment spray system pump flow.

APPLICABILITY: MODES $1,2,3$ and 4.

\section{ACTION:}

With the spray additive system inoperable, restore the system to OPERABLE status within 72 hours or be in at least HOT STANDBY within the next 6 hours; restore the spray additive system to OPERABLE status within the next 48 hours or be in COLD SHUTDOWN within the following 30 hours.

\section{SURVEILLANCE REQUIREMENTS}

4.6.2.2 The spray additive system shall be demonstrated OPERABLE:

a. At least once per 31 days by verifying that each valve (manual, power operated or automatic) in the flow path that is not locked, sealed, or otherwise secured in position, is in its correct position.

b. At least once per 6 months by:

1. Verifying the contained solution volume in the tank, and

2. Verifying the concentration of the $\mathrm{NaOH}$ solution by chemical analysis.

c. At least once per 18 months during shutdown, by verifying that each automatic valve in the flow path actuates to its correct position on a test signal.

d. At least once per 5 years by verifying each solution flow rate (to be determined during pre-operational tests) from the following drain connections in the spray additive system:

1. (Drain line location) $\pm$ gpm

2. (Drain line location)

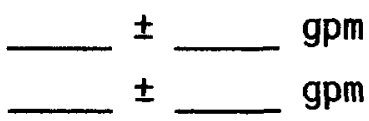


CONTAINMENT COOLING SYSTEM (OPTIONAL) (Credit taken for iodine removal by spray systems)

\section{LIMITING CONDITIONS FOR OPERATION}

3.6.2.3 (Two) independent groups of containment cooling fans shall be OPERABLE with (two) fan systems to each group. (Equivalent to $100 \%$ cooling capacity.)

APPLICABILITY: MODES $1,2,3$ and 4.

ACTION:

a. With one group of the above required containment cooling fans inoperable and both containment spray systems OPERABLE, restore the inoperable group of cooling fans to OPERABLE status within 7 days or be in at least HOT STANDBY within the next 6 hours and in COLD SHUTDOWN within the following 30 hours.

b. With two groups of the above required containment cooling fans inoperable, and both containment spray systems OPERABLE, restore at least one group of cooling fans to OPERABLE status within 72 hours or be in at least HOT STANDBY within the next 6 hours and in COLD SHUTDOWN within the following 30 hours. Restore both above required groups of cooling fans to OPERABLE status within 7 days of initial loss or be in at least HOT STANDBY within the next 6 hours and in COLD SHUTDOWN within the following 30 hours.

c. With one group of the above required containment cooling fans inoperable and one containment spray system inoperable, restore the inoperable spray system to OPERABLE status within 72 hours or be in at least HOT STANDBY within the next 6 hours and in COLD SHUTDOWN within the following 30 hours. Restore the inoperable group of containment cooling fans to OPERABLE status within 7 days of initial loss or be in at least HOT STANDBY within the next 6 hours and in COLD SHUTDOWN within the following 30 hours.

4.6.2.3 Each group of containment cooling fans shall be demonstrated OPERABLE:

a. At least once per 31 days by:

1. Starting each fan group from the control room, and verifying that each fan group operates for at least 15 minutes.

2. Verifying a cooling water flow rate of greater than or equal to gpm to each cooler.

b. At least once per 18 months by verifying that each fan group starts automatically on a test signal. 
CONTAINMENT SYSTEMS

CONTAINMENT COOLING SYSTEM (OPTIONAL) (No credit taken for iodine removal by spray systems)

\section{LIMITING CONDITION FOR OPERATION}

3.6.2.3 (Two) independent groups of containment cooling fans shall be OPERABLE with (two) fan systems to each group. (Equivalent to $100 \%$ cooling capacity.)

APPLICABILITY: MODES $1,2,3$ and 4 .

ACTION:

a. With one group of the above required containment cooling fans inoperable and both containment spray systems OPERABLE, restore the inoperable group of cooling fans to OPERABLE status within 7 days or be in at least HOT STANDBY within the next 6 hours and in COLD SHUTDOWN within the following 30 hours.

b. With two groups of the above required containment cooling fans inoperable, and both containment spray systems OPERABLE, restore at least one group of cooling fans to OPERABLE status within 72 hours or be in at least HOT STANDBY within the next 6 hours and in COLD SHUTDOWN within the following 30 hours. Restore both above required groups of cooling fans to OPERABLE status within 7 days of initial loss or be in at least HOT STANDBY within the next 6 hours and in COLD SHUTDOWN within the following 30 hours.

c. With one group of the above required containment cooling fans inoperable and one containment spray system inoperable, restore either the inoperable group of containment cooling fans or the inoperable spray system to OPERABLE status within 72 hours or be in at least HOT STANDBY within the next 6 hours and in COLD SHUTDOWN within the following 30 hours. Restore both the inoperable group of containment cooling fans and the inoperable spray system to OPERABLE status within 7 days of initial loss or be in at least HOT STANDBY within the next 6 hours and in COLD SHUTDOWN within the following 30 hours.

4.6.2.3 Each group of containment cooling fans shall be demonstrated OPERABLE:

a. At least once per 31 days by:

1. Starting each fan group from the control room and verifying that each fan group operates for at least 15 minutes.

2. Verifying a cooling water flow rate of greater than or equal to gpm to each cooler.

b. At least once per 18 months by verifying that each fan group starts automatically on a test signal. 
CONTAINMENT SYSTEMS

3/4.6.3 IODINE CLEANUP SYSTEM (OPTIONAL)

LIMITING CONDITION FOR OPERATION

3.6.3 Two independent containment iodine cleanup systems shall be OPERABLE. APPLICABILITY: MODES $1,2,3$ and 4.

ACTION:

With one iodine cleanup system inoperable, restore the inoperable system to OPERABLE status within 7 days or be in at least HOT STANDBY within the next 6 hours and in COLD SHUTDOWN within the following 30 hours.

4.6.3 Each iodine cleanup system shall be demonstrated OPERABLE:

a. At least once per 31 days on a STAGGERED TEST BASIS by initiating, from the control room, flow through the HEPA filters and charcoal absorbers and verifying that the system operates for at least 10 hours with the heaters on.

b. At least once per 18 months or (1) after any structural maintenance on the HEPA filter or charcoal adsorber housings, or (2) following painting, fire or chemical release in any ventilation zone communicating with the system by:

1. Verifying that the cleanup system satisfies the in-place testing acceptance criteria and uses the test procedures of Regulatory Positions C.5.a, C.5.C and C.5.d of Regulatory Guide 1.52, Revision 2, March 1978, and the system flow rate is $\mathrm{cfm} \pm$ $10 \%$.

2. Verifying within 31 days after removal that a laboratory analysis of a representative carbon sample obtained in accordance with Regulatory Position C.6.b of Regulatory Guide 1.52, Revision 2, March 1978, meets the laboratory testing criteria of Regulatory Position C.6.a of Regulatory Guide 1.52, Revision 2, March 1978.

3. Verifying a system flow rate of cfm $\pm 10 \%$ during system operation when tested in accordance with ANSI N510-1975. 
c. After every 720 hours of charcoal adsorber operation by verifying within 31 days after removal that a laboratory analysis of a representative carbon sample obtained in accordance with Regulatory Position C.6.b of Regulatory Guide 1.52, Revision 2, March 1978, meets the laboratory testing criteria of Regulatory Position C.6.a of Regulatory Guide 1.52, Revision 2, March 1978.

d. At least once per 18 months by:

1. Verifying that the pressure drop across the combined HEPA filters and charcoal adsorber banks is less than (6) inches Water Gauge while operating the system at a flow rate of $\mathrm{cfm} \pm 10 \%$.

2. Verifying that the system starts on either a Safety Injection Test Signal or on a Containment Pressure -High Test Signal.

3. Verifying that the filter cooling bypass valves can be opened by operator action.

4. Verifying that the heaters dissipate tested in accordance with ANSI N510-1 $\overline{975 .}$

$\pm$ kw when

e. After each complete or partial replacement of a HEPA filter bank by verifying that the HEPA filter banks remove greater than or equal to (99.95)\%* of the DOP when they are tested in-place in accordance with ASNI N510-1975 while operating the system at a flow rate of cfm $\pm 10 \%$.

f. After each complete or partial replacement of a charcoal adsorber bank by verifying that the charcoal adsorbers remove greater than or equal to $99.95 \%$ of a halogenated hydrocarbon refrigerant test gas when they are tested in-place in accordance with ANSI N510-1975 while operating the system at a flow rate of $\mathrm{cfm} \pm 10 \%$.

* $99.95 \%$ applicable when a filter efficiency of $99 \%$ is assumed in the safety analyses; $99 \%$ when a filter efficiency of $90 \%$ is assumed. 
3.6.4 The containment isolation valves specified in Table 3.6-1 shall be OPERABLE with isolation times as shown in Table 3.6-1.

APPLICABILITY: MODES $1,2,3$ and 4.

ACTION:

With one or more of the isolation valve(s) specified in Table 3.6-1 inoperable, maintain at least one isolation valve OPERABLE in each affected penetration that is open and either:

a. Restore the inoperable valve(s) to OPERABLE status within 4 hours, or

b. Isolate each affected penetration within 4 hours by use of at least one deactivated automatic valve secured in the isolation position, or

c. Isolate each affected penetration within 4 hours by use of at least one closed manual valve or blind flange; or

d. Be in at least HOT STANDBY within the next 6 hours and in COLD SHUTDOWN within the following 30 hours.

4.6.4.1 The isolation valves specified in Table 3.6-1 shall be demonstrated OPERABLE prior to returning the valve to service after maintenance, repair or replacement work is performed on the valve or its associated actuator, control or power circuit by performance of a cycling test, and verification of isolation time. 
4.6.4.2 Each isolation valve specified in Table 3.6-1 shall be demonstrated OPERABLE during the COLD SHUTDOWN or REFUELING MODE at least once per 18 months by:

a. Verifying that on a Phase A containment isolation test signal, each Phase $A$ isolation valve actuates to its isolation position.

b. Verifying that on a Phase B containment isolation test signal, each Phase $B$ isolation valve actuates to its isolation position.

c. Verifying that on a Containment Purge and Exhaust isolation test signal, each Purge and Exhaust valve actuates to its isolation position.

4.6.4.3 The isolation time of each power operated or automatic valve of Table 3.6-1 shall be determined to be within its limit when tested pursuant to Specification 4.0.5.

4.6.4.4 Each containment purge isolation valve shall be demonstrated OPERABLE within 24 hours after each closing of the valve, except when the valve is being used for multiple cyclings, then at least once per 72 hours, by verifying that when the measured leakage rate is added to the leakage rates determined pursuant to specification 4.6.1.2d. for all other Type $B$ and $C$ penetrations, the combined leakage rate is less than or equal to $0.60 \mathrm{~L}$. 
$\frac{1=}{n}$

TABLE $3.6-1$

CONTAINMENT ISOLATION VALVES

VALVE NUMBER

FUNCTION

ISOLATION TIME

( ) seconds

A. PHASE "A" ISOLATION

B. PHASE "B" ISOLATION

C. CONTAINMENT PURGE AND EXHAUST

D. MANUAL

E. OTHER

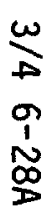

May be opened on an intermittent basis under administrative control. \# Not subject to Type $C$ leakage tests.

要
담
$\overrightarrow{0}$ 


\section{CONTAINMENT SYSTEMS}

3/4.6.5 COMBUSTIBLE GAS CONTROL

HYDROGEN ANALYZERS

LIMITING CONDITION FOR OPERATION

3.6.5.1 Two independent containment hydrogen analyzers shal1 be OPERABLE. APPLICABILITY: MODES 1 and 2.

ACTION:

With one hydrogen analyzer inoperable, restore the inoperable analyzer to OPERABLE status within 30 days or be in at least HOT STANDBY within the next 6 hours.

\section{SURVEILLANCE REQUIREMENTS}

4.6.5.1 Each hydrogen analyzer shall be demonstrated OPERABLE at least once per 92 days on a STAGGERED TEST BASIS by performing a CHANNEL CALIBRATION using sample gases containing:

a. One volume percent hydrogen, balance nitrogen.

b. Four volume percent hydrogen, balance nitrogen. 
ELECTRIC HYDROGEN RECOMBINERS - $W$

LIMITING CONDITION FOR OPERATION

3.6.5.2 Two independent containment hydrogen recombiner systems shall be OPERABLE.

APPLICABILITY: MODES 1 and 2.

ACTION:

With one hydrogen recombiner system inoperable, restore the inoperable system to OPERABLE status within 30 days or be in at least HOT STANDBY within the next 6 hours.

SURVEILLANCE REQUIREMENTS

4.6.5.2 Each hydrogen recombiner system shall be demonstrated OPERABLE:

a. At least once per 6 months by verifying during a recombiner system functional test that the minimum heater sheath temperature increases to greater than or equal to $700^{\circ} \mathrm{F}$ within 90 minutes and is maintained for at least 2 hours.

b. At least once per 18 months by:

1. Performing a CHANNEL CALIBRATION of all recombiner instrumentation and control circuits.

2. Verifying through a visual examination that there is no evidence of abnormal conditions within the recombiners (i.e., loose wiring or structural connections, deposits of foreign materials, etc.)

3. Verifying during a recombiner system functional test that the heater sheath temperature increases to greater than or equal to $1200^{\circ} \mathrm{F}$ within 5 hours and is maintained for at least 4 hours.

4. Verifying the integrity of all heater electrical circuits by performing a continuity and resistance to ground test following the above required functional test. The resistance to ground for any heater phase shall be greater than or equal to 10,000 ohms. 
HYDROGEN PURGE CLEANUP SYSTEM (If less than 2 hydrogen recombiners available)

3.6.5.3 A containment hydrogen purge cleanup system shall be OPERABLE and capable of being powered from a minimum of one OPERABLE emergency bus.

APPLICABILITY: MODES 1 and 2.

ACTION:

With the containment hydrogen purge cleanup system inoperable, restore the hydrogen purge cleanup system to OPERABLE status within 30 days or be in at least HOT STANDBY within 6 hours.

SURVEILLANCE REQUIREMENTS

4.6.5.3 The hydrogen purge cleanup system shall be demonstrated OPERABLE:

a. At least once per 31 days by initiating, from the control room, flow through the HEPA filters and charcoal adsorbers and verifying that the system operates for at least 10 hours with the heaters on.

b. At least once per 18 months or (1) after any structural maintenance of the HEPA filter or charcoal adsorber housings, or (2) following painting, fire or chemical release in any ventilation zone communicating with the system by:

1. Verifying that the cleanup system satisfies the in-place testing acceptance criteria and uses the test procedures of Regulatory Positions C.5.a, C.5.C and C.5.d of Regulatory Guide 1.52, Revision 2, March 1978, and the system flow rate is $\mathrm{cfm}$ $\pm 10 \%$.

2. Verifying within 31 days after removal that a laboratory analysis of a representative carbon sample obtained in accordance with Regulatory Position C.6.b of Regulatory Guide 1.52, Revision 2, March 1978, meets the laboratory testing criteria of Regulatory Position C.6.a of Regulatory Guide 1.52, Revision 2, March 1978.

3. Verifying a system flow rate of $\quad \mathrm{cfm} \pm 10 \%$ during system operation when tested in accordance with ANSI N510-1975. 
c. After every 720 hours of charcoal adsorber operation by verifying within 31 days after removal that a laboratory analysis of a representative carbon sample obtained in accordance with Regulatory Position C.6.b of Regulatory Guide 1.52, Revision 2, March 1978, meets the laboratory testing criteria of Regulatory Position C.6.a of Regulatory Guide 1.52, Revision 2, March 1978.

d. At least once per 18 months by:

1. Verifying that the pressure drop across the combined HEPA filters and charcoal adsorber banks is less than (6) inches Water Gauge while operating the system at a flow rate of $\mathrm{cfm} \pm 10 \%$.

2. Verifying that the filter cooling bypass valves can be manually opened.

3. Verifying that the heaters dissipate $\pm \ldots$ when tested in accordance with ANSI N510-1 $\overline{975 .}$

e. After each complete or partial replacement of a HEPA filter bank by verifying that the HEPA filter banks remove greater than or equal to (99.95)\%* of the DOP when they are tested in-place in accordance with ANSI N510-1975 while operating the system at a flow rate of cfm $\pm 10 \%$.

f. After each complete or partial replacement of a charcoal adsorber bank by verifying that the charcoal adsorbers remove greater than or equal to $99.95 \%$ of a halogenated hydrocarbon refrigerant test gas when they are tested in-place in accordance with ANSI N510-1975 while operating the system at a flow rate of $\mathrm{cfm} \pm 10 \%$.

ॠ99.95\% applicable when a filter efficiency of $99 \%$ is assumed in the safety analyses; $99 \%$ when a filter efficiency of $90 \%$ is assumed. 
3.6.5.4 Two independent hydrogen mixing systems shall be OPERABLE. APPLICABILITY: MODES 1 and 2.

\section{ACTION:}

With one hydrogen mixing system inoperable, restore the inoperable system to OPERABLE status within 30 days or be in at least HOT STANDBY within the next 6 hours.

\section{SURVEILLANCE REQUIREMENTS}

4.6.5.4 Each hydrogen mixing system shall be demonstrated OPERABLE:

a. At least once per 92 days on a STAGGERED TEST BASIS by starting each system from the control room and verifying that the system operates for at least 15 minutes.

b. At least once per 18 months by verifying a system flow rate of at least $\mathrm{cfm}$. 
3/4.6.6 PENETRATION ROOM EXHAUST AIR CLEANUP SYSTEM (OPTIONAL)

3.6.6 Two independent containment penetration room exhaust air cleanup systems shall be OPERABLE.

APPLICABILITY: MODES $1,2,3$, and 4 .

ACTION:

With one containment penetration room exhaust air cleanup system inoperable, restore the inoperable system to OPERABLE status within 7 days or be in at least HOT STANDBY within the next 6 hours and in COLD SHUTDOWN within the following 30 hours.

4.6.6 Each containment penetration room exhaust air cleanup system shall be demonstrated OPERABLE:

a. At least once per 31 days on a STAGGERED TEST BASIS by initiating, from the control room, flow through the HEPA filters and charcoal adsorbers and verifying that the system operates for at least 10 hours with the heaters on.

b. At least once per 18 months or (1) after any structural maintenance on the HEPA filter or charcoal adsorber housings, or (2) following painting, fire or chemical release in any ventilation zone communicating with the system by:

1. Verifying that with the system operating at a flow rate of $\mathrm{cfm} \pm 10 \%$ and exhausting through the HEPA filters and charcoal adsorbers, the total bypass flow of the system to the facility vent, including leakage through the system diverting valves, is less than or equal to $1 \%$ when the system is tested by admitting cold DOP at the system intake. (For systems with diverting valves.)

2. Verifying that the cleanup system satisfies the in-place testing acceptance criteria and uses the test procedures of Regulatory Positions C.5.a, C.5.C and C.5.d of Regulatory Guide 1.52, Revision 2, March 1978, and the system flow rate is $\mathrm{cfm} \pm$ $10 \%$. 
3. Verifying within 31 days after removal that a laboratory analysis of a representative carbon sample obtained in accordance with Regulatory Position C.6.b of Regulatory Guide 1.52, Revision 2, March 1978, meets the laboratory testing criteria of Regulatory Position C.6. a of Regulatory Guide 1.52, Revision 2, March 1978.

4. Verifying a system flow rate of $\quad \mathrm{cfm} \pm 10 \%$ during system operation when tested in accordance with ANSI N510-1975.

c. After every 720 hours of charcoal adsorber operation by verifying within 31 days after removal that a laboratory analysis of a representative carbon sample obtained in accordance with Regulatory Position C.6.b of Regulatory Guide 1.52, Revision 2, March 1978, meets the laboratory testing criteria of Regulatory Position C.6.a of Regulatory Guide 1.52, Revision 2, March 1978.

d. At least once per 18 months by:

1. Verifying that the pressure drop across the combined HEPA filters and charcoal adsorber banks is less than (6) inches Water Gauge while operating the system at a flow rate of $\mathrm{cfm} \pm 10 \%$.

2. Verifying that the system starts on a Safety Injection Test Signal.

3. Verifying that the filter cooling bypass valves can be manually opened.

4. Verifying that the heaters dissipate
tested in accordance with ANSI N510-1975.

e. After each complete or partial replacement of a HEPA filter bank by verifying that the HEPA filter banks remove greater than or equal to (99.95)\%* of the DOP when they are tested in-place in accordance with ANSI N510-1975 while operating the system at a flow rate of $\mathrm{cfm} \pm 10 \%$.

f. After each complete or partial replacement of a charcoal adsorber bank by verifying that the charcoal adsorbers remove greater than or equal to $99.95 \%$ of a halogenated hydrocarbon refrigerant test gas when they are tested in-place in accordance with ANSI N510-1975 while operating the system at a flow rate of $\mathrm{cfm} \pm 10 \%$.

\footnotetext{
*99.95\% applicable when a filter efficiency of $99 \%$ is assumed in the safety analyses; $99 \%$ when a filter efficiency of $90 \%$ is assumed.
} 
3.6.7 The primary containment to atmosphere vacuum relief valves shall be OPERABLE with an actuation set point of less than or equal to _ psid.

APPLICABILITY: MODES $1,2,3$ and 4.

ACTION:

With one primary containment to atmosphere vacuum relief valve inoperable, restore the valve to OPERABLE status within 4 hours or be in at least HOT STANDBY within the next 6 hours and in COLD SHUTDOWN within the following 30 hours.

4.6.7 No additional Surveillance Requirements other than those required by Specification 4.0.5. 


\section{SECTION 3/4.6B \\ CONTAINMENT SYSTEMS SPECIFICATIONS \\ FOR \\ WEST INGHOUSE \\ ICE CONDENSER TYPE CONTAINMENTS}


-

-

- 
$3 / 4.6$ CONTAINMENT SYSTEMS

3/4.6.1 PRIMARY CONTAINMENT

CONTAINMENT INTEGRITY

LIMITING CONDITION FOR OPERATION

\subsubsection{Primary CONTAINMENT INTEGRITY shall be maintained.}

APPLICABILITY: MODES $1,2,3$ and 4 .

ACTION:

Without primary CONTAINMENT INTEGRITY, restore CONTAINMENT INTEGRITY within one hour or be in at least HOT STANDBY within the next 6 hours and in COLD SHUTDOWN within the following 30 hours.

\section{SURVEILLANCE REQUIREMENTS}

4.6.1.1 Primary CONTAINMENT INTEGRITY shal1 be demonstrated:

a. At least once per 31 days by verifying that all penetrations* not capable of being closed by OPERABLE containment automatic isolation valves and required to be closed during accident conditions are closed by valves, blind flanges, or deactivated automatic valves secured in their positions, except as provided in Table 3.6-2 of Specification 3.6.4.1.

b. By verifying that each containment air lock is OPERABLE per Specification 3.6.1.3.

c. After each closing of the equipment hatch, by leak rate testing the equipment hatch seals with gas at $P_{\text {, }}(20 \mathrm{psig})$ and verifying that when the measured leakage rate for these seals is added to the leakage rates determined pursuant to Specification 4.6.1.2.d for all other Type $B$ and $C$ penetrations, the combined leakage rate is less than or equal to $0.06 \mathrm{~L}_{\mathrm{a}}$.

*Except valves, blind flanges, and deactivated automatic valves which are located inside the containment and are locked, sealed or otherwise secured in the closed position. These penetrations shall be verified closed during each COLD SHUTDOWN except that such verification need not be performed more often than once per 92 days. 


\subsubsection{Containment leakage rates shall be limited to:}

a. An overall integrated leakage rate of:

1. Less than or equal to $L_{0},(0.20)$ percent by weight of the containment air per 24 hours at $P_{a}(20$ psig), or

2. Less than or equal to $L_{t},(0.10)$ percent by weight of the containment air per 24 hours at a reduced pressure of $P_{t}$ (10 psig).

b. A combined leakage rate of less than or equal to $0.60 \mathrm{~L}$ for all penetrations and valves subject to Type $B$ and $C$ tests, when pressurized to $\mathrm{P}_{\mathrm{a}}$.

c. A combined leakage rate of less than or equal to $(0.10) \mathrm{L}$ for all penetrations identified in Table 3.6-1 as secondary contalnment bypass leakage paths when pressurized to $\mathrm{P}_{\mathrm{a}}$.

APPLICABILITY: MODES $1,2,3$ and 4.

ACTION:

With either (a) the measured overall integrated containment leakage rate exceeding $0.75 \mathrm{~L}$ or $0.75 \mathrm{~L}_{\mathrm{t}}$, as applicable, or (b) with the measured combined leakage rate for all penetrations and valves subject to Types $B$ and $C$ tests exceeding $0.60 \mathrm{~L}_{a}$, or (c) with the combined bypass leakage rate exceeding (0.10) $\mathrm{L}_{\mathrm{a}}$, restofe the overall integrated leakage rate to less than or equal to $0.75 \mathrm{Q}$ or less than or equal to $0.75 \mathrm{~L}_{t}$, as applicable, and the combined leakage rate for all penetrations and valves subject to Type $B$ and $C$ tests to less than or equal to $0.06 \mathrm{~L}_{a}$, and the combined bypass leakage rate to less than or equal to $(0.10) \mathrm{L}_{\text {a }}$ prior to increasing the Reactor Coolant System temperature above $200^{\circ} \mathrm{F}$.

\section{SURVEILLANCE REQUIREMENTS}

4.6.1.2 The containment leakage rates shall be demonstrated at the following test schedule and shall be determined in conformance with the criteria specified in Appendix $J$ of 10 CFR 50 using the methods and provisions of ANSI N45.4-(1972): 
a. Three Type A tests (Overall Integrated Containment Leakage Rate) shall be conducted at $40 \pm 10$ month intervals during shutdown at either $P_{2}$ (20 psig) or at $P_{t}(10 \mathrm{psig})$ during each 10-year service period. The third test of each set shall be conducted during the shutdown for the 10-year plant inservice inspection.

b. If any periodic Type $A$ test fails to meet either $0.75 \mathrm{~L}_{\text {or }} 0.75 \mathrm{~L}_{\mathrm{f}}$, the test schedule for subsequent Type $A$ tests shall be leviewed and approved by the Commission. If two consecutive Type $A$ tests fail to meet either $0.75 \mathrm{~L}_{\text {or }} 0.75 \mathrm{~L}_{t}$, a Type $A$ test shall be performed at least every 18 months until two consecutive Type $A$ tests meet either $0.75 \mathrm{~L}_{a}$ or $0.75 \mathrm{~L}_{t}$ at which time the above test schedule may be resumed.

c. The accuracy of each Type $A$ test shall be verified by a supplemental test which:

1. Confirms the accuracy of the Type A test by verifying that the difference between supplemental and Type $A$ test data is within $0.25 \mathrm{~L}_{\mathrm{a}}$, or $0.25 \mathrm{~L}_{\mathrm{t}}$,

2. Has a duration sufficient to establish accurately the change in leakage rate between the Type $A$ test and the supplemental test.

3. Requires the quantity of gas injected into the containment or bled from the containment during the supplemental test to be equivalent to at least 25 percent of the total measured leakage at $P_{a}$ (20 psig) or $P_{t}$ (25 psig).

d. Type $B$ and $C$ tests shall be conducted with gas at $P$ (20 psig) at intervals no greater than 24 months except for tests involving:

1. Air locks,

2. Penetrations using continuous leakage monitoring systems, and

3. Valves pressurized with fluid from a seal system.

e. The combined bypass leakage rate shall be determined to be less than (0.10) $L$ by applicable Type B and C tests at least once per 24 months except for penetrations which are not individually testable; penetrations not individually testable shall be determined to have no detectable leakage when tested with soap bubbles while the containment is pressurized to $P_{a}(20$ psig) during each Type $A$ test. 
f. Air locks shall be tested and demonstrated OPERABLE per Surveillance Requirement 4.6.1.3.

g. Type B periodic tests are not required for penetrations continuously monitored by the Containment Isolation Valve and Channel Weld Pressurization Systems, provided the systems are OPERABLE per Surveillance Requirement 4.6.1.4.

h. Leakage from isolation valves that are sealed with fluid from a seal system may be excluded, subject to the provisions of Appendix J, Section III.C.3, when determining the combined leakage rate provided the seal system and valves are pressurized to at least $1.10 \mathrm{P}$ (22 psig) and the seal system capacity is adequate to maintain system pressure for at least 30 days.

i. Type $B$ tests for penetrations employing a continuous leakage monitoring system shall be conducted at $P_{a}(20$ psig) at intervals no greater than once per 3 years.

j. All test leakage rates shall be calculated using observed data converted to absolute values. Error analyses shall be performed to select a balanced integrated leakage measurement system.

k. The provisions of Specification 4.0.2 are not applicable. 
TABLE $3.6-1$

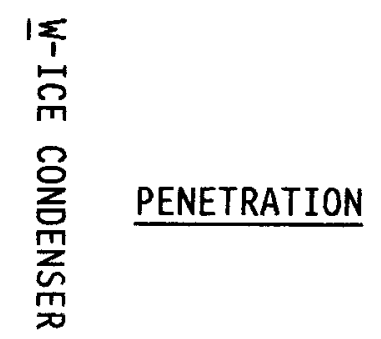

SECONDARY CONTAINMENT BYPASS LEAKAGE PATHS

\section{RELEASE LOCATION}

$\omega$
\pm
$\sigma$
$\vdots$
$\vdots$
0

m

or

$\vec{\infty}$ 
CONTAINMENT SYSTEMS

CONTAINMENT AIR LOCKS

3.6.1.3 Each containment air lock shall be OPERABLE with:

a. Both doors closed except when the air lock is being used for normal transit entry and exist through the containment, then at least one air lock door shall be closed, and

b. An overall air lock leakage rate of less than or equal to $0.05 \mathrm{~L}_{a}$ at $P_{a}(20$ psig).

APPLICABILITY: MODES 1, 2, 3 and 4.

ACTION:

a. With one containment air lock door inoperable:

1. Maintain at least the OPERABLE air lock door closed and either restore the inoperable air lock door to OPERABLE status within 24 hours or lock the OPERABLE air lock door closed.

2. Operation may then continue until performance of the next required overall air lock leakage test provided that the OPERABLE air lock door is verified to be locked closed at least once per 31 days.

3. Otherwise, be in at least HOT STANDBY within the next 6 hours and in COLD SHUTDOWN within the following 30 hours.

4. The provisions of Specification 3.0.4 are not applicable.

b. With the containment air lock inoperable, except as the result of an inoperable air lock door, maintain at least one air lock door closed; restore the inoperable air lock to OPERABLE status within 24 hours or be in at least HOT STANDBY within the next 6 hours and on COLD SHUTDOWN within the following 30 hours. 
4.6.1.3 Each containment air lock shall be demonstrated OPERABLE:

a. *After each opening, except when the air lock is being used for multiple entries, then at least once per 72 hours, by verifying no detectable seal leakage by pressure decay when the volume between the door seals is pressurized to greater than or equal to $\mathrm{P}_{\mathrm{a}}(20$ psig) for at least 15 minutes,

b. At least once per 6 months by conducting an overall air lock leakage test at $P_{1}(20 \mathrm{psig})$ and by verifying that the overall air lock leakage răte is within its limit\#, and

c. At least once per 6 months by verifying that only one door in each air lock can be opened at a time.

ॠExemption to Appendix "J" of 10 CFR 50.

\# The provisions of Specification 4.0 .2 are not applicable. 
3.6.1.4 The containment isolation valve and channel weld pressurization systems shall be OPERABLE.

APPLICABILITY: MODES 1, 2, 3 and 4.

ACTION:

With the containment isolation valve or channel weld pressurization system inoperable, restore the inoperable system to OPERABLE status within 7 days or be in at least HOT STANDBY within the next 6 hours and in COLD SHUTDOWN within the following 30 hours.

4.6.1.4.1 The containment isolation valve pressurization system shall be demonstrated OPERABLE at least once per 31 days by verifying that the system is pressurized to greater than or equal to $1.10 \mathrm{P}$ (22 psig) and has adequate capacity to maintain system pressure for at least $\mathrm{a}_{30}$ days.

4.6.1.4.2 The containment channel weld pressurization system shall be demonstrated OPERABLE at least once per 31 days by verifying that the system is pressurized to greater than or equal to $P$ (20 psig) and has adequate capacity to maintain system pressure for at least 30 days. 


\section{CONTAINMENT SYSTEMS}

INTERNAL PRESSURE

LIMITING CONDITION FOR OPERATION

3.6.1.5 Primary containment internal pressure shall be maintained between and psig.

APPLICABILITY: MODES $1,2,3$ and 4.

ACTION:

With the containment internal pressure outside of the limits above, restore the internal pressure to within the limits within 1 hour or be in at least HOT STANDBY within the next 6 hours and in COLD SHUTDOWN within the following 30 hours.

4.6.1.5 The primary containment internal pressure shall be determined to within the limits at least once per 12 hours. 
3.6.1.6 Primary containment average air temperature shall be maintained:
a. Between and ${ }^{\circ} \mathrm{F}$ in the containment upper compartment, and
b. Between and of in the containment lower compartment.

APPLICABILITY: MODES $1,2,3$ and 4.

ACTION:

With the containment average air temperature not conforming to the above limits, restore the air temperature to within the limits within 8 hours or be in at least HOT STANDBY within the next 6 hours and in COLD SHUTDOWN within the following 30 hours.

\section{SURVEILLANCE REQUIREMENTS}

4.6.1.6.1 The primary containment upper compartment average air temperature shall be the arithmetical average of the temperatures at the following locations:

Location

a.

b.

c.

4.6.1.6.2 The primary containment lower compartment average air temperature shall be the arithmetical average of the temperatures at the following locations:

\section{Location}

a.

b.

c.

4.6.1.6.3 The primary containment average air temperatures shall be determined at least once per 24 hours. 
3.6.1.7 The structural integrity of the containment vessel shall be maintained at a level consistent with the acceptance criteria in Specification 4.6.1.7.

APPLICABILITY: MODES $1,2,3$ and 4.

ACTION:

With the structural integrity of the containment vessel not conforming to the above requirements, restore the structural integrity to within the limits prior to increasing the Reactor Coolant System temperature above $200^{\circ} \mathrm{F}$.

4.6.1.7 The structural integrity of the containment vessel shall be determined during the shutdown for each Type A containment leakage rate test (reference Specification 4.6.1.2) by a visual inspection of the exposed accessible interior and exterior surfaces of the vessel. This inspection shall be performed prior to the Type A containment leakage rate test to verify no apparent changes in appearance of the surfaces or other abnormal degradation. Any abnormal degradation of the containment vessel detected during the above required inspections shall be reported to the Commission pursuant to Specification 6.9.1. 
SHIELD BUILDING STRUCTURAL INTEGRITY

3.6.1.8 The structural integrity of the shield building shall be maintained at a level consistent with the acceptance criteria in Specification 4.6.1.8.

APPLICABILITY: MODES $1,2,3$ and 4.

\section{ACTION:}

With the structural integrity of the shield building not conforming to the original acceptance standards, restore the structural integrity to within the limits within 24 hours or be in at least HOT STANDBY within the next 6 hours and in COLD SHUTDOWN within the following 30 hours.

\section{SURVEILLANCE REQUIREMENTS}

4.6.1.8 The structural integrity of the shield building shall be determined during the shutdown for each Type A containment leakage rate test (reference Specification 4.6.1.2) by a visual inspection of the exposed accessible interior and exterior surfaces of the shield building and verifying no apparent changes in appearance of the concrete surfaces or other abnormal degradation. Any abnormal degradation of the shield building detected during the above required inspections shall be reported to the Commission pursuant to Specification 6.9.1. 
CONTAINMENT SYSTEMS

AIR CLEANUP SYSTEM

LIMITING CONDITION FOR OPERATION

3.6.1.9 Two independent shield building air cleanup systems shall be OPERABLE. APPLICABILITY: MODES $1,2,3$ and 4.

ACTION:

With one shield building air cleanup system inoperable, restore the inoperable system to OPERABLE status within 7 days or be in at least HOT STANDBY within the next 6 hours and in COLD SHUTDOWN within the following 30 hours.

\section{SURVEILLANCE REQUIREMENTS}

4.6.1.9 Each shield building air cleanup system shall be demonstrated OPERABLE:

a. At least once per 31 days on a STAGGERED TEST BASIS by initiating, from the control room, flow through the HEPA filters and charcoal adsorbers and verifying that the system operates for at least 10 hours with the heaters on.

b. At least once per 18 months or (1) after any structural maintenance on the HEPA filter or charcoal adsorber housings, or (2) following painting, fire or chemical release in any ventilation zone communicating with the system by:

1. Verifying that with the system operating at a flow rate of $\mathrm{cfm} \pm 10 \%$ and exhausting through the HEPA filters and charcoal adsorbers, the total bypass flow of the system to the facility vent, including leakage through the system diverting valves, is less than or equal to $1 \%$ when the system is tested by admitting cold DOP at the system intake. (For systems with diverting valves.)

2. Verifying that the cleanup system satisfies the in-place testing acceptance criteria and uses the test procedures of Regulatory Positions C.5.a, C.5.C and C.5.d of Regulatory Guide 1.52, Revision 2, March 1978, and the system flow rate is $10 \%$.

3. Verifying within 31 days after removal that a laboratory analysis of a representative carbon sample obtained in accordance with Regulatory Position C.6.b of Regulatory Guide 1.52, Revision 2, 
March 1979, meets the laboratory testing criteria of Regulatory Position C.6. a of Regulatory Guide 1.52, Revision 2, March 1978.

4. Verifying a system flow rate of c cfm $\pm 10 \%$ during system operation when tested in accordance with ANSI N510-1975.

c. After every 720 hours of charcoal adsorber operation by verifying within 31 days after removal that a laboratory analys is of a representative carbon sample obtained in accordance with Regulatory Position C.6.b of Regulatory Guide 1.52, Revision 2, March 1978, meets the laboratory testing criteria of Regulatory Position C.6.a of Regulatory Guide 1.52, Revision 2, March 1978.

d. At least once per 18 months by:

1. Verifying that the pressure drop across the combined HEPA filters and charcoal adsorber banks is less than (6) inches Water Gauge while operating the system at a flow rate of $\mathrm{cfm} \pm 10 \%$.

2. Verifying that the system starts automatically on any containment isolation test signal.

3. Verifying that the filter cooling bypass valves can be manually opened.

4. Verifying that each system produces a negative pressure of greater than or equal to $(0.25)$ inches W.G. in the annulus within (1) minute after a start signal.

5. Verifying that the heaters dissipate _ $\pm \ldots$ when tested in accordance with ANSI N5. 1-1975.

e. After each complete or partial replacement of a HEPA filter bank by verifying that the HEPA filter banks remove greater than or equal to (99.95)\%* of the DOP when they are tested in-place in accordance with ANSI N510-1975 while operating the system at a flow rate of cfm $\pm 10 \%$.

f. After each complete or partial replacement of a charcoal adsorber bank by verifying that the charcoal adsorbers remove greater than or equal to $99.95 \%$ of a halogenated hydrocarbon refrigerant test gas when they are tested in-place in accordance with ANSI N510-1975 while operating the system at a flow rate of $\mathrm{cfm} \pm 10 \%$.

*99.95\% applicable when a filter efficiency of $99 \%$ is assumed in the safety analyses; $99 \%$ when a filter efficiency of $90 \%$ is assumed. 
3.6.1.10 The containment purge supply and exhaust isolation valves shall be closed.

APPLICABILITY: MODES $1,2,3$ and 4.

ACTION:

With one containment purge supply and/or one exhaust isolation valve open, close the open valve(s) within one hours or be in at least HOT STANDBY within the next 6 hours and in COLD SHUTDOWN within the following 30 hours.

4.6.1.10 The containment purge supply and exhaust isolation valves shall be determined closed at least once per 31 days.

ॠThis specification may be modified if the facility design conforms to Branch Technical Position CSB 6-4 of the Standard Review Plan. 
3/4.6.2 DEPRESSURIZATION AND COOLING SYSTEMS

CONTAINMENT SPRAY SYSTEM (Credit taken for iodine removal)

LIMITING CONDITION FOR OPERATION

3.6.2.1 Two independent containment spray systems shall be OPERABLE with each spray system capable of taking suction from the RWST and transferring suction to the containment sump.

APPLICABILITY: MODES $1,2,3$ and 4 .

ACTION:

With one containment spray system inoperable, restore the inoperable spray system to OPERABLE status within 72 hours or be in at least HOT STANDBY within the next 6 hours; restore the inoperable spray system to OPERABLE status within the next 48 hours or be in COLD SHUTDOWN within the following 30 hours.

\section{SURVEILLANCE REQUIREMENTS}

4.6.2.1 Each containment spray system shall be demonstrated OPERABLE:

a. At least once per 31 days by verifying that each valve (manual, power operated or automatic) in the flow path that is not locked sealed, or otherwise secured in position, is in its correct positon.

b By verifying, that on recirculation flow, each pump develops a discharge pressure of greater than or equal to tested pursuant to Specification 4.0.5. psig when

c. At least once per 18 months during shutdown, by:

1. Verifying that each automatic valve in the flow path actuates to its correct position on a test signal.

2. Verifying that each spray pump starts automatically on a test signal.

d. At least once per 5 years by performing an air or smoke flow test through each spray header and verifying each spray nozzle is unobstructed. 
3/4.6.2 DEPRESSURIZATION AND COOLING SYSTEMS

CONTAINMENT SPRAY SYSTEM (No credit taken for iodine removal)

LIMITING CONDITION FOR OPERATION

3.6.2.1 Two independent containment spray systems shal1 be OPERABLE with each spray system capable of taking suction from the RWST and transferring suction to the containment sump.

APPLICABILITY: MODES I, 2, 3 and 4.

ACTION:

a. With one containment spray system inoperable and at least (four) containment cooling fans OPERABLE, restore the inoperable spray system to OPERABLE status within 7 days or be in at least HOT STANDBY within the next 6 hours and in COLD SHUTDOWN within the following 30 hours.

b. With two containment spray systems inoperable and at least (four) containment cooling fans OPERABLE, restore at least one spray system to OPERABLE status within 72 hours or be in at least HOT STANDBY within the next 6 hours and in COLD SHUTDOWN within the following 30 hours. Restore both spray systems to OPERABLE status within 7 days of initial loss or be in at least HOT STANDBY within the next 6 hours and in COLD SHUTDOWN within the following 30 hours.

c. With one containment spray system inoperable and one group of required containment cooling fans inoperable, restore either the inoperable spray system or the inoperable group of cooling fans to OPERABLE status within 72 hours or be in at least HOT STANDBY within the next 6 hours and in COLD SHUTDOWN within the following 30 hours. Restore both the inoperable spray system and the inoperable group of cooling fans to OPERABLE status within 7 days of initial loss or be in at least HOT STANDBY within the next 6 hours and in COLD SHUTDOWN within the following 30 hours.

\section{SURVEILLANCE REQUIREMENTS}

4.6.2.1 Each containment spray system shall be demonstrated OPERABLE:

a. At least once per 31 days by verifying that each valve (manual, power operated or automatic) in the flow path that is not locked, sealed or otherwise secured in position, is in its correct position. 
b. By verifying, that on recirculation flow, each pump develops a discharge pressure of greater than or equal to tested pursuant to Specification 4.0.5. psig when

c. At least once per 18 months, during shutdown, by:

1. Verifying that each automatic valve in the flow path actuates to its correct position on a test signal.

2. Verifying that each spray pump starts automatically on a test signal.

d. At least once per 5 years by performing an air or smoke flow test through each spray header and verifying each spray nozzle is unobstructed. 
SPRAY ADDITIVE SYSTEM (OPTIONAL)

LIMITING CONDITION FOR OPERATION

3.6.2.2 The spray additive system shall be OPERABLE with:

a. A spray additive tank containing a volume of between and solution, and gallons of between and percent by weight $\mathrm{NaOH}$

b. Two spray additive eductors each capable of adding $\mathrm{NaOH}$ solution from the chemical additive tank to a containment spray system pump flow.

APPLICABILITY: MODES $1,2,3$ and 4.

ACTION:

With the spray additive system inoperable, restore the system to OPERABLE status within 72 hours or be in at least HOT STANDBY within the next 6 hours; restore the spray additive system to OPERABLE status within the next 48 hours or be in COLD SHUTDOWN within the following 30 hours.

\section{SURVEILLANCE REQUIREMENTS}

4.6.2.2 The spray additive system shall be demonstrated OPERABLE:

a. At least once per 31 days by verifying that each valve (manual, power operated or automatic) in the flow path that is not locked, sealed, or otherwise secured in position, is in its correct position.

b. At least once per 6 months by:

1. Verifying the contained solution volume in the tank, and

2. Verifying the concentration of the $\mathrm{NaOH}$ solution by chemical analysis.

c. At least once per 18 months during shutdown, by verifying that each automatic valve in the flow path actuates to its correct position on a test signal.

d. At least once per 5 years by verifying each solution flow rate (to be determined during preoperational tests) from the following drain connections in the spray additive system:

1. (Drain line location)

2. (Drain line location)

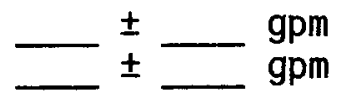


CONTAINMENT COOLING SYSTEM (OPTIONAL) (Credit taken for iodine removal by spray systems)

\section{LIMITING CONDITION FOR OPERATION}

3.6.2.3 (Two) independent groups of containment cooling fans shall be OPERABLE with (two) fan systems to each group. (Equivalent to $100 \%$ cooling capacity.)

APPLICABILITY: MODES $1,2,3$ and 4.

ACTION:

a. With one group of the above required containment cooling fans inoperable and both containment spray systems OPERABLE, restore the inoperable group of cooling fans to OPERABLE status within 7 days or be in at least HOT STANDBY within the next 6 hours and in COLD SHUTDOWN within the following 30 hours.

b. With two groups of the above required containment cooling fans inoperable, and both containment spray systems OPERABLE, restore at least one group of cooling fans to OPERABLE status within 72 hours or be in at least HOT STANDBY within the next 6 hours and in COLD SHUTDOWN within the following 30 hours. Restore both above required groups of cooling fans to OPERABLE status within 7 days of initial loss or be in at least HOT STANDBY within the next 6 hours and in COLD SHUTDOWN within the following 30 hours.

c. With one group of the above required containment cooling fans inoperable and one containment spray system inoperable, restore the inoperable spray system to OPERABLE status within 72 hours or be in at least HOT STANDBY within the next 6 hours and in COLD SHUTDOWN within the following 30 hours. Restore the inoperable group of containment cooling fans to OPERABLE status within 7 days of initial loss or be in at least HOT STANDBY within the next 6 hours and in COLD SHUTDOWN within the following 30 hours.

4.6.2.3 Each group of containment cooling fans shall be demonstrated OPERABLE:

a. At least once per 31 days by:

1. Starting each fan group from the control room and verifying that each fan group operates for at least 15 minutes.

2. Verifying a cooling water flow rate of greater than or equal to gpm to each cooler.

b. At least once per 18 months by verifying that each fan group starts automatically on a test signal. 
CONTAINMENT COOLING SYSTEM (OPTIONAL) (No credit taken for iodine removal by spray systems )

\section{LIMITING CONDITION FOR OPERATION}

3.6.2.3 (Two) independent groups of containment cooling fans shall be OPERABLE with (two) fan systems to each group. (Equivalent to $100 \%$ cooling capacity.)

APPLICABILITY: MODES 1, 2, 3 and 4.

\section{ACTION:}

a. With one group of the above required containment cooling fans inoperable and both containment spray systems OPERABLE, restore the inoperable group of cooling fans to OPERABLE status within 7 days or be in at least HOT STANDBY within the next 6 hours and in COLD SHUTDOWN within the following 30 hours.

b. With two groups of the above required containment cooling fans inoperable, and both containment spray systems OPERABLE, restore at least one group of cooling fans to OPERABLE status within 72 hours or be in at least HOT STANDBY within the next 6 hours and in COLD SHUTDOWN within the following 30 hours. Restore both above required groups of cooling fans to OPERABLE status within 7 days of initial loss or be in at least HOT STANDBY within the next 6 hours and in COLD SHUTDOWN within the following 30 hours.

c. With one group of the above required containment cooling fans inoperable and one containment spray system inoperable, restore either the inoperable group of containment cooling fans or the inoperable spray system to OPERABLE status within 72 hours or be in at least HOT STANDBY within the next 6 hours and in COLD SHUTDOWN within the following 30 hours. Restore both the inoperable group of containment cooling fans and the inoperable spray system to OPERABLE status within 7 days of initial loss or be in at least HOT STANDBY within the next 6 hours and in COLD SHUTDOWN within the following 30 hours.

\section{SURVEILLANCE REQUIREMENTS}

4.6.2.3 Each group of containment cooling fans shall be demonstrated OPERABLE:

a. At least once per 31 days by:

1. Starting each fan group from the control room and verifying that each fan group operates for at least 15 minutes. 
2. Verifying a cooling water flow rate of greater than or equal to gpm to each cooler.

b. At least once per 18 months by verifying that each fan group starts automatically on a test signal. 
3/4.6.3 IODINE CLEANUP SYSTEM (OPTIONAL)

LIMITING CONDITION FOR OPERATION

3.6.3 Two independent containment iodine cleanup systems shall be OPERABLE. APPLICABILITY: MODES 1,2, 3 and 4.

ACTION:

With one iodine cleanup system inoperable, restore the inoperable system to OPERABLE status within 7 days or be in at least HOT STANDBY within the next 6 hours and in COLD SHUTDOWN within the following 30 hours.

\section{SURVEILLANCE REQUIREMENTS}

4.6.3 Each jodine cleanup system shall be demonstrated OPERABLE:

a. At least once per 31 days on a STAGGERED TEST BASIS by initiating, from the control room, flow through the HEPA filters and charcoal adsorbers and verifying that the system operates for at least 10 hours with the heaters on.

b. At least once per 18 months or (1) after any structural maintenance on the HEPA filter or charcoal adsorber housings, or (2) following painting, fire or chemical release in any ventilation zone communicating with the system by:

1. Verifying that the cleanup system satisfies the in-place testing acceptance criteria and uses the test procedures of Regulatory Positions C.5.a, C.5.C and C.5.d of Regulatory Guide 1.52, Revision 2, March 1978, and the system flow rate is _ cfm \pm $10 \%$.

2. Verifying within 31 days after removal that a laboratory analysis of a representative carbon sample obtained in accordance with Regulatory Position C.6.b of Regulatory Guide 1.52, Revision 2, March 1978, meets the laboratory testing criteria of Regulatory Position C.6.a of Regulatory Guide 1.52, Revision 2, March 1978.

3. Verifying a system flow rate of cfm $\pm 10 \%$ during system operation when tested in accordance with ANSI N510-1975. 
c. After every 720 hours of charcoal adsorber operation by verifying within 31 days after removal that a laboratory analysis of a representative carbon sample obtained in accordance with Regulatory Position C.6.b of Regulatory Guide 1.52, Revision 2, March 1978, meets the laboratory testing criteria of Regulatory Position C. 6. a of Regulatory Guide 1.52, Revision 2, March 1978.

d. At least once per 18 months by:

1. Verifying that the pressure drop across the combined HEPA filters and charcoal adsorber banks is less than (6) inches Water Gauge while operating the system at a flow rate of $\mathrm{cfm} \pm 10 \%$.

2. Verifying that the system starts on either a Safety Injection Test Signal or on a Containment Pressure -High Test Signal.

3. Verifying that the filter cooling bypass valves can be opened by operator action.

4. Verifying that the heaters dissipate tested in accordance with ANSI N510-1975. $\pm$ $\mathrm{kw}$ when

e. After each complete or partial replacement of a HEPA filter bank by verifying that the HEPA filter banks remove greater than or equal to (99.95)\%* of the DOP when they are tested in-place in accordance with ANSI N510-1975 while operating the system at a flow rate of $\mathrm{cfm} \pm 10 \%$.

f. After each complete or partial replacement of a charcoal adsorber bank by verifying that the charcoal adsorbers remove greater than or equal to $99.95 \%$ of a halogenated hydrocarbon refrigerant test gas when they are tested in-place in accordance with ANSI N510-1975 while operating the system at a flow rate of cfm $\pm 10 \%$.

*99.95\% applicable when a filter efficiency of $99 \%$ is assumed in the safety analyses; $99 \%$ when a filter efficiency of $90 \%$ is assumed. 
3/4.6.4 CONTAINMENT ISOLATION VALVES

LIMITING CONDITION FOR OPERATION

3.6.4 The containment isolation valves specified in Table $3.6-2$ shall be OPERABLE with isolation times as shown in Table 3.6-2.

APPLICABILITY: MODES $1,2,3$ and 4.

ACTION:

With one or more of the isolation valve(s) specified in Table 3.6-2 inoperable, maintain at least one isolation valve OPERABLE in each affected penetration that is open and either:

a. Restore the inoperable valve(s) to OPERABLE status within 4 hours, or

b. Isolate each affected penetration within 4 hours by use of at least one deactivated automatic valve secured in the isolation position, or

c. Isolate each affected penetration within 4 hours by use of at least one closed manual valve or blind flange, or

d Be in at least HOT STANDBY within the next 6 hours and in COLD SHUTDOWN within the following 30 hours.

\section{SURVEILLANCE REQUIREMENTS}

4.6.4.1 The isolation valves specified in Table 3.6-2 shall be demonstrated OPERABLE prior to returning the valve to service after maintenance, repair or replacement work is performed on the valve or its associated actuator, control or power circuit by performance of a cycling test and verification of isolation time. 
4.6.4.2 Each isolation valve specified in Table 3.6-2 shall be demonstrated OPERABLE during the COLD SHUTDOWN or REFUELING MODE at least once per 18 months by:

a. Verifying that on a Phase $A$ containment isolation test signal, each Phase $A$ isolation valve actuates to its isolation position.

b. Verifying that on a Phase B containment isolation test signal, each Phase $B$ isolation valve actuates to its isolation position.

c. Verifying that on a Containment Purge and Exhaust isolation test signal, each Purge and Exhaust valve actuates to its isolation position.

4.6.4.3 The isolation time of each power operated or automatic valve of Table 3.6-2 shall be determined to be within its limit when tested pursuant to Specification 4.0.5.

4.6.4.4 Each containment purge isolation valve shall be demonstrated OPERABLE within 24 hours after each closing of the valve, except when the valve is being used for multiple cyclings, then at least once per 72 hours, by verifying that when the measured leakage rate is added to the leakage rates determined pursuant to specification 4.6.1.2d. for all other Type $B$ and $C$ penetrations, the combined leakage rate is less than or equal to $0.60 \mathrm{~L}$ a 
TABLE $3.6-2$

CONTAINMENT ISOLATION VALVES

VALVE NUMBER

FUNCTION

ISOLATION TIME

$\leq \ldots$ seconds

A. PHASE "A" ISOLATION

1.

2.

B. PHASE "B" ISOLATION

1.

2.

C. CONTAINMENT PURGE AND EXHAUST

1 .

2.

D. MANUAL

1.

2.

E. OTHER

1.

2.

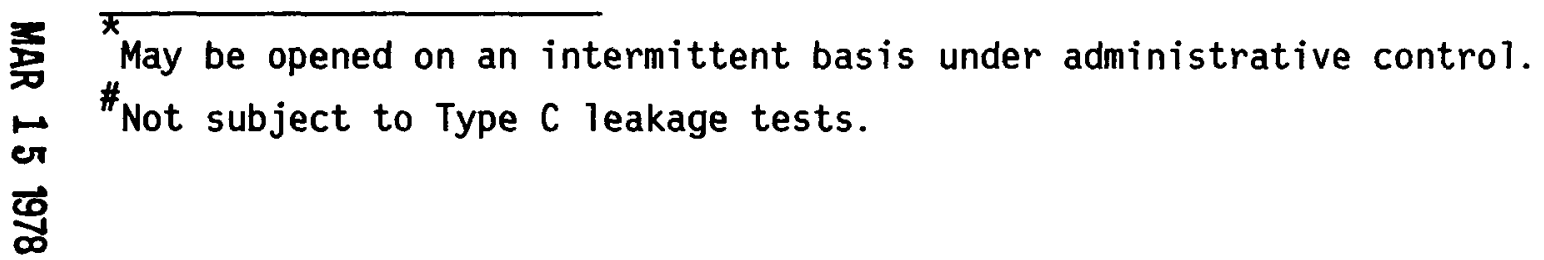




\section{$3 / 4.6 .5$ COMBUSTIBLE GAS CONTROL}

HYDROGEN ANALYZERS

LIMITING CONDITION FOR OPERATION

3.6.5.1 Two independent containment hydrogen analyzers shall be OPERABLE. APPLICABILITY: MODES 1 and 2.

ACTION:

With one hydrogen analyzer inoperable, restore the inoperable analyzer to OPERABLE status within 30 days or be in at least HOT STANDBY within the next 6 hours.

\section{SURVEILLANCE REQUIREMENTS}

4.6.5.1 Each hydrogen analyzer shall be demonstrated OPERABLE at least once per 92 days on a STAGGERED TEST BASIS by performing a CHANNEL CALIBRATION using sample gas containing:

a. One volume percent hydrogen, balance nitrogen.

b. Four volume percent hydrogen, balance nitrogen. 
ELECTRIC HYDROGEN RECOMBINERS - W

LIMITING CONDITION FOR OPERATION

3.6.5.2 Two independent containment hydrogen recombiner systems shall be OPERABLE.

APPLICABILITY: MODES 1 and 2.

ACTION:

With one hydrogen recombiner system inoperable, restore the inoperable system to OPERABLE status within 30 days or be in at least HOT STANDBY within the next 6 hours.

\section{SURVEILLANCE REQUIREMENTS}

4.6.5.2 Each hydrogen recombiner system shall be demonstrated OPERABLE:

a. At least once per 6 months by verifying during a recombiner system functional test that the minimum heater sheath temperature increases to greater than or equal to $700^{\circ} \mathrm{F}$ within 90 minutes and is maintained for at least 2 hours.

b. At least once per 18 months by:

1. Performing a CHANNEL CALIBRATION of all recombiner instrumentation and control circuits.

2. Verifying through a visual examination that there is no evidence of abnormal conditions within the recombiners (i.e., loose wiring or structural connections, deposits of foreign materials, etc. )

3. Verifying during a recombiner system functional test that the heater sheath temperature increases to greater than or equal to $1200^{\circ} \mathrm{F}$ within 5 hours and is maintained for at least 4 hours.

4. Verifying the integrity of all heater electrical circuits by performing a continuity and resistance to ground test following the above required functional test. The resistance to ground for any heater phase shall be greater than or equal to 10,000 ohms. 
HYDROGEN PURGE CLEANUP SYSTEM (If less than two hydrogen recombiners available)

3.6.5.3 A containment hydrogen purge cleanup system shall be OPERABLE and capable of being powered from a minimum of one OPERABLE emergency bus.

APPLICABILITY: MODES 1 and 2.

\section{ACTION:}

With the containment hydrogen purge cleanup system inoperable, restore the hydrogen purge cleanup system to OPERABLE status within 30 days or be in at least HOT STANDBY within 6 hours.

\section{SURVEILLANCE REQUIREMENTS}

4.6.5.3 The hydrogen purge cleanup system shall be demonstrated OPERABLE:

a. At least once per 31 days by initiating, from the control room, flow through the HEPA filters and charcoal adsorbers and verifying that the system operates for at least 10 hours with the heaters on.

b. As least once per 18 months or (1) after any structural maintenance on the HEPA filter or charcoal adsorber housings, or (2) following painting fire or chemical release in any ventilation zone communicating with the system by:

1. Verifying that the cleanup system satisfies the in-place testing acceptance criteria and uses of test procedures of Regulatory Positions C.5.a, C.5.C and C.5.d of Regulatory Guide 1.52, Revision 2, March 1978, and the system flow rate is $10 \%$.

2. Verifying within 31 days after removal that a laboratory analysis of a representative carbon sample obtained in accordance with Regulatory Position C.6.b of Regulatory Guide 1.52, Revision 2, March 1978, meets the 1aboratory testing criteria of Regulatory Position C.6. a of Regulatory Guide 1.52, Revision 2, March 1978.

3. Verifying a system flow rate of cfm $\pm 10 \%$ during system operation when tested in accordance with ANSI N510-1975. 
c. After every 720 hours of charcoal adsorber operation by verifying within 31 days after removal that a laboratory analysis of a representative carbon sample obtained in accordance with Regulatory Position C.6.b of Regulatory Guide 1.52, Revision 2, March 1978, meets the laboratory testing criteria of Regulatory Position C.6.a of Regulatory Guide 1.52, Revision 2, March 1978.

d. At least once per 18 months by:

1. Verifying that the pressure drop across the combined HEPA filters and charcoal adsorber banks is less than (6) inches Water Gauge while operating the system at a flow rate of $\mathrm{cfm} \pm 10 \%$.

2. Verifying that the filter cooling bypass valves can be manually opened.

3. Verifying that the heaters dissipate tested in accordance with ANSI N510-1 $\overline{975 .}$

$\pm$ kw when

e. After each complete or partial replacement of a HEPA filter bank by verifying that the HEPA filter banks remove greater than or equal to (99.95)\%* of the DOP when they are tested in-place in accordance with ANSI N510-1975 while operating the system at a flow rate of $\mathrm{cfm} \pm 10 \%$.

f. After each complete or partial replacement of a charcoal adsorber bank by verifying that the charcoal adsorbers remove greater than or equal to $99.95 \%$ of a halogenated hydrocarbon refrigerant test gas when they are tested in-place in accordance with ANSI N510-1975 while operating the system at a flow rate of $\mathrm{cfm} \pm 10 \%$.

ॠ99.95\% applicable when a filter efficiency of $99 \%$ is assumed in the safety analyses; $99 \%$ when a filter efficiency of $90 \%$ is assumed. 
3.6.5.4 Two independent hydrogen mixing systems shall be OPERABLE. APPLICABILITY: MODES 1 and 2.

ACTION:

With one hydrogen mixing system inoperable, restore the inoperable system to OPERABLE status within 30 days or be in at least HOT STANDBY within the next 6 hours.

4.6.5.4 Each hydrogen mixing system shall be demonstrated OPERABLE:

a. At least once per 92 days on a STAGGERED TEST BASIS by starting each system from the control room and verifying that the system operates for a least 15 minutes.

b. At least once per 18 months by verifying a system flow rate of at least $\mathrm{cfm}$. 


\section{3/4.6.6 PENETRATION ROOM EXHAUST AIR CLEANUP SYSTEM (OPTIONAL)}

3.6.6 Two independent containment penetration room exhaust air cleanup systems shall be OPERABLE.

APPLICABILITY: MODES 1, 2, 3 and 4.

ACTION:

With one containment penetration room exhaust air cleanup system inoperable, restore the inoperable system to OPERABLE status within 7 days or be in at least HOT STANDBY within the next 6 hours and in COLD SHUTDOWN within the following 30 hours.

\section{SURVEILLANCE REQUIREMENTS}

4.6.6 Each containment penetration room exhaust air cleanup system shall be demonstrated OPERABLE:

a. At least once per 31 days on a STAGGERED TEST BASIS by initiating, from the control room, flow through the HEPA filters and charcoal adsorbers and verifying that the system operates for at least 10 hours with the heaters on.

b. At least once per 18 months or (1) after any structural maintenance on the HEPA filter or charcoal adsorber housings, or (2) following painting, fire or chemical release in any ventilation zone communicating within the system by:

1. Verifying that with the system operating at a flow rate of $\mathrm{cfm} \pm 10 \%$ and exhausting through the HEPA filters and charcoal adsorbers, the total bypass flow of the system to the facility vent, including leakage through the system diverting valves, is less than or equal to $1 \%$ when the system is tested by admitting cold DOP at the system intake. (For systems with diverting valves.)

2. Verifying that the cleanup system satisfies the in-place testing acceptance criteria and uses the test procedures of Regulatory Positions C.5.a, C.5.C and C.5.d of Regulatory Guide 1.52, Revision 2, March 1978, and the system flow rate is $\mathrm{cfm} \pm$ $10 \%$. 
3. Verifying within 31 days after removal that a laboratory analysis of a representative carbon sample obtained in accordance with Regulatory Position C.6.b of Regulatory Guide 1.52, Revision 2 , March 1978, meets the laboratory testing criteria of Regulatory Position C.6.a of Regulatory Guide 1.52, Revision 2, March 1978.

4. Verifying a system flow rate of cfm $\pm 10 \%$ during system operation when tested in accordance with ANSI N510-1975.

c. After every 720 hours of charcoal adsorber operation by verifying within 31 days after removal that a laboratory analysis of a representative carbon sample obtained in accordance with Regulatory Position C.6.b of Regulatory Guide 1.52, Revision 2, March 1978, meets the laboratory testing criteria of Regulatory Position C.6.a of Regulatory Guide 1.52, Revision 2, March 1978.

d. At least once per 18 months by:

1. Verifying that the pressure drop across the combined HEPA filters and charcoal adsorber banks is less than (6) inches Water Gauge while operating the system at a flow rate of $\mathrm{cfm} \pm 10 \%$.

2. Verifying that the system starts on a Safety Injection Test Signal.

3. Verifying that the filter cooling bypass valves can be manually opened.

4. Verifying that the heaters dissipate tested in accordance with ANSI N510-1 $\overline{975 .}$ $\pm$ $\mathrm{kw}$ when

e. After each complete or partial replacement of a HEPA filter bank by verifying that the HEPA filter banks remove greater than or equal to (99.95)\%* of the DOP when they are tested in-place in accordance with ANSI N510-1975 while operating the system at a flow rate of $\mathrm{cfm} \pm 10 \%$.

f. After each complete or partial replacement of a charcoal adsorber bank by verifying that the charcoal adsorbers remove greater than or equal to $99.95 \%$ of a halogenated hydrocarbon refrigerant test gas when they are tested in-place in accordance with ANSI N510-1975 while operating the system at a flow rate of $\mathrm{cfm} \pm 10 \%$.

$99.95 \%$ applicable when a filter efficiency of $99 \%$ is assumed in the safety analyses; $99 \%$ when a filter efficiency of $90 \%$ is assumed. 
CONTAINMENT SYSTEMS

3/4.6.7 ICE CONDENSER

ICE BED

LIMITING CONDITION FOR OPERATION

3.6.7.1 The ice bed shall be OPERABLE with:

a. The stored ice having a boron concentration of at least $1800 \mathrm{ppm}$ boron as sodium tetraborate and a $\mathrm{pH}$ of 9.0 to 9.5 ,

b. Flow channels through the ice condenser,

c. A maximum ice bed temperature of less than or equal to $27^{\circ} \mathrm{F}$,

d. A total ice weight of at least $(2,721,600)$ pounds at a $95 \%$ level of confidence, and

e. 1944 ice baskets.

APPLICABILITY: MODES 1, 2, 3 and 4.

ACTION:

With the ice bed inoperable, restore the ice bed to OPERABLE status within 48 hours or be in at least HOT STANDBY within the next 6 hours and in COLD SHUTDOWN within the following 30 hours.

SURVEILLANCE REQUIREMENTS

4.6.7.1 The ice condenser shall be determined OPERABLE:

a. At least once per 12 hours by using the ice bed temperature monitoring system to verify that the maximum ice bed temperature is less than or equal to $27^{\circ} \mathrm{F}$.

b. At least once per 9 months by:

1. Chemical analyses which verify that at least 9 representative samples of stored ice have a boron concentration of at least $1800 \mathrm{ppm}$ as sodium tetraborate and a pH of 9.0 to 9.5 at $20^{\circ} \mathrm{C}$.

2. Weighing a representative sample of at least 144 ice baskets and verifying that each basket contains at least 1400 lbs of ice. The representative sample shall include 6 baskets from each of the 24 ice condenser bays and shall be constituted of 
one basket each from Radial Rows $1,2,4,6,8$ and 9 (or from the same row of an adjacent bay if a basket from a designated row cannot be obtained for weighing) within each bay. If any basket is found to contain less than 1400 pounds of ice, a representative sample of 20 additional baskets from the same bay shall be weighed. The minimum average weight of ice from the 20 additional baskets and the discrepant basket shall not be less than 1400 pounds/basket at a 95\% level of confidence.

The ice condenser shall also subdivided into 3 groups of baskets, as follows: Group 1 - bays 1 through 8, Group 2 bays 9 through 16, and Group 3 - bays 17 through 24 . The minimum average ice weight of the sample baskets from Radial Rows $1,2,4,6,8$ and 9 in each group shall not be less than 1400 pounds/basket at a $95 \%$ level of confidence.

The minimum total ice condenser ice weight at a 95\% level of confidence shall be calculated using all ice basket weights determined during this weighing program and shall not be less than $2,721,600$ pounds.

3. Verifying, by a visual inspection of at least two flow passages per ice condenser bay, that the accumulation of frost or ice on flow passages between ice baskets, past lattice frames, through the intermediate and top deck floor grating, or past the lower inlet plenum support structures and turning vanes is restricted to a thickness of less than or equal to 0.38 inches. If one flow passage per bay is found to have an accumulation of frost or ice with a thickness of greater than or equal to 0.38 inches, a representative sample of 20 additional flow passages from the same bay shall be visually inspected. If these additional flow passages are found acceptable, the surveillance program may proceed considering the single deficiency as unique and acceptable. More than one restricted flow passage per bay is evidence of abnormal degradation of the ice condenser.

c. At least once per 40 months by lifting and visually inspecting the accessible portions of at least two ice baskets from each $1 / 3$ of the ice condenser and verifying that the ice baskets are free of detrimental structural wear, cracks, corrosion or other damage. The ice baskets shall be raised at least 12 feet for this inspection. 
ICE BED TEMPERATURE MONITORING SYSTEM

LIMITING CONDITION FOR OPERATION

3.6.7.2 The ice bed temperature monitoring system shall be OPERABLE with at least 2 OPERABLE RTD channels in the ice bed at each of 3 basic elevations (_, and above the floor of the ice condenser) for each one third of the ice condenser.

APPLICABILITY: MODES $1,2,3$ and 4.

ACTION:

a. With the ice bed temperature monitoring system inoperable, POWER OPERATION may continue for up to 30 days provided:

1. The ice compartment lower inlet doors, intermediate deck doors, and top deck doors are closed;

2. The last recorded mean ice bed temperature was less than or equal to $20^{\circ} \mathrm{F}$ and steady; and

3. The ice condenser cooling system is OPERABLE with at least:
a) 21 OPERABLE air handling units,
b) 2 OPERABLE glycol circulating pumps, and
c) 3 OPERABLE refrigerant units;

Otherwise, be in at least HOT STANDBY within 6 hours and in COLD SHUTDOWN within the following 30 hours.

b. With the ice bed temperature monitoring system inoperable and with the ice condenser cooling system not satisfying the minimum components OPERABILITY requirements of a. 3 above, POWER OPERATION may continue for up to 6 days provided the ice compartment lower inlet doors, intermediate deck doors, and top deck doors are closed and the last recorded mean ice bed temperature was less than or equal to $15^{\circ} \mathrm{F}$ and steady; otherwise, be in at least HOT STANDBY within the next 6 hours and in COLD SHUTDOWN within the following 30 hours.

\section{SURVEILLANCE REQUIREMENTS}

4.6.7.2 The ice bed temperature monitoring system shall be determined OPERABLE by performance of a CHANNEL CHECK at least once per 12 hours. 
ICE CONDENSER DOORS

LIMITING CONDITION FOR OPERATION

3.6.7.3 The ice condenser inlet doors, intermediate deck doors, and top deck doors shall be closed and OPERABLE.

APPLICABILITY: MODES $1,2,3$ and 4.

\section{ACTION:}

With one or more ice condenser doors open or otherwise inoperable, POWER OPERATION may continue for up to 14 days provided the ice bed temperature is monitored at least once per 4 hours and the maximum ice bed temperature is maintained less than or equal to $27^{\circ} \mathrm{F}$; otherwise, restore the doors to their closed positions or OPERABLE status (as applicable) within 48 hours or be in at least HOT STANDBY within the next 6 hours and in COLD SHUTDOWN within the following 30 hours.

\section{SURVEILLANCE REQUIREMENTS}

\subsection{Inlet Doors - Ice condenser inlet doors shall be:}

a. Continuously monitored and determined closed by the inlet door position monitoring system, and

b. Demonstrated OPERABLE during shutdown at least once per 3 months during the first year after the ice bed is fully loaded and at least once per 6 months thereafter by:

1. Verifying that the torque required to initially open each door is less than or equal to (675) inch pounds.

2. Verifying that opening of each door is not impaired by ice, frost or debris.

3. Testing a sample of at least $25 \%$ of the doors and verifying that the torque required to open each door is less than (195) inch-pounds when the door is (40) degrees open. This torque is defined as the "door opening torque" and is equal to the nominal door torque plus a frictional torque component. The doors selected for determination of the "door opening torque" shall be selected to ensure that all doors are tested at least once during four test intervals. 
4. Testing a sample of at least $25 \%$ of the doors and verifying that the torque required to keep each door from closing is greater than 78 inch-pounds when the door is 40 degrees open. This torque is defined as the "door closing torque" and is equal to the nominal door torque minus a frictional torque component. The doors selected for determination of the "door closing torque" shall be selected to ensure that all doors are tested at least once during four test intervals.

5. Calculation of the frictional torque of each door tested in accordance with 3 and 4 , above. The calculated frictional torque shall be less than or equal to 40 inch-pounds.

4.6.7.3.2 Intermediate Deck Doors - Each ice condenser intermediate deck door shall be:

a. Verified closed and free of frost accumulation by a visual inspection at least once per 7 days, and

b. Demonstrated OPERABLE at least once per 3 months during the first year after the ice bed is fully loaded and at least once per 18 months thereafter by visually verifying no structural deterioration, by verifying free movement of the vent assemblies, and by ascertaining free movement when 1 ifted with the applicable force shown below:

Door

1.

2.

3.

4.
Lifting Force

$\leq$

Ibs.

$\leq$ Ibs.

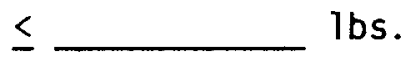

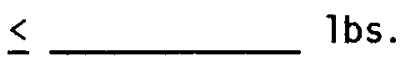

4.6.7.3.3 Top Deck Doors - Each ice condenser top deck door shall be determined closed and OPERABLE at least once per 92 days by visually verifying:

a. That the doors are in placed, and

b. That no condensation, frost, or ice has formed on the doors or blankets which would restrict their lifting and opening if required. 
INLET DOOR POSITION MONITORING SYSTEM

3.6.7.4 The inlet door position monitoring system shall be OPERABLE.

APPLICABILITY: MODES $1,2,3$ and 4.

ACTION:

With the inlet door position monitoring system inoperable, POWER OPERATION may continue for up to 14 days, provided the ice bed temperature monitoring system is OPERABLE and the maximum ice bed temperature is less than or equal to $27^{\circ} \mathrm{F}$ when monitored at least once per 4 hours; otherwise, restore the inlet door position monitoring system to OPERABLE status within 48 hours or be in at least HOT SHUTDOWN within the next 6 hours and in COLD SHUTDOWN within the following 30 hours.

4.6.7.4 The inlet door position monitoring system shall be determined OPERABLE by:

a. Performing a CHANNEL CHECK at least once per 12 hours,

b. Performing a CHANNEL FUNCTIONAL TEST at least once per 18 months, and

c. Verifying that the monitoring system correctly indicates the status of each inlet door as the door is opened and reclosed during its testing per Specification 4.6.7.3.1. 


\section{CONTAINMENT SYSTEMS}

DIVIDER BARRIER PERSONNEL ACCESS DOORS AND EQUIPMENT HATCHES

LIMITING CONDITION FOR OPERATION

3.6.7.5 The personnel access doors and equipment hatches between the containment's upper and lower compartments shall be OPERABLE and closed.

APPLICABILITY: MODES $1,2,3$ and 4.

ACTION:

With a personnel access door or equipment hatch inoperable or open except for personnel transit entry, restore the door or hatch to OPERABLE status or to its closed position (as applicable) within 1 hour or be in at least HOT STANDBY within the next 6 hours and in COLD SHUTDOWN within the following 30 hours.

\section{SURVEILLANCE REQUIREMENTS}

4.6.7.5.1 The personnel access doors and equipment hatches between the containment's upper and lower compartments shall be determined closed by a visual inspection prior to increasing the Reactor Coolant System $T_{\text {avg }}$ above $200^{\circ} \mathrm{F}$ and after each personnel transit entry when the Reactor Coolant System $T_{a v g}$ is above $200^{\circ} \mathrm{F}$.

4.6.7.5.2 The personnel access doors and equipment hatches between the containment's upper and lower compartments shall be determined OPERABLE by visually inspecting the seals and sealing surfaces of these penetrations and verifying no detrimental misalignments, cracks or defects in the sealing surfaces, or apparent deterioration of the seal material:

a. Prior to final closure of the penetration each time it has been opened, and

b. At least once per 10 years for penetrations containing seals fabricated from resilient materials. 
3.6.7.6 Two independent containment air recirculation systems shall be OPERABLE. APPLICABILITY: MODES $1,2,3$ and 4.

ACTION:

With one containment air recirculation system inoperable, restore the inoperable system to OPERABLE status within 72 hours or be in at least HOT STANDBY within the next 6 hours and in COLD SHUTDOWN within the following 30 hours.

SURVEILLANCE REQUIREMENTS

4.6.7.6 Each containment air recirculation system shall be demonstrated OPERABLE at least once per 92 days on a STAGGERED TEST BASIS by:

a. Verifying that the return air fan starts on an auto-start signal after a $10 \pm 1$ minute delay and operates for at least 15 minutes.

b. Verifying that with the return air fan dampers closed, the fan motor current is $\pm$ amps when the fan speed is $\pm$ RPM.

c. Verifying that with the fan off, the return air fan damper opens when a force of less than or equal to counterweight. lbs is applied to the

d. Verifying that the motor operated valve in the suction line to the containment's lower compartment opens after a $10 \pm 1$ minute delay. 
3.6.7.7 The ice condenser floor drains shall be OPERABLE.

APPLICABILITY: MODES $1,2,3$ and 4.

ACTION:

With the ice condenser floor drain inoperable, restore the floor drain to OPERABLE status prior to increasing the Reactor Coolant System temperature above $200^{\circ} \mathrm{F}$.

4.6.7.7 Each ice condenser floor drain shall be demonstrated OPERABLE at least once per 18 months during shutdown by:

a. Verifying that valve gate opening is not impaired by ice, frost or debris,

b. Verifying that the valve seat is not damaged,

c. Verifying that the valve gate opens when a force of less than or equal to lbs is applied, and

d. Verifying that the drain line from the ice condenser floor to the containment lower compartment is unrestricted. 
CONTAINMENT SYSTEMS

REFUELING CANAL DRAINS

LIMITING CONDITION FOR OPERATION

3.6.7.8 The refueling canal drains shall be OPERABLE.

APPLICABILITY: MODES $1,2,3$ and 4.

ACTION:

With a refueling canal drain inoperable, restore the drain to OPERABLE status prior to increasing the Reactor Coolant System temperature above $200^{\circ} \mathrm{F}$.

4.6.7.8 Each refueling canal drain shall be demonstrated OPERABLE prior to increasing the Reactor Coolant System temperature above $200^{\circ} \mathrm{F}$ after each partial or complete filling of the canal with water by verifying that the blind flange is removed from the drain line and that the drain is not obstructed by debris. 
3.6.7.9 The divider barrier seal shall be OPERABLE.

APPLICABILITY: MODES 1, 2, 3 and 4 .

ACTION:

With the divider barrier seal inoperable, restore the seal to OPERABLE status prior to increasing the Reactor Coolant System temperature above $200^{\circ} \mathrm{F}$.

4.6.7.9 The divider barrier seal shall be determined OPERABLE at least once per 18 months during shutdown by:

a. Removing two divider barrier seal test coupons and verifying that the physical properties. of the test coupons are within the acceptable range of values shown in Table 3.6-3.

b. Visually inspecting at least (95) percent of the seal's entire length and:

1. Verifying that the seal and seal mounting bolts are properly installed, and

2. Verifying that the seal material shows no visual evidence of deterioration due to holes, ruptures, chemical attack, abrasion, radiation damage, or changes in physical appearances. 


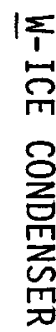

Material

(Uniroyal 3807)
TABLE $3.6-3$

\section{DIVIDER BARRIER SEAL}

ACCEPTABLE PHYSICAL PROPERTIES

Tensile

Strength

(120) psi
Elongation

$(100) \%$

$\omega$
p
a
1
吕

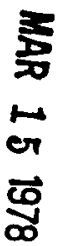


3/4.6.8 VACUUM RELIEF VALVES (OPTIONAL)

3.6.8 The primary containment to atmosphere vacuum relief valves shall be OPERABLE with an actuation set point of less than or equal to psid.

APPLICABILITY: MODES $1,2,3$ and 4.

ACTION:

With one primary containment to atmosphere vacuum relief valve inoperable, restore the valve to OPERABLE status within 4 hours or be in at least HOT STANDBY within the next 6 hours and in COLD SHUTDOWN within the following 30 hours.

4.6.8 No additional Surveillance Requirements other than those required by Specification 4.0.5. 
-
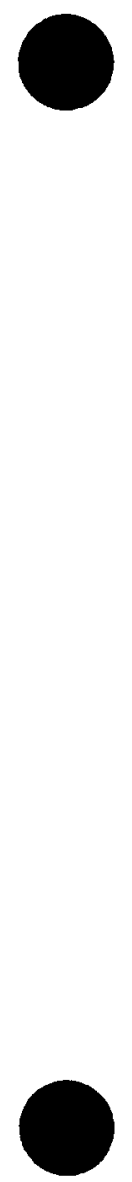


\author{
SECTION $3 / 4.6 \mathrm{C}$ \\ CONTAINMENT SYSTEMS SPECIFICATIONS \\ FOR \\ WEST INGHOUSE \\ SUBATOMOSPHERIC TYPE CONTAINMENT
}


-

-

• 


\section{3/4.6 CONTAINMENT SYSTEMS}

3/4.6.1 PRIMARY CONTAINMENT

CONTAINMENT INTEGRITY

LIMITING CONDITION FOR OPERATION

3.6.1.1 Primary CONTAINMENT INTEGRITY shall be maintained.

APPLICABILITY: MODES $1,2,3$ and 4.

ACTION:

Wi thout primary CONTAINMENT INTEGRITY, restore CONTAINMENT INTEGRITY within one hour or be in at least HOT STANDBY within the next 6 hours and in COLD SHUTDOWN within the following 30 hours.

4.6.1.1 Primary CONTAINMENT INTEGRITY shall be demonstrated:

a. At least once per 31 days by verifying that all penetrations* not capable of being closed by OPERABLE containment automatic isolation valves and required to be closed during accident conditions are closed by valves, blind flanges, or deactivated automatic valves secured in their positions, except as provided in Table 3.6-1 of Specification 3.6.4.1.

b. By verifying that each containment air lock is OPERABLE per Specification 3.6.1.3.

c. After each closing of the equipment hatch, by leak rate testing the equipment hatch seals with gas at $P$ ( 50 psig) and verifying that when the measured leakage rate for these seals is added to the leakage rates determined purusuant to Specification 4.6.1.2.d for all other Type $B$ and $C$ penetrations, the combined leakage rate is less than $0.60 \mathrm{~L}_{\mathrm{a}}$.

FExcept valves, blind flanges, and deactivated automatic valves which are located inside the containment and are locked, sealed or otherwise secured in the closed position. These penetrations shall be verified closed during each COLD SHUTDOWN except that such verification need not be performed more often than once per 92 days. 


\subsubsection{Containment leakage rates shal1 be limited to:}

a. An overall integrated leakage rate of:

1. Less than or equal to $L,(0.20)$ percent by weight of the containment air per 24 hours at $P_{a}(50$ psig), or

2. Less than or equal to $L_{t},(0.10)$ percent by weight of the containment air per 24 hours at a reduced pressure of $\mathrm{P}_{t}(25 \mathrm{psig})$.

b. A combined leakage rate of less than or equal to $0.60 \mathrm{~L}$ for all penetrations and valves subject to Type $B$ and $C$ tests, when pressurized to $\mathrm{P}_{\mathrm{a}}$.

APPLICABILITY: MODES $1,2,3$ and 4.

\section{ACTION:}

With either (a) the measured overall integrated containment leakage rate exceeding $0.75 \mathrm{~L}_{\text {a }}$ or $0.75 \mathrm{~L}_{t}$, as applicable, or (b) with the measured combined leakage rate for all penetrations and valves subject to Types $B$ and $C$ tests exceeding $0.60 \mathrm{~L}_{\mathrm{a}}$, restore the overall integrated leakage rate to less than or equal to $0.75 \mathrm{~L}_{\text {a }}$ or less than or equal to $0.75 \mathrm{~L}_{t}$, as applicable, and the combined leakage rate for all penetrations subject to Type $B$ and $C$ tests to less than or equal to $0.60 \mathrm{~L}_{\mathrm{a}}$ prior to increasing the Reactor Coolant System temperature above $200^{\circ} \mathrm{F}$.

\section{SURVEILLANCE REQUIREMENTS}

4.6.1.2 The containment leakage rates shall be demonstrated at the following test schedule and shall be determined in conformance with the criteria specified in Appendix $J$ of 10 CFR 50 using the methods and provisions of ANSI N45.4-(1972):

a. Three Type A tests (Overall Integrated Containment Leakage Rate) shall be conducted at $40+10$ month intervals during shutdown at either $P_{a}$ (50 psig) or at $P_{t}$ (25 psig) during each 10-year service period. ${ }^{a}$ The third test of each set shall be conducted during the shutdown for the 10-year plant inservice inspection.

b. If any periodic Type $A$ test fails to meet either $.75 L_{\text {a }}$ or $.75 L_{t}$, the test schedule for subsequent Type $A$ tests shall be ${ }^{a}$ reviewed and approved by the Commission. If two consecutive Type $A$ tests fail to meet either $.75 \mathrm{~L}$ or $.75 \mathrm{~L}_{t}$, a Type $A$ test shall be performed at least every 18 months until two consecutive Type $A$ tests meet either $.75 \mathrm{~L}_{\mathrm{a}}$ or $.75 \mathrm{~L}_{t}$ at which time the above test schedule may be resumed. 
c. The accuracy of each Type $A$ test shall be verified by a supplemental test which:

1. Confirms the accuracy of the Type $A$ test by verifying that the difference between supplemental and Type A test data is within $0.25 \mathrm{~L}_{\mathrm{a}}$, or $0.25 \mathrm{~L}_{\mathrm{t}}$.

2. Has a duration sufficient to establish accurately the change in leakage rate between the Type $A$ test and the supplemental test.

3. Requires the quantity of gas injected into the containment or bled from the containment during the supplemental test to be equivalent to at least 25 percent of the total measured leakage at $P_{a}$ (50 psig) or $P_{t}(25$ psig).

d. Type $B$ and $C$ tests shall be conducted with gas at $P_{\text {a }}$ (50 psig) at intervals no greater than 24 months except for tests involving:

1. Air locks,

2. Penetrations using continuous leakage monitoring systems, and

3. Valves pressurized with fluid from a seal system.

d. Type $B$ and $C$ test shall be conducted with gas at $P_{2}$ (50 psig) at intervals no greater than 24 months except for tesls involving:

1. Air locks,

2. Penetrations using continuous leakage monitoring systems, and

3. Valves pressurized with fluid from a seal system.

e. Air locks shall be tested and demonstrated OPERABLE per Surveillance Requirement 4.6.1.3.

f. Type B periodic tests are not required for penetrations continuously monitored by the Containment Isolation Valve and Channel Weld Pressurization Systems, provided the systems are OPERABLE per Surveillance Requirement 4.6.1.4.

g. Leakage from isolation valves that are sealed with fluid from a seal system may be excluded, subject to the provisions of Appendix $J$, Section III.C. 3, when determining the combined leakage rate provided the seal system and valves are pressurized to at least $1.10 \mathrm{P}_{\text {(55 }}$ psig) and the seal system capacity is adequate to maintain system pressure for at least 30 days. 
h. Type $B$ tests for penetrations employing a continuous leakage monitoring system shall be conducted at $P_{a}(50$ psig) at intervals no greater than once per 3 years.

i. All test leakage test rates shall be calculated using observed data converted to absolute values. Error analyses shall be performed to select a balanced integrated leakage measurement system.

j. The provisions of Specification 4.0.2 are not applicable. 
CONTAINMENT SYSTEMS

CONTAINMENT AIR LOCKS

LIMITING CONDITION FOR OPERATION

3.6.1.3 Each containment air lock sha11 be OPERABLE with:

a. Both doors closed except when the air lock is being used for normal transit entry and exit through the containment, then at least one air lock door shall be closed, and

b. An overall air lock leakage rate of less than or equal to $0.05 \mathrm{~L}_{\mathrm{a}}$ at $P_{a}$, (50 psig).

APPLICABILITY: MODES $1,2,3$ and 4.

ACTION:

a. With one containment air lock door inoperable:

1. Maintain at least the OPERABLE air lock door closed and either restore the inoperable air lock door to OPERABLE status within 24 hours or lock the OPERABLE air lock door closed.

2. Operation may then continue until performance of the next required overall air lock leakage test provided that the OPERABLE air lock door is verified to be locked closed at least once per 31 days.

3. Otherwise, be in at least HOT STANDBY within the next 6 hours and in COLD SHUTDOWN within the following 30 hours.

4. The provisions of Specification 3.0.4 are not applicable.

b. With the containment air lock inoperable, except as the result of an inoperable air lock door, maintain at least one air lock door closed; restore the inoperable air lock to OPERABLE status within 24 hours or be in at least HOT STANDBY within the next 6 hours and in COLD SHUTDOWN within the following 30 hours. 


\section{CONTAINMENT SYSTEMS}

4.6.1.3 Each containment air lock shall be demonstrated OPERABLE:

a. *After each opening, except when the air lock is being used for multiple entries, then at least once per 72 hours, by verifying no detectable seal leakage by pressure decay when the volume between the door seals is pressurized to greater than or equal to $\mathrm{P}_{\mathrm{a}}$ (50 psig) for at least 15 minutes,

b. At least once per 6 months by conducting an overall air lock leakage test at $P(50)$ psig and by verifying that the overall air lock leakage răte is within its limit\#, and

c. At least once per 18 months during shutdown by verifying that only one door in each air lock can be opened at a time.

*Exemption to Appendix "J" of 10 CFR 50.

\# The provisions of Specification 4.0 .2 are not applicable. 
CONTAINMENT ISOLATION VALVE AND CHANNEL WELD PRESSURIZATION SYSTEMS (OPTIONAL)

3.6.1.4 The containment isolation valve and channel weld pressurization systems shall be OPERABLE.

APPLICABILITY: MODES $1,2,3$ and 4.

ACTION:

With the containment isolation valve or channel weld pressurization system inoperable, restore the inoperable system to OPERABLE status within 7 days or be in at least HOT STANDBY within the next 6 hours and in COLD SHUTDOWN with in the following 30 hours.

SURVEILLANCE REQUIREMENTS

4.6.1.4.1 The containment isolation valve pressurization system shall be demonstrated OPERABLE at least once per 31 days by verifying that the system is pressurized to greater than or equal to $1.10 \mathrm{P}$ ( $55 \mathrm{psig}$ ) and has adequate capacity to maintain system pressure for at least 30 days.

4.6.1.4.2 The containment channel weld pressurization system shall be demonstrated OPERABLE at least once per 31 days by verifying that the system is pressurized to greater than or equal to $P$ ( $50 \mathrm{psig}$ ) and has adequate capacity to maintain system pressure for at least 30 days. 
CONTAINMENT SYSTEMS

INTERNAL PRESSURE

LIMITING CONDITION FOR OPERATION

3.6.1.5 Primary containment internal pressure shall be maintained greater than or equal to psia and within the acceptable operation range (below and to the left of the RWST water temperature limit lines) shown on Figure 3.6-1 as a function of RWST water temperature and service water temperature.

APPLICABILITY: MODES 1, 2, 3 and 4.

ACTION:

With the containment internal pressure less than or equal to psia or above the applicable RWST water temperature limit line shown on Figure 3.6-1, restore the internal pressure to within the limits within 1 hour or be in at least HOT STANDBY within the next 6 hours and in COLD SHUTDOWN within the following 30 hours.

4.6.1.5 The primary containment internal pressure shall be determined to be within the limits at least once per 12 hours. 


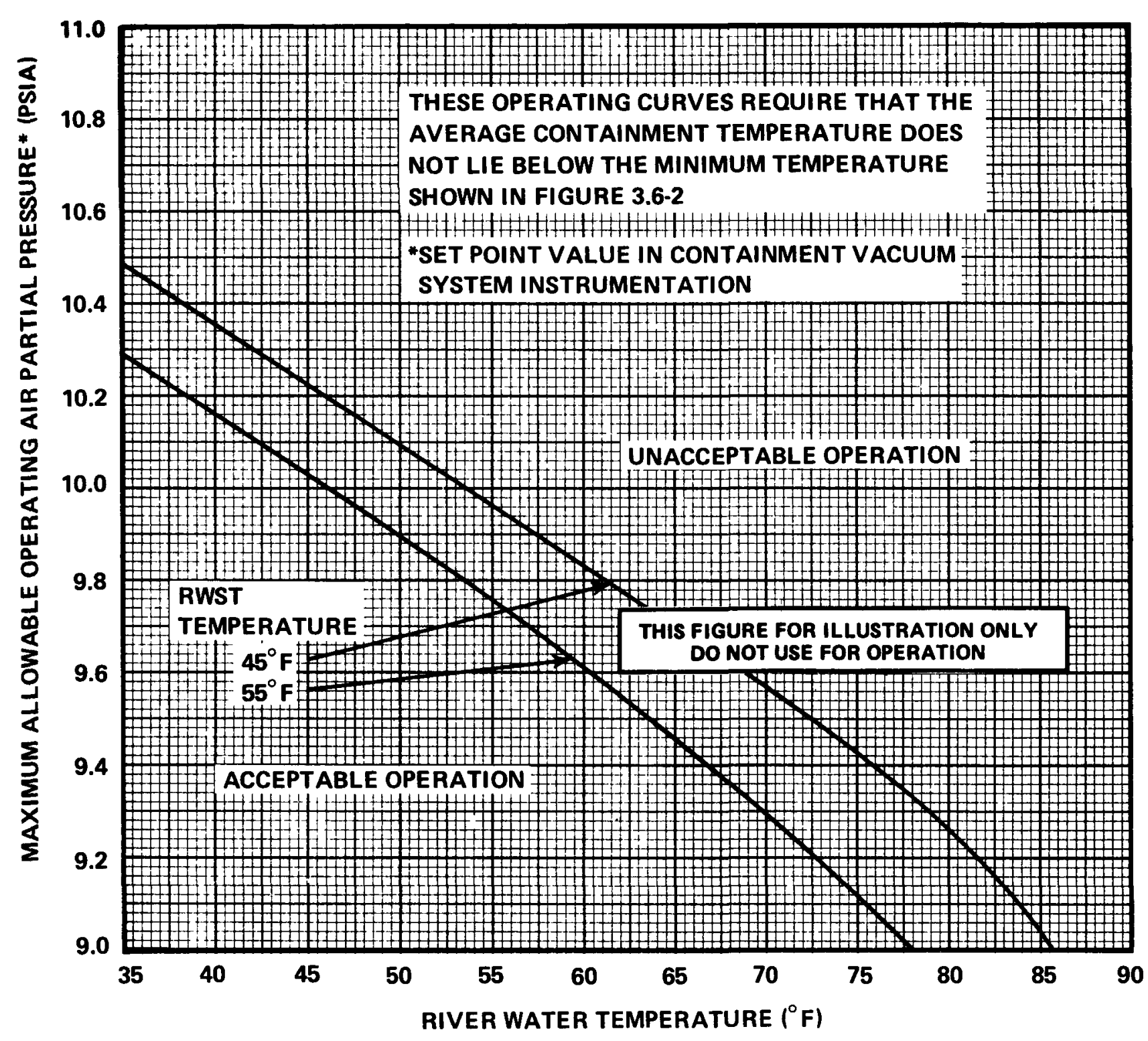

FIGURE 3.6-1 MAXIMUM ALLOWABLE PRIMARY CONTAINMENT AIR PRESSURE VERSUS RIVER WATER TEMPERATURE AND RWST WATER TEMPERATURE 
3.6.1.6 Primary containment average air temperature shall be maintained less than or equal to ${ }^{\circ} \mathrm{F}$ and above the temperature limit line shown on Figure 3.6-2 as a function of service water temperature.

\section{APPLICABILITY: MODES $1,2,3$ and 4.}

\section{ACTION:}

With the containment average air temperature greater than or equal to ${ }^{\circ} \mathrm{F}$ or below the limit line shown on Figure $3.6-2$, restore the average air temperature to within the limit shown within 8 hours or be in at least HOT STANDBY within the next 6 hours and in COLD SHUTDOWN within the following 30 hours.

\section{SURVEILLANCE REQUIREMENTS}

4.6.1.6 The primary containment average air temperature shall be the arithmetical average of the temperatures at the following locations and shall be determined at least once per 24 hours:

\section{Location}
a.
b.
c.
d.
e. 


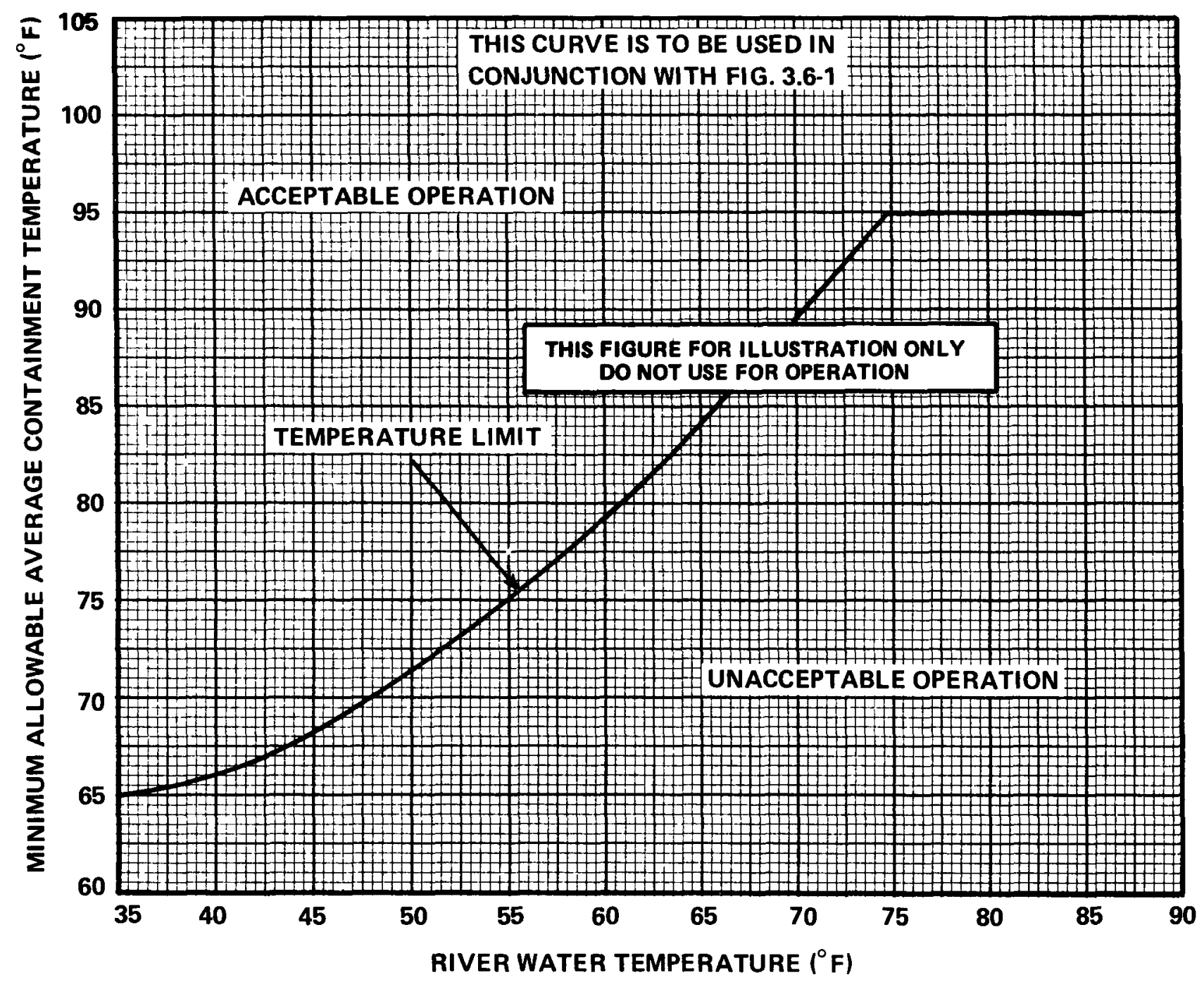

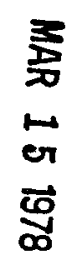

FIGURE 3.6-2 MINIMUM ALLOWABLE PRIMARY CONTAINMENT AVERAGE AIR TEMPERATURE VERSUS RIVER WATER TEMPERATURE 
CONTAINMENT STRUCTURAL INTEGRITY (Prestressed concrete containment with ungrouted tendons and typical dome.)

\section{LIMITING CONDITION FOR OPERATION}

3.6.1.7 The structural integrity of the containment shall be maintained at a level consistent with the acceptance criteria in Specification 4.6.1.7.

APPLICABILITY: $\quad$ MODES $1,2,3$ and 4.

ACTION:

With the structural integrity of the containment not conforming to the above requirements, restore the structural integrity to within the limits within 24 hours or be in at least HOT STANDBY within the next 6 hours and in COLD SHUTDOWN within the following 30 hours.

\section{SURVEILLANCE REQUIREMENTS}

4.6.1.7.1 Containment Tendons The containment tendons' structural integrity shall be demonstrated at the end of one, three and five years following the initial containment strucutral integrity test and at five year intervals thereafter. The tendons' structural integrity shall be demonstrated by:

a. Determining that a representative sample* of at least 21 tendons (6 dome, 5 vertical, and 10 hoop) each have a 1 ift off force of between (minimum) and (maximum) pounds at the first year inspection. For subsequent inspections, the maximum allowable lift off force shall be decreased from the value determined at the first year inspection by the amount: $\quad \log t$ and the minimum allowable lift off force shall be decreased from the value determined at the first year inspection by the amount: $\quad \log t$ where $t$ is the time interval in years from initial tensioning of the tendon to the current testing date. This test shall include an unloading cycle in which each of these tendons is detensioned to determine if any wires or strands are broken or damaged. Tendons found acceptable during this test shall be retensioned to their observed lift off force, $+3 \%$. During retensioning of these tendons, the change in load and $\bar{e}$ longation shall be measured simultaneously. If the 1 ift off force of any one tendon in the total sample population is out of the

\footnotetext{
FFor each inspection, the tendons shall be selected on a random but representative basis so that the sample group will change somewhat for each inspection; however, to develop a history of tendon performance and to correlate the observed data, one tendon from each group (dome, vertical, and hoop) may be kept unchanged after the initial selection.
} 
predicted bounds (less than minimum or greater than maximum), an adjacent tendon on each side of the defective tendon shall also be checked for lift off force. If both of these adjacent tendons are found acceptable, the surveillance program may proceed considering the single deficiency as unique and acceptable. This single tendon shall be restored to the required level of integrity. More than one defective tendon out of the original sample population is evidence of abnormal degradation of the containment structure. Unless there is evidence of abnormal degradation of the containment tendons during the first three tests of the tendons, the number of tendons checked for lift off force and change in elongation during subsequent tests may be reduced to a representative sample of at least 9 tendons ( 3 dome, 3 vertical and 3 hoop).

b. Removing one wire or strand from each of a dome, vertical and hoop tendon checked for $1 \mathrm{ift}$ off force and determining that over the entire length of the removed wire or strand that:

1. The tendon wires or strands are free of corrosion, cracks and damage.

2. There are no changes in the presence or physical appearance of the sheathing filler grease.

3. A minimum tensile strength value of strength of the tendon material) for at least three wire or strand samples (one from each end and one at mid-length) cut from each removed wire or strand. Failure of any one of the wire or strand samples to the meet the minimum tensile strength test is evidence of abnormal degradation of the containment structure.

4.6.1.7.2 End Anchorages and Adjacent Concrete Surfaces The structural integrity of the end anchorages of all tendons inspected pursuant to Specification 4.6.1.7.1 and the adjacent concrete surfaces shall be demonstrated by determining through inspection that no apparent changes have occurred in the visual appearance of the end anchorage or the concrete crack patterns adjacent ot the end anchorages. Inspections of the concrete shall be performed during the Type A containment leakage rate tests (reference Specification 4.6.1.2) while the containment is at its maximum test pressure. 
4.6.1.7.3 Containment Surfaces The structural integrity of the exposed accessible interior and exterior surfaces of the containment, including the liner plate, shall be determined during the shutdown for each Type A containment leakage rate test (reference Specification 4.6.1.2) by a visual inspection of these surfaces. This inspection shall be performed prior to each Type $A$ containment leakage rate test to verify no apparent changes in appearance or other abnormal degradation.

4.6.1.7.4 Reports Any abnormal degradation of the containment structure detected during the above required tests and inspections shall be reported to the Commission pursuant to Specification 6.9.1. This report shall include a description of the tendon condition, the condition of the concrete (especially at tendon anchorages), the inspection procedure, the tolerances on cracking, and the corrective actions taken. 


\section{CONTAINMENT SYSTEMS}

CONTAINMENT STRUCTURAL INTEGRITY (Prestressed concrete containment with ungrouted tendons and hemispherícal dome.)

3.6.1.7 The structural integrity of the containment shall be maintained at a level consistent with the acceptance criteria in Specification 4.6.1.7.

APPLICABILITY: MODES $1,2,3$, and 4 .

ACTION:

With the structural integrity of the containment not conforming to the above requirements, restore the structural integrity to within the limits within 24 hours or be in at least HOT STANDBY within the next 6 hours and in COLD SHUTDOWN within the following 30 hours.

SURVEILLANCE REQUIREMENTS

4.6.1.7.1 Containment Tendons The containment tendons' structural integrity shall be demonstrated at the end of one, three and five years following the initial containment structural integrity test and at five years intervals thereafter. The tendons' structural integrity shall be demonstrated by:

a. Determining that a representative sample* of at least $4 \%$ but no less than 4 , of the $U$ tendons each have a lift off force of between (minimum) and (maximum) pounds at the first year inspection and that a representative sample* of at least $4 \%$, but no less than 9 , of the hoop tendons each have a lift off force of between (minimum) and (maximum) pounds at the first year inspection. For subsequent inspections, the maximum allowable lift off forces shall be decreased from the value determined at the first year inspection by the amount: $\log t$ and the minimum allowable lift off force shall be decreased from the value determined at the first year inspection by the amount: $\log t$ where $t$ is the time interval in years from initial tensioning of the tendon to the current testing date. This test shall include an unloading cycle in which each of these tendons is detensioned to determine if any wires or strands are broken or damaged. Tendons found acceptable during this test shall be retensioned to their observed lift off force $\pm 3 \%$. During

*For each inspection, the tendons shall be selected on a random but representative basis so that the sample group will change somewhat for each inspection; however, to develop a history of tendon performance and to correlate the observed data, one tendon from each group ( $U$ and hoop) may be kept unchanged after the initial selection. 
retensioning of these tendons, the change in load and elongation shall be measured simultaneously. If the lift off force of any one tendon in the total sample population is out of the predicted bounds (less than minimum or greater than maximum), an adjacent tendon on each side of the defective tendon shall also be checked for lift off force. If both of these adjacent tendons are found acceptable, the surveillance program may proceed considering the single deficiency as unique and acceptable. This single tendon shall be restored to the required level of integrity. More than one defective tendon out of the original sample population is evidence of abnormal degradation of the containment structure. Unless there is evidence of abnormal degradation of the containment tendons during the first three tests of the tendons, the number of tendons checked for lift off force and change in elongation during subsequent tests may be reduced to a representative sample of at least $2 \%$, but no less than 2 , of the $U$ tendons and a representative sample of at least $2 \%$, but no less than 3 , of the hoop tendons.

b. Removing one wire or strand from one $U$ tendon and one hoop tendon checked for lift off force and determining that over the entire length of the removed wire or strand that:

1. The tendon wires or strands are free of corrosion, cracks and damage.

2. There are no changes in physical appearance of the sheathing filler grease.

3. A minimum tensile strength value of psi (quaranteed utimate strength of the tendon material) for at least three wire or strand samples (one from each end and one at mid-length) cut from each removed wire or strand. Failure of any one of the wire of strand samples to meet the minimum tensile strength test is evidence of abnormal degradation of the containment structure.

4.6.1.7.2 End Anchorages and Adjacent Concrete Surfaces The structural integrity of the end anchorages of all tendons inspected pursuant to Specification 4.6.1.7.1 and the adjacent concrete surfaces shall be demonstrated by determining through inspection that no apparent changes have occurred in the visual appearance of the end anchorage or the concrete crack patterns adjacent ot the end anchorages. Inspections of the concrete shall be performed during the Type A containment leakage rate tests (reference Specification 4.6.1.2) while the containment is at its maximum test pressure. 
4.6.1.7.3 Containment Surfaces The structural integrity of the exposed accessible interior and exterior surfaces of the containment, including the liner plate, shall be determined during the shutdown for each Type A containment leakage rate test (reference Specification 4.6 .1 .2 ) by a visual inspection of these surfaces. This inspection shall be performed prior to each Type $A$ containment leakage rate test to verify no apparent changes in appearance or other abnormal degradation.

4.6.1.7.4 Reports Any abnormal degradation of the containment structure detected during the above required tests and inspections shall be reported to the Commission pursuant to Specification 6.9.1. This report shall include a description of the tendon condition, the condition of the concrete (especially at tendon anchorages), the inspection procedure, the tolerances on cracking, and the corrective actions taken. 
CONTAINMENT STRUCTURAL INTEGRITY (Reinforced concrete containment)

3.6.1.7 The structural integrity of the containment shall be maintained at a level consistent with the acceptance criteria in Specification 4.6.1.7.

APPLICABILITY: MODES $1,2,3$ and 4.

ACTION:

With the structural integrity of the containment not conforming to the above requirements, restore the structural integrity to within the limits within 24 hours or be in at least HOT STANDBY within the next 6 hours and in COLD SHUTDOWN within the following 30 hours.

\section{SURVEILLANCE REQUIREMENTS}

4.6.1.7.1 Containment Surfaces The structural integrity of the exposed accessible interior and exterior surfaces of the containment, including the liner plate, shall be determined during the shutdown for each Type A containment leakage rate test (reference Specification 4.6 .1 .2 ) by a visual inspection of these surfaces. This inspection shall be performed prior to the Type A containment leakage rate test to verify no apparent changes in appearance or other abnormal degradation.

4.6.1.7.2 Reports Any abnormal degradation of the containment structure detected during the above required inspections shall be reported to the Commission pursuant to Specification 6.9.1. This report shall include a description of the condition of the concrete, the inspection procedure, the tolerances on cracking, and the corrective actions taken. 
3.6.1.8 The containment purge supply and exhaust isolation valves shall be closed.

APPLICABILITY: MODES $1,2,3$, and 4 .

ACTION:

With one containment purge supply and/or one exhaust isolation valve open, close the open valve(s) within one hour or be in at least HOT STANDBY within the next 6 hours and in COLD SHUTDOWN within the following 30 hours.

4.6.1.8 The containment purge supply and exhaust isolation valves shall be determined closed at least once per 31 days.

*This specification may be modified if the facility design conforms to Branch Technical Position CSB 6-4 of the Standard Review Plan. 
CONTAINMENT SYSTEMS

3/4.6.2 DEPRESSURIZATION AND COOLING SYSTEMS

CONTAINMENT QUENCH SPRAY SYSTEM

LIMITING CONDITION FOR OPERATION

3.6.2.1 Two independent containment quench spray subsystems shall be OPERABLE. APPLICABILITY: MODES 1, 2, 3 and 4.

ACTION:

With one containment quench spray subsystem inoperable, restore the inoperable subsystem to OPERABLE status within 72 hours or be in at least HOT STANDBY within the next 6 hours and in COLD SHUTDOWN within the following 30 hours.

4.6.2.1 Each containment quench spray subsystem shall be demonstrated OPERABLE:

a. At least once per 31 days by:

1. Verifying that each valve (manual, power operated or automatic) in the flow path that is not locked, sealed or otherwise secured in position, is in its correct position.

2. Verifying the temperature of the borated water in the refueling water storage tank is within the limits shown on Figure 3.6-1.

b. By verifying, that on recirculation flow, each pump develops a discharge pressure of greater than or equal to tested pursuant to Specification 4.0.5. psig when

c. At least once per 18 months during shutdown, by:

1. Verifying that each automatic valve in the flow path actuates to its correct position on a test signal.

2. Verifying that each spray pump starts automatically on a test signa?.

d. At least once per 5 years by performing an air or smoke flow test through each spray header and verifying each spray nozzle is unobstructed. 


\section{CONTAINMENT SYSTEMS}

CONTAINMENT RECIRCULATION SPRAY SYSTEM

LIMITING CONDITION FOR OPERATION

3.6.2.2 Two independent containment recirculation spray subsystems shall be OPERABLE.

APPLICABILITY: MODES $1,2,3$ and 4.

ACTION:

With one containment recirculation spray subsystem inoperable, restore the inoperable subsystem to OPERABLE status within 72 hours or be in at least HOT STANDBY within the next 6 hours; restore the inoperable spray system to OPERABLE status within the next 48 hours or be in COLD SHUTDOWN within the following 30 hours.

\section{SURVEILLANCE REQUIREMENTS}

4.6.2.2 Each containment recirculation spray subsystem shall be demonstrated OPERABLE:

a. At least once per 31 days by verifying that each valve (manual, power operated or automatic) in the flow path is not locked, sealed or otherwise secured in position, is in its correct position.

b. By verifying, that on recirculation flow, each pump develops a discharge pressure of greater than or equal to tested pursuant to Specification 4.0.5. psig when

c. At least once per 18 months by verifying that on a Containment Pressure --High-High test signal, each recirculation spray pump starts automatically after a $(350 \pm 50)$ second delay.

d. At least once per 18 months during shutdown, by verifying that each automatic valve in the flow path actuates to its correct position on a test signal.

e. At least once per 5 years by performing an air or smoke flow test through each spray header and verifying each spray nozzle is unobstructed. 
3.6.2.3 The spray additive system shall be OPERABLE with:

a. A spray additive tank containing a volume of between and solution, and and percent by weight $\mathrm{NaOH}$

b. Two spray additive eductors each capable of adding $\mathrm{NaOH}$ solution from the chemical additive tank to a containment spray system pump flow.

\section{APPLICABILITY: MODES $1,2,3$ and 4.}

\section{ACTION:}

With the spray additive system inoperable, restore the system to OPERABLE status within 72 hours or be in at least HOT STANDBY within the next 6 hours; restore the spray additive system to OPERABLE status within the next 48 hours or be in COLD SHUTDOWN within the following 30 hours.

\section{SURVEILLANCE REQUIREMENTS}

4.6.2.3 The spray additive system shall be demonstrated OPERABLE:

a. At least once per 31 days by verifying that each valve (manual, power operated or automatic) in the flow path that is not locked, sealed or otherwise secured in position, is in its correct position.

b. At least once per 6 months by:

1. Verifying the contained solution volume in the tank, and

2. Verifying the concentration of the $\mathrm{NaOH}$ solution by chemical analys is.

c. At least once per 18 months, during shutdown, by verifying that each automatic valve in the flow path actuates to its correct position on a test signal.

d. At least once per 5 years by verifying each solution flow rate (to be determined during pre-operational tests) from the following drain connections in the spray additive system:

1. (Drain line location)

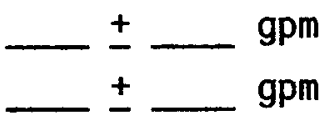

2. (Drain line location) gpm 
CONTAINMENT SYSTEMS

3/4.6.3 CONTAINMENT ISOLATION VALVES

LIMITING CONDITION FOR OPERATION

3.6.3 The containment isolation valves specified in Table $3.6-1$ shall be OPERABLE with isolation times as shown in Table 3.6-1.

APPLICABILITY: MODES $1,2,3$ and 4.

ACTION:

With one or more of the isolation valve(s) specified in Table 3.6-1 inoperable, maintain at least one isolation valve OPERABLE in each affected penetration that is open and either:

a. Restore the inoperable valve(s) to OPERABLE status within 4 hours, or

b. Isolate each affected penetration within 4 hours by use of at least one deactivated automatic valve secured in the isolation position, or

c. Isolate each affected penetration within 4 hours by use of at least one closed manual valve or blind flange; or

d. Be in at least HOT STANDBY within the next 6 hours and in COLD SHUTDOWN within the following 30 hours.

4.6.3.1 The isolation valves specified in Table 3.6-1 shall be demonstrated OPERABLE:

a. At least once per 92 days by cycling each weight or spring loaded check valve testable during plant operation, through one complete cycle of full travel and verifying that each check valve remains closed when the differential pressure in the direction of flow is less than or equal to (1.2) psid and opens when the differential pressure in the direction of flow is greater than or equal to (1.2) psid but less than (5.0) psid.

b. Prior to returning the valve to service after maintenance, repair or replacement work is performed on the valve or its associated actuator, control or power circuit by performance of a cycling test and verification of isolation time. 
4.6.3.1.2 Each isolation valve specified in Table 3.6-1 shall be demonstrated OPERABLE during the COLD SHUTDOWN or REFUELING MODE at least once per 18 months by:

a. Verifying that on a Phase A containment isolation test signal, each Phase $A$ isolation valve actuates to its isolation position.

b. Verifying that on a Phase B containment isolation test signal, each

Phase $B$ isolation valve actuates to its isolation position.

c. Verifying that on a Containment Purge and Exhaust isolation test signal, each Purge and Exhaust valve actuates to its isolation position.

d. Cycling each weight or spring loaded check valve not testable during plant operation, through one complete cycle of full travel and verifying that each check valve remains closed when the differential pressure in the direction of flow is less than (1.2) psid and opens when the differential pressure in the direction of flow is greater than or equal to (1.2) psid but less than (5.0) psid.

4.6.3.3 The isolation time of each power operated or automatic valve of Table 3.6-1 shall be determined to be within its limit when tested pursuant to Specification 4.0.5.

4.6.3.4 Each containment purge isolation valve shall be demonstrated OPERABLE within 24 hours after each closing of the valve, except when the valve is being used for multiple cyclings, then at least once per 72 hours, by verifying that when the measured leakage rate is added to the leakage rates determined pursuant to Specification 4.6.1.2d. for all other Type B and C penetrations, the combined leakage rate is less than or equal to $0.60 \mathrm{~L}_{\mathrm{a}}$. 
TABLE 3.6-1

CONTAINMENT ISOLATION VALVES

VALVE NUMBER

A. PHASE "A" ISOLATION

FUNCTION ISOLATION TIME

1.

2.

B. PHASE " $B$ " ISOLATION

1.

2.

C. CONTAINMENT PURGE AND EXHAUST 1.

2.

D. MANUAL

1.

2.

E. OTHER

1.

2.

*May be opened on an intermittent basis under administrative control.

\#Not subject to Type C leakage tests.
\#\#May be opened under administrative control in MODE 4 pursuant to

$\rightarrow$ Specification 3.6.5.1.

छేర్ల 


\section{3/4.6.4 COMBUSTIBLE GAS CONTROL}

HYDROGEN ANALYZERS

3.6.4.1 Two independent containment hydrogen analyzers shall be OPERABLE. APPLICABILITY: MODES 1 and 2.

\section{ACTION:}

With one hydrogen analyzer inoperable, restore the inoperable analyzer to OPERABLE status within 30 days or be in at least HOT STANDBY within the next 6 hours.

4.6.4.1 Each hydrogen analyzer shall be demonstrated OPERABLE at least once per 92 days on a STAGGERED TEST BASIS by performing a CHANNEL CALIBRATION using sample gases containing:

a. One volume percent hydrogen, balance nitrogen.

b. Four volume percent hydrogen, balance nitrogen. 


\section{CONTAINMENT SYSTEMS}

ELECTRIC HYDROGEN RECOMBINERS - W

3.6.4.2 Two independent containment hydrogen recombiner systems shall be OPERABLE.

APPLICABILITY: MODES 1 and 2.

ACTION:

With one hydrogen recombiner system inoperable, restore the inoperable system to OPERABLE status within 30 days or be in at least HOT STANDBY within the next 6 hours.

\section{SURVEILLANCE REQUIREMENTS}

4.6.4.2 Each hydrogen recombiner system shall be demonstrated OPERABLE:

a. At least once per 6 months by verifying during a recombiner system functional test that the minimum heater sheath temperature increases to greater than or equal to $(700)^{\circ} \mathrm{F}$ within (90) minutes and is maintained for at least (2) hours.

b. At least once per 18 months by:

1. Performing a CHANNEL CALIBRATION of all recombiner instrumentation and control circuits.

2. Verifying through a visual examination that there is no evidence of abnormal conditions within the recombiners (i.e., loose wiring or structural connections, deposits of foreign materials, etc.).

3. Verifying during a recombiner system functional test that the heater sheath temperature increases to greater than or equal to $(1200)^{\circ} \mathrm{F}$ within (5) hours and is maintained for at least (4) hours.

4. Verifying the integrity of all heater electrical circuits by performing a continuity and resistance to ground test following the above required functional test. The resistance to ground for any heater phase shall be greater than or equal to 10,000 ohms. 
HYDROGEN PURGE CLEANUP SYSTEM (If less than two hydrogen recombiners available)

3.6.4.3 A containment hydrogen purge cleanup system shall be OPERABLE and capable of being powered from a minimum of one OPERABLE emergency bus.

APPLICABILITY: MODES 1 and 2.

ACTION:

With the containment hydrogen purge cleanup system inoperable, restore the hydrogen purge cleanup system to OPERABLE status within 30 days or be in at least HOT STANDBY within 6 hours.

\section{SURVEILLANCE REQUIREMENTS}

4.6.4.3 The hydrogen purge cleanup system shall be demonstrated OPERABLE:

a. At least once per 31 days by initiating, from the control room, flow through the HEPA filters and charcoal adsorbers and verifying that the system operates for at least 10 hours with the heaters on.

b. At least once per 18 months or (1) after any structural maintenance on the HEPA filter or charcoal absorber housings, or (2) following painting, fire or chemical release in any ventilation zone communicating with the system by:

1. Verifying that the cleanup system satisfies the in-place testing acceptance criteria and uses the test procedures of Regulatory Positions C.5.a, C.5.c and C.5.d of Regulatory Guide 1.52, Revision 2, March 1978, and the system flow rate is $\mathrm{cfm} \pm 10 \%$.

2. Verifying within 31 days after removal that a laboratory analysis of a representative carbon sample obtained in accordance with Regulatory Position C.6.b of Regulatory Guide 1.52, Revision 2, March 1978, meets the laboratory testing criteria of Regulatory Position C.6. a of Regulatory Guide 1.52, Revision 2, March 1978.

3. Verifying a system flow rate of $c \mathrm{~m}+10 \%$ during system operation when tested in accordance with AN SI N510-1975. 
c. After every 720 hours of charcoal adsorber operation by verifying within 30 days after removal that a laboratory analys is of a representative carbon sample obtained in accordance with Regulatory Position C.6.b of Regulatory Guide 1.52, Revision 2, March 1978, meets the laboratory testing criteria of Regulatory Position C.6.a of Regulatory Guide 1.52, Revision 2, March 1978.

d. At least once per 18 months by:

1. Verifying that the pressure drop across the combined HEPA filters and charcoal adsorber banks is less than (6) inches Water Gauge while operating the system at a flow rate of cfm $\pm 10 \%$.

2. Verifying that the filter cooling bypass valves can be manually opened.

3. Verifying that the heaters dissipate tested in accordance with ASNI N510-1975. $\mathrm{kw}$ when

e. After each complete or partial replacement of a HEPA filter bank by verifying that the HEPA filter banks remove greater than or equal to (99.95)\%* of the DOP when they are tested in-place in accordance with ANSI N510-1975 while operating the system at a flow rate of $\mathrm{cfm} \pm 10 \%$.

f. After each complete or partial replacement of a charcoal adsorber bank by verifying that the charcoal adsorbers remove greater than or equal to $99.95 \%$ of a halogenated hydrocarbon refrigerant test gas when they are tested in-place in accordance with ANSI N510-1975 while operating the system at a flow rate of $\mathrm{cfm} \pm 10 \%$.

ॠ99.95\% applicable when a filter efficiency of $99 \%$ is assumed in the safety analyses; $99 \%$ when a filter efficiency of $90 \%$ is assumed. 
HYDROGEN MIXING SYSTEM (Optional)

3.6.4.4 Two independent hydrogen mixing systems shall be OPERABLE.

APPLICABILITY: MODES 1 and 2.

ACTION:

With one hydrogen mixing system inoperable, restore the inoperable system to OPERABLE status within 30 days or be in at least HOT STANDBY within the next 6 hours.

4.6.4.4 Each hydrogen mixing system shall be demonstrated OPERABLE:

a. At least once per 92 days on a STAGGERED TEST BASIS by starting each system from the control room and verifying that the system operates for at least 15 minutes.

b. At least once per 18 months by verifying a system flow rate of at least cfm. 
3/4.6.5 SUBATMOSPHERIC PRESSURE CONTROL SYSTEM

STEAM JET AIR EJECTOR

LIMITING CONDITION FOR OPERATION

3.6.5.1 The inside and outside manual isolation valves in the steam jet air ejector suction line shall be closed.

APPLICABILITY: MODES 1, 2 and 3.

ACTION:

With the inside or outside manual isolation valve in the steam jet air ejector suction line not closed, restore the valve to the closed position within 1 hour or be in HOT SHUTDOWN within the next 12 hours.

\section{SURVEILLANCE REQUIREMENTS}

4.6.5.1.1 The steam jet air ejector suction line outside manual isolation valve shall be determined to be in the closed position by a visual inspection prior to increasing the Reactor Coolant System temperature above $350^{\circ} \mathrm{F}$ and at least once per 31 days thereafter.

4.6.5.1.2 The steam jet air ejector suction line inside manual isolation valve shall be determined to be sealed or locked in the closed position by a visual inspection prior to increasing the Reactor Coolant System temperature above $350^{\circ} \mathrm{F}$. 
MECHANICAL VACUUM PUMPS

LIMITING CONDITION FOR OPERATION

3.6.5.2 Two mechanical vacuum pumps shall be OPERABLE.

APPLICABILITY: MODES 1,2 and 3.

ACTION:

With one mechanical vacuum pump inoperable, restore the inoperable pump to OPERABLE status within 30 days or be in at least HOT STANDBY within the next 6 hours and in COLD SHUTDOWN within the following 30 hours.

4.6.5.2 Each mechanical vacuum pump shall be demonstrated OPERABLE at least once per 31 days on a STAGGERED TEST BASIS by:

a. Starting (unless already operating) each pump from the control room.

b. Verifying that each pump develops a pumping capacity of greater than or equal to system. scfm and discharges to the gaseous radwaste disposal

c. Verifying that each pump operates for at least 15 minutes. 
3/4 6.6 VACUUM RELIEF VALVES (OPTIONAL)

3.6.6 The primary containment to atmosphere vacuum relief valves shall be OPERABLE with an actuation set point of less than or equal to psid.

APPLICABILITY: MODES $1,2,3$ and 4.

ACTION:

With one primary containment to atmosphere vacuum relief valve inoperable, restore the valve to OPERABLE status within 4 hours or be in at least HOT STANDBY within the next 6 hours and in COLD SHUTDOWN within the following 30 hours.

4.6.6 No additional Surevillance Requirements other than those required by Specification 4.0.5. 
-

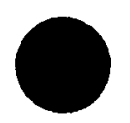

• 
SECTION $3 / 4.6 D$

CONTAINMENT SYSTEMS SPECIFICATIONS

FOR

WEST INGHOUSE

DUAL TYPE CONTAINMENT 
-
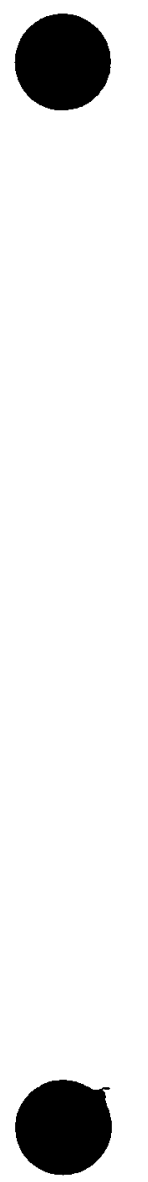
$3 / 4.6$ CONTAINMENT SYSTEMS

3/4.6.1 PRIMARY CONTAINMENT

CONTAINMENT INTEGRITY

LIMITING CONDITION FOR OPERATION

3.6.1.1 Primary CONTAINMENT INTEGRITY shall be maintained.

APPLICABILITY: MODES $1,2,3$ and 4.

ACTION:

Without primary CONTAINMENT INTEGRITY, restore CONTAINMENT INTEGRITY within one hour or be in at least HOT STANDBY within the next 6 hours and in COLD SHUTDOWN within the following 30 hours.

\section{SURVEILLANCE REQUIREMENTS}

\subsubsection{Primary CONTAINMENT INTEGRITY shall be demonstrated:}

a. At least once per 31 days by verifying that all penetrations* not capable of being closed by OPERABLE containment automatic isolation valves and required to be closed during accident conditions are closed by valves, blind flanges, or deactivated automatic valves secured in their positions except as provided in Table 3.6-2 of Specification 3.6.4.1.

b. By verifying that each containment air lock is OPERABLE per Specification 3.6.1.3.

c. After each closing of the equipment hatch, by leak rate testing the equipment hatch seals with gas at $P_{a}$ (50 psig) and verifying that when the measured leakage rate for these seals is added to the leakage rates determined pursuant to Specification 4.6.1.2.d for all other Type $B$ and $C$ penetrations, the combined leakage rate is less than or equal to $0.60 \mathrm{~L}_{\mathrm{a}}$.

*Except valves, blind $f l$ anges, and deactivated automatic valves which are located inside the containment and are locked, sealed or otherwise secured in the closed position. These penetrations shall be verified closed during each COLD SHUTDOWN except that such verification need not be performed more often than once per 92 days. 
CONTAINMENT SYSTEMS

CONTAINMENT LEAKAGE

LIMITING CONDITION FOR OPERATION

3.6.1.2 Containment leakage rates shall be limited to:

a. An overall integrated leakage rate of:

1. Less than or equal to $L_{a},(0.20)$ percent by weight of the containment air per 24 hours at $P_{a}$, (50 psig), or

2. Less than or equal to $L_{t}$, $(0.10)$ percent by weight of the containment air per 24 hours at a reduced pressure of $P_{t},(25$ psig).

b. A combined leakage rate of less than or equal to $0.60 \mathrm{~L}_{\mathrm{a}}$ for all penetrations and valves subject to Type $B$ and $C$ tests, when pressurized to $P_{a}$.

c. A combined leakage rate of less than or equal to $(0.10) \mathrm{L}_{\mathrm{a}}$ for a11 penetrations identified in Table 3.6-1 as secondary containment bypass leakage paths when pressurized to $P_{a}$.

APPLICABILITY: MODES $1,2,3$ and 4.

ACTION:

With either (a) the measured overall integrated containment leakage rate exceeding $0.75 \mathrm{~L}_{a}$ or $0.75 \mathrm{~L}_{t}$, as applicable, or (b) with the measured combined leakage rate for all penetrations and valves subject to Types $B$ and $C$ tests exceeding $0.60 \mathrm{~L}_{a}$, or (c) with the combined bypass leakage rate exceeding (0.10) $L_{a}$, restore the overall integrated leakage rate to less than or equal to $0.75 \mathrm{~L}_{a}$ or less than or equal to $0.75 \mathrm{~L}_{t}$, as applicable, the combined leakage rate for all penetrations and valves subject to Type $B$ and $C$ tests to less than or equal to $0.60 \mathrm{~L}_{a}$, and the combined bypass leakage rate to less than or equal to $(0.10) \mathrm{L}_{\mathrm{a}}$ prior to increasing the Reactor Coolant System temperature above $200^{\circ} \mathrm{F}$. 
4.6.1.2 The containment leakage rates shall be demonstrated at the following test schedule and shall be determined in conformance with the criteria specified in Appendix $\mathrm{J}$ of 10 CFR 50 using the methods and provisions of ANSI N45.4-(1972):

a. Three Type A tests (Overall Integrated Containment Leakage Rate) shall be conducted at $40 \pm 10$ month intervals during shutdown at either $P_{a}(50 \mathrm{psig})$ or at $P_{t}(25$ psig) during each 10 -year service period. The third test of each set shall be conducted during the shutdown for the 10-year plant inservice inspection.

b. If any periodic Type $A$ fails to meet either. $75 \mathrm{~L}_{a}$ or $.75 \mathrm{~L}_{t}$, the test schedule for subsequent Type $A$ tests shall be reviewed and approved by the Commission. If two consecutive Type A tests fail to meet either $.75 \mathrm{~L}_{a}$ or $.75 \mathrm{~L}_{t}$, a Type $A$ test shall be performed at least every 18 months until two consecutive Type. A tests meet either $.75 \mathrm{~L}_{\mathrm{a}}$ or $.75 \mathrm{~L}_{\mathrm{t}}$ at which time the above test schedule may be resumed.

c. The accuracy of each Type A test shall be verified by a supplemental test which:

1. Confirms the accuracy of the Type A test by verifying that the difference between supplemental and Type $A$ test data is within $0.25 \mathrm{~L}_{\mathrm{a}}$, or $0.25 \mathrm{~L}_{\mathrm{t}}$.

2. Has a duration sufficient to establish accurately the change in leakage rate between the Type $A$ test and the supplemental test.

3. Requires the quantity of gas injected into the containment or bled from the containment during the supplemental test to be equivalent to at least 25 percent of the total measured leakage at $P_{a}\left(50\right.$ psig) or $P_{t}(25$ psig).

d. Type $B$ and $C$ tests shall be conducted with gas at $P_{a}$ (50 psig) at intervals no greater than 24 months except for tests involving:

1. Air locks,

2. Penetrations using continuous leakage monitoring systems, and 
3. Valves pressurized with fluid from a seal system.

e. The combined bypass leakage rate shall be determined to be less than or equal to $(0.10) \mathrm{L}_{\mathrm{a}}$ by applicable Type $B$ and $C$ tests at least once per 24 months except for penetrations which are not individually testable; penetrations not individually testable shall be determined to have no detectable leakage when tested with soap bubbles while the containment is pressurized to $P_{a}$ (50 psig) during each Type A test.

f. Air Locks shall be tested and demonstrated OPERABLE per Surveillance Requirement 4.6.1.3.

g. Type $B$ periodic tests are not required for penetrations continuously monitored by the Containment Isolation Valve and Channel Weld Pressurization Systems provided the systems are OPERABLE per Surveillance Requirement 4.6.1.4.

h. Leakage from isolation valves that are sealed with fluid from a seal system may be excluded, subject to the provisions of Appendix $J$, Section III.C.3, when determining the combined leakage rate provided the seal system and valves are pressurized to at least $1.10 \mathrm{~Pa}$ (55 psig) and the seal system capacity is adequate to maintain system pressure for at least 30 days.

i. Type B tests for penetrations employing a continuous leakage monitoming system shall be conducted at $P_{2}(50$ psig) at intervals no greater than once per 3 years.

j. All test leakage rates shall be calculated using observed data converted to absolute values. Error analyses shall be performed to select a balanced integrated leakage measurement system.

k. The provisions of Specification 4.0.2 are not applicabie. 
$x$
1
$\stackrel{D}{E}$

TABLE $3.6-1$

SECONDARY CONTAINMENT BYPASS LEAKAGE PATHS

RELEASE LOCATION

产

er

产 
3.6.1.3 Each containment air lock shall be OPERABLE with:

a. Both doors closed except when the air lock is being used for normal transit entry and exit through the containment, then at least one air lock door shall be closed, and

b. An overall air lock leakage rate of less than or equal to $0.05 \mathrm{~L}_{\mathrm{a}}$ at $P_{a},(50$ psig).

APPLICABILITY: $\quad$ MODES $1,2,3$ and 4.

ACTION:

a. With one containment air lock door inoperable:

1. Maintain at least the OPERABLE air lock door closed and either restore the inoperable air lock door to OPERABLE status within 24 hours or lock the OPERABLE air lock door closed.

2. Operation may then continue until performance of the next required overall air lock leakage test provided that the OPERABLE air lock door is verified to be locked closed at least once per 31 days.

3. Otherwise, be in at least HOT STANDBY within the next 6 hours and in COLD SHUTDOWN within the following 30 hours.

4. The provisions of Specification 3.0.4 are not applicable.

b. With the containment air lock inoperable, except as the result of an inoperable air lock door, maintain at least one air lock door closed; restore the inoperable air lock to OPERABLE status within 24 hours or be in at least HOT STANDBY within the next 6 hours and in COLD SHUTDOWN within the following 30 hours. 
4.6.1.3 Each containment air lock shall be demonstrated OPERABLE:

a. *After each opening, except when the air lock is being used for multiple entries, then at least once per 72 hours, by verifying no detectable seal leakage by pressure decay when the volume between the door seals is pressurized to greater than or equal to $P_{a}$ (50 psig) for at least 15 minutes,

b. At least once per 6 months by conducting an overall air lock leakage test at $P_{a}(50 \mathrm{psig})$ and by verifying that the overall air lock leakage rate is within its limit\#, and

c. At least once per 6 months by verifying that only one door in each air lock can be opened at a time.

*Exemption to Appendix "J" of 10 CFR 50.

\# The provisions of Specification 4.0 .2 are not applicable. 
3.6.1.4 The containment isolation valve and channel weld pressurization systems shall be OPERABLE.

APPLICABILITY: MODES $1,2,3$ and 4.

ACTION:

With the containment isolation valve or channel weld pressurization system inoperable, restore the inoperable system to OPERABLE status within 7 days or be in at least HOT STANDBY within the next 6 hours and in COLD SHUTDOWN within the following 30 hours.

4.6.1.4.1 The containment isolation valve pressurization system shall be demonstrated OPERABLE at least once per 31 days by verifying that the system is pressurized to greater than or equal to $1.10 \mathrm{P}_{\mathrm{a}}$ (55 psig) and has adequate capacity to maintain system pressure for at least 30 days.

4.6.1.4.2 The containment channel weld pressurization system shall be demonstrated OPERABLE at least once per 31 days by verifying that the system is pressurized to greater than or equal to $P_{a}(50 \mathrm{psig})$ and has adequate capacity to maintain system pressure for at least 30 days. 


\section{CONTAINMENT SYSTEMS}

INTERNAL PRESSURE

LIMITING CONDITION FOR OPERATION

3.6.1.5 Primary containment internal pressure shall be maintained between and psig.

APPLICABILITY: MODES $1,2,3$ and 4.

ACTION:

With the containment internal pressure outside of the limits above, restore the internal pressure to within the limits within 1 hour or be in at least HOT STANDBY within the next 6 hours and in COLD SHUTDOWN within the following 30 hours.

4.6.1.5 The primary containment internal pressure shall be determined to be within the limits at least once per 12 hours. 
3.6.1.6 Primary containment average air temperature shall not exceed ${ }^{\circ} \mathrm{F}$ APPLICABILITY: MODES 1, 2, 3 and 4.

\section{ACTION:}

With the containment average air temperature greater than __ ${ }^{\circ} \mathrm{F}$, reduce the average air temperature to within the limit within 8 hours, or be in at least HOT STANDBY within the next 6 hours and in COLD SHUTDOWN within the following 30 hours.

4.6.1.6 The primary containment average air temperature shall be the arithmetical average of the temperatures at the following locations and shall be determined at least once per 24 hours:

\section{Location}

a.

b.

c.

d.

e. 
3.6.1.7 The structural integrity of the containment vessel shall be maintained at a level consistent with the acceptance criteria in Specification 4.6.7.7.

APPLICABILITY: MODES $1,2,3$ and 4.

ACTION:

With the structural integrity of the containment vessel not conforming to the above requirements, restore the structural integrity to within the limits prior to increasing the Reactor Coolant System temperature above $200^{\circ} \mathrm{F}$.

\section{SURVEILLANCE REQUIREMENTS}

4.6.1.7 The structural integrity of the containment vessel shall be determined during the shutdown for each Type A containment leakage rate test (reference Specification 4.6.1.2) by a visual inspection of the exposed accessible interior and exterior surfaces of the vessel. This inspection shall be performed prior to the Type A containment leakage rate test to verify no apparent changes in appearance of the surfaces or other abnormal degradation. Any abnormal degradation of the containment vessel detected during the above required inspections shall be reported to the Commission pursuant to Specification 6.9.1. 
3.6.1.8 The containment purge supply and exhaust isolation valves shall be closed.

APPLICABILITY: MODES $1,2,3$, and 4 .

ACTION:

With one containment purge supply and/or one exhaust isolation valve open, close the open valve(s) within one hour or be in at least HOT STANDBY within the next 6 hours and in COLD SHUTDOWN within the following 30 hours.

4.6.1.8 The containment purge supply and exhaust isolation valves shall be determined closed at least once per 31 days.

*This specification may be modified if the facility design conforms to Branch Technical Position CSB 6.4 of the Standard Review Plan. 
3/4.6.2 DEPRESSURIZATION AND COOLING SYSTEMS

CONTAINMENT SPRAY SYSTEM (credit taken for iodine removal)

\section{LIMITING CONDITION FOR OPERATION}

3.6.2.1 Two independent containment spray systems shall be OPERABLE with each spray system capable of taking suction from the RWST and transferring suction to the containment sump.

APPLICABILITY: MODES $1,2,3$ and 4.

ACTION:

With one containment spray system inoperable, restore the inoperable spray system to OPERABLE status within 72 hours or be in at least HOT STANDBY within the next 6 hours; restore the inoperable spray system to OPERABLE status within the next 48 hours or be in COLD SHUTDOWN within the following 30 hours.

\section{SURVEILLANCE REQUIREMENTS}

\subsubsection{Each containment spray system shall be demonstrated OPERABLE:}

a. At least once per 31 days by verifying that each valve (manual, power operated or automatic) in the flow path that is not locked, sealed, or otherwise secured in position, is in its correct position.

b. By verifying, that on recirculation flow, each pump develops a discharge pressure of greater than or equal to tested pursuant to Specification 4.0.5. psig when

c. At least once per 18 months during shutdown, by:

1. Verifying that each automatic valve in the flow path actuates to its correct position on a test signal.

2. Verifying that each spray pump starts automatically on a test signal.

d. At least once per 5 years by performing an air or smoke flow test through each spray header and verifying each spray nozzle is unobstructed. 
CONTAINMENT SYSTEMS

3/4.6.2 DEPRESSURIZATION AND COOLING SYSTEMS

CONTAINMENT SPRAY SYSTEM (No credit taken for iodine removal)

LIMITING CONOITION FOR OPERATION

3.6.2.1 Two independent containment spray systems shall be OPERABLE with each spray system capable of taking suction from the RWST and transferring suction to the containment sump.

APPLICABILITY: MODES $1,2,3$ and 4.

ACTION:

a. With one containment spray system inoperable and at least (four) containment cooling fans OPERABLE, restore the inoperable spray system to OPERABLE status within 7 days or be in at least HOT STANDBY within the next 6 hours and in COLD SHUTDOWN within the following 30 hours.

b. With two containment spray systems inoperable and at least (four) containment cooling fans OPERABLE, restore at least one spray system to OPERABLE status within 72 hours or be in at least HOT STANDBY within the next 6 hours and in COLD SHUTDOWN within the following 30 hours. Restore both spray systems to OPERABLE status within 7 days of initial loss or be in at least HOT STANDBY within the neXt 6 hours and in COLD SHUTDOWN within the following 30 hours.

c. With one containment spray system inoperable and one group of required containment cooling fans inoperable, restore either the inoperable spray system or the inoperable group of cooling fans to OPERABLE status within 72 hours or be in at least HOT STANDBY within the next 6 hours and in COLD SHUTDOWN within the following 30 hours. Restore both the inoperable spray system and the inoperable group of cooling fans to OPERABLE status within 7 days of initial loss or be in at least HOT STANDBY within the next 6 hours and in COLD SHUTDOWN within the following 30 hours.

SURVEILLANCE REQUIREMENTS

4.6.2.1 Each containment spray system shall be demonstrated OPERABLE:

a. At least once per 31 days by verifying that each valve (manual, power operated or automatic) in the flow path that is not locked sealed or otherwise secured in position, is in its correct position. 
b. By verifying, that on recirculation flow, each pump develops a discharge pressure of greater than or equal to psig when tested pursuant to Specification 4.0.5.

c. At least once per 18 months, during shutdown, by:

1. Verifying that each automatic valve in the flow path actuates to its correct position on a test signal, and

2. Verifying that each spray pump starts automatically on a test signal.

d. At least once per 5 years by performing on air or smoke flow test through each spray header and verifying each spray nozzle is unobstructed. 
3.6.2.2 The spray additive system shall be OPERABLE with:
a. A spray additive tank containing a volume of between and solution, and and percent by weight $\mathrm{NaOH}$

b. Two spray additive eductors each capable of adding $\mathrm{NaOH}$ solution from the chemical additive tank to a containment spray system pump flow.

APPLICABILITY: MODES $1,2,3$ and 4.

ACTION:

With the spray additive system inoperable, restore the system to OPERABLE status within 72 hours or be in at least HOT STANDBY within the next 6 hours; restore the spray additive system to OPERABLE status within the next 48 hours or be in COLD SHUTDOWN within the following 30 hours.

\section{SURVEILLANCE REQUIREMENTS}

4.6.2.2 The spray additive system shall be demonstrated OPERABLE:

a. At least once per 31 days by verifying that each valve (manual, power operated or automatic) in the flow path that is not locked, sealed, or otherwise secured in position, is in its correct position.

b. At least once per 6 months by:

1. Verifying the contained solution volume in the tank, and

2. Verifying the concentration of the $\mathrm{NaOH}$ solution by chemical analysis.

c. At least once per 18 months, during shutdown, by verifying that each automatic valve in the flow path actuates to its correct position on a test signal.

d. At least once per 5 years by verifying each solution flow rate (to be determined during pre-operational tests) from the following drain connections in the spray additive system:

1. (Drain line location)

2. (Drain line location)

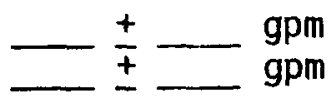


CONTAINMENT SYSTEMS

CONTAINMENT COOLING SYSTEM (OPTIONAL) (Credit taken for iodine removal by spray systems)

LIMITING CONDITION FOR OPERATION

3.6.2.3 (Two) independent groups of containment cooling fans shall be OPERABLE with (two) fan systems to each group. (Equivalent to $100 \%$ cooling capacity.)

APPLICABILITY: MODES $1,2,3$ and 4.

ACTION:

a. With one group of the above required containment cooling fans inoperable and both containment spray systems OPERABLE, restore the inoperable group of cooling fans to OPERABLE status within 7 days or be in at least HOT STANDBY within the next 6 hours and in COLD SHUTDOWN within the following 30 hours.

b. With two groups of the above required containment cooling fans inoperable, and both containment spray systems OPERABLE, restore at least one group of cooling fans to OPERABLE status within 72 hours or be in at least HOT STANDBY within the next 6 hours and in COLD SHUTDOWN within the following 30 hours. Restore both above required groups of cooling fans to OPERABLE status within 7 days of initial loss or be in at least HOT STANDBY within the next 6 hours and in COLD SHUTDOWN within the following 30 hours.

c. With one group of the above required containment cooling fans inoperable and one containment spray system inoperable, restore the inoperable spray system to OPERABLE status within 72 hours or be in at least HOT STANDBY within the next 6 hours and in COLD SHUTDOWN within the following 30 hours. Restore the inoperable group of containment cooling fans to OPERABLE status within 7 days of initial loss or be in at least HOT STANDBY within the next 6 hours and in COLD SHUTDOWN within the following 30 hours.

\section{SURVEILLANCE REQUIREMENTS}

4.6.2.3 Each group of containment cooling fans shall be demonstrated OPERABLE:

a. At least once per 31 days by:

1. Starting each fan group from the control room and verifying that each fan group operates for at least 15 minutes.

2. Verifying a cooling water flow rate of greater than or equal to gpm to each cooler.

b. At least once per 18 months by verifying that each fan group starts automatically on a test signal. 
CONTAINMENT SYSTEMS

CONTAINMENT COOLING SYSTEM (OPTIONAL) (No credit taken for iodine removal by spray systems)

LIMITING CONDITION FOR OPERATION

3.6.2.3 (Two) independent groups of containment cooling fans shall be OPERABLE with (two) fan systems to each group. (Equivalent to $100 \%$ cooling capacity.)

APPLICABILITY: MODES $1,2,3$ and 4.

ACTION:

a. With one group of the above required containment cooling fans inoperable and both containment spray systems OPERABLE, restore the inoperable group of cooling fans to OPERABLE status within 7 days or be in at least HOT STANDBY within the next 6 hours and in COLD SHUTDOWN within the following 30 hours.

b. With two groups of the above required containment cooling fans inoperable, and both containment spray systems OPERABLE, restore at least one group of cooling fans to OPERABLE status within 72 hours or be in at least HOT STANDBY within the next 6 hours and in COLD SHUTDOWN within the following 30 hours. Restore both above required groups of cooling fans to OPERABLE status within 7 days of initial loss or be in at least HOT STANDBY within the next 6 hours and in COLD SHUTDOWN within the following 30 hours.

c. With one group of the above required containment cooling fans inoperable and one containment spray system inoperable, restore either the inoperable group of containment cooling fans or the inoperable spray system to OPERABLE status within 72 hours or be in at least HOT STANDBY within the next 6 hours and in COLD SHUTDOWN within the following 30 hours. Restore both the inoperable group of containment cooling fans and the inoperable spray system to OPERABLE status within 7 days of initial loss or be in at least HOT STANDBY within the next 6 hours and in COLD SHUTDOWN within the following 30 hours.

4.6.2.3 Each group of containment cooling fans shall be demonstrated OPERABLE:

a. At least once per 31 days by:

1. Starting each fan group from the control room verifying that each fan group operates for at least 15 minutes.

2. Verifying a cooling water flow rate of greater than or equal to gpm to each cooler.

b. At least once per 18 months by verifying that each fan group starts automatically on a test signal. 
3/4.6.3 IODINE CLEANUP SYSTEM (OPTIONAL)

LIMITING CONDITION FOR OPERATION

3.6.3 Two independent containment iodine cleanup systems shall be OPERABLE.

APPLICABILITY: MODES $1,2,3$ and 4.

ACTION:

With one iodine cleanup system inoperable, restore the inoperable system to OPERABLE status within 7 days or be in at least HOT STANDBY within the next 6 hours and in COLD SHUTDOWN within the following 30 hours.

\section{SURVEILLANCE REQUIREMENTS}

4.6.3 Each iodine cleanup system shall be demonstrated OPERABLE:

a. At least once per 31 days on a STAGGERED TEST BASIS by initiating, from the control room, flow through the HEPA filters and charcoal adsorbers and verifying that the system operates for at least 10 hours with the heaters on.

b. At least once per 18 months or (1) after any structural maintenance on the HEPA filter or charcoal adsorber housings, or (2) following painting, fire or chemical release in any ventilation zone communicating with the system by:

1. Verifying that the cleanup system satisfies the in-place testing acceptance criteria and uses the test procedures of Regulatory Positions C.5.a, C.5.c and C.5.d of Regulatory Guide 1.52, Revision 2, March 1978, and the system flow rate is $+10 \%$.

2. Verifying within 31 days after removal that a laboratory analysis of a representative carbon sample obtained in accordance with Regulatory Position C.6.b of Regulatory Guide 1.52, Revision 2, March 1978, meets the laboratory testing criteria of Regulatory Position C.6.a of Regulatory Guide 1.52, Revision 2, March 1978.

3. Verifying a system flow rate of $\mathrm{cfm} \pm 10 \%$ during system operation when tested in accordance with ANSI N510-1975. 
c. After every 720 hours of charcoal adsorber operation by verifying within 31 days after removal that a laboratory analysis of a representative carbon sample obtained in accordance with Regulatory Position C.6.b of Regulatory Guide 1.52, Revision 2, March 1978, meets the laboratory testing criteria of Regulatory Position C.6.a of Regulatory Guide 1.52, Revision 2, March 1978.

d. At least once per 18 months by:

1. Verifying that the pressure drop across the combined HEPA filters and charcoal adsorber banks is less than (6) inches Water Gauge while operating the system at a flow rate of $\mathrm{cfm} \pm 10 \%$.

2. Verifying that the system starts on either a Safety Injection Test Signal or on a Containment Pressure -High Test Signal.

3. Verifying that the filter cooling bypass valves can be opened by operator action.

4. Verifying that the heaters dissipate tested in accordance with ANSI N510-1975. kw when

e. After each complete or partial replacement of a HEPA filter bank by verifying that the HEPA filter banks remove greater than or equal to (99.95)\%* of the DOP when they are tested in-place in accordance with ANSI N510-1975 while operating the system at a flow rate of $\mathrm{cfm} \pm 10 \%$.

f. After each complete or partial replacement of a charcoal adsorber bank by verifying that the charcoal adsorbers remove greater than or equal to $99.95 \%$ of a halogenated hydrocarbon refrigerant test gas when they are tested in-place in accordance with ANSI N510-1975 while operating the system at a flow rate of $\mathrm{cfm} \pm 10 \%$.

99.95\% applicable when a filter efficiency of $99 \%$ assumed in the safety analyses; $99 \%$ when a filter efficiency of $90 \%$ is assumed. 
3/4.6.4 CONTAINMENT ISOLATION VALVES

LIMITING CONDITION FOR OPERATION

3.6.4 The containment isolation valves specified in Table $3.6-2$ shall be OPERABLE with isolation times as shown in Table 3.6-2.

APPLICABILITY: MODES $1,2,3$ and 4.

ACTION:

With one or more of the isolation valve(s) specified in Table 3.6-2 inoperable, maintain at least one isolation valve OPERABLE in each affected penetration that is open and either:

a. Restore the inoperable valve(s) to OPERABLE status within 4 hours, or

b. Isolate each affected penetration within 4 hours by use of at least one deactivated automatic valve secured in the isolation position, or

c. Isolate each affected penetration within 4 hours by use of at least one closed manual valve or blind flange; or

d. Be in at least HOT STANDBY within the next 6 hours and in COLD SHUTDOWN within the following 30 hours.

\section{SURVEILLANCE REQUIREMENTS}

4.6.4.1 The isolation valves specified in Table 3.6-2 shall be demonstrated OPERABLE prior to returning the valve to service after maintenance, repair or replacement work is performed on the valve or its associated actuator, control or power circuit by performance of a cycling test and verification of isolation time. 
4.6.4.2 Each isolation valve specified in Table 3.6-2 shall be demonstrated OPERABLE during the COLD SHUTDOWN or REFUELING MODE at least once per 18 months by:

a. Verifying that on a Phase A containment isolation test signal, each Phase $A$ isolation valve actuates to its isolation position.

b. Verifying that on a Phase $B$ containment isolation test signal, each Phase $B$ isolation valve actuates to its isolation position.

c. Verifying that on a Containment Purge and Exhaust isolation test signal, each Purge and Exhaust valve actuates to its isolation position.

4.6.4.3 The isolation time of each power operated or automatic valve of Table 3.6-2 shall be determined to be within its limit when tested pursuant to Specification 4.0.5.

4.6.4.4 Each containment purge isolation valve shall be demonstrated OPERABLE within 24 hours after each closing of the valve, except when the valve is being used for multiple cyclings, then at least once per 72 hours, by verifying that when the measured leakage rate is added to the leakage rates determined pursuant to specification 4.6.1.2d. for all other Type B and C penetrations, the combined leakage rate is less than or equal to $0.60 \mathrm{~L}_{\mathrm{a}}$. 
1
1
号
I

TABLE $3.6-2$

\section{CONTAINMENT ISOLATION VALVES}

VALVE NUMBER

FUNCTION

ISOLATION TIME

A. PHASE "A" ISOLATION

$\leq(\quad)$ seconds

2.

B. PHASE "B" ISOLATION

1.

2.

C. CONTAINMENT PURGE AND EXHAUST

1.

2.

D. MANUAL

1.

2.

E. OTHER

1.

2.

*May be opened on an intermittent basis under administrative control.

er

$\underset{\mathbf{0}}{\mathbf{0}}$

\# Not subject to Type C leakage tests. 
$3 / 4.6 .5$ COMBUSTIBLE GAS CONTROL

HYDROGEN ANALYZERS

LIMITING CONDITION FOR OPERATION

3.6.5.1 Two independent containment hydrogen analyzers shall be OPERABLE. APPLICABILITY: MODES 1 and 2.

ACTION:

With one hydrogen analyzer inoperable, restore the inoperable analyzer to OPERABLE status within 30 days or be in at least HOT STANDBY within the next 6 hours.

\section{SURVEILLANCE REQUIREMENTS}

4.6.5.1 Each hydrogen analyzer shall be demonstrated OPERABLE at least once per 92 days on a STAGGERED TEST BASIS by performing a CHANNEL CALIBRATION using sample gases containing:

a. One volume percent hydrogen, balance nitrogen.

b. Four volume percent hydrogen, balance nitrogen. 
ELECTRIC HYDROGEN RECOMBINERS - W

3.6.5.2 Two independent containment hydrogen recombiner systems shall be OPERABLE.

APPLICABILITY: MODES 1 and 2.

ACTION:

With one hydrogen recombiner system inoperable, restore the inoperable system to OPERABLE status within 30 days or be in at least HOT STANDBY within the next 6 hours.

\section{SURVEILLANCE REQUIREMENTS}

\subsubsection{Each hydrogen recombiner system shall be demonstrated OPERABLE:}

a. At least once per 6 months by verifying during a recombiner system functional test that the minimum heater sheath temperature increases to greater than or equal $700^{\circ} \mathrm{F}$ within 90 minutes and is maintained for at least 2 hours.

b. At least once per 18 months by:

1. Performing a CHANNEL CALIBRATION of all recombiner instrumentation and control circuits.

2. Verifying through a visual examination that there is no evidence of abnormal conditions within the recombiners (i.e., loose wiring or structural connections, deposits of foreign materials, etc.)

3. Verifying during a recombiner system functional test that the heater sheath temperature increases to greater than or equal to $1200^{\circ} \mathrm{F}$ within 5 hours and is maintained for at least 4 hours.

4. Verifying the integrity of all heater electrical circuits by performing a continuity and resistance to ground test following the above required functional test. The resistance to ground for any heater phase shall be greater than or equal to 10,000 ohms. 


\section{CONTAINMENT SYSTEMS}

HYDROGEN PURGE CLEANUP SYSTEM (If less than two hydrogen recombiners available)

3.6.5.3 A containment hydrogen purge cleanup system shall be OPERABLE and capable of being powered from a minimum of one OPERABLE emergency bus.

APPLICABILITY: MODES 1 and 2.

ACTION:

With the containment hydrogen purge cleanup system inoperable, restore the hydrogen purge cleanup system to OPERABLE status within 30 days or be in at least HOT STANDBY within 6 hours.

\section{SURVEILLANCE REQUIREMENTS}

4.6.5.3 The hydrogen purge cleanup system shall be demonstrated OPERABLE:

a. At least once per 31 days by initiating, from the control room, flow through the HEPA filters and charcoal adsorbers and verifying that the system operates for at least 10 hours with the heaters on.

b. At least once per 18 months or (1) after any structural maintenance on the HEPA filter or charcoal adsorber housings, or (2) following painting, fire or chemical release in any ventilation zone communicating with the system by:

1. Verifying that the cleanup system satisfies the in-place testing acceptance criteria and uses the test procedures of Regulatory Positions C.5.a, C.5.C and C.5.d of Regulatory Guide 1.52, Revision 2, March 1978, and the system flow rate is $10 \%$.

2. Verifying within 31 days after removal that a laboratory analys is of a representative carbon sample obtained in accordance with Regulatory Position C.6.b of Regulatory Guide 1.52, Revision 2, March 1978, meets the laboratory testing criteria of Regulatory Position C.6.a of Regulatory Guide 1.52, Revision 2, March 1978.

3. Verifying a system flow rate of _ $\mathrm{cfm} \pm 10 \%$ during system operation when tested in accordance with ANSI N510-1975. 
c. After every 720 hours of charcoal adsorber operation by verifying within 31 days after removal that a laboratory analysis of a representative carbon sample obtained in accordance with Regulatory Position C.6.b of Regulatory Guide 1.52, Revision 2, March 1978, meets the laboratory testing criteria of Regulatory Position C.6.a of Regulatory Guide 1.52, Revision 2, March 1978.

d. At least once per 18 months by:

1. Verifying that the pressure drop across the combined HEPA filters and charcoal adsorber banks is less than (6) inches Water Gauge while operating the system at a flow rate of $\mathrm{cfm} \pm 10 \%$.

2. Verifying that the filter cooling bypass valves can be manually opened.

3. Verifying that the heaters dissipate tested in accordance with ANSI N510-1975.

$\pm$ kw when

e. After each complete or partial replacement of a HEPA filter bank by verifying that the HEPA filter banks remove greater than or equal to (99.95)\%* of the DOP when they are tested in-place in accordance with ANSI N510-1975 while operating the system at a flow rate of $\mathrm{cfm} \pm 10 \%$.

f. After each complete or partial replacement of a charcoal adsorber bank by verifying that the charcoal adsorbers remove greater than or equal to $99.95 \%$ of a halogenated hydrocarbon refrigerant test gas when they are tested in-place in accordance with ANSI N510-1975 while operating the system at a flow rate of $\mathrm{cfm} \pm 10 \%$.

99.95\% applicable when a filter efficiency of $99 \%$ is assumed in the safety analyses; $99 \%$ when a filter efficiency of $90 \%$ is assumed. 
3.6.5.4 Two independent hydrogen mixing systems shall be OPERABLE. APPLICABILITY: MODES 1 and 2.

ACTION:

With one hydrogen mixing system inoperable, restore the inoperable system to OPERABLE status within 30 days or be in at least HOT STANDBY within the next 6 hours.

\section{SURVEILLANCE REQUIREMENTS}

4.6.5.4 Each hydrogen mixing system shal1 be demonstrated OPERABLE:

a. At least once per 92 days on a STAGGERED TEST BASIS by starting each system from the control room and verifying that the system operates for at least 15 minutes.

b. At least once per 18 months by verifying a system flow rate of at least $\mathrm{cfm}$. 
3/4.6.6 PENETRATION ROOM EXHAUST AIR CLEANUP SYSTEM (OPTIONAL)

LIMITING CONDITION FOR OPERATION

3.6.6 Two independent containment penetration room exhaust air cleanup systems shall be OPERABLE.

APPLICABILITY: MODES $1,2,3$ and 4 .

ACTION:

With one containment penetration room exhaust air cleanup system inoperable, restore the inoperable system to OPERABLE status within 7 days or be in at least HOT STANDBY within the next 6 hours and in COLD SHUTDOWN within the following 30 hours.

\section{SURVEILLANCE REQUIREMENTS}

4.6.6 Each containment penetration room exhaust air cleanup system shall be demonstrated OPERABLE:

a. At least once per 31 days on a STAGGERED TEST BASIS by initiating, from the control room, flow through the HEPA filters and charcoal adsorbers and verifying that the system operates for at least 10 hours with the heaters on.

b. At least once per 18 months or (1) after any structura? maintenance on the HEPA filter or charcoal adsorber housings, or (2) following painting, fire or chemica' release in any ventilation zor e communicating with the system by:

1. Verifying that with the system operating at a flow rate of $\mathrm{cfm}+10 \%$ and exhausting through the HEPA filters and charcoal adsorbers, the total bypass flow of the system to the facility vent, including leakage through the system diverting valves, is less than or equal to $1 \%$ when the system is tested by admitting cold DOP at the system intake. (For systems with diverting valves.)

2. Verifying that the cleanup system satisfies the in-place testing acceptance criteria and uses the test procedures of Regulatory Positions C.5.a, C.5.c and C.5.d of Regulatory Guide 1.52, Revision 2, March 1978, and the system flow rate is $\mathrm{cfm} \pm 10 \%$. 
3. Verifying within 31 days after removal that a laboratory analysis of a representative carbon sample obtained in accordance with Regulatory Position C.6.b of Regulatory Guide 1.52, Revision 2, March 1978, meets the laboratory testing criteria of Regulatory Position C.6. a of Regulatory Guide 1.52, Revision 2, March 1978.

4. Verifying a system flow rate of _ cfm $+10 \%$ during system operation when tested in accordance with ANNSI N510-1975.

c. After every 720 hours of charcoal adsorber operation by verifying within 31 days after removal that a laboratory analysis of a representative carbon sample obtained in accordance with Regulatory Position C.6.b of Regulatory Guide 1.52, Revision 2, March 1978, meets the laboratory testing criteria of Regulatory Position C.6.a of Regulatory Guide 1.52, Revision 2, March 1978.

d. At least once per 18 months by:

1. Verifying that the pressure drop across the combined HEPA filters and charcoal adsorber banks is less than (6) inches Water Gauge while operating the system at a flow rate of $\mathrm{cfm} \pm 10 \%$.

2. Verifying that the system starts on a Safety Injection Test Signal.

3. Verifying that the filter cooling bypass valves can be manually opened.

4. Verifying that the heaters dissipate tested in accordance with ANSI N510-1975. kw when

e. After each complete or partial replacement of HEPA filter bank by verifying that the HEPA filter banks remove greater than or equal to (99.95)\%* of the DOP when they are tested in-place in accordance with ANSI N510-1975 while operating the system at a flow rate of $\mathrm{cfm} \pm 10 \%$.

f. After each complete or partial replacement of a charcoal adsorber bank by verifying that the charcoal adsorbers remove greater than or equal to $99.95 \%$ of a halogenated hydrocarbon refrigerant test gas when they are tested in-place in accordance with ANSI N510-1975 while operating the system at a flow rate of _ cfm $\pm 10 \%$.

99.95\% applicable when a filter efficiency of $99 \%$ is assumed in the safety analyses; $99 \%$ when a filter efficiency of $90 \%$ is assumed. 
$3 / 46.7$ VACUUM RELIEF VALVES

LIMITING CONDITION FOR OPERATION

3.6.7 The primary containment to atmosphere vacuum relief valves shall be OPERABLE with an actuation set point of less than or equal to psid.

APPLICABILITY: MODES $1,2,3$ and 4.

ACTION:

With one primary containment to atmosphere vacuum relief valve inoperable, restore the valve to OPERABLE status within 4 hours or be in at least HOT STANDBY with the next 6 hours and in COLD SHUTDOWN within the following 30 hours.

4.6.7 No additional Surveillance Requirements other than those required by Specification 4.0.5. 
CONTAINMENT SYSTEMS

3/4.6.8 SECONDARY CONTAINMENT

SHIELD BUILDING AIR CLEANUP SYSTEM

LIMITING CONDITION FOR OPERATION

3.6.8.1 Two independent shield building air cleanup systems shall be OPERABLE. APPLICABILITY: MODES $1,2,3$ and 4.

ACTION:

With one shield building air cleanup system inoperable, restore the inoperable system to OPERABLE status within 7 days or be in at least HOT STANDBY within the next 6 hours and in COLD SHUTDOWN within the following 30 hours.

\section{SURVEILLANCE REQUIREMENTS}

4.6.8.1 Each shield building air cleanup system shall be demonstrated OPERABLE:

a. At least once per 31 days on a STAGGERED TEST BASIS by initiating, from the control room, flow through the HEPA filters and charcoal adsorbers and verifying that the system operates for at least 10 hours with the heaters on.

b. At least once per 18 months or (1) after any structural maintenance on the HEPA filter or charcoal adsorber housings, or (2) following painting, fire or chemical release in any ventilation zone communicating with the system by:

1. Verifying that with the system operating at a flow rate of cfm $\pm 10 \%$ and exhausting through the HEPA filters and charcoal adsorbers, the total bypass flow of the system to the facility vent, including leakage through the system diverting valves, is less than or equal to. $1 \%$ when the system is tested by admitting cold DOP at the system intake. (For systems with diverting valves).

2. Verifying that the cleanup system satisfies the in-place testing acceptance criteria and uses the test procedures of Regulatory Positions C.5.a, C.5.C and C.5.d of Regulatory Guide 1.52, Revision 2, March 1978, and the system flow rate is $c f m \pm 10 \%$ 
3. Verifying within 31 days after removal that a laboratory analysis of a representative carbon sample obtained in accordance with Regulatory Position C.6.b of Regulatory Guide 1.52, Revision 2, March 1978, meets the laboratory testing criteria of Regulatory Position C.6.a of Regulatory Guide 1.52, Revision 2, March 1978.

4. Verifying a system flow rate of _ cfm $+10 \%$ during system operation when tested in accordance with ANSI N510-1975.

c. After every 720 hours of charcoal adsorber operation by verifying within 31 days after removal that a laboratory analysis of a representative carbon sample obtained in accordance with Regulatory Position C.6.b of Regulatory Guide 1.52, Revision 2, March 1978, meets the laboratory testing criteria of Regulatory Position C.6.a of Regulatory Guide 1.52, Revision 2, March 1978.

d. At least once per 18 months by:

1. Verifying that the pressure drop across the combined HEPA filters and charcoal adsorber banks is less than (6) inches Water Gauge while operating the system at a flow rate of cfm $\pm 10 \%$.

2. Verifying that the system starts on a Safety Injection Test Signal.

3. Verifying that the filter cooling bypass valves can be manualiy opened.

4. Verifying that each system produces a negative pressure of greater than or equal to (0.25) inches W.G. in the annulus within (1) minute after a start signal.

5. Verifying that the heaters dissipate $\pm \ldots \mathrm{kw}$ when tested in accordance with ANSI N510-1975.

e. After each complete or partial replacement of a HEPA filter bank by verifying that the HEPA filter banks remove greater than or equal to (99.95)\%* of the DOP when they are tested in-place in accordance with ANSI N510-1975 while operating the system at a flow rate of $\mathrm{cfm} \pm 10 \%$.

f. After each complete or partial replacement of a charcoal adsorber bank by verifying that the charcoal adsorbers remove greater than or equal to $99.95 \%$ of a halogenated hydrocarbon refrigerant test gas when they are tested in-place in accordance with ANSI N510-1975 while operating the system at a flow rate of _ $\mathrm{cfm} \pm 10 \%$.

ॠ99.95\% applicable when a filter efficiency of $99 \%$ is assumed in the safety analyses; $99 \%$ when a filter efficiency of $90 \%$ is assumed. 
SHIELD BUILDING INTEGRITY

3.6.8.2 SHIELD BUILDING INTEGRITY shall be maintained.

APPLICABILITY: MODES $1,2,3$ and 4.

ACTION:

Without SHIELD BUILDING INTEGRITY, restore SHIELD BUILDING INTEGRITY within 24 hours or be in at least HOT STANDBY within the next 6 hours and in COLD SHUTDOWN within the following 30 hours.

3.6.8.2 SHIELD BUILDING INTEGRITY shall be demonstrated at least once per 31 days by verifying that each door in each access opening is closed except when the access opening is being used for normal transit entry and exit, then at least one door shall be closed. 
3.6.8.3 The structural integrity of the shield building shall be maintained at a level consistent with the acceptance criteria in Specification 4.6.8.3.

APPLICABILITY: MODES 1, 2, 3 and 4.

ACTION:

With the structural integrity of the shield building not conforming to the above requirements, restore the structural integrity to within the limits within 24 hours or be in at least HOT STANDBY within the next 6 hours and in COLD SHUTDOWN within the following 30 hours.

\section{SURVEILLANCE REQUIREMENTS}

4.6.8.3 The structural integrity of the shield building shall be determined during the shutdown for each Type $A$ containment leakage rate test (reference Specification 4.6.1.2) by a visual inspection of the exposed accessible interior and exterior surfaces of the shield building and verifying no apparent changes in appearance of the concrete surfaces or other abnormal degradation. Any abnormal degradation of the shield building detected during the above required inspections shall be reported to the Commission pursuant to Specification 6.9.1. 
-

-

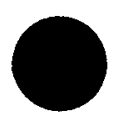




\section{$3 / 4.7$ PLANT SYSTEMS}

3/4.7.1 TURBINE CYCLE

SAFETY VALVES

LIMITING CONDITION FOR OPERATION

3.7.1.1 All main steam line code safety valves associated with each steam generator of an unisolated reactor coolant loop shall be OPERABLE with lift settings as specified in Table 3.7-3.

APPLICABILITY: MODES 1,2 and 3.

ACTION:

a. With ( $n$ ) reactor coolant loops and associated steam generators in operation and with one or more main steam line code safety valves inoperable, operation in MODES 1,2 and 3 may proceed provided, that within 4 hours, either the inoperable valve is restored to OPERABLE status or the Power Range Neutron Flux High Trip Setpoint is reduced per Table 3.7-1; otherwise, be in at least HOT STANDBY within the next 6 hours and in COLD SHUTDOWN within the following 30 hours.

b. With $(n-1)$ reactor coolant loops and associated steam generators in operation and with one or more main steam line code safety valves associated with an operating loop inoperable, operation in MODES 1 , 2 and 3 may proceed provided, that within 4 hours, either the inoperable valve is restored to OPERABLE status or the Power Range Neutron Flux High Trip Setpoint is reduced per Table 3.7-2; otherwise, be in at least HOT STANDBY within the next 6 hours and in COLD SHUTDOWN within the following 30 hours.

c. The provisions of Specification 3.0.4 are not applicable.

4.7.1.1 No additional Surveillance Requirements other than those required by Specification 4.0.5. 
TABLE $3.7-1$

MAXIMUM ALLOWABLE POWER RANGE NEUTRON FLUX HIGH SETPOINT WITH INOPERABLE STEAM LINE SAFETY VALVES DURING N LOOP OPERATION

Maximum Number of Inoperable Safety Valves on Any Operating Steam Generator

Maximum Allowable Power Range Neutron Flux High Setpoint (Percent of RATED THERMAL POWER)

1

2

3

(42)

TABLE 3.7-2

MAXIMUM ALLOWABLE POWER RANGE NEUTRON FLUX HIGH SETPOINT WITH INOPERABLE STEAM LINE SAFETY VALVES DURING $\mathrm{N}-1$ LOOP OPERATION

Maximum Number of Inoperable Safety Valves on Any Operating Steam Generator*

1

2

3

1

3
Maximum Allowable Power Range Neutron Flux High Setpoint (Percent of RATED THERMAL POWER)

*At least two safety valves shall be OPERABLE on the non-operating steam generator. 
$\stackrel{n}{n}$

TABLE $3.7-3$

STEAM LINE SAFETY VALVES PER LOOP

VALVE NUMBER

a.

b.

c.

d.

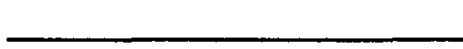

$\omega$
$\stackrel{\omega}{\alpha}$
$\dot{\omega}$

₹The lift setting pressure shall correspond to ambient conditions of the valve at nominal operating temperature and pressure.

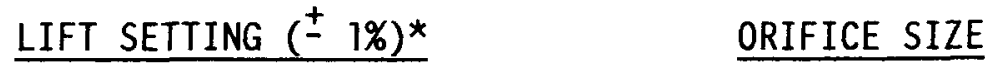

psig

psig

psig

psig 
PLANT SYSTEMS

AUXILIARY FEEDWATER SYSTEM

LIMITING CONDITION FOR OPERATION

3.7.1.2 At least three independent steam generator auxiliary feedwater pumps and associated flow paths shall be OPERABLE with:

a. Two feedwater pumps, each capable of being powered from separate emergency busses, and

b. One feedwater pump capable of being powered from an OPERABLE steam supply system.

APPLICABILITY: MODES 1,2 and 3.

ACTION:

With one auxiliary feedwater pump inoperable, restore at least three auxiliary feedwater pumps (two capable of being powered from separate emergency busses and one capable of being powered by an OPERABLE steam supply system) to OPERABLE status within 72 hours or be in at least HOT STANDBY within the next 6 hours and in HOT SHUTDOWN within the following 6 hours.

\section{SURVEILLANCE REQUIREMENTS}

4.7.1.2 Each auxiliary feedwater pump shall be demonstrated OPERABLE:

a. At least once per 31 days by:

1. Verifying that each motor driven pump develops a discharge pressure of greater than or equal to greater than or equal to $\mathrm{gpm}$. psig at a flow of

2. Verifying that the steam turbine driven pump develops a discharge pressure of greater than or equal to psig at a flow of greater than or equal to $\mathrm{gpm}$ when the secondary steam supply pressure is greater than psig. The provisions of Specification 4.0.4 are not applicable for entry into MODE 3.

3. Verifying that each non-automatic valve in the flow path that is not locked, sealed, or otherwise secured in position, is in its correct position. 
4. Verifying that each automatic valve in the flow path is in the fully open position whenever the auxiliary feedwater system is placed in automatic control or when above 10\% RATED THERMAL POWER.

b. At least once per 18 months during shutdown by:

1. Verifying that each automatic valve in the flow path actuates to its correct position on a test signal.

2. Verifying that each motor driven pump starts automatically upon receipt of a test signal. 
3.7.1.3 The condensate storage tank (CST) shall be OPERABLE with a minimum contained volume of gallons of water.

APPLICABILITY: MODES 1, 2 and 3.

ACTION:

With the condensate storage tank inoperable, within 4 hours either:

a. Restore the CST to OPERABLE status or be in at least HOT STANDBY within the next 6 hours and in HOT SHUTDOWN within the following 6 hours, or

b. Demonstrate the OPERABILITY of the (alternate water source) as a backup supply to the auxiliary feedwater pumps and restore the condensate storage tank to OPERABLE status within 7 days or be in at least HOT STANDBY within the next 6 hours and in HOT SHUTDOWN within the following 6 hours.

\section{SURVEILLANCE REQUIREMENTS}

4.7.1.3.1 The condensate storage tank shall be demonstrated OPERABLE at least once per 12 hours by verifying the contained water volume is within its limits when the tank is the supply source for the auxiliary feedwater pumps.

4.7.1.3.2 The (alternate water source) shall be demonstrated OPERABLE at least once per 12 hours by (method dependent upon alternate source) whenever the (alternate water source) is the supply source for the auxiliary feedwater pumps. 


\section{PLANT SYSTEMS}

ACTIVITY

LIMITING CONDITION FOR OPERATION

3.7.1.4 The specific activity of the secondary coolant system shall be less than or equal to 0.10 microcuries/gram DOSE EQUIVALENT I-131.

APPLICABILITY: MODES 1, 2, 3, and 4 .

ACTION:

With the specific activity of the secondary coolant system greater than 0.10 microcuries/gram DOSE EQUIVALENT I-131, be in at least HOT STANDBY within 6 hours and in COLD SHUTDOWN within the following 30 hours.

4.7.1.4 The specific activity of the secondary coolant system shall be determined to be within the limit by performance of the sampling and analysis program of Table 4.7-1. 
TABLE $4.7-1$

SECONDARY COOLANT SYSTEM SPECIFIC ACTIVITY

SAMPLE AND ANALYSIS PROGRAM

TYPE OF MEASUREMENT

AND ANALYSIS

1. Gross Activity Determination

2. Isotopic Analys is for DOSE EQUIVALENT I-131 Concentration
SAMPLE AND ANALYSIS FREQUENCY

At least once per 72 hours.

a) 1 per 31 days, whenever the gross activity determination indicates iodine concentrations greater than $10 \%$ of the allowable limit.

b) 1 per 6 months, whenever the gross activity determination indicates iodine concentrations below $10 \%$ of the allowable limit. 
MAIN STEAM LINE ISOLATION VALVES

3.7.1.5 Each main steam line isolation valve shall be OPERABLE. APPLICABILITY: MODES 1, 2 and 3.

ACTION:

MODES 1 - With one main steam line isolation valve inoperable, POWER OPERATION may continue provided the inoperable valve is either restored to OPERABLE status or closed within 4 hours;

Otherwise, be in HOT STANDBY within the next 6 hours and in HOT SHUTDOWN within the following 6 hours.

MODES 2 - With one main steam line isolation valve inoperable, subsequent and 3 operation in MODES 1,2 or 3 may proceed provided:

a. The isolation valve is maintained closed.

b. The provisions of Specification 3.0.4 are not applicable.

Otherwise, be in HOT STANDBY within the next 6 hours and in HOT SHUTDOWN within the following 6 hours.

4.7.1.5 Each main steam line isolation valve shall be demonstrated OPERABLE by verifying full closure within Specification 4.0.5. seconds when tested pursuant to 
3.7.2 The temperatures of both the primary and secondary coolants in the steam generators shall be greater than $(70)^{\circ} \mathrm{F}$ when the pressure of either coolant in the steam generator is greater than (200) psig.

APPLICABILITY: At all times.

\section{ACTION:}

With the requirements of the above specification not satisfied:

a. Reduce the steam generator pressure of the applicable side to less than or equal to (200) psig within 30 minutes, and

b. Perform an engineering evaluation to determine the effect of the overpressurization on the structural integrity of the steam generator. Determine that the steam generator remains acceptable for continued operation prior to increasing its temperatures above $200^{\circ} \mathrm{F}$.

\section{SURVEILLANCE REQUIREMENTS}

4.7.2 The pressure in each side of the steam generator shall be determined to be less than $200 \mathrm{psig}$ at least once per hour when the temperature of either the primary or secondary coolant is less than $70^{\circ} \mathrm{F}$. 


\section{PLANT SYSTEMS}

$3 / 4.7 .3$ COMPONENT COOLING WATER SYSTEM

LIMITING CONDITION FOR OPERATION

3.7.3 At least two independent component cooling water loops shall be OPERABLE. APPLICABILITY: MODES 1, 2, 3 and 4.

\section{ACTION:}

With only one component cooling water loop OPERABLE, restore at least two loops to OPERABLE status within 72 hours or be in at least HOT STANDBY within the next 6 hours and in COLD SHUTDOWN within the following 30 hours.

\section{SURVEILLANCE REQUIREMENTS}

4.7.3 At least two component cooling water loops shall be demonstrated OPERABLE:

a. At least once per 31 days by verifying that each valve (manual, power operated or automatic) servicing safety related equipment that is not locked, sealed, or otherwise secured in position, is in its correct position.

b. At least once per 18 months during shutdown, by verifying that each automatic valve servicing safety related equipment actuates to its correct position on a test signal. 
3/4.7.4 SERVICE WATER SYSTEM

LIMITING CONDITION FOR OPERATION

3.7.4 At least two independent service water loops shall be OPERABLE.

APPLICABILITY: MODES 1, 2, 3 and 4.

ACTION:

With only one service water loop OPERABLE, restore at least two loops to OPERABLE status within 72 hours or be in at least HOT STANDBY within the next 6 hours and in COLD SHUTDOWN within the following 30 hours.

\section{SURVEILLANCE REQUIREMENTS}

4.7.4 At least two service water loops shall be demonstrated OPERABLE:

a. At least once per 31 days by verifying that each valve (manual, power operated or automatic) servicing safety related equipment that is not locked, sealed, or otherwise secured in position, is in its. correct position.

b. At least once per 18 months during shutdown, by verifying that each automatic valve servicing safety related equipment actuates to its correct position on a test signal. 
3.7.5 The ultimate heat sink shall be OPERABLE with:

a. A minimum water level at or above elevation ( ) Mean Sea Level, USGS datum, and

b. An average water temperature of less than or equal to ()$^{\circ} \mathrm{F}$.

APPLICABILITY: MODES $1,2,3$ and 4.

ACTION:

With the requirements of the above specification not satisfied, be in at least HOT STANDBY within 6 hours and in COLD SHUTDOWN within the following 30 hours.

4.7.5 The ultimate heat sink shall be determined OPERABLE at least once per 24 hours by verifying the average water temperature and water level to be within their limits. 


\section{3/4.7.6 FLOOD PROTECTION (OPTIONAL*)}

3.7.6 Flood protection shall be provided for all safety related systems, components and structures when the water level of the (usually the ultimate heat sink) exceeds Mean Sea Level USGS datum, at

APPLICABILITY: At all times.

\section{ACTION:}

With the water level at above elevation Mean Sea Leve] USGS datum:

a. (Be in at least HOT STANDBY within 6 hours and in at least COLD SHUTDOWN within the following 30 hours) and

b. Initiate and complete within hours, the following flood protection measures:

1. (P lant dependent)

2. (Plant dependent)

\section{SURVEILLANCE REQUIREMENTS}

4.7.6 The water level at shall be determined to be within the limits by:

a. Measurement at least once per 24 hours when the water level is below elevation Mean Sea Leve 1 USGS datum, and

b. Measurement at least once per 2 hours when the water leve 1 is equal to or above elevation Mean Sea Level USGS datum.

* This specification not required if the facility design has adequate passive flood control protection features sufficient to accommodate the Design Basis Flood identified in Regulatory Guide 1.59, August 1973. 
PLANT SYSTEMS

3/4.7.7 CONTROL ROOM EMERGENCY AIR CLEANUP SYSTEM

LIMITING CONDITION FOR OPERATION

3.7.7 Two independent control room emergency air cleanup systems shall be OPERABLE.

APPLICABILITY: MODES $1,2,3$, and 4.

ACTION:

With one control room emergency air cleanup system inoperable, restore the inoperable system to OPERABLE status within 7 days or be in at least HOT STANDBY within the next 6 hours and in COLD SHUTDOWN within the following 30 hours.

SURVEILLANCE REQUIREMENTS

4.7.7 Each control room emergency air cleanup system shall be demonstrated OPERABLE:

a. At least once per 12 hours by verifying that the control room air temperature is less than or equal to $(120)^{\circ} \mathrm{F}$.

b. At least once per 31 days on a STAGGERED TEST BASIS by initiating, from the control room, flow through the HEPA filters and charcoal adsorbers and verifying that the system operates for at least 10 hours with the heaters on.

c. At least once per 18 months or (1) after any structural maintenance on the HEPA filter or charcoal adsorber housings, or (2) following painting, fire or chemical release in any ventilation zone communicating with the system by:

1. Verifying that with the system operating at a flow rate of cfm $\pm 10 \%$ and exhausting through the HEPA filters and charcoal adsorbers, the total bypass flow of the system to the facility vent, including leakage through the system diverting valves, is less than or equal to $1 \%$ when the system is tested by admitting cold DOP at the system intake. (For systems with diverting valves.)

2. Verifying that the cleanup system satisfies the in-place testing acceptance criteria and uses the test procedures of Regulatory Positions C.5.a, C.5.C and C.5.d of Regulatory Guide 1.52, Revision 2, March 1978, and the system flow rate is $c f m \pm 10 \%$ 
3. Verifying, within 31 days after removal, that a laboratory analysis of a representative carbon sample obtained in accordance with Regulatory Position C.6.b of Regulatory Guide 1.52, Revision 2, March 1978, meets the laboratory testing criteria of Regulatory Position C.6. a of Regulatory Guide 1.52, Revision 2, March 1978.

4. Verifying a system flow rate of cfm $+10 \%$ during system operation when tested in accordance with ANSI N510-1975.

d. After every 720 hours of charcoal adsorber operation by verifying within 31 days after removal, that a laboratory analysis of a representative carbon sample obtained in accordance with Regulatory Position C.6.b of Regulatory Guide 1.52, Revision 2, March 1978, meets the laboratory testing criteria of Regulatory Position C.6.a of Regulatory Guide 1.52, Revision 2, March 1978.

e. At least once per 18 months by:

1. Verifying that the pressure drop across the combined HEPA filters and charcoal adsorber banks is less than (6) inches Water Gauge while operating the system at a flow rate of cfm $\pm 10 \%$.

2. Verifying that on a containment phase $A$ isolation test signal, the system automatically switches into a recirculation mode of operation with flow through the HEPA filters and charcoal adsorber banks.

3. Verifying that the system maintains the control room at a positive pressure of greater than or equal to (1/4) inch W.G. relative to the outside atmosphere during system operation.

4. Verifying that the heaters dissipate
tested in accordance with ANSI N510-1975.

f. After each complete or partial replacement of a HEPA filter bank by verifying that the HEPA filter banks remove greater than or equal to (99.95)\%* of the DOP when they are tested in-place in accordance with ANSI N510-1975 while operating the system at a flow rate of cfm $\pm 10 \%$.

g. After each complete or partial replacement of a charcoal adsorber bank by verifying that the charcoal adsorbers remove greater than or equal to $99.95 \%$ of a halogenated hydrocarbon refrigerant test gas when they are tested in-place in accordance with ANSI N510-1975 while operating the system at a flow rate of $\mathrm{cfm} \pm 10 \%$.

\footnotetext{
ॠ99.95\% applicable when a filter efficiency of $99 \%$ is assumed in the safety
} analyses; $99 \%$ when a filter efficiency of $90 \%$ is assumed. 
3/4.7.8 ECCS PUMP ROOM EXHAUST AIR CLEANUP SYSTEM

\section{LIMITING CONDITION FOR OPERATION}

3.7.8 Two independent ECCS pump room exhaust air cleanup systems shall be OPERABLE.

APPLICABILITY: MODES $1,2,3$ and 4.

\section{ACTION:}

With one ECCS pump room exhaust air cleanup system inoperable, restore the inoperable system to OPERABLE status within 7 days or be in at least HOT STANDBY within the next 6 hours and in COLD SHUTDOWN within the following 30 hours.

\section{SURVEILLANCE REQUIREMENTS}

4.7.8 Each ECCS pump room exhaust air cleanup system shall be demonstrated OPERABLE:

a. At least once per 31 days on a STAGGERED TEST BASIS by initiating, from the control room, flow through the HEPA filters and charcoal adsorbers and verifying that the system operates for at least 10 hours with the heaters on.

b. At least once per 18 months or (1) after any structural maintenance on the HEPA filter or charcoal adsorber housings, or (2) following painting, fire or chemical release in any ventilation zone communicating with the system by:

1. Verifying that with the system operating at a flow rate of $c f m \pm 10 \%$ and exhausting through the HEPA filters and charcoal adsorbers, the total bypass flow of the system to the facility vent, including leakage through the system diverting valves, is less than or equal to $1 \%$ when the system is tested by admitting cold DOP at the system intake. (For systems with diverting valves.)

2. Verifying that the cleanup system satisfies the in-place testing acceptance criteria and uses the test procedures of Regulatory Positions C.5.a, C.5.C and C.5.d of Regulatory Guide 1.52, Revision 2, March 1978, and the system flow rate is cfm $\pm 10 \%$. 
3. Verifying within 31 days after removal that a laboratory analysis of a representative carbon sample obtained in accordance with Regulatory Position C.6.b of Regulatory Guide 1.52, Revision 2, March 1978, meets the laboratory testing criteria of Regulatory Position C.6.a of Regulatory Guide 1.52, Revision 2, March 1978.

4. Verifying a system flow rate of cfm $\pm 10 \%$ during system operation when tested in accordance with ANSI N510-1975.

c. After every 720 hours of charcoal adsorber operation by verifying within 31 days after removal that a laboratory analys is of a representative carbon sample obtained in accordance with Regulatory Position C.6.b of Regulatory Guide 1.52, Revision 2, March 1978, meets the laboratory testing criteria of Regulatory Position C.6.a of Regulatory Guide 1.52, Revision 2, March 1978.

d. At least once per 18 months by:

1. Verifying that the pressure drop across the combined HEPA filters and charcoal adsorber banks of less than (6) inches Water Gauge while operating the system at a flow rate of cfm $\pm 10 \%$.

2. Verifying that the system starts on a Safety Injection Test Signal.

3. Verifying that the filter cooling bypass valves can be manually opened.

4. Verifying that the heaters dissipate tested in accordance with ANSI N510-1975. kw when

e. After each complete or partial replacement of a HEPA filter bank by verifying that the HEPA filter banks remove greater than or equal to (99.95)\%* of the DOP when they are tested in-place in accordance with ANSI N510-1975 while operating the system at a flow rate of cfm $\pm 10 \%$.

f. After each complete or partial replacement of a charcoal adsorber bank by verifying that the charcoal adsorbers remove greater than or equal to $99.95 \%$ of a halogenated hydrocarbon refrigerant test gas when they are tested in-place in accordance with ANSI N510-1975 while operating the system at a flow rate of _ cfm $\pm 10 \%$.

*99.95\% applicable when a filter efficiency of $99 \%$ is assumed in the safety analyses; $99 \%$ when a filter efficiency of $90 \%$ is assumed. 


\section{PLANT SYSTEMS}

\section{3/4.7.9 HYDRAULIC SNUBBERS}

\section{LIMITING CONDITION FOR OPERATION}

\subsubsection{All hydraulic snubbers listed in Table 3.7-9 shall be OPERABLE.}

APPLICABILITY: MODES $1,2,3$ and 4.

\section{ACTION:}

With one or more hydraulic snubbers inoperable, replace or restore the inoperable snubber(s) to OPERABLE status within 72 hours or be in at least HOT STANDBY within the next 6 hours and in COLD SHUTDOWN within the following 30 hours.

\section{SURVEILLANCE REQUIREMENTS}

4.7.9 Hydraulic snubbers shall be demonstrated OPERABLE by performance of the following augmented inservice inspection program and the requirements of Specification 4.0.5.

a. Each hydraulic snubber with seal material fabricated from ethylene propylene or other materials demonstrated compatible with the operating environment and approved as such by the NRC, shall be determined OPERABLE at least once after not less than 4 months but within 6 months of initial criticality and in accordance with the inspection schedule of Table 4.7-9 thereafter, by a visual inspection of the snubber. Visual inspections of the snubbers shall include, but are not necessarily limited to, inspection of the hydraulic fluid reservoirs, fluid connections, and linkage connections to the piping and anchors. Initiation of the Table 4.7-9 inspection schedule shall be made assuming the unit was previously at the 6 month inspection interval.

b. Each hydraulic snubber with seal material not fabricated from ethylene propylene or other materials demonstrated compatible with the operating environment shall be determined OPERABLE at least once per 31 days by a visual inspection of the snubber. Visual inspections of the snubbers shall include, but are not necessarily limited to, inspection of the hydraulic fluid reservoirs, fluid connections, and linkage connections to the piping and anchors. 
c. At least once per 18 months during shutdown, a representative sample of at least 10 hydraulic snubbers or at least $10 \%$ of all snubbers listed in Table 3.7-9, whichever is less, shall be selected and functionaliy tested to verify correct piston movement, lock up and bleed. Snubbers greater than 50,000 lb capacity may be excluded from functional testing requirements. Snubbers selected for functional testing shall be selected on a rotating basis. Snubbers identified as either "Especially Difficult to Remove" or in "High Radiation Zones" may be exempted from functional testing provided these snubbers were demonstrated OPERABLE during previous functional tests. Snubbers found inoperable during functional testing shall be restored to OPERABLE status prior to resuming operation. For each snubber found inoperable during these functional tests, an additional minimum of $10 \%$ of all snubbers or 10 snubbers, whichever is less, shall also be functionally tested until no more failures are found or all snubbers have been functionally tested. 


\section{TABLE 3.7-9}

告

\section{SAFETY RELATED HYDRAULIC SNUBBERS*}

SNUBBER NO.

$\begin{array}{ccc}\text { SYSTEM SNUBBER INSTALLED } & \text { ACCESSIBLE OR } & \text { HIGH RADIATION } \\ \text { ON, LOCATION AND ELEVATION } & \begin{array}{c}\text { INACCESSIBLE } \\ \text { ZONE DURING SHUTDOWN** }\end{array} & \frac{\text { ZO I }}{\text { (Yes or No })}\end{array}$

ESPECIALLY DIFFICULT

TO REMOVE

(Yes or No)

‡ Snubbers may be added to safety related systems without prior License Amendment to Table 3.7-9 provided that a revision to Table 3.7-9 is included with the next License Amendment request.

** Modifications to this column due to changes in high radiation areas may be made without prior License Amendment provided that a revision to Table 3.7-9 is included with the next License Amendment request. 
NUMBER OF SNUBBERS FOUND INOPERABLE

DURING INSPECTION OR DURING INSPECTION INTERVAL\#

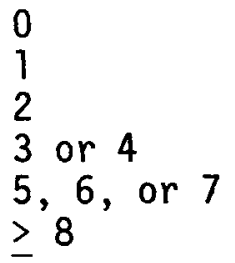

NEXT REQUIRED INSPECTION INTERVAL \#\#
18 months $+25 \%$
12 months $\mp 25 \%$
6 months $\mp 25 \%$
124 days $\mp 25 \%$
62 days $\mp 25 \%$
31 days $\mp 25 \%$

\# Snubbers may be categorized into two groups, "accessible" and "inaccessible." This categorization shall be based upon the snubber's accessibility for inspection during reactor operation. These two groups may be inspected independently according to the above schedule.

\#\# The required inspection interval shall not be lengthened more than one step at a time and the provisions of Specification 4.0 .2 are not applicable.

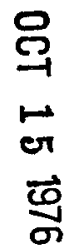




\section{3/4.7.10 SEALED SOURCE CONTAMINATION}

3.7.10 Each sealed source containing radioactive material either in excess of 100 microcuries of beta and/or gamma emitting material or 5 microcuries of alpha emitting material, shall be free of greater than or equal to 0.005 microcuries of removable contamination.

\section{APPLICABILITY: At all times.}

\section{ACTION:}

a. Each sealed source with removable contamination in excess of the above limits shall be immediately withdrawn from use and:

1. Either decontaminated and repaired, or

2. Disposed of in accordance with Commission Regulations.

b. The provisions of Specifications 3.0.3 and 3.0.4 are not applicable.

\section{SURVEILLANCE REQUIREMENTS}

4.7.10.1 Test Requirements - Each sealed source shall be tested for leakage and/or contamination by:

a. The licensee, or

b. Other persons specifically authorized by the Commission or an Agreement State.

The test method shall have a detection sensitivity of at least 0.005 microcuries per test sample.

4.7.10.2 Test Frequencies - Each category of sealed sources (excluding startup sources and fission detectors previously subjected to core flux) shall be tested at the frequency described below.

a. Sources in use - At least once per six months for all sealed sources containing radioactive materials: 
1. With a half-life greater than 30 days (excluding Hydrogen 3 ), and

2. In any form other than gas.

b. Stored sources not in use - Each sealed source and fission detector shall be tested prior to use or transfer to another licensee unless tested within the previous six months. Sealed sources and fission detectors transferred without a certificate indicating the last test date shall be tested prior to being placed into use.

c. Startup sources and fission detectors - Each sealed startup source and fission detector shall be tested within 31 days prior to being subjected to core flux or installed in the core and following repair or maintenance to the source.

4.7.10.3 Reports - A report shall be prepared and submitted to the Commission on an annual basis if sealed source or fission detector leakage tests reveal the presence of greater than or equal to 0.005 microcuries of removable contamination. 


\section{3/4.7.11 FIRE SUPPRESSION SYSTEMS}

\section{FIRE SUPPRESSION WATER SYSTEM}

\section{LIMITING CONDITION FOR OPERATION}

3.7.11.1 The fire suppression water system shall be OPERABLE with:

a. (Two) fire suppression pumps, each with a capacity of $\mathrm{gpm}$, with their discharge aligned to the fire suppression header,

b. Separate water supplies, each with a minimum contained volume of gallons, and

c. An OPERABLE flow path capable of taking suction from the and the tank and transferring the water through distribution piping with OPERABLE sectionalizing control or isolation valves to the yard hydrant curb valves, the last valve ahead of the water flow alarm device on each sprinkler or hose standpipe, and the last valve ahead of the deluge valve on each deluge or spray system required to be OPERABLE per Specifications 3.7.11.2 and 3.7.11.6.

\section{APPLICABILITY: At all times.}

\section{ACTION:}

a. With one pump and/or one water supply inoperable, restore the inoperable equipment to OPERABLE status within 7 days or, in lieu of any other report required by Specification 6.9.1, prepare and submit a Special Report to the Commission pursuant to Specification 6.9.2 within the next 30 days outlining the plans and procedures to be used to restore the inoperable equipment to OPERABLE status or to provide an alternate backup pump or supply. The provisions of Specifications 3.0 .3 and 3.0.4 are not applicable.

b. With the fire suppression water system otherwise inoperable:

1. Establish a backup fire suppression water system within 24 hours, and

2. In lieu of any other report required by Specification 6.9.1, submit a Special Report in accordance with Specification 6.9.2:
a) By telephone within 24 hours,
b) Confirmed by telegraph, mailgram or facsimile transmission no later than the first working day following the event, and


PLANT SYSTEMS

ACTION: (Continued)

c) In writing within 14 days following the event, outlining the action taken, the cause of the inoperability and the plans and schedule for restoring the system to OPERABLE status.

\section{SURVEILLANCE REQUIREMENTS}

4.7.11.1.1 The fire suppression water system shal1 be demonstrated OPERABLE:

a. At least once per 7 days by verifying the contained water supply volume.

b. At least once per 31 days on a STAGGERED TEST BASIS by starting each pump and operating it for at least 15 minutes on recirculation flow.

c. At least once per 31 days by verifying that each valve (manual, power operated or automatic) in the flow path that is not locked, sealed, or otherwise secured in position, is in its correct position.

d. (At least once per 6 months by performance of a system flush.)

e. At least once per 12 months by cycling each testable valve in the flow path through at least one complete cycle of full travel.

f. At least once per 18 months by performing a system functional test which includes simulated automatic actuation of the system throughout its operating sequence, and:

1. Verifying that each automatic valve in the flow path actuates to its correct position,

2. Verifying that each pump develops at least (2500) gpm at a system head of (250) feet,

3. Cycling each valve in the flow path that is not testable during plant operation through at least one complete cycle of full trave 7 , and

4. Verifying that each fire suppression pump starts (sequentialiy) to maintain the fire suppression water system pressure greater than or equal to psig.

g. At least once per 3 years by performing a flow test of the system in accordance with Chapter 5, Section 11 of the Fire Protection Handbook, 14th Edition, published by the National Fire Protection Association. 
4.7.11.1.2 The fire pump diesel engine shall be demonstrated OPERABLE:

a. At least once per 31 days by verifying:

1. The fuel storage tank contains at least _ gallons of fuel, and

2. The diesel starts from ambient conditions and operates for at least 30 minutes.

b. At least once per 92 days by verifying that a sample of diesel fuel from the fuel storage tank, obtained in accordance with ASTM-D270-65, is within the acceptable limits specified in Table 1 of ASTM D975-74 when checked for viscosity, water and sediment.

c. At least once per 18 months, during shutdown, by:

1. Subjecting the diesel to an inspection in accordance with procedures prepared in conjunction with its manufacturer's recommendations for the class of service, and

2. Verifying the diesel starts from ambient conditions on the auto-start signal and operates for greater than or equal to 30 minutes while loaded with the fire pump.

4.7.11.1.3 The fire pump diesel starting 24-volt battery bank and charger shall be demonstrated OPERABLE:

a. At least once per 7 days by verifying that:

1. The electrolyte level of each battery is above the plates, and

2. The overall battery voltage is greater than or equal to 24 volts.

b. At least once per 92 days by verifying that the specific gravity is appropriate for continued service of the battery.

c. At least once per 18 months by verifying that:

1. The batteries, cell plates and battery racks show no visual indication of physical damage or abnormal deterioration, and

2. The battery-to-battery and terminal connections are clean, tight, free of corrosion and coated with anti-corrosion material. 
PLANT SYSTEMS

SPRAY AND/OR SPRINKLER SYSTEMS

LIMITING CONDITION FOR OPERATION

3.7.11.2 The following spray and/or sprinkler systems shall be OPERABLE:

a. (Plant dependent - to be listed by name and location.)

b.

c.

APPLICABILITY: Whenever equipment in the spray/sprinkler protected areas is required to be OPERABLE.

ACTION:

a. With one or more of the above required spray and/or sprinkler systems inoperable, establish a continuous fire watch with backup fire suppression equipment for the unprotected area(s) within 1 hour; restore the system to OPERABLE status within 14 days or, in 1 ieu of any other report required by Specification 6.9.1, prepare and submit a Special Report to the Commission pursuant to Specification 6.9.2 within the next 30 days outlining the action taken, the cause of the inoperability and the plans and schedule for restoring the system to OPERABLE status.

b. The provisions of Specification 3.0 .3 and 3.0.4 are not applicable.

\section{SURVEILLANCE REQUIREMENTS}

4.7.11.2 Each of the above required spray and/or sprinkler systems shall be demonstrated OPERABLE:

a. At least once per 12 months by cycling each testable valve in the flow path through at least one complete cycle of full travel.

b. At least once per 18 months:

1. By performing a system functional test which includes simulated automatic actuation of the system, and:

a) Verifying that the automatic valves in the flow path actuate to their correct positions on a test signal, and 
b) Cycling each valve in the flow path that is not testable during plant operation through at least one complete cycle of full travel.

2. By a visual inspection of the spray headers to verify their integrity, and

3. By a visual inspection of each nozzle's spray area to verify the spray pattern is not obstructed.

c. At least once per 3 years by performing an air flow test through each open head spray/sprinkler header and verifying each open head spray/ sprinkler nozzle is unobstructed. 
LOW PRESSURE CO 2 SYSTEMS

3.7.11.3 The following low pressure $\mathrm{CO}_{2}$ systems shall be OPERABLE with a minimum level of $\operatorname{tank}(s)$. and a minimum pressure of in the associated storage
a. (Plant dependent - to be listed by name and location.)
b.
c. APPLICABILITY: Whenever equipment in the low pressure $\mathrm{CO}_{2}$ protected areas is
required to be OPERABLE.

ACTION:

a. With one or more of the above required low pressure $\mathrm{CO}_{2}$ systems inoperable, establish a continuous fire watch with backup fire suppression equipment for the unprotected area(s) within 1 hour; restore the system to OPERABLE status within 14 days or, in lieu of any other report required by Specification 6.9.1, prepare and submit a Special Report to the Commission pursuant to Specification 6.9.2 within the next 30 days outlining the action taken, the cause of the inoperability and the plans and schedule for restoring the system to OPERABLE status.

b. The provisions of Specifications 3.0.3 and 3.0.4 are not applicable. SURVEILLANCE REQUIREMENTS

4.7.11.3 Each of the above required low pressure $\mathrm{CO}_{2}$ systems shall be demonstrated OPERABLE: a. At least once per 7 days by verifying $\mathrm{CO}_{2}$ storage tank level and
pressure, and

b. At least once per 18 months by verifying:

1. The system valves and associated ventilation dampers and fire door release mechanisms actuate manually and automatically, upon receipt of a simulated actuation signal, and

2. Flow from each nozzle during a "Puff Test." 
PLANT SYSTEMS

HIGH PRESSURE CO 2

LIMITING CONDITION FOR OPERATION

3.7.11.4 The following high pressure $\mathrm{CO}_{2}$ systems shall be OPERABLE with the storage tanks having at least $90 \%$ of fulf charge weight.

a. (Plant dependent - to be listed by name and location.)

b.

c.

APPLICABILITY: Whenever equipment in the high pressure $\mathrm{CO}_{2}$ protected areas is required to be OPERABLE.

ACTION:

a. With one or more of the above required high pressure $\mathrm{CO}_{2}$ systems inoperable, establish a continuous fire watch with backap fire suppression equipment for the unprotected area(s) within 1 hour; restore the system to OPERABLE status within 14 days or, in lieu of any other report required by Specification 6.9.1, prepare and submit a Special Report to the Commission pursuant to Specification 6.9.2 within the next 30 days outlining the action taken, the cause of the inoperability and the plans and schedule for restoring the system to OPERABLE status.

b. The provisions of Specifications 3.0.3 and 3.0.4 are not applicable. SURVEILLANCE REQUIREMENTS

4.7.11.4 Each of the above required high pressure $\mathrm{CO}_{2}$ systems shall be demonstrated OPERABLE:

a. At least once per 6 months by verifying $\mathrm{CO}_{2}$ storage tank weight.

b. At least once per 18 months by:

1. Verifying the system, including associated ventilation dampers and fire door release mechanisms, actuates manually and automatically, upon receipt of a simulated actuation signal, and

2. Performance of a flow test through headers and nozzles to assure no blockage. 


\section{PLANT SYSTEMS}

HALON SYSTEMS

3.7.11.5 The following Halon systems shal1 be OPERABLE with the storage tanks having at least $95 \%$ of full charge weight and $90 \%$ of full charge pressure.

a. (Plant dependent - to be listed by name and location.)

b.

c.

APPLICABILITY: Whenever equipment in the Halon protected areas is required to be OPERABLE.

\section{ACTION:}

a. With one or more of the above required Halon systems inoperable, establish a continuous fire watch with backup fire suppression equipment for the unprotected area(s) within 1 hour; restore the system to OPERABLE status within 14 days or, in lieu of any other report required by Specification 6.9.1, prepare and submit a Special Report to the Commission pursuant to Specification 6.9.2 within the next 30 days outlining the action taken, the cause of the inoperability and the plans and schedule for restoring the system to OPERABLE status.

b. The provisions of Specifications 3.0.3 and 3.0.4 are not applicable.

\section{SURVEILLANCE REQUIREMENTS}

4.7.11.5 Each of the above required Halon systems shall be demonstrated OPERABLE:

a. At least once per 6 months by verifying $\mathrm{Hal}$ lon storage tank weight and pressure.

b. At least once per 18 months by:

1. Verifying the system, including associated ventilation dampers and fire door release mechanisms, actuates manually and automatically, upon receipt of a simulated actuation signal, and

2. Performance of a flow test through headers and nozzles to assure no blockage. 
PLANT SYSTEMS

FIRE HOSE STATIONS

LIMITING CONDITION FOR OPERATION

3.7.11.6 The fire hose stations shown in Table 3.7-10 shall be OPERABLE. APPLICABILITY: Whenever equipment in the areas protected by the fire hose stations is required to be OPERABLE.

ACTION:

a. With one or more of the fire hose stations shown in Table 3.7-10 inoperable, route an additional equivalent capacity fire hose to the unprotected area(s) from an OPERABLE hose station within 1 hour.

b. The provisions of Specifications 3.0.3 and 3.0.4 are not applicable.

\section{SURVEILLANCE REQUIREMENTS}

4.7.11.6 Each of the fire hose stations shown in Table 3.7-10 shall be demonstrated OPERABLE:

a. At least once per 31 days by a visual inspection of the fire hose station to assure all required equipment is at the station.

b. At least once per 18 months by:

1. Removing the hose for inspection and re-racking, and

2. Inspecting all gaskets and replacing any degraded gaskets in the couplings.

c. At least once per 3 years by:

1. Partially opening each hose station valve to verify valve OPERABILITY and no flow blockage.

2. Conducting a hose hydrostatic test at a pressure at least 50 psig greater than the maximum pressure available at any hose station. 
TABLE $3.7-10$

FIRE HOSE STATIONS

* List all Fire Hose Stations required to ensure the OPERABLILITY of safety related equipment. 
YARD FIRE HYDRANTS AND HYDRANT HOSE HOUSES

LIMITING CONDITION FOR OPERATION

3.7.11.7 The yard fire hydrants and associated hydrant hose houses shown in Table 3.7-11 shal1 be OPERABLE.

APPLICABILITY: Whenever equipment in the areas protected by the yard fire hydrants is required to be OPERABLE.

ACTION:

a. With one or more of the yard fire hydrants or associated hydrant hose houses shown in Table 3.7-11 inoperable, within 1 hour have sufficient additional lengths of 2 1/2 inch diameter hose located in an adjacent OPERABLE hydrant hose house to provide service to the unprotected area(s).

b. The provisions of Specification 3.0.3 and 3.0.4 are not applicable.

SURVEILLANCE REQUIREMENTS

4.7.11.7 Each of the yard fire hydrants and associated hydrant hose houses shown in Table 3.7-11 shal1 be demonstrated OPERABLE:

a. At least once per 31 days by visual inspection of the hydrant hose house to assure all required equipment is at the hose house.

b. At least once per 6 months (once during March, April or May and once during September, October or November) by visually inspecting each yard fire hydrant and verifying that the hydrant barrel is dry and that the hydrant is not damaged.

c. At least once per 12 months by:

1. Conducting a hose hydrostatic test at a pressure at least 50 psig greater than the maximum pressure available at any yard fire hydrant.

2. Inspecting all the gaskets and replacing any degraded gaskets in the couplings.

3. Performing a flow check of each hydrant to verify its OPERABILITY. 
TABLE $3.7-11$

YARD FIRE HYDRANTS AND ASSOCIATED HYDRANT HOSE HOUSES

HYDRANT NUMBER

*List all Yard Fire Hydrants and Hydrant Hose Houses required to ensure the OPERABLILITY of safety related equipment. 
PLANT SYSTEMS

\section{3/4.7.12 FIRE BARRIER PENETRATIONS}

LIMITING CONDITION FOR OPERATION

3.7.12 All fire barrier penetrations (including cable penetration barriers, firedoors and fire dampers), in fire zone boundaries, protecting safety related areas shall be functional.

APPLICABILITY: At all times.

\section{ACTION:}

a. With one or more of the above required fire barrier penetrations non-functional, within one hour either, establish a continuous fire watch on at least one side of the affected penetration, or verify the OPERABILITY of fire detectors on at least one side of the nonfunctional fire barrier and establish a hourly fire watch patrol. Restore the non-functional fire barrier penetration(s) to functional status within 7 days or, in lieu of any other report required by Specification 6.9.1, prepare and submit a Special Report to the Commission pursuant to Specification 6.9.2 within the next 30 days outlining the action taken, the cause of the non-functional penetration and plans and schedule for restoring the fire barrier penetration(s) to functional status.

b. The provisions of Specifications 3.0 .3 and 3.0.4 are not applicable.

\section{SURVEILLANCE REQUIREMENTS}

4.7.12 Each of the above required fire barrier'penetrations shall be verified to be functional:

a. At least once per 18 months by a visual inspection.

b. Prior to returning a fire barrier penetration to functional status following repairs or maintenance by performance of a visual inspection of the affected fire barrier penetration(s). 
3.7.13 The temperature of each area shown in Table 3.7-13 shall be maintained within the limits indicated in Table 3.7-13.

APPLICABILITY: Whenever the equipment in an affected area is required to be OPERABLE.

ACTION:

a. With one or more areas exceeding the temperature limit(s) for equipment not operating shown in Table 3.7-13 for more than eight hours, prepare and submit a Special Report to the Commission pursuant to Specification 6.9.2 within the next 30 days providing a record of the cumulative time the temperature in the affected area exceeded its limit.

b. With a temperature exceeding the limit for equipment operating, in addition to submitting a Special Report as described in ACTION a. above, within 4 hours, either restore the area to within its temperature limit or declare the equipment in the affected area inoperable.

c. The provisions of Specifications 3.0.3 and 3.0.4 are not applicable.

4.7.13 The temperature in each of the areas of Specification 3.7 .13 shall be determined to be within its limit at least once per 24 hours. 
TABLE 3.7-13

AREA TEMPERATURE MONITORING

AREA

TEMPERATURE LIMIT $\left({ }^{\circ} \mathrm{F}\right)$

EQUIPMENT

EQUIPMENT

NOT OPERATING OPERATING

1.

2.

3.

4.

5. 
-

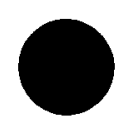

• 
3/4.8 ELECTRICAL POWER SYSTEMS

3/4.8.1 A.C. SOURCES

OPERATING

LIMITING CONDITION FOR OPERATION

3.8.1.1 As a minimum, the following A.C. electrical power sources shall be OPERABLE:

a. Two physically independent circuits between the offsite transmission network and the onsite Class IE distribution system, and

b. Two separate and independent diesel generators each with:

1. Separate day and engine-mounted fuel tanks containing a minimum volume of gallons of fuel,

2. A separate fuel storage system containing a minimum volume of gallons of fuel, and

3. A separate fuel transfer pump.

APPLICABILITY: MODES $1,2,3$ and 4.

ACTION:

a. With either an offsite circuit or diesel generator of the above required A.C. electrical power sources inoperable, demonstrate the OPERABILITY of the remaining A.C. sources by performing Surveillance Requirements 4.8.1.1.1.a and 4.8.1.1.2.a.4 within one hour and at least once per 8 hours thereafter; restore at least two offsite circuits and two diesel generators to OPERABLE status within 72 hours or be in at least HOT STANDBY within the next 6 hours and in COLD SHUTDOWN within the following 30 hours.

b. With one offsite circuit and one diesel generator of the above required A.C. electrical power sources inoperable, demonstrate the OPERABILITY of the remaining A.C. sources by performing Surveillance Requirements 4.8.1.1.1.a and 4.8.1.1.2.a.4 within one hour and at least once per 8 hours thereafter; restore at least one of the inoperable sources to OPERABLE status within 12 hours or be in at least HOT STANDBY within the next 6 hours and in COLD SHUTDOWN within the following 30 hours. Restore at least two offsite circuits and two diesel generators to OPERABLE status within 72 hours from the time of initial loss or be in at least HOT STANDBY within the next 6 hours and in COLD SHUTDOWN within the following 30 hours. 
ELECTRICAL POWER SYSTEMS

ACTION: (Continued)

c. With two of the above required offsite A.C. circuits inoperable, demonstrate the OPERABILITY of two diesel generators by performing Surveillance Requirement 4.8.1.1.2.a.4 within one hour and at least once per 8 hours thereafter, unless the diesel generators are already operating; restore at least one of the inoperable offsite sources to OPERABLE status within 24 hours or be in at least HOT STANDBY within the next 6 hours. With only one offsite source restored, restore at least two offsite circuits to OPERABLE status within 72 hours from time of initial loss or be in at least HOT STANDBY within the next 6 hours and in COLD SHUTDOWN within the following 30 hours.

d. With two of the above required diesel generators inoperable, demonstrate the OPERABILITY of two offsite A.C. circuits by performing Surveillance Requirement 4.8.1.1.1.a within one hour and at least once per 8 hours thereafter; restore at least one of the inoperable diesel generators to OPERABLE status within 2 hours or be in at least HOT STANDBY within the next 6 hours and in COLD SHUTDOWN within the following 30 hours. Restore at least two diesel generators to OPERABLE status within 72 hours from time of initial loss or be in least HOT STANDBY within the next 6 hours and in COLD SHUTDOWN within the following 30 hours.

4.8.1.1.1 Each of the above required independent circuits between the offsite transmission network and the onsite Class $\mathrm{TE}$ distribution system shall be:

a. Determined OPERABLE at least once per 7 days by verifying correct breaker alignments, indicated power availability, and

b. Demonstrated OPERABLE at least once per 18 months during shutdown by transferring (manually and automatically) unit power supply from the normal circuit to the alternate circuit.

4.8.1.1.2 Each diesel generator shall be demonstrated OPERABLE:

a. In accordance with the frequency specified in Table 4.8-1 on a STAGGERED TEST BASIS by:

1. Verifying the fuel level in the day and engine-mounted fuel tank, 
2. Verifying the fuel level in the fuel storage tank,

3. Verifying the fuel transfer pump can be started and transfers fuel from the storage system to the day and engine-mounted tank,

4. Verifying the diesel starts from ambient condition and accelerates to at least (900) rpm in less than or equal to (10) seconds. The generator voltage and frequency shall be volts and $\quad \mathrm{Hz}$ within seconds after the start signal. The diesel generator shall be started for this test by using the following signals which shall be changed on a rotating basis:

a) Manua1.

b) Simulated loss of offsite power by itself.

c) Simulated loss of offsite power in conjunction with an ESF actuation test signal.

d) An ESF actuation test signal by itself.

5. Verifying the generator is synchronized, loaded to greater than or equal to (continuous rating) in less than or equal to (60) seconds, and operates for greater than or equal to 60 minutes,

6. Verifying the diesel generator is aligned to provide standby power to the associated emergency busses, and

b. At least once per 92 days by verifying that a sample of diesel fuel from the fuel storage tank obtained in accordance with ASTM-D270-65, is within the acceptable limits specified in Table 1 of ASTM D975-74 when checked for viscosity, water and sediment.

c. At least once per 18 months during shutdown by:

1. Subjecting the diese 1 to an inspection in accordance with procedures prepared in conjunction with its manufacturer's recommendations for this class of standby service,

2. Verifying the generator capability to reject a load of greater than or equal to (largest single emergency load) $k w$ while maintaining voltage at $\pm$ volts and frequency at 
ELECTRICAL POWER SYSTEMS

SURVEILLANCE REQUIREMENTS (Continued)

3. Verifying the generator capability to reject a load of (continuous rating) $\mathrm{kW}$ without exceeding $75 \%$ of the difference between nominal speed and the overspeed trip setpoint, or $15 \%$ above nominal, whichever is lower. The generator voltage shall not exceed volts during and following the load rejection.

4. Simulating a loss of offsite power by itself, and:

a) Verifying de-energization of the emergency busses and load shedding from the emergency busses.

b) Verifying the diesel starts on the auto-start signal, energizes the emergency busses with permanently connected loads within seconds, energizes the auto-connected shutdown loads through the load sequencer and operates for greater than or equal to 5 minutes while its generator is loaded with the shutdown loads. After energization, the voltage and frequency of the emergency busses shall be maintained at $\mathrm{Hz}$ during this test. volts and $\pm$

5. Verifying that on an ESF actuation test signal (without loss of offsite power) the diesel generator starts on the auto-start signal and operates on standby for greater than or equal to 5 minutes. The generator voltage and frequency shall be

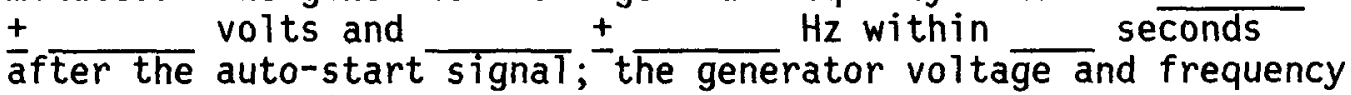
shall be maintained within these limits during this test

6. Verifying that on a simulated loss of the diesel generator (with offsite power not available), the loads are shed from the emergency busses and that subsequent loading of the diese 1 generator is in accordance with design requirements.

7. Simulating a loss of offsite power in conjunction with an ESF actuation test signal, and

a) Verifying de-energization of the emergency busses and load shedding from the emergency busses.

b) Verifying the diesel starts from ambient condition on the auto-start signal, energizes the emergency busses with permanently connected loads, energizes the auto-connected emergency (accident) loads within seconds, energizes the auto-connected shutdown loads through the load sequencer and operates for greater than or equal to 5 minutes while 
ELECTRICAL POWER SYSTEMS

SURVEILLANCE REQUIREMENTS (Continued)

its generator is loaded with the emergency loads. After energization, the voltage and frequency of the emergency busses shall be maintained at $\pm$ $\mathrm{Hz}$ during this test. volts and

c) Verifying that all automatic diesel generator trips, except engine overspeed and generator differential, are automatically bypassed upon loss of voltage on the emergency bus concurrent with a safety injection actuation signal.

8. Verifying the diesel generator operates for at least 24 hours. During the first 2 hours of this test, the diesel generator shall be loaded to greater than or equal to (2-hour rating) $\mathrm{kw}$ and during the remaining 22 hours of this test, the diesel generator shall be loaded to greater than or equal to (continuous rating) $\mathrm{kw}$. Within 5 minutes after completing this 24 hour test, perform Specification 4.8.1.1.2.c.4. The generator voltage and frequency shall be $\mathrm{Hz}$ within \pm volts and seconds after the start signal; the generator voltage and frequency shall be maintained within these limits during this test.

9. Verifying that the auto-connected loads to each diesel generator do not exceed the 2000 hour rating of $\mathrm{kw}$.

10. Verifying the diesel generator's capability to:

a) Synchronize with the offsite power source while the generator is loaded with its emergency loads upon a simulated restoration of offsite power,

b) Transfer its loads to the offsite power source, and

c) Be restored to its standby status.

11. Verifying that with the diesel generator operating in a test mode (connected to its bus), a simulated safety injection signal overrides the test mode by (1) returning the diesel generator to standby operation and (2) automatically energizes the emergency loads with offsite power.

12. Verifying that the fuel transfer pump transfers fuel from each fuel storage tank to the day and engine-mounted tank of each diesel via the installed cross connection lines. 
ELECTRICAL POWER SYSTEMS

SURVEILLANCE REQUIREMENTS (Continued)

13. Verifying that the automatic load sequence timer is OPERABLE with the interval between each load block within $\pm 10 \%$ of its design interval.

14. Verifying that the following diesel generator lockout features prevent diesel generator starting only when required:

a)

b)

d. At least once per 10 years or after any modifications which could affect diesel generator interdependence by starting both diesel generators simultaneously, during shutdown, and verifying that both diesel generators accelerate to at least (900) rpm in less than or equal to (10) seconds.

4.8.1.1.3 Reports - All diesel generator failures, valid or non-valid, shall be reported to the Commission pursuant to Specification 6.9.1. Reports of diesel generator failures shall include the information recommended in Regulatory Position C.3.b of Regulatory Guide 1.108, Revision 1, August 1977. If the number of failures in the last 100 valid tests (on a per nuclear unit basis) is greater than or equal to 7 , the report shall be supplemented to include the additional information recommended in Regulatory Position C.3.b of Regulatory Guide 1.108, Revision 1, August 1977. 
TABLE 4.8-1

\section{DIESEL GENERATOR TEST SCHEDULE}

Number of Failures In

Last 100 Valid Tests*

Test Frequency

$\leq 1$

At least once per 31 days

2

At least once per 14 days

3

At least once per 7 days

$\geq 4$

At least once per 3 days

*Criteria for determining number of failures and number of valid tests shall be in accordance with Regulatory Position C.2.e of Regulatory Guide 1.108, Revision 1, August 1977, where the last 100 tests are determined on a per nuclear unit basis. For the purposes of this test schedule, only valid tests conducted after the $O L$ issuance date shall be included in the computation of the "last 100 valid tests." Entry into this test schedule shall be made at the 31 day test frequency. 


\section{ELECTRICAL POWER SYSTEMS}

SHUTDOWN

\section{LIMITING CONDITION FOR OPERATION}

3.8.1.2 As a minimum, the following A.C. electrical power sources shall be OPERABLE:

a. One circuit between the offsite transmission network and the onsite Class $1 E$ distribution system, and

b. One diesel generator with:

1. Day and engine-mounted fuel tanks containing a minimum volume of gallons of fuel,

2. A fuel storage system containing a minimum volume of gallons of fuel, and

3. A fuel transfer pump.

APPLICABILITY: MODES 5 and 6.

\section{ACTION:}

With less than the above minimum required A.C. electrical power sources OPERABLE, suspend all operations involving CORE ALTERATIONS or positive reactivity changes.

4.8.1.2 The above required A.C. electrical power sources shall be demonstrated OPERABLE by the performance of each of the Surveillance Requirements of 4.8.1.1.1, 4.8.1.1.2 (except for requirement 4.8.1.1.2.a.5) and 4.8.1.1.3. 


\section{ELECTRICAL POWER SYSTEMS}

\section{3/4.8.2 ONSITE POWER DISTRIBUTION SYSTEMS}

\section{A.C. DISTRIBUTION - OPERATING}

\section{LIMITING CONDITION FOR OPERATION}

3.8.2.1 The following A.C. electrical busses shall be OPERABLE and energized with tie breakers open between redundant busses:

$$
\begin{aligned}
& \text { volt Emergency Bus \# } \\
& \text { volt Emergency Bus \# } \\
& \text { volt Emergency Bus \# } \\
& \text { volt Emergency Bus \# } \\
& \text { volt A.C. Vital Bus \# } \\
& \text { volt A.C. Vital Bus \# } \\
& \text { volt A.C. Vital Bus \# } \\
& \text { volt A.C. Vital Bus \# }
\end{aligned}
$$

APPLICABILITY: MODES $1,2,3$ and 4.

\section{ACTION:}

With less than the above complement of A.C. busses OPERABLE, restore the inoperable bus to OPERABLE status within 8 hours or be in at least HOT STANDBY within the next 6 hours and in COLD SHUTDOWN within the following 30 hours.

4.8.2.1 The specified A.C. busses shall be determined OPERABLE with tie breakers open between redundant busses at least once per 7 days by verifying correct breaker alignment and indicated power availability. 


\section{ELECTRICAL POWER SYSTEMS}

A.C. DISTRIBUTION - SHUTDOWN

3.8.2.2 As a minimum, the following A.C. electrical busses shall be OPERABLE:

$$
\begin{aligned}
& 1-(4160) \text { volt Emergency Bus } \\
& 1-(480) \text { volt Emergency Bus } \\
& 2-(120) \text { volt A.C. Vital Busses }
\end{aligned}
$$

APPLICABILITY: MODES 5 and 6.

\section{ACTION:}

With less than the above complement of A.C. busses OPERABLE and energized, establish CONTAINMENT INTEGRITY within 8 hours.

4.8.2.2 The specified A.C. busses shall be determined OPERABLE at least once per 7 days by verifying correct breaker alignment and indicated power availability. 
ELECTRICAL POWER SYSTEMS

D.C. DISTRIBUTION - OPERATING

LIMITING CONDITION FOR OPERATION

3.8.2.3 The following D.C. bus trains shall be energized and OPERABLE:

TRAIN "A" consisting of (250/125)-volt D.C. bus No. 1, (250/125)-volt battery bank No. 1 and a full capacity charger.

TRAIN "B" consisting of (250/125)-volt D.C. bus No. 2, (250/125)-volt battery bank No. 2 and a full capacity charger.

APPLICABILITY: MODES $1,2,3$ and 4.

ACTION:

With one (250/125)-volt D.C. bus train inoperable, restore the inoperable bus train to OPERABLE status within 2 hours or be in at least HOT STANDBY within the next 6 hours and in COLD SHUTDOWN within the following 30 hours.

4.8.2.3.1 Each D.C. bus train shall be determined OPERABLE and energized with tie breakers open at least once per 7 days by verifying correct breaker alignment and indicated power availability with an overall voltage of greater than or equal to $(250 / 125)$ volts.

4.8.2.3.2 Each (250/125)-volt battery bank and charger shall be demonstrated OPERABLE:

a. At least once per 7 days by verifying that:

1. The electrolyte level of each pilot cell is between the minimum and maximum level indication marks,

2. The pilot cell specific gravity, corrected to (77) ${ }^{\circ} \mathrm{F}$ and full electrolyte level, is greater than or equal to , and

3. The pilot cell voltage is greater than or equal to volts.

b. At least once per 92 days by verifying that:

1. The electrolyte level of each cell is between the minimum and maximum leve? indication marks, 
2. The average specific gravity of all connected cells, corrected to $(77)^{\circ} \mathrm{F}$ and full electrolyte level, is greater than or equal to $(1.200)$,

3. The electrolyte temperatures in a representative sample of cells consisting of at least every sixth cell are within $\pm 5^{\circ} \mathrm{F}$,

4. The minimum specific gravity, corrected to (77) ${ }^{\circ} \mathrm{F}$ and full electrolyte level, of each connected cell is within 0.010 of the average corrected value of all the connected cells.

5. The voltage of each connected cell is within \pm 0.04 volts of the average voltage of all the connected cells,

6. The total battery terminal voltage is greater than or equal to volts, and

7. The battery load (charger current) with the battery on float charge is less than amps.

c. At least once per 18 months by verifying that:

1. The cells, cell plates and battery racks show no visual indication of physical damage or abnormal deterioration,

2. The cell-to-cell and terminal connections are clean, tight, and coated with anti-corrosion material,

3. The resistance of each cell-to-cell and terminal connection is less than or equal to ohms, and

4. The battery charger will supply at least amperes at volts for at least (8) hours.

d. At least once per 18 months, during shutdown, by verifying that the battery capacity is adequate to supply and maintain in OPERABLE status all of the actual emergency loads for ( 8 ) hours when the battery is subjected to a battery service test.

e. At least once per 60 months, during shutdown, by verifying that the battery capacity is at 1east $90 \%$ of the manufacturer's rating when subjected to a performance discharge test. This performance discharge test shall be performed subsequent to the satisfactory completion of the required battery service test. 


\section{ELECTRICAL POWER SYSTEMS}

\section{D.C. DISTRIBUTION - SHUTDOWN}

3.8.2.4 As a minimum, one D.C. bus train consisting of the following shall be energized and OPERABLE:

1 - (250/125)-volt D.C. bus, and

1 - (250/125)-volt battery bank and full capacity charger associated with the above D.C. bus.

APPLICABILITY: MODES 5 and 6.

ACTION:

With less than the above complement of D.C. equipment and bus OPERABLE, establish CONTAINMENT INTEGRITY within 8 hours.

4.8.2.4.1 The above required (250/125)-volt D.C. bus shall be determined OPERABLE and energized at least once per 7 days by verifying correct breaker alignment and indicated power availability with an overall voltage of greater than or equal to $(250 / 125)$ volts.

4.8.2.4.2 The above required (250/125)-volt battery bank and charger shall be demonstrated OPERABLE per Surveillance Requirement 4.8.2.3.2. 


\section{3/4.8.3 ELECTRICAL EQUIPMENT PROTECTIVE DEVICES}

CONTAINMENT PENETRATION CONDUCTOR OVERCURRENT PROTECTIVE DEVICES

\section{LIMITING CONDITION FOR OPERATION}

3.8.3.I A11 containment penetration conductor overcurrent protective devices shown in Table 3.8-1 shall be OPERABLE.

APPLICABILITY: MODES $1,2,3$ and 4.

\section{ACTION:}

With one or more of the containment penetration conductur overcurrent protective device(s) shown in Table 3.8-1 inoperable:

a. Restore the protective device(s) to OPERABLE stauts or de-energize the circuit(s) by tripping the associated backup circuit breaker within 72 hours and verify the backup circuit breaker to be tripped at least once per 7 days thereafter; the provisions of Specification 3.0.4 are not applicable to overcurrent devices in circuits which have their backup circuit breakers tripped, or

b. Be in at least HOT STANDBY within the next 6 hours and in COLD SHUTDOWN within the following 30 hours.

\section{SURVEILLANCE REQUIREMENTS}

4.8.3.1 All containment penetration conductor overcurrent protective devices shown in Table 3.8-1 shall be demonstrated OPERABLE:

a. At least once per 18 months:

1. By verifying that the medium voltage (4-15 KV) circuit breakers are OPERABLE by selecting, on a rotating basis, at least $10 \%$ of the circuit breakers of each voltage level, and performing the following:

(a) A CHANNEL CALIBRATION of the associated protective relays, and

(b) An integrated system functional test which includes simulated automatic actuation of the system and verifying that each relay and associated circuit breakers and control circuits function as designed and as specified in Table 3.8-1. 
(c) For each circuit breaker found inoperable during these at functional test, an additional representative sample of at least $10 \%$ of all the circuit breakers of the inoperable type shall also be functionally tested until no more failures are found or all circuit breakers of that type have been functionally tested.

2. By selecting and functionally testing a representative sample of at least $10 \%$ of each type of lower voltage circuit breakers. Circuit breakers selected for functional testing shall be selected on a rotating basis. The functional test shall consist of injecting a current input at the specified setpoint to each selected circuit breaker and verifying that each circuit breaker functions as designed. Circuit breakers found inoperable during functional testing shall be restored to OPERABLE status prior to resuming operation. For each circuit breaker found inoperable during these functional tests, an additional representative sample of at least $10 \%$ of all the circuit breakers of the inoperable type shall also be functionally tested until no more failures are found or all circuit breakers of that type have been functionally tested.

3. By selecting and functionally testing a representative sample of each type of fuse on a rotating basis. Each representative sample of fuses shall include at least $10 \%$ of all fuses of that type. The functional test shall consist of a non-destructive resistance measurement test which demonstrates that the fuse meets its manufacturer's design criteria. Fuses found inoperable during these functional tests shall be replaced with OPERABLE fuses prior to resuming operation. For each fuse found inoperable during these functional tests, an additional representative sample of at least $10 \%$ of all fuses of that type shall be functionally tested until no more failures are found or all fuses of that type have been functionally tested.

b. At least once per 60 months by subjecting each circuit breaker to an inspection and preventive maintenance in accordance with procedures prepared in conjunction with its manufacturer's recommendations. 
CONTAINMENT PENETRATION CONDUCTOR

OVERCURRENT PROTECTIVE DEVICES

Device Number and Location

1. 6900 VAC

(Primary breaker)

(Back-up breaker)

2. 480 VAC from MOAD Centers

List al1; primary breakers Back-up breakers

3. 480 VAC from MCC

List all; primary breakers Back-up breakers

II

II

4. $125 \mathrm{~V}$ DC Lighting

List al1; primary breakers Back-up breakers

5. 440 VAC CRDM Power

Primary breakers

Back-up breakers

\begin{tabular}{ccc} 
Trip & Response & \\
Setpoint & Time & System \\
(Amperes) & (sec/cycles) & Powered \\
\hline
\end{tabular}

Reactor Coolant pump

1

2

3

4 


\section{ELECTRICAL POWER SYSTEMS}

MOTOR OPERATED VALVES THERMAL OVERLOAD PROTECTION AND/OR BYPASS DEVICES

LIMITING CONDITION FOR OPERATION

3.8.3.2 The thermal overload protection and/or bypass devices, integral with the motor starter, of each valve listed in Table 3.8-2 shall be OPERABLE.

APPLICABILITY: Whenever the motor operated valve is required to be OPERABLE.

ACTION:

With one or more of the thermal overload protection and/or bypass devices inoperable, declare the affected valve(s) inoperable and apply the appropriate ACTION Statement(s).

\section{SURVEILLANCE REQUIREMENTS}

4.8.3.2 The above required thermal overload protection and/or bypass devices shall be demonstrated OPERABLE:

a. At least once per 18 months, by the performance of a CHANNEL FUNCTIONAL TEST of the bypass circuitry for those thermal overload devices which are either:

1. Continuously bypassed and temporarily placed in force only when the valve motors are undergoing periodic or maintenance testing, or

2. Normally in force during plant operation and bypassed under accident conditions.

b. At least once per 18 months by the performance of a CHANNEL CALIBRATION of a representative sample of at least $25 \%$ of all thermal overload devices which are not bypassed, such that each non-bypassed device is calibrated at least once per 6 years. 
TABLE $\quad 3.8-2$

MOTOR OPERATED VALVES THERMAL OVERLOAD

\section{PROTECTION AND/OR BYPASS DEVICES}

VALVE NUMBER

FUNCTION

BYPASS DEVICE

(YES/NO) 
3/4.9 REFUELING OPERATIONS

3/4.9. 1 BORON CONCENTRATION

LIMITING CONDITION FOR OPERATION

3.9.1 With the reactor vessel head unbolted or removed, the boron concentration of all filled portions of the Reactor Coolant System and the refueling canal shall be maintained uniform and sufficient to ensure that the more restrictive of the following reactivity conditions is met:

a. Either a $\mathrm{K}_{\mathrm{eff}}$ of 0.95 or less, which includes a $1 \%$ delta $\mathrm{k} / \mathrm{k}$ conservative allowance for uncertainties, or

b. A boron concentration of greater than or equal to (2000) $\mathrm{ppm}$, which includes a $50 \mathrm{ppm}$ conservative allowance for uncertainties.

\section{APPLICABILITY: MODE 6*}

ACTION:

With the requirements of the above specification not satisfied, immediately suspend all operations involving CORE ALTERATIONS or positive reactivity changes and initiate and continue boration at greater than or equal to ( ) gpm of ( ) ppm boric acid solution or its equivalent until $\mathrm{K}_{\text {eff }}$ is reduced to less than or equal to 0.95 or the boron concentration is restored to greater than or equal to $2000 \mathrm{ppm}$, whichever is the more restrictive. The provisions of Specification 3.0 .3 are not applicable.

\section{SURVEILLANCE REQUIREMENTS}

4.9.1.1 The more restrictive of the above two reactivity conditions shall be determined prior to:

a. Removing or unbolting the reactor vessel head, and

b. Withdrawal of any full length contral rod in excess of 3 feet from its fully inserted position within the reactor pressure vessel.

4.9.1.2 The boron concentration of the reactor coolant system and the refueling canal shall be determined by chemical analysis at least once per 72 hours.

* The reactor shall be maintained in MODE 6 when the reactor vessel head is unbolted or removed. 
3.9.2 As a minimum, two source range neutron flux monitors shall be operating, each with continuous visual indication in the control room and one with audible indication in the containment and control room.

APPLICABILITY: MODE 6.

ACTION:

a. With one of the above required monitors inoperable, immediately suspend all operations involving CORE ALTERATIONS or positive reactivity changes.

b. With both of the required monitors inoperable, determine the boron concentration of the reactor coolant system at least once per 12 hours.

c. The provisions of Specification 3.0.3 are not applicable.

4.9.2 Each source range neutron flux monitor shall be demonstrated OPERABLE by performance of:

a. A CHANNEL CHECK at least once per 12 hours,

b. A CHANNEL FUNCTIONAL TEST within 8 hours prior to the initial start of CORE ALTERATIONS, and

c. A CHANNEL FUNCTIONAL TEST at least once per 7 days. 
REFUELING OPERATIONS

3/4.9.3 DECAY TIME

LIMITING CONDITION FOR OPERATION

3.9.3 The reactor shall be subcritical for at least 100 hours.

APPLICABILITY: During movement of irradiated fuel in the reactor pressure vessel.

ACTION:

With the reactor subcritical for less than 100 hours, suspend all operations involving movement of irradiated fuel in the reactor pressure vessel. The provisions of Specification 3.0 .3 are not applicable.

4.9.3 The reactor shall be determined to have been subcritical for at least 100 hours by verification of the date and time of subcriticality prior to movement of irradiated fuel in the reactor pressure vessel. 


\section{3/4.9.4CONTAINMENT BUILDING PENETRATIONS}

\section{LIMITING CONDITION FOR OPERATION}

3.9.4 The containment building penetrations shall be in the following status:

a. The equipment door closed and held in place by a minimum of four bolts,

b. A minimum of one door in each airlock is closed, and

c. Each penetration providing direct access from the containment atmosphere to the outside atmosphere shall be either:

1. Closed by an isolation valve, blind flange, or manual valve, or

2. Be capable of being closed by an OPERABLE automatic Containment Purge and Exhaust isolation valve.

APPLICABILITY: During CORE ALTERATIONS or movement of irradiated fuel within the containment.

ACTION:

With the requirements of the above specification not satisfied, immediately suspend all operations involving CORE ALTERATIONS or movement of irradiated fuel in the containment building. The provisions of Specification 3.0.3 are not applicable.

\section{SURVEILLANCE REQUIREMENTS}

4.9.4 Each of the above required containment building penetrations shall be determined to be either in its closed/isolated condition or capable of being closed by an OPERABLE automatic Containment Purge and Exhaust isolation valve within 100 hours prior to the start of and at least once per 7 days during CORE ALTERATIONS or movement of irradiated fuel in the containment building by:

a. Verifying the penetrations are in their closed/isolated condition, or

b. Testing the Containment Purge and Exhaust isolation valves per the applicable portions of Specification (4.6.4.1.2). 
REFUELING OPERATIONS

3/4.9.5 COMMUNICATIONS

LIMITING CONDITION FOR OPERATION

3.9.5 Direct communications shall be maintained between the control room and personnel at the refueling station.

APPLICABILITY: During CORE ALTERATIONS.

ACTION:

When direct communications between the control room and personnel at the refueling station cannot be maintained, suspend al1 CORE ALTERATIONS. The provisions of Specification 3.0.3 are not applicable.

4.9.5 Direct communications between the control room and personnel at the refueling station shall be demonstrated within one hour prior to the start of and at least once per 12 hours during CORE ALTERATIONS. 
REFUELING OPERATIONS

3/4.9.6 MANIPULATOR CRANE OPERABILITY

LIMITING CONDITION FOR OPERATION

3.9.6 The manipulator crane and auxiliary hoist shall be used for movement of drive rods or fuel assemblies and shall be OPERABLE with:

a. The manipulator crane used for movement of fuel assemblies having:

1. A minimum capacity of (3250) pounds, and

2. An overload cut off limit less than or equal to (3200) pounds.

b. The auxiliary hoist used for latching and unlatching drive rods having:

1. A minimum capacity of (3000) pounds, and

2. A load indicator which shall be used to prevent lifting loads in excess of (1000) pounds.

APPLICABILITY: During movement of drive rods or fuel assemblies within the reactor pressure vesse].

ACTION:

With the requirements for crane and/or hoist OPERABILITY not satisfied, suspend use of any inoperable manipulator crane and/or auxiliary hoist from operations involving the movement of drive rods and fuel assemblies within the reactor pressure vessel. The provisions of Specification 3.0.3 are not applicable.

SURVEILLANCE REQUIREMENTS

4.9.6.1 Each manipulator crane used for movement of fuel assemblies within the reactor pressure vessel shall be demonstrated OPERABLE within 100 hours prior to the start of such operations by performing a load test of at least (4063) pounds and demonstrating an automatic load cut off when the crane load exceeds (3200) pounds.

4.9.6.2 Each auxiliary hoist and associated load indicator used for movement of drive rods within the reactor pressure vessel shall be demonstrated OPERABLE within 100 hours prior to the start of such operations by performing a load test of at least (3750) pounds. 
REFUELING OPERATIONS

3/4.9.7 CRANE TRAVEL - SPENT FUEL STORAGE POOL BUILDING

LIMITING CONDITION FOR OPERATION

3.9.7 Loads in excess of __ pounds shall be prohibited from travel over fuel assemblies in the sto $\overline{r a g e}$ pool.

APPLICABILITY: With fuel assemblies in the storage pool.

ACTION:

With the requirements of the above specification not satisfied, place the crane load in a safe condition. The provisions of Specification 3.0.3 are not applicable.

4.9.7 Crane interlocks and physical stops which prevent crane travel with loads in excess of pounds over fuel assemblies shall be demonstrated OPERABLE within 7 days prior to crane use and at least once per 7 days thereafter during crane operation. 
3.9.8 At least one residual heat removal loop shall be in operation. APPLICABILITY: MODE 6.

ACTION:

a. With less than one residual heat removal loop in operation, except as provided in $b$. below, suspend all operations involving an increase in the reactor decay heat load or a reduction in boron concentration of the Reactor Coolant System. Close all containment penetrations providing direct access from the containment atmosphere to the outside atmosphere within 4 hours.

b. The residual heat removal loop may be removed from operation for up to 1 hour per 8 hour period during the performance of CORE ALTERATIONS in the vicinity of the reactor pressure vessel hot legs.

c. The provisions of Specification 3.0.3 are not applicable.

4.9.8 A residual heat removal loop shall be determined to be in operation and circulating reactor coolant at a flow rate of greater than or equal to (3000) gpm at least once per 24 hours. 
REFUELING OPERATIONS

3/4.9.9 CONTAINMENT PURGE AND EXHAUST ISOLATION SYSTEM

LIMITING CONDITION FOR OPERATION

3.9.9 The Containment Purge and Exhaust isolation system shall be OPERABLE. APPLICABILITY: During CORE ALTERNATIONS or movement of irradiated fuel within the containment.

ACTION:

With the Containment Purge and Exhaust isolation system inoperable, close each of the Purge and Exhaust penetrations providing direct access from the containment atmosphere to the outside atmosphere. The provisions of Specifications 3.0 .3 and 3.0.4 are not applicable.

4.9.9 The Containment Purge and Exhaust isolation system shall be demonstrated OPERABLE within 100 hours prior to the start of and at least once per 7 days during CORE ALTERATIONS by verifying that containment Purge and Exhaust isolation occurs on manual initiation and on a high radiation test signal from each of the containment radiation monitoring instrumentation channels. 


\section{3/4.9.10 WATER LEVEL - REACTOR VESSEL}

3.9.10 At least, 23 feet of water shall be maintained over the top of irradiated fuel assemblies seated within the reactor pressure vessel.

APPLICABILITY: During movement of fuel assemblies or control rods within the reactor pressure vessel while in MODE 6.

ACTION:

With the requirements of the above specification not satisfied, suspend all operations involving movement of fuel assemblies or control rods within the pressure vessel. The provisions of Specification 3.0.3 are not applicable.

4.9.10 The water level shall be determined to be at least its minimum required depth within 2 hours prior to the start of and at least once per 24 hours thereafter during movement of fuel assemblies or control rods. 


\section{REFUELING OPERATIONS}

\section{3/4.9.11 WATER LEVEL-STORAGE POOL}

3.9.11 At least 23 feet of water shall be maintained over the top of irradiated fuel assemblies seated in the storage racks.

APPLICABILITY: Whenever irradiated fuel assemblies are in the storage pool.

\section{ACTION:}

With the requirements of the above specification not satisfied, suspend all movement of fuel assemblies and crane operations with loads in the fuel storage areas and restore the water level to within its limit within 4 hours. The provisions of Specification 3.0.3 are not applicable.

4.9.11 The water level in the storage pool shall be determined to be at least its minimum required depth at least once per 7 days when irradiated fuel assemblies are in the fuel storage pool. 
REFUELING OPERATIONS

3/4.9.12 STORAGE POOL AIR CLEANUP SYSTEM

LIMITING CONDITION FOR OPERATION

3.9.12 Two independent fuel storage pool air cleanup systems shall be OPERABLE.

APPLICABILITY: Whenever irradiated fuel is in the storage pool.

ACTION:

a. With one fuel storage pool air cleanup system inoperable, fuel movement within the storage pool or crane operation with loads over the storage pool may proceed provided the OPERABLE fuel storage pool air cleanup system is in operation and discharging thru at least one train of HEPA filters and charcoal adsorbers.

b. With no fuel storage pool air cleanup system OPERABLE, suspend all operations involving movement of fuel within the storage pool or crane operation with loads over the storage pool until at least one spent fuel storage pool air cleanup system is restored to OPERABLE status.

c. The provisions of Specifications 3.0.3 and 3.0.4 are not applicable.

4.9.12 The above required fuel storage pool air cleanup systems shall be demonstrated OPERABLE:

a. At least once per 31 days on a STAGGERED TEST BASIS by initiating, from the control room, flow through the HEPA filters and charcoal adsorbers and verifying that the system operates for at least 10 hours with the heaters on.

b. At least once per 18 months or (1) after any structural maintenance on the HEPA filter or charcoal adsorber housings, or (2) following painting, fire or chemical release in any ventilation zone communicating with the system by: 
1. Verifying that with the system operating at a flow rate of $\mathrm{cfm}+10 \%$ and exhausting through the HEPA filters and charcoal adsorbers, the total bypass flow of the system to the facility vent, including leakage through the system diverting valves, is less than or equal to $1 \%$ when the system is tested by admitting cold DOP at the system intake. (For systems with diverting valves.)

2. Verifying that the cleanup system satisfies the in-place testing acceptance criteria and uses the test procedures of Regulatory Positions C.5.a, C.5.c and C.5.d of Regulatory Guide 1.52, Revision 2, March 1978, and the system flow rate is $\mathrm{cfm} \pm 10 \%$

3. Verifying within 31 days after removal that a laboratory analys is of a representative carbon sample obtained in accordance with Regulatory Position C.6.b of Regulatory Guide 1.52, Revision 2, March 1978, meets the laboratory testing criteria of Regulatory Position C.6.a of Regulatory Guide 1.52, Revision 2, March 1978.

4. Verifying a system flow rate of _ cfm $+10 \%$ during system operation when tested in accordance with A NSI N510-1975.

c. After every 720 hours of charcoal adsorber operation by verifying within 31 days after removal that a laboratory analysis of a representative carbon sample obtained in accordance with Regulatory Position C.6.b of Regulatory Guide 1.52, Revision 2, March 1978, meets the laboratory testing criteria of Regulatory Position C.6.a of Regulatory Guide 1.52, Revision 2, March 1978.

d. At least once per 18 months by:

1. Verifying that the pressure drop across the combined HEPA filters and charcoal adsorber banks is less than (6) inches Water Gauge while operating the system at a flow rate of $\mathrm{cfm} \pm 10 \%$.

2. Verifying that on a high radiation test signal, the system automatically starts (unless already operating) and directs its exhaust flow through the HEPA filters and charcoal adsorber banks. 
3. Verifying that the system maintains the spent fuel storage pool area at a negative pressure of greater than or equal to (1/4) inches Water Gauge relative to the outside atmosphere during system operation.

4. Verifying that the filter cooling bypass valves can be manualiy opened.

5. Verifying that the heaters dissipate tested in accordance with ANSI N510-1975. $\pm$ kw when

e. After each complete or partial replacement of a HEPA filter bank by verifying that the HEPA filter banks remove greater than or equal to (99.95)\%* of the DOP when they are tested in-place in accordance with ANSI N510-1975 while operating the system at a flow rate of $\mathrm{cfm} \pm 10 \%$.

f. After each complete or partial replacement of a charcoal adsorber bank by verifying that the charcoal adsorbers remove greater than or equal to $99.95 \%$ of a halogenated hydrocarbon refrigerant test gas when they are tested in-place in accordance with ANSI N510-1975 while operating the system at a flow rate of $c f m \pm 10 \%$.

*99.95\% applicable when a filter efficiency of $99 \%$ is assumed in the safety analyses; $99 \%$ when a filter efficiency of $90 \%$ is assumed. 
3/4.10 SPECIAL TEST EXCEPTIONS

3/4.10.1 SHUTDOWN MARGIN

LIMITING CONDITION FOR OPERATION

3.10.1 The SHUTDOWN MARGIN requirement of Specification 3.1.1.1 may be suspended for measurement of control rod worth and shutdown margin provided:

a. Reactivity equivalent to at least the highest estimated control rod worth is available for trip insertion from OPERABLE control rod(s), and

b. All part length rods are withdrawn to at least the 180 step position and OPERABLE.

APPLICABILITY: MODE 2.

ACTION:

a. With any full length control rod not fully inserted and with less than the above reactivity equivalent available for trip insertion or the part length rods not within their withdrawal limits, immediately initiate and continue boration at greater than or equal to ( ) gpm of ( ) ppm boric acid solution or its equivalent until the SHUTDOWN MARGIN required by Specification 3.1.1.1 is restored.

b. With all full length control rods inserted and the reactor subcritical by less than the above reactivity equivalent, immediately initiate and continue boration at greater than or equal to ( ) gpm of ( ) ppm boric acid solution or its equivalent until the SHUTDOWN MARGIN required by Specification 3.1.1.1 is restored.

SURVEILLANCE REQUIREMENTS

4.10.1.1 The position of each full length and part length rod either partially or fully withdrawn shall be determined at least once per 2 hours.

4.10.1.2 Each full length rod not fully inserted shall be demonstrated capable of full insertion when tripped from at least the $50 \%$ withdrawn position within 24 hours prior to reducing the SHUTDOWN MARGIN to less than the limits of Specification 3.1.1.1.

4.10.1.3 The part length rods shall be demonstrated OPERABLE by moving each part length rod greater than or equal to 10 steps within 4 hours prior to reducing the SHUTDOWN MARGIN to less than the limits of Specification 3.1.1.1. 
3/4.10.2 GROUP HEIGHT, INSERTION AND POWER DISTRIBUTION LIMITS

3.10.2 The group height, insertion and power distribution limits of Specifications 3.1.3.1,3.1.3.5,3.1.3.6,3.1.3.7, 3.2.1 and 3.2 .4 may be suspended during the performance of PHYSICS TESTS provided:

a. The THERMAL POWER is maintained less than or equal to $85 \%$ of RATED THERMAL POWER, and

b. The limits of Specifications 3.2 .2 and 3.2 .3 are maintained and determined at the frequencies specified in Specification 4. 10.2.2 below.

\section{APPLICABILITY: MODE 1}

ACTION:

With any of the limits of Specifications 3.2 .2 or 3.2 .3 being exceeded while the requirements of Specifications $3.1 .3 .1,3.1 .3 .5,3.1 .3 .6,3.1 .3 .7,3.2 .1$ and 3.2.4 are suspended, either:

a. Reduce THERMAL POWER sufficient to satisfy the ACTION requirements of Specifications 3.2.2 and 3.2.3, or

b. Be in HOT STANDBY within 6 hours.

\section{SURVEILLANCE REQUIREMENTS}

4.10.2.1 The THERMAL POWER shall be determined to be less than or equal to 85\% of RATED THERMAL POWER at least once per hour during PHYSICS TESTS.

4.10.2.2 The Surveillance Requirements of Specifications 4.2.2 and 4.2.3.2 shall be performed at the following frequencies during PHYSICS TESTS:

a. Specification 4.2.2 - At least once per 12 hours.

b. Specification 4.2.3.2 - At least once per 12 hours. 
3.10.3 The limitations of Specifications 3.1.1.3, 3.1.3.1,3.1.3.5, 3.1.3.6 and 3.1.3.7 may be suspended during the performance of PHYSICS TESTS provided:

a. The THERMAL POWER does not exceed 5\% of RATED THERMAL POWER, and

b. The reactor trip setpoints on the OPERABLE Intermediate and Power Range Nuclear Channels are set at less than or equal to $25 \%$ of RATED THERMAL POWER.

\section{APPLICABILITY: MODE 2 .}

\section{ACTION:}

With the THERMAL POWER greater than 5\% of RATED THERMAL POWER, immediately open the reactor trip breakers.

SURVEILLANCE REQUIREMENTS

4.10.3.1 The THERMAL POWER shall be determined to be less than or equal to $5 \%$ of RATED THERMAL POWER at least once per hour during PHYSICS TESTS.

4.10.3.2 Each Intermediate and Power Range Channel shall be subjected to a CHANNEL FUNCTIONAL TEST within 12 hours prior to initiating PHYSICS TESTS. 
SPECIAL TEST EXCEPTIONS

3/4.10.4 REACTOR COOLANT LOOPS

LIMITING CONDITION FOR OPERATION

3.10.4 The limitations of Specification 3.4.1.1 may be suspended during the performance of start up and PHYSICS TESTS provided:

a. The THERMAL POWER does not exceed the P-7 Interlock Setpoint, and

b. The Reactor Trip Setpoints on the OPERABLE Intermediate and Power Range Channels are set less than or equal to $25 \%$ of RATED THERMAL POWER.

APPLICABILITY: During operation below the P-7 Interlock Setpoint.

ACTION:

With the THERMAL POWER greater than the P-7 Interlock Setpoint, immediately open the reactor trip breakers.

SURVEILLANCE REQUIREMENTS

4.10.4.1 The THERMAL POWER shall be determined to be less than P-7 Interlock Setpoint at least once per hour during start up and PHYSICS TESTS.

4.10.4.2 Each Intermediate, Power Range Channel and P-7 Interlock shall be subjected to a CHANNEL FUNCTIONAL TEST within 12 hours prior to initiating start up or PHYSICS TESTS. 
3/4.10.5 POSITION INDICATION SYSTEM - SHUTDOWN

LIMITING CONDITION FOR OPERATION

3.10.5 The limitations of Specification 3.1 .3 .3 may be suspended during the performance of individual full length (shutdown and control) rod drop time measurements provided;

a. Only one shutdown or control bank is withdrawn from the fully inserted position at a time, and

b. The rod position indicator is OPERABLE during the withdrawal of the rods. *

APPLICABILITY: MODES 3, 4 and 5 during performance of rod drop time measurements.

ACTION:

With the position indication system inoperable, or more than one bank of rods withdrawn, immediately open the reactor trip breakers.

\section{SURVEILLANCE REQUIREMENTS}

4.10.5 The above required rod position indication systems shall be determined to be OPERABLE within 24 hours prior to the start of and at least once per 24 hours thereafter during rod drop time measurements by verifying the demand position indication system and the rod position indication systems agree:

a. Within 12 steps when the rods are stationary, and

b. Within 24 steps during rod motion.

* This requirement is not applicable during the initial calibration of the rod position indication system provided (1) $\mathrm{K}_{\text {eff }}$ is maintained less than or equal to 0.95 , and (2) only one shutdown or control rod bank is withdraw from the fully inserted position at one time. 
-

-

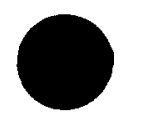




\author{
BASES FOR \\ SECTIONS 3.0 AND 4.0 \\ LIMITING CONDITIONS FOR OPERATION \\ AND \\ SURVEILLANCE REQUIREMENTS
}


-

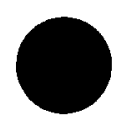

• 


\section{NOTE}

The summary statements contained in this section provide the bases for the specifications in Sections 3.0 and 4.0 and are not considered a part of these Technical Specifications as provided in 10 CFR 50.36. 
-

-

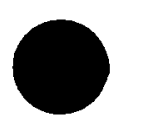


The specifications of this section provide the general requirements applicable to each of the Limiting Conditions for Operation and Surveillance Requirements within Section $3 / 4$.

3.0.1 This specification defines the applicability of each specification in terms of defined OPERATIONAL MODES or other specified conditions and is provided to delineate specifically when each specification is applicable.

3.0.2 This specification defines those conditions necessary to constitute compliance with the terms of an individual Limiting Condition for Operation and associated ACTION requirement.

3.0.3 This specification delineates the ACTION to be taken for circumstances not directly provided for in the ACTION statements and whose occurrence would violate the intent of the specification. For example, Specification 3.5.1 requires each Reactor Coolant System accumulator to be OPERABLE and provides explicit ACTION requirements if one accumulator is inoperable. Under the terms of Specification 3.0.3, if more than one accumulator is inoperable, the unit is required to be in at least HOT STANDBY within 1 hour and in at least HOT SHUTDOWN within the following 6 hours. As a further example, Specification 3.6.2.1 requires two Containment Spray Systems to be OPERABLE and provides explicit ACTION requirements if one spray system is inoperable: Under the terms of Specification 3.0.3, if both of the required Containment Spray Systems are inoperable, the unit is required to be in at least HOT STANDBY within 1 hour, in at least HOT SHUTDOWN within the following 6 hours and in at least COLD SHUTDOWN in the next 24 hours.

3.0.4 This specification provides that entry into an OPERATIONAL MODE or other specified applicability condition must be made with (a) the full complement of required systems, equipment or components OPERABLE and (b) all other parameters as specified in the Limiting Conditions for Operation being met without regard for allowable deviations and out of service provisions contained in the ACTION statements.

The intent of this provision is to insure that facility operation is not initiated with either required equipment or systems inoperable or other specified limits being exceeded.

Exceptions to this provision have been provided for a limited number of specifications when startup with inoperable equipment would not affect plant safety. These exceptions are stated in the ACTION statements of the appropriate specifications. 
APPLICABILITY

BASES

4.0.1 This specification provides that surveillance activities necessary to insure the Limiting Conditions for Operation are met and will be performed during the OPERATIONAL MODES or other conditions for which the Limiting Conditions for Operation are applicable. Provisions for additional surveillance activities to be performed without regard to the applicable OPERATIONAL MODES or other conditions are provided in the individual Surveillance Requirements. Surveillance Requirements for Special Test Exceptions need only be performed when the Special Test Exception is being utilized as an exception to an individual specification.

4.0.2 The provisions of this specification provide allowable tolerances for performing surveillance activities beyond those specified in the nominal surveillance interval. These tolerances are necessary to provide operational flexibility because of scheduling and performance considerations. The phrase "at least" associated with a surveillance frequency does not negate this allowable tolerance value and permits the performance of more frequent surveillance activities.

The tolerance values, taken either individually or consecutively over 3 test intervals, are sufficiently restrictive to ensure that the reliability associated with the surveillance activity is not significantly degraded beyond that obtained from the nominal specified interval.

4.0.3 The provisions of this specification set forth the criteria for determination of compliance with the OPERABILITY requirements of the Limiting Conditions for Operation. Under this criteria, equipment, systems or components are assumed to be OPERABLE if the associated surveillance activities have been satisfactorily performed within the specified time interval. Nothing in this provision is to be construed as defining equipment, systems or components OPERABLE, when such items are found or known to be inoperable although still meeting the Surveillance Requirements.

4.0.4 This specification ensures that the surveillance activities associated with a Limiting Condition for Operation have been performed within the specified time interval prior to entry into an OPERATIONAL MODE or other applicable condition. The intent of this provision is to ensure that surveillance activities have been satisfactorily demonstrated on a current basis as required to meet the OPERABILITY requirements of the Limiting Condition for Operation.

Under the terms of this specification, for example, during initial plant startup or following extended plant outages, the applicable surveillance activities must be performed within the stated surveillance interval prior to placing or returning the system or equipment into OPERABLE status. 
4.0.5 This specification ensures that inservice inspection of ASME Code Class 1,2 and 3 components and inservice testing of ASME Code Class 1, 2 and 3 pumps and valves will be performed in accordance with a periodically updated version of Section XI of the ASME Boiler and Pressure Vessel Code and Addenda as required by $10 \mathrm{CFR} 50.55 \mathrm{a}$. Relief from any of the above requirements has been provided in writing by the Commission and is not a part of these Technical Specifications.

This specification includes a clarification of the frequencies for performing the inservice inspection and testing activities required by Section $X I$ of the ASME Boiler and Pressure Vessel Code and applicable Addenda. This clarification is provided to ensure consistency in surveillance intervals thoughout these Technical Specifications and to remove any ambiguities relative to the frequencies for performing the required inservice inspection and testing activities.

Under the terms of this specification, the more restrictive requirements of the Technical Specifications take precedence over the ASME Boiler and Pressure Vessel Code and applicable Addenda. For example, the requirements of Specification 4.0.4 to perform surveillance activities prior to entry into an OPERATIONAL MODE or other specified applicability condition takes precedence over the ASME Boiler and Pressure Vessel Code provision which allows pumps to be tested up to one week after return to normal operation. And for example, the Technical Specification definition of OPERABLE does not grant a grace period before a device that is not capable of performing its specified function is declared inoperable and takes precedence over the ASME Boiler and Pressure Vessel Code provision which allows a valve to be incapable of performing its specified function for up to 24 hours before being declared inoperable. 
-

-

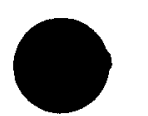




\section{3/4.1.1 BORATION CONTROL}

\section{3/4.1.1.1 and 3/4.1.1.2 SHUTDOWN MARGIN}

A sufficient SHUTDOWN MARGIN ensure that 1) the reactor can be made subcritical from all operating conditions, 2) the reactivity transients associated with postulated accident conditions are controllable within acceptable limits, and 3 ) the reactor will be maintained sufficiently subcritical to preclude inadvertent criticality in the shutdown condition.

SHUTDOWN MARGIN requirements vary throughout core life as a function of fuel depletion, RCS boron concentration, and RCS $\mathrm{T}_{\text {avg }}$. The most restrictive condition occurs at EOL, with $T_{\text {avg }}$ at no load operating temperature, and is associated with a postulated steam line break accident and resulting uncontrolled RCS cooldown. In the analysis of this accident, a minimum SHUTDOWN MARGIN of (1.6\%) delta $\mathrm{k} / \mathrm{k}$ is required to control the reactivity transient. Accordingly, the SHUTDOWN MARGIN requirement is based upon this limiting condition and is consistent with FSAR safety analysis assumptions. With $T$ avg less than $200^{\circ} \mathrm{F}$, the reactivity transients resulting from a postulated steam line break cooldown are minimal and a $1 \%$ delta $k / k$ SHUTDOWN MARGIN provides adequate protection.

\section{3/4.1.1.3 MODERATOR TEMPERATURE COEFFICIENT (MTC)}

The limitations on MTC are provided to ensure that the value of this coefficient remains within the limiting condition assumed in the FSAR accident and transient analyses.

The MTC values of this specification are applicable to a specific set of plant conditions; accordingly, verification of MTC values at conditions other than those explicitly stated will require extrapolation to those conditions in order to permit an accurate comparison.

The most negative MTC value equivalent to the most positive moderator density coefficient (MDC), was obtained by incrementally correcting the MDC used in the FSAR analyses to nominal operating conditions. These corrections 
3/4.1.1.3 MODERATOR TEMPERATURE COEFFICIENT (MTC) (Continued)

involved subtracting the incremental change in the MDC associated with a core condition of all rods inserted (most positive MDC) to an all rods withdrawn condition and, a conversion for the rate of change of moderator density with temperature at RATED THERMAL POWER conditions. This value of the MDC was then transformed into the limiting MTC value $(-3.9) \times 10^{-4} \mathrm{delta} k / \mathrm{k} /{ }^{\circ} \mathrm{F}$. The MTC value of $(-3.0) \times 10^{-4}$ delta $\mathrm{k} / \mathrm{k} /{ }^{\circ} \mathrm{F}$ represents a conservative value (with corrections for burnup and soluble boron) at a core condition of $300 \mathrm{ppm}$ equilibrium boron concentration and is obtained by making these corrections to the limiting MTC value of $(-3.9) \times 10^{-4} \mathrm{k} / \mathrm{k} /{ }^{\circ} \mathrm{F}$.

The surveillance requirements for measurement of the MTC at the beginning and near the end of the fuel cycle are adequate to confirm that the MTC remains within its limits since this coefficient changes slowly due principally to the reduction in RCS boron concentration associated with fuel burnup.

\section{3/4.1.1.4 MINIMUM TEMPERATURE FOR CRITICALITY}

This specification ensures that the reactor will not be made critical with the Reactor Coolant System average temperature less than $(541)^{\circ} \mathrm{F}$. This limitation is required to ensure 1) the moderator temperature coefficient is within it analyzed temperature range, 2) the protective instrumentation is within its normal operating range, 3) the $P-12$ interlock is above its setpoint, 4) the pressurizer is capable of being in a OPERABLE status with a steam bubble, and 5 ) the reactor pressure vessel is above its minimum RT ${ }_{\text {NDT }}$ temperature.

\section{3/4.1.2 BORATION SYSTEMS}

The boron injection system ensures that negative reactivity control is available during each mode of facility operation. The components required to perform this function include 1) borated water sources, 2) charging pumps, 3) separate flow paths, 4) boric acid transfer pumps, 5) associated heat tracing systems, and 6) an emergency power supply from OPERABLE diesel generators.

With the RCS average temperature above $200^{\circ} \mathrm{F}$, a minimum of two boron injection flow paths are required to ensure single functional capability in the event an assumed failure renders one of the flow paths inoperable. The boration capability of either flow path is sufficient to provide a SHUTDOWN 
REACTIVITY CONTROL SYSTEMS

BASES

MARGIN from expected operating conditions of $1.6 \%$ de 1 ta $k / k$ after xenon decay and cooldown to $200^{\circ} \mathrm{F}$. The maximum expected boration capability requirement occurs at EOL from full power equilibrium xenon conditions and requires (5106) gallons of $20,000 \mathrm{ppm}$ borated water from the boric acid storage tanks or $(52,622)$ gallons of $2000 \mathrm{ppm}$ borated water from the refueling water storage tank.

With the RCS temperature below $200^{\circ} \mathrm{F}$, one injection system is acceptable without single failure consideration on the basis of the stable reactivity condition of the reactor and the additional restrictions prohibiting CORE ALTERATIONS and positive reactivity changes in the event the single injection system becomes inoperable.

The limitation for a maximum of one centrifugal charging pump to be OPERABLE and the Surveillance Requirement to verify all charging pumps except the required OPERABLE pump to be inoperable below (275) ${ }^{\circ} \mathrm{F}$ provides assurance that a mass addition pressure transient can be relieved by the operation of a single PORV.

The boron capability required below $200^{\circ} \mathrm{F}$ is sufficient to provide a SHUTDOWN MARGIN of $1 \%$ delta $\mathrm{k} / \mathrm{k}$ after xenon decay and cooldown from $200^{\circ} \mathrm{F}$ to $140^{\circ} \mathrm{F}$. This condition requires either ( ) gallons of $20,000 \mathrm{ppm}$ borated water from the boric acid storage tanks or ( ) gallons of $2000 \mathrm{ppm}$ borated water from the refueling water storage tank.

The contained water volume limits include allowance for water not available because of discharge line location and other physical characteristics.

The limits on contained water volume and boron concentration of the RWST also ensure a pH value of between (8.5) and (11.0) for the solution recirculated within containment after a LOCA. This $\mathrm{pH}$ band minimizes the evolution of iodine and minimizes the effect of chloride and caustic stress corrosion on mechanical systems and components.

The OPERABILITY of boron injection system during REFUELING ensures that this system is available for reactivity control while in MODE 6.

\section{3/4.1.3 MOVABLE CONTROL ASSEMBLIES}

The specifications of this section ensure that (1) acceptable power distribution limits are maintained, (2) the minimum SHUTDOWN MARGIN is maintained, and (3) limit the potential effects of rod misalignment on associated accident analyses. OPERABILITY of the control rod position indicators is required to determine control rod positions and thereby ensure compliance with the control rod alignment and insertion limits. 
The ACTION statements which permit limited variations from the basic requirements are accompanied by additional restrictions which ensure that the original design criteria are met. Misalignment of a rod requires measurement of peaking factors or a restriction in THERMAL POWER; either of these restrictions provide assurance of fuel rod integrity during continued operation. In addition, those safety analyses affected by a misaligned rod are reevaluated to confirm that the results remain valid during future operation.

The maximum rod drop time restriction is consistent with the assumed rod drop time used in the safety analyses. Measurement with $T_{\text {avg }}$ greater than or equal to $(541)^{\circ} \mathrm{F}$ and with all reactor coolant pumps operating ensures that the measured drop times will be representative of insertion times experienced during a reactor trip at operating conditions.

Control rod positions and OPERABILITY of the rod position indicators are required to be verified on a nominal basis of once per 12 hours with more frequent verifications required if an automatic monitoring channel is inoperable. These verification frequencies are adequate for assuring that the applicable LCO's are satisfied.

\section{(ALTERNATE)}

The restriction prohibiting part length rod insertion ensures that adverse power shapes and rapid local power changes which may effect DNB considerations do not occur as a result of part length rod insertion during operation. 
The specifications of this section provide assurance of fuel integrity during Condition I (Normal Operation) and II (Incidents of Moderate Frequency) events by: (a) maintaining the minimum DNBR in the core greater than or equal to 1.30 during normal operation and in short term transients, and (b) limiting the fission gas release, fuel pellet temperature and cladding mechanical properties to within assumed design criteria. In addition, limiting the peak linear power density during Condition I events provides assurance that the initial conditions assumed for the LOCA analyses are met and the ECCS acceptance criteria limit of $2200^{\circ} \mathrm{F}$ is not exceeded.

The definitions of certain hot channel and peaking factors as used in these specifications are as follows:

$F_{Q}(Z)$ Heat Flux Hot Channe] Factor, is defined as the maximum local heat flux on the surface of a fuel rod at core elevation $Z$ divided by the average fuel rod heat flux, allowing for manufacturing tolerances on fuel pellets and rods.

$F_{\Delta H}^{N} \quad$ Nuclear Enthalpy Rise Hot Channel Factor, is defined as the ratio of the integral of linear power along the rod with the highest integrated power to the average rod power.

$F_{x y}(Z)$ Radial Peaking Factor, is defined as the ratio of peak power density to average power density in the horizontal plane at core elevation $Z$.

\section{3/4.2.1 AXIAL FLUX DIFFERENCE (AFD)}

The limits on AXIAL FLUX DIFFERENCE assure that the $F_{Q}(Z)$ upper bound envelope of 2.32 times the normalized axial peaking factor is not exceeded during either normal operation or in the event of xenon redistribution following power changes.

Target flux difference is determined at equilibrium xenon conditions with the part length control rods withdrawn from the core. The full length rods may be positioned within the core in accordance with their respective insertion limits and should be inserted near their normal position for steady state operation at high power levels. The value of the target flux difference obtained under these conditions divided by the fraction of RATED THERMAL POWER is the target flux difference at RATED THERMAL POWER for the associated core burnup conditions. Target flux differences for other THERMAL POWER levels are obtained by multiplying the RATED THERMAL POWER value by the appropriate fractional THERMAL POWER level. The periodic updating of the target flux difference value is necessary to reflect core burnup considerations. 
Although it is intended that the plant will be operated with the AXIAL FLUX DIFFERENCE within the $+(5) \%$ target band about the target flux difference, during rapid plant THERMAL POWER reductions, control rod motion will cause the AFD to deviate outside of the target band at reduced THERMAL POWER levels. This deviation will not affect the xenon redistribution sufficiently to change the envelope of peaking factors which may be reached on a subsequent return to RATED THERMAL POWER (with the AFD within the target band) provided the time duration of the deviation is limited. Accordingly, a 1 hour penalty deviation limit cumulative during the previous 24 hours is provided for operation outside of the target band but within the limits of Figure (3.2-1) while at THERMAL POWER leve1s between $50 \%$ and $90 \%$ of RATED THERMAL POWER. For THERMAL POWER levels between $15 \%$ and $50 \%$ of RATED THERMAL POWER, deviations of the AFD outside of the target band are less significant. The penalty of 2 hours actual time reflects this reduced significance.

Provisions for monitoring the AFD on an automatic basis are derived from the plant process computer through the AFD Monitor Alarm. The computer determines the one minute average of each of the OPERABLE excore detector outputs and provides an alarm message immediately if the AFD for at least 2 of 4 or 2 of 3 OPERABLE excore channels are outside the target band and the THERMAL POWER is greater than $90 \%$ of RATED THERMAL POWER. During operation at THERMAL POWER levels between $50 \%$ and $90 \%$ and between $15 \%$ and $50 \%$ RATED THERMAL POWER, the computer outputs an alarm message when the penalty deviation accumulates beyond the limits of 1 hour and 2 hours, respectively.

Figure B 3/4 2-1 shows a typical monthly target band.

\section{3/4.2.2 and 3/4.2.3 HEAT FLUX HOT CHANNEL FACTOR, RCS FLOWRATE AND} NUCLEAR ENTHALPY RISE HOT CHANNEL FACTOR

The limits on heat flux hot channel factor, RCS flowrate, and nuclear enthalpy rise hot channel factor ensure that 1) the design limits on peak local power density and minimum DNBR are not exceeded and 2) in the event of a LOCA the peak fuel clad temperature will not exceed the $2200^{\circ} \mathrm{F}$ ECCS acceptance criteria limit.

Each of these is measurable but will normally only be determined periodically as specified in Specifications 4.2.2 and 4.2.3. This periodic surveillance is sufficient to insure that the limits are maintained provided:

a. Control rods in a single group move together with no individual rod insertion differing by more than \pm 13 steps, indicated, from the group demand position.

b. Control rod groups are sequenced with overlapping groups as described in Specification 3.1.3.6. 
Percent of Rated

Thermal Power $5 \% \quad 5 \%$

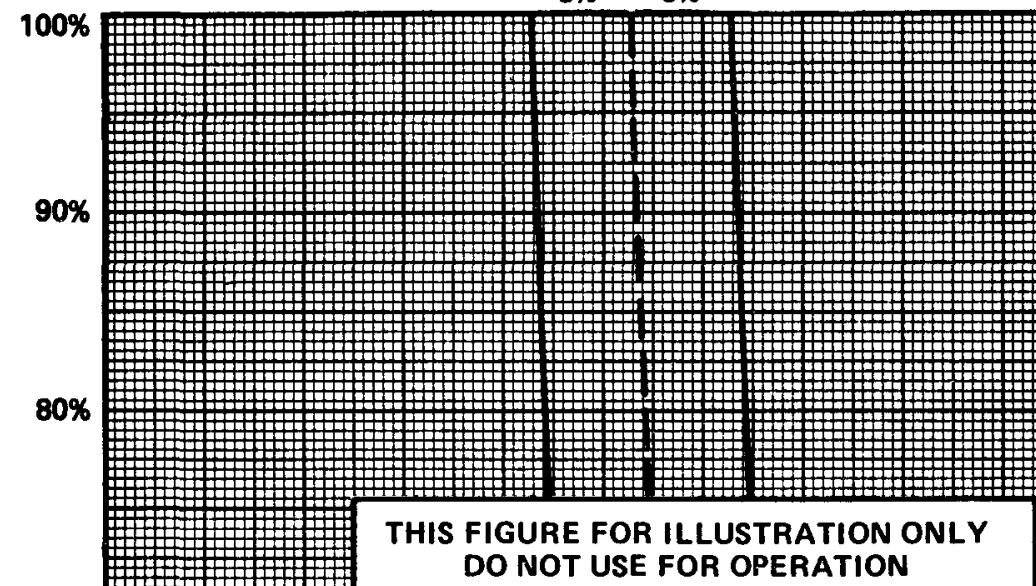

$70 \%$ 鹿

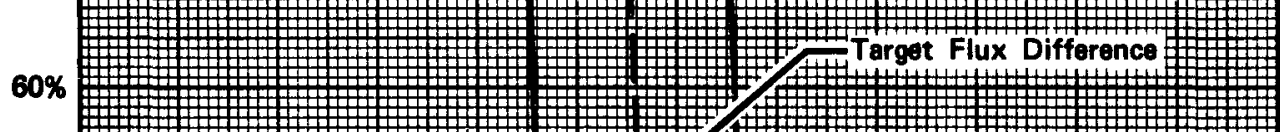
约

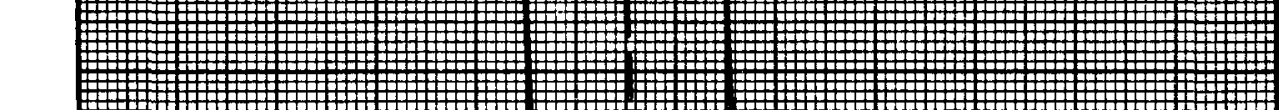

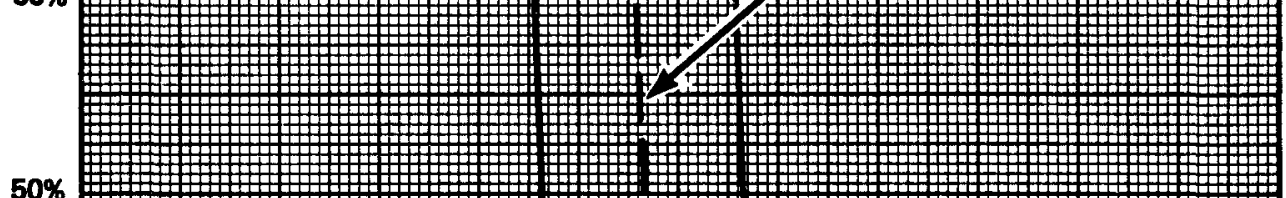

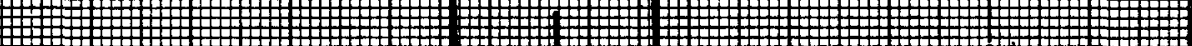

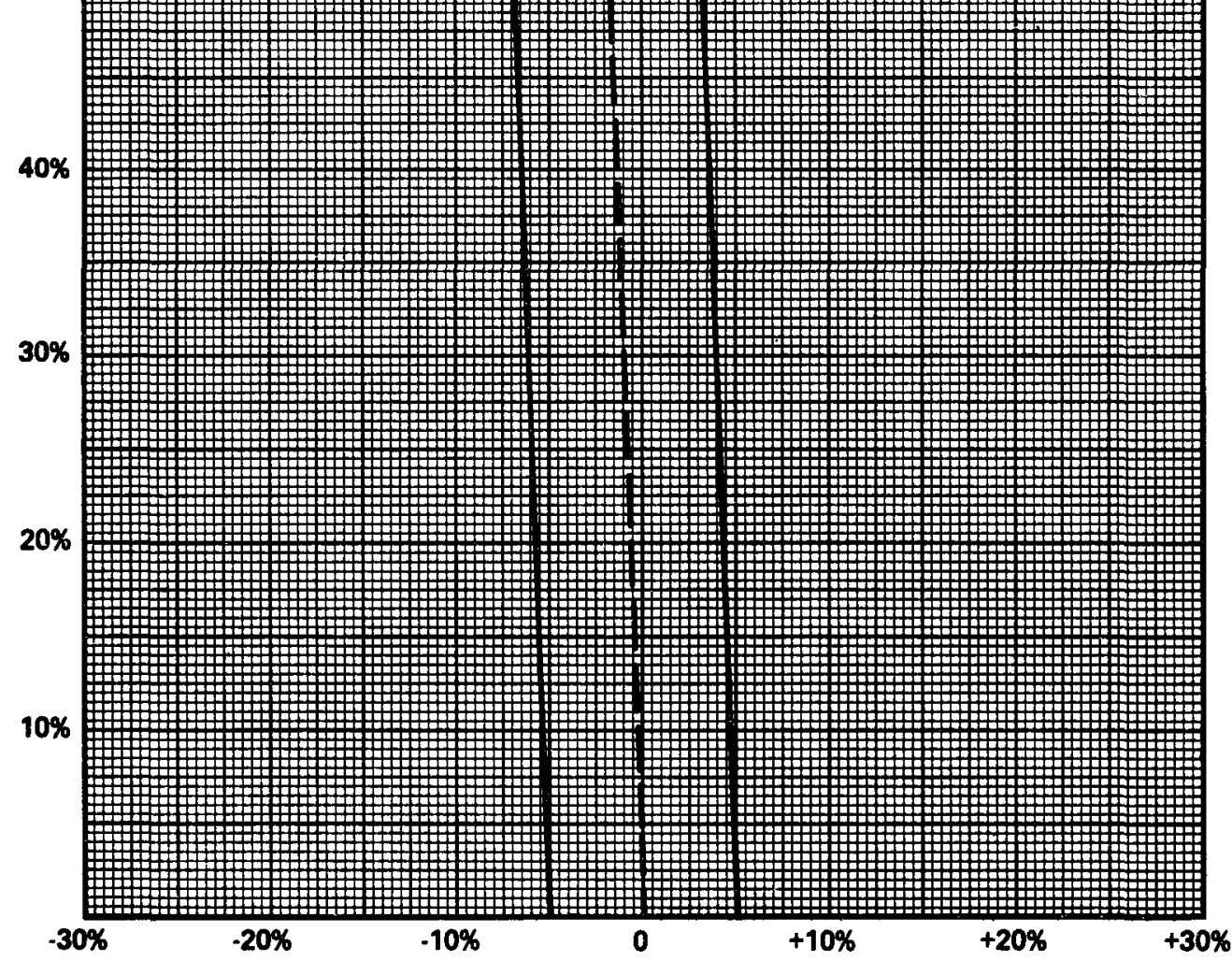

INDICATED AXIAL FLUX DIFFERENCE

Figure B 3/4 2-1 TYPICAL INDICATED AXIAL FLUX DIFFERENCE VERSUS THERMAL POWER 
c. The control rod insertion limits of Specifications 3.1.3.5 and 3.1.3.6 are maintained.

d. The axial power distribution, expressed in terms of AXIAL FLUX DIFFERENCE, is maintained within the limits.

$F_{\Delta H}^{N}$ wi il be maintained within its limits provided conditions a. through d. above are maintained. As noted on Figures 3.2-3 and 3.2-4, RCS flow rate and $F_{\Delta H}^{N}$ may be "traded off" against one another (i.e., a low measured RCS flow rate is acceptable if the measured $F_{\Delta H}^{N}$ is also low) to ensure that the calculated DNBR will not be below the design DNBR value. The relaxation of $F_{\Delta H}^{N}$ as a function of THERMAL POWER allows changes in the radial power shape for all permissible rod insertion limits.

When an $F_{Q}$ measurement is taken, an allowance for both experimental error and manufacturing tolerance must be made. An allowance of $5 \%$ is appropriate for a full core map taken with the incore detector flux mapping system and a 3\% allowance is appropriate for manufacturing tolerance.

When RCS flow rate and $F_{\Delta H}^{N}$ are measured, no additional allowances are necessary prior to comparison with the limits of Figures 3.2-3 and 3.2-4. Measurement errors of $3.5 \%$ for RCS total flow rate and $4 \%$ for $F_{\Delta H}^{N}$ have been allowed for in determination of the design DNBR value.

The 12 hour periodic surveillance of indicated RCS flow is sufficient to detect only flow degradation which could lead to operation outside the acceptable region of operation shown on Figure 3.2-3. 


\section{3/4.2.4 QUADRANT POWER TILT RATIO}

The quadrant power tilt ratio limit assures that the radial power distribution satisfies the design values used in the power capability analysis. Radial power distribution measurements are made during startup testing and periodically during power operation.

The limit of 1.02 , at which corrective action is required, provides DNB and linear heat generation rate protection with $x-y$ plane power tilts.

The two hour time allowance for operation with a tilt condition greater than 1.02 but. less than 1.09 is provided to allow identification and correction of a dropped or misaligned control rod. In the event such action does not correct the tilt, the margin for uncertainty on $F_{Q}$ is reinstated by reducing the maximum allowed power by 3 percent for each percent of tilt in excess of 1.0 .

\section{3/4.2.5 DNB PARAMETERS}

The limits on the DNB related parameters assure that each of the parameters are maintained within the normal steady state envelope of operation assumed in the transient and accident analyses. The limits are consistent with the initial FSAR assumptions and have been analytically demonstrated adequate to maintain a minimum DNBR of 1.30 throughout each analyzed transient.

The 12 hour periodic surveillance of these parameters through instrument readout is sufficient to ensure that the parameters are restored within their limits following load changes and other expected transient operation. 
-

-

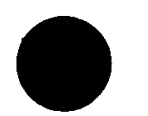




\section{$3 / 4.3$ INSTRUMENTATION}

BASES

3/4.3.1 and 3/4.3.2 REACTR TRIP AND ENGINEERED SAFETY FEATURE (ESF) SYSTEMS INSTRUMENTATION

The OPERABILITY of the reactor trip and ESF systems instrumentation and interlocks ensure that 1) the associated ESF action and/or reactor trip will be initiated when the parameter monitored by each channel or combination thereof reaches its setpoint, 2) the specified coincidence logic is maintained, 3) sufficient redundancy is maintained to permit a channel to be out of service for testing or maintenance, and 4) sufficient system functional capability is available for protective and ESF purposes from diverse parameters.

The OPERABILITY of these systems is required to provide the overall reliability, redundancy and diversity assumed available in the facility design for the protection and mitigation of accident and transient conditions. The integrated operation of each of these systems is consistent with the assumptions used in the accident analyses.

The Engineered Safety Features System interlocks perform the functions indicated below on increasing the required parameter, consistent with the setpoints listed in Table 3.3-4:

P-11 Defeats the manual block of safety injection actuation on low pressurizer pressure.

P-12 Defeats the manual block of safety injection actuation on high steam line flow and low steam line pressure.

P-14 Trip of all feedwater pumps, turbine trip, closure of feedwater isolation valves and inhibits feedwater control valve modulation.

On decreasing the required parameter the opposite function is performed at reset setpoints, with the exception of $\mathrm{P}-12$ as noted below:

P-12 Allows manual block of safety injection actuation on high steam line flow and low steam line pressure. Causes steam line isolation on high steam flow. Affects steam dump blocks (i.e., prevents premature block of the noted function).

The surveillance requirements specified for these systems ensure that the overall system functional capability is maintained comparable to the original design standards. The periodic surveillance tests performed at the minimum frequencies are sufficient to demonstrate this capability. 
The measurement of response time at the specified frequencies provides assurance that the protective and ESF action function associated with each channel is completed within the time limit assumed in the accident analyses. No credit was taken in the analyses for those channels with response times indicated as not applicable.

Response time may be demonstrated by any series of sequential, overlapping or total channel test measurements provided that such tests demonstrate the total channel response time as defined. Sensor response time verification may be demonstrated by either 1) in place, onsite or offsite test measurements or 2) utilizing replacement sensors with certified response times.

\section{3/4.3.3 MONITORING INSTRUMENTATION}

\section{3/4.3.3.1 RADIATION MONITORING INSTRUMENTATION}

The OPERABILITY of the radiation monitoring channels ensures that 1) the radiation levels are continually measured in the areas served by the individual channels and 2) the alarm or automatic action is initiated when the radiation level trip setpoint is exceeded.

\section{3/4.3.3.2 MOVABLE INCORE DETECTORS}

The OPERABILITY of the movable incore detectors with the specified minimum complement of equipment ensures that the measurements obtained from use of this system accurately represent the spatial neutron flux distribution of the reactor core. The OPERABILITY of this system is demonstrated by irradiating each detector used and determining the acceptability of its voltage curve.

For the purpose of measuring $F_{Q}(Z)$ or $F_{\Delta H}^{N}$ a full incore flux map is used. Quarter-core flux maps, as defined in WCAP-8648, June 1976, may be used in recalibration of the excore neutron flux detection system, and full incore flux maps or symmetric incore thimbles may be used for monitoring the QUADRANT POWER TILT RATIO when one Power Range Channel is inoperable. 
INSTRUMENTATION

BASES

\section{3/4.3.3.3 SEISMIC INSTRUMENTATION}

The OPERABILITY of the seismic instrumentation ensures that sufficient capability is available to promptly determine the magnitude of a seismic event and evaluate the response of those features important to safety. This capability is required to permit comparison of the measured response to that used in the design basis for the facility to determine if plant shutdown is required pursuant to Appendix " $A$ " of 10 CFR Part 100. The instrumentation is consistent with the recommendations of Regulatory Guide 1.12, "Instrumentation for Earthquakes," April 1974.

\section{3/4.3.3.4 METEOROLOGICAL INSTRUMENTATION}

The OPERABILITY of the meteorological instrumentation ensures that sufficient meteorological data is available for estimating potential radiation doses to the public as a result of routine or accidental release of radioactive materials to the atmosphere. This capability is required to evaluate the need for initiating protective measures to protect the health and safety of the public and is consistent with the recommendations of Regulatory Guide 1.23, "Onsite Meteorological Programs," February 1972.

\section{3/4.3.3.5 REMOTE SHUTDOWN INSTRUMENTATION}

The OPERABILITY of the remote shutdown instrumentation ensures that sufficient capability is available to permit shutdown and maintenance of HOT STANDBY of the facility from locations outside of the control room. This capability is required in the event control room habitability is lost and is consistent with General Design Criteria 19 of 10 CFR 50.

\section{3/4.3.3.6 POST-ACCIDENT INSTRUMENTATION}

The OPERABILITY of the post-accident instrumentation ensures that sufficient information is available on selected plant parameters to monitor and assess these variables following an accident. This capability is consistent with the recommendations of Regulatory Guide 1.97, "Instrumentation for Light-Water-Cooled Nuclear Power Plants to Assess Plant Conditions During and Following an Accident," December 1975. 


\section{3/4.3.3.7 CHLORINE DETECTION SYSTEMS}

The OPERABILITY of the chlorine detection system ensures that sufficient capability is available to promptly detect and initiate protective action in the event of an accidental chlorine release. This capability is required to protect control room personnel and is consistent with the recommendations of Regulatory Guide 1.95, "Protection of Nuclear Power Plant Control Room Operators Against an Accidental Chlorine Release," February 1975.

\section{3/4.3.3.8 FIRE DETECTION INSTRUMENTATION}

OPERABILITY of the fire detection instrumentation ensures that adequate warning capability is available for the prompt detection of fires. This capability is required in order to detect and locate fires in their early stages. Prompt detection of fires will reduce the potential for damage to safety related equipment and is an integral element in the overall facility fire protection program.

In the event that a portion of the fire detection instrumentation is inoperable, the establishment of frequent fire patrols in the affected areas is required to provide detection capability until the inoperable instrumentation is restored to OPERABILITY.

\section{3/4.3.4 TURBINE OVERSPEED PROTECTION}

This specification is provided to ensure that the turbine overspeed protection instrumentation and the turbine speed control valves are OPERABLE and will protect the turbine from excessive overspeed. Protection from turbine excessive overspeed is required since excessive overspeed of the turbine could generate potentially damaging missiles which could impact and damage safety related components, equipment or structures. 
$3 / 4.4$ REACTOR COOLANT SYSTEM

BASES

\section{3/4.4.1 REACTOR COOLANT LOOPS}

The plant is designed to operate with all reactor coolant loops in operation, and maintain DNBR above 1.30 during all normal operations and anticipated transients. With one reactor coolant loop not in operation, THERMAL POWER is restricted to less than (31) percent of RATED THERMAL POWER until the Overtemperature delta $T$ trip is reset. Either action ensures that the DNBR will be maintained above 1.30. A loss of flow in two loops will cause a reactor trip if operating above P-7 (11 percent of RATED THERMAL POWER) while a loss of flow in one loop will cause a reactor trip if operating above P-8 (31 percent of RATED THERMAL POWER).

A single reactor coolant loop provides sufficient heat removal capability for removing core decay heat while in HOT STANDBY; however, single failure considerations require placing a RHR loop into operation in the shutdown cooling mode if component repairs and/or corrective actions cannot be made within the allowable out-of-service time.

The operation of one Reactor Coolant Pump or one RHR pump provides adequate flow to ensure mixing, prevent stratification and produce gradual reactivity changes during boron concentration reductions in the Reactor Coolant System. The reactivity change rate associated with boron reduction will, therefore, be within the capability of operator recognition and control.

The restrictions on starting a Reactor Coolant Pump below P-7 with one or more RCS cold legs less than or equal to $(275)^{\circ} \mathrm{F}$ are provided to prevent RCS pressure transients, caused by energy additions from the secondary system, which could exceed the limits of Appendix G to 10 CFR Part 50. The RCS will be protected against overpressure transients and will not exceed the limits of Appendix $G$ by either (1) restricting the water volume in the pressurizer and thereby providing a volume for the primary coolant to expand into or (2) by restricting starting from the RCPS to when the secondary water temperature of each steam generator is less than ()$^{\circ} \mathrm{F}$ above each of the RCS cold leg temperatures.

\section{(OPTIONAL)}

The requirement to maintain the boron concentration of an isolated loop greater than or equal to the boron concentration of the operating loops ensures that no reactivity addition to the core could occur during startup of an isolated loop. Verification of the boron concentration in an idle loop prior to opening the stop valves provides a reassurance of the adequacy of the boron concentration in the isolated loop. Operating the isolated loop on recirculating flow for at least 90 minutes prior to opening its stop valves ensures adequate mixing of the coolant in this loop and prevents any reactivity effects due to boron concentration stratifications. 


\section{(OPTIONAL)}

Startup of an idle loop will inject cool water from the loop into the core. The reactivity transient resulting from this cool water injection is minimized by delaying isolated loop startup until its temperature is within $20^{\circ} \mathrm{F}$ of the operating loops. Making the reactor subcritical prior to loop startup prevents any power spike which could result from this cool water induced reactivity transient.

\section{$3 / 4.4 .2$ and $3 / 4.4 .3$ SAFETY VALVES}

The pressurizer code safety valves operate to prevent the RCS from being pressurized above its Safety Limit of 2735 psig. Each safety valve is designed to relieve lbs per hour of saturated steam at the valve set point. The relief capacity of a single safety valve is adequate to relieve any overpressure condition which could occur during shutdown. In the event that no safety valves are OPERABLE, an operating RHR loop, connected to the RCS, provides overpressure relief capability and will prevent RCS overpressurization. In addition, the Overpressure Protection System provides a diverse means of protection against RCS overpressurization at low temperatures.

During operation, all pressurizer code safety valves must be OPERABLE to prevent the RCS from being pressurized above its safety limit of 2735 psig. The combined relief capacity of all of these valves is greater than the maximum surge rate resulting from a complete loss of load assuming no reactor trip until the first Reactor Protective System trip set point is reached (i.e., no credit is taken for a direct reactor trip on the loss of load) and also assuming no operation of the power operated relief valves or steam dump valves.

Demonstration of the safety valves' 1 ift settings will occur only during shutdown and will be performed in accordance with the provisions of Section XI of the ASME Boiler and Pressure Code.

\section{3/4.4.4 PRESSURIZER}

The limit on the maximum water volume in the pressurizer assures that the parameter is maintained within the normal steady state envelope of operation assumed in the SAR. The limit is consistent with the initial SAR assumptions. The 12 hour periodic surveillance is sufficient to ensure that the parameter is restored to within its limit following expected transient operation. The maximum water volume also ensures that a steam bubble is formed and thus the RCS is not a hydraulically solid system. 
The power operated relief valves and steam bubble function to relieve RCS pressure during all design transients up to and including the design step load decrease with steam dump. Operation of the power operated relief valves minimizes the undesirable opening of the spring-loaded pressurizer code safety valves.

\section{$3 / 4.4 .5$ STEAM GENERATORS}

The Surveillance Requirements for inspection of the steam generator tubes ensure that the structural integrity of this portion of the RCS will be maintained. The program for inservice inspection of steam generator tubes is based on a modification of Regulatory Guide 1.83, Revision 1. Inservice inspection of steam generator tubing is essential in order to maintain surveillance of the conditions of the tubes in the event that there is evidence of mechanical damage or progressive degradation due to design, manufacturing errors, or inservice conditions that lead to corrosion. Inservice inspection of steam generator tubing also provides a means of characterizing the nature and cause of any tube degradation so that corrective measures can be taken.

The plant is expected to be operated in a manner such that the secondary coolant will be maintained within those chemistry limits found to result in negligible corrosion of the steam generator tubes. If the secondary coolant chemistry is not maintained within these limits, localized corrosion may likely result in stress corrosion cracking. The extent of cracking during plant operation would be limited by the limitation of steam generator tube leakage between the primary coolant system and the secondary coolant system (primary-to-secondary leakage $=500$ gallons per day per steam generator). Cracks having a primary-to-secondary leakage less than this limit during operation will have an adequate margin of safety to withstand the loads imposed during normal operation and by postulated accidents. Operating plants have demonstrated that primary-to-secondary leakage of 500 gallons per day per steam generator can readily be detected by radiation monitors of steam generator blowdown. Leakage in excess of this limit will require plant shutdown and an unscheduled inspection, during which the leaking tubes will be located and plugged.

Wastage-type defects are unlikely with proper chemistry treatment of the secondary coolant. However, even if a defect should develop in service, it will be found during scheduled inservice steam generator tube examinations. Plugging will be required for all tubes with imperfections exceeding the plugging limit of (40)\% of the tube nominal wall thickness. Steam generator tube inspections of operating plants have demonstrated the capability to reliably detect degradation that has penetrated $20 \%$ of the original tube wall thickness. 
Whenever the results of any steam generator tubing inservice inspection fall into Category $\mathrm{C}-3$, these results will be promptly reported to the Commission pursuant to Specification 6.9.1 prior to resumption of plant operation. Such cases will be considered by the Commission on a case-by-case basis and may result in a requirement for analysis, laboratory examinations, tests, additional eddy-current inspection, and revision of the Technical Specifications, if necessary.

\section{3/4.4.6 REACTOR COOLANT SYSTEM LEAKAGE}

\section{3/4.4.6.1 LEAKAGE DETECTION SYSTEMS}

The RCS leakage detection systems required by this specification are provided to monitor and detect leakage from the Reactor Coolant Pressure Boundary. These detection systems are consistent with the recommendations of Regulatory Guide 1.45, "Reactor Coolant Pressure Boundary Leakage Detection Systems," May 1973.

\section{3/4.4.6.2 OPERATIONAL LEAKAGE}

Industry experience has shown that while a limited amount of leakage is expected from the RCS, the unidentified portion of this leakage can be reduced to a threshold value of less than $1 \mathrm{GPM}$. This threshold value is sufficiently low to ensure early detection of additional leakage.

The 10 GPM IDENTIFIED LEAKAGE limitation provides allowance for a limited amount of leakage from known sources whose presence will not interfere with the detection of UNIDENTIFIED LEAKAGE by the leakage detection systems.

The CONTROLLED LEAKAGE limitation restricts operation when the total flow supplied to the reactor coolant pump seals exceeds ( ) GPM with the modulating valve in the supply line fully open at a nominal RCS pressure of 2235 psig. This limitation ensures that in the event of a LOCA, the safety injection flow will not be less than assumed in the accident analyses.

The total steam generator tube leakage 1 imit of 1 GPM for all steam generators not isolated from the RCS ensures that the dosage contribution from the tube leakage will be limited to a small fraction of Part 100 limits in the event of either a steam generator tube rupture or steam line break. The 1 GPM limit is consistent with the assumptions used in the analysis of these accidents. The $500 \mathrm{gpd}$ leakage limit per steam generator ensures that steam generator tube integrity is maintained in the event of a main steam line rupture or under LOCA conditions. 
REACTOR COOLANT SYSTEM

BASES

PRESSURE BOUNDARY LEAKAGE of any magnitude is unacceptable since it may be indicative of an impending gross failure of the pressure boundary. Therefore, the presence of any PRESSURE BOUNDARY LEAKAGE requires the unit to be promptly placed in COLD SHUTDOWN.

\section{3/4.4.7 CHEMISTRY}

The limitations on Reactor Coolant System chemistry ensure that corrosion of the Reactor Coolant System is minimized and reduces the potential for Reactor Coolant System leakage or failure due to stress corrosion. Maintaining the chemistry within the Steady State Limits provides adequate corrosion protection to ensure the structural integrity of the Reactor Coolant System over the life of the plant. The associated effects of exceeding the oxygen, chloride and fluoride limits are time and temperature dependent. Corrosion studies show that operation may be continued with contaminant concentration levels in excess of the Steady State Limits, up to the Transient Limits, for the specified limited time intervals without having a significant effect on the structural integrity of the Reactor Coolant System. The time interval permitting continued operation within the restrictions of the Transient Limits provides time for taking corrective actions to restore the contaminant concentrations to within the Steady State Limits.

The survejllance requirements provide adequate assurance that concentrations in excess of the limits will be detected in sufficient time to take corrective action.

\section{3/4.4.8 SPECIFIC ACTIVITY}

The limitations on the specific activity of the primary coolant ensure that the resulting 2 hour doses at the site boundary will not exceed an appropriately small fraction of Part 100 limits following a steam generator tube rupture accident in conjunction with an assumed steady state primary-tosecondary steam generator leakage rate of $1.0 \mathrm{GPM}$. The values for the limits on specific activity represent limits based upon a parametric evaluation by the NRC of typical site locations. These values are conservative in that specific site parameters of the () site, such as site boundary location and meteorological conditions, were not considered in this evaluation. 
The ACTION statement permitting POWER OPERATION to continue for limited time periods with the primary coolant's specific activity greater than 1.0 microcuries/gram DOSE EQUIVALENT I-131, but within the allowable 1imit shown on Figure 3.4-1, accommodates possible iodine spiking phenomenon which may occur following changes in THERMAL POWER. Operation with specific activity levels exceeding 1.0 microcuries/gram DOSE EQUIVALENT I-131 but within the limits shown on Figure 3.4-1 must be restricted to no more than 800 hours per year (approximately 10 percent of the unit's yearly operating time) since the activity levels allowed by Figure 3.4-1 increase the 2 hour thyroid dose at the site boundary by a factor of up to 20 following a postulated steam generator tube rupture. The reporting of cumulative operating time over 500 hours in any 6 month consecutive period with greater than $1.0 \mathrm{microcuries} / \mathrm{gram}$ DOSE EQUIVALENT I-131 will allow sufficient time for Commission evaluation of the circumstances prior to reaching the 800 hour limit.

Reducing $\mathrm{T}_{\mathrm{avg}}$ to less than $500^{\circ} \mathrm{F}$ prevents the release of activity should a steam generator tube rupture since the saturation pressure of the primary coolant is below the lift pressure of the atmospheric steam relief valves.

The surveillance requirements provide adequate assurance that excessive specific activity levels in the primary coolant will be detected in sufficient time to take corrective action. Information obtained on iodine spiking will be used to assess the parameters associated with spiking phenomena. A reduction in frequency of isotopic analyses following power changes may be permissible if justified by the data obtained.

\section{3/4.4.9 PRESSURE/TEMPERATURE LIMITS}

The temperature and pressure changes during heatup and cooldown are limited to be consistent with the requirements given in the ASME Boiler and Pressure Vessel Code, Section III, Appendix G.

1) The reactor coolant temperature and pressure and system heatup and cooldown rates (with the exception of the pressurizer) shall be 1 imited in accordance with Figures 3.4-2 and 3.4-3 for the first full-power service period.

a) Allowable combinations of pressure and temperature for specific temperature change rates are below and to the right of the limit lines shown. Limit lines for cooldown rates between those presented may be obtained by interpolation. 
b) Figures 3.4-2 and 3.4-3 define limits to assure prevention of nonductile failure only. For normal operation, other inherent plant characteristics, e.g., pump heat addition and pressurizer heater capacity, may limit the heatup and cooldown rates that can be achieved over certain pressure-temperature ranges.

2) These limit lines shall be calculated periodically using methods provided below.

3) The secondary side of the steam generator must not be pressurized above 200 psig if the temperature of the vessel is below $70^{\circ} \mathrm{F}$.

4) The pressurizer heatup and cooldown rates shall not exceed $100^{\circ} \mathrm{F} / \mathrm{hr}$ and $200^{\circ} / \mathrm{hr}$ respectively. The spray shall not be used if the temperature difference between the pressurizer and the spray fluid is greater than $320^{\circ} \mathrm{F}$.

5) System preservice hydrotests and in-service leak and hydrotests shall be performed at pressures in accordance with the requirements of ASME Boiler and Pressure Vessel Code, Section XI.

The fracture toughness properties of the ferritic materials in the reactor vessel are determined in accordance with the 1976 Summer Addenda to Section III of the ASME Boiler and Pressure Vessel Code, and ASTM E185-73, and in accordance with additional reactor vessel requirements. These properties are then evaluated in accordance with Appendix G of the 1976 Summer Addenda to Section III of the ASME Boiler and Pressure Vesse 1 Code and the calculation methods described in WCAP-7924-A, "Bas is for Heatup and Cooldown Limit Curves, April 1975."

Heatup and cooldown limit curves are calculated using the most limiting value of the nil-ductility reference temperature, RT ${ }_{N D T}$, at the end of (12) effective full power years of service life. The (12) EFPY service 1ife period is chosen such that the limiting RT ${ }_{\text {NDT }}$ at the 1/4T location in the core region is greater than the RT ${ }_{\text {NDT }}$ of the limiting unirradiated material. The selection of such a limiting RT $_{\text {NDT }}$ assures that all components in the Reactor Coolant System will be operated conservatively in accordance with applicable Code requirements. 
The reactor vessel materials have been tested to determine their initial $\mathrm{RT}_{\text {NDT; }}$ the results of these tests are shown in Table B 3/4.4-1. Reactor operation and resultant fast neutron (E greater than 1 MEV) irradiation can cause an increase in the $\mathrm{RT}_{\mathrm{NDT}}$. Therefore, an adjusted reference temperature, based upon the fluence and copper content of the material in question, can be predicted using Figures $B$ 3/4.4-1 and $B$ 3/4.4-2. The heatup and cooldown limit curves of Figures 3.4-2 and 3.4-3 include predicted adjustments for this shift in RT ${ }_{\text {NDT }}$ at the end of (12) EFPY, as well as adjustments for possible errors in the pressure and temperature sensing instruments.

Values of $\triangle R T_{N D T}$ determined in this manner may be used until the results from the material surveillance program, evaluated according to ASTM E185, are available. The first capsule will be removed at the end of the first core cycle. Successive capsules will be removed in accordance with the requirements of ASTM E185-73 and 10 CFR 50, Appendix H. The heatup and cooldown curves must be recalculated when the $\triangle R T_{\text {NDT }}$ determined from the surveillance capsule exceeds the calculated $\Delta R T_{\text {NDT }}$ for the equivalent capsule radiation exposure.

Allowable pressure -temperature relationships for various heatup and cooldown rates are calculated using methods derived from Appendix $G$ in Section III of the ASME Boiler and Pressure Vessel Code as required by Appendix $G$ to 10 CFR Part 50 and these methods are discussed in detail in WCAP-7924-A.

The general method for calculating heatup and cooldown limit curves is based upon the principles of the linear elastic fracture mechanics (LEFM) technology. In the calculation procedures a semi-elliptical surface defect with a depth of one-quarter of the wall thickness, $T$, and a length of $3 / 2 T$ is assumed to exist at the inside of the vessel wall as well as at the outside of the vessel wall. The dimenstions of this postulated crack, referred to in Appendix G of ASME III as the reference flaw, amply 
TABLE B 3/4.4-1

REACTOR VESSEL TOUGHNESS

\begin{tabular}{|c|c|c|c|c|c|c|c|c|}
\hline & COMP & MATERIAL & CU & $P$ & NDTT & $\begin{array}{l}50 \mathrm{FT}-\mathrm{LB} / 35 \\
\text { MIL TEMP F }\end{array}$ & ${ }^{R T}{ }_{N D T}$ & $\begin{array}{c}\text { MIN. UPPER SHELF } \\
\text { FT-LB }\end{array}$ \\
\hline COMPONENT & CODE & TYPE & $\underline{\%}$ & $\underline{\%}$ & $\mathrm{~F}$ & LONG IRANS & $\mathrm{F}$ & $\underline{L O \overline{N G}}$ \\
\hline
\end{tabular}

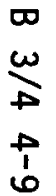

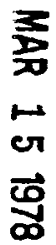




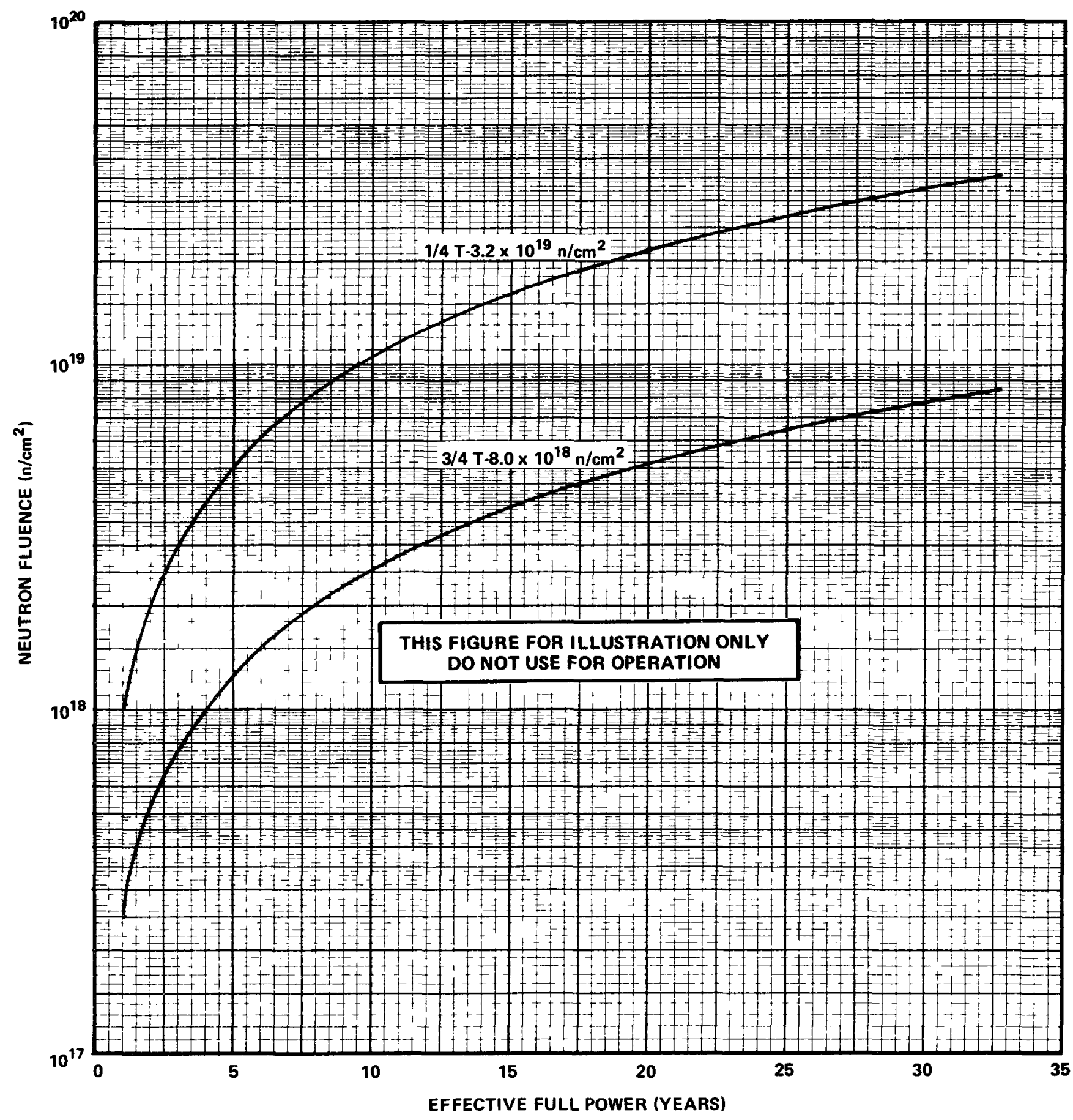

FIGURE B 3/4 4.1 FAST NEUTRON FLUENCE (E>1mev) AS A FUNCTION OF FULL POWER SERVICE LIFE 


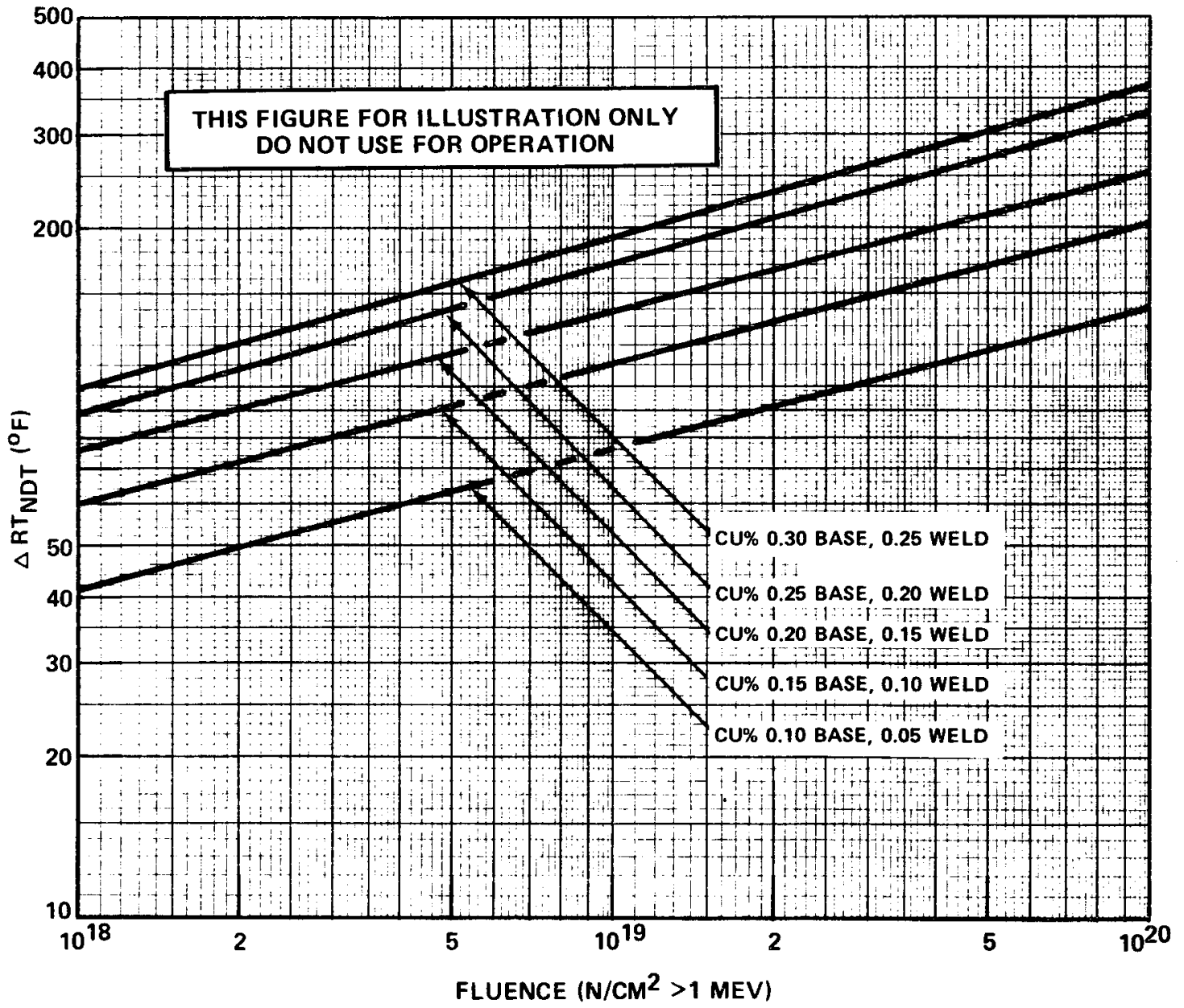

Figure B 3/4.4-2

Effect of Fluence and Copper Content on Shift of RT NDT for Reactor Vessels Exposed to $550^{\circ} \mathrm{F}$ Temperature 
exceed the current capabilities of inservice inspection techniques.

Therefore, the reactor operation limit curves developed for this reference crack are conservative and provide sufficient safety margins for protection against non-ductile failure. To assure that the radiation embrittlement effects are accounted for in the calculation of the limit curves, the most limiting value of the nil ductility reference temperature, $R_{N D T}$, is used and this includes the radiation induced shift, $\triangle R T_{N D T}$, corresponding to the end of the period for which heatup and cooldown curves are generated.

The ASME approach for calculating the allowable limit curves for various heatup and cooldown rates specifies that the total stress intensity factor, $K_{I}$, for the combined thermal and pressure stresses at any time during heatup or cooldown cannot be greater than the reference stress intensity factor, $K_{I R}$, for the metal temperature at that time. $K_{I R}$ is obtained from the reference fracture toughness curve, defined in Appendix $G$ to the ASME Code. The KIR curve is given by the equation:

$$
\mathrm{K}_{\mathrm{IR}}=26.78+1.223 \exp \left[0.0145\left(\mathrm{~T}-\mathrm{RT} \mathrm{NDT}_{\mathrm{N}}+160\right)\right]
$$

where $K_{I R}$ is the reference stress intensity factor as a function of the metal temperature $T$ and the metal nil ductility reference temperature ${ }^{R T}{ }_{N D T}$. Thus, the governing equation for the heatup-cooldown analysis is:

$C \mathrm{~K}_{I M}+\mathrm{K}_{\mathrm{It}} \leq \mathrm{K}_{\mathrm{IR}}$

Where, $K_{I M}$ is the stress intensity factor caused by membrane (pressure) stress.

$\mathrm{K}_{\text {It }}$ is the stress intensity factor caused by the thermal gradients. 
$K_{I R}$ is provided by the code as a function of temperature relative to the RT $T_{N D T}$ of the material.

$C=2.0$ for normal and upset conditions per Appendix $G$ of the ASME Code, and

$C=1.5$ for test conditions during which the reactor core is not critical.

At any time during the heautp or cooldown transient, $K_{I R}$ is determined by the metal temperature at the tip of the postulated flaw, the approprivate value for $\mathrm{RT}_{\mathrm{NDT}}$, and the reference fracture toughness curve. The thermal stresses resulting from temperature gradients through the vessel wall are calculated and then the corresponding (thermal) stress intensity factors, $\mathrm{K}_{I T}$, for the reference flaw are computed. From Equation (2) the pressure stress intensity factors are obtained and from these the allowabel pressures are calculated.

\section{COOLDOWN}

For the calculation of the allowable pressure versus coolant temperature during cooldown, the Code reference flaw is assumed to exist at the inside of the vessel wall. During cooldown, the controlling location of the flaw is always at the inside of the wall because the thermal gradients produce tensile stresses at the inside, which increase with increasing cooldown rates. Allowable pressure-temperature relations are generated for both steady-state and finite cooldown rate situations. From these relations composite limit curves are constructed for each cooldown rate of interest.

The use of the composite curve in the cooldown analysis is necessary because control of the cooldown procedure is based on measurement of reactor coolant temperature, whereas the limiting pressure is actually dependent on the material temperature at the tip of the assumed flaw. During cooldown, the 1/4T vesse 1 location is at a higher temperature than the fluid adjacent to the vesse 1 ID. This condition, of course, is not true for the steady-state situation. It follows that at any given reactor coolant temperature, the delta $T$ developed 
REACTOR COOLANT SYSTEM

BASES

during cooldown results in a higher value of $K_{I R}$ at the 1/4T location for finite cooldown rates than for steady-state operation. Furthermore, if conditions exist such that the increase in $K_{I R}$ exceeds $K_{I t}$, the calculated allowable pressure during cooldown will be greater than the steady-state value.

The above procedures are needed because there is no direct control on temperature at the 1/4T location; therefore, allowable pressures may unknowingly be violated if the rate of cooling is decreased at various intervals along a cooldown ramp. The use of the composite curve eliminates this problem and assures conservative operation of the system for the entire cooldown period.

HEATUP

Three separate calculations are required to determine the limit curves for finite heatup rates. As is done in the cooldown analysis, allowable pressure-temperature relationships are developed for steady-state conditions as well as finite heatup rate conditions assuming the presence of a 1/4T defect at the inside of the vessel wall. The thermal gradients during heatup produce compressive stresses at the inside of the wall that alleviate the tensile stresses produced by internal pressure. The metal temperature at the crack tip lags the coolant temperature; therefore, the $K_{I R}$ for the $1 / 4 T$ crack during heatup is lower than the $K_{I R}$ for the $1 / 4 \mathrm{~T}$ crack during steady-state conditions at the same coolant temperature. During heatup, especially at the end of the transient, conditions may exist such that the effects of compressive thermal stresses and different $K_{I R}$ 's for steady-state and finite heatup rates do not offset each other and the pressure-temperature curve based on steady-state conditions no longer represents a lower bound of al1 similar curves for finite heatup rates when the 1/4T flaw is considered. Therefore, both cases have to be analyzed in order to assure that at any coolant temperature the lower value of the allowable pressure calculated for steady-state and finite heatup rates is obtained. 
REACTOR COOLANT SYSTEM

The second portion of the heatup analysis concerns the calculation of pressure-temperature limitations for the case in which a 1/4T deep outside surface flaw is assumed. Unlike the situation at the vessel inside surface, the thermal gradients established at the outside surface during heatup produce stresses which are tensile in nature and thus tend to reinforce any pressure stresses present. These thermal stresses, of course, are dependent on both the rate of heatup and the time (or coolant temperature) along the heatup ramp. Furthermore, since the thermal stresses, at the outside are tensile and increase with increasing heatup rate, a lower bound curve cannot be defined. Rather, each heatup rate of interest must be analyzed on an individual basis.

Following the generation of pressure-temperature curves for both the steady-state and finite heatup rate situations, the final limit curves are produced as follows. A composite curve is constructed based on a point-bypoint comparison of the steady-state and finite heatup rate data. At any given temperature, the allowable pressure is taken to be the lesser of the three values taken from the curves under consideration.

The use of the composite curve is necessary to set conservative heatup limitations because it is possible for conditions to exist such that over the course of the heatup ramp the controlling condition switches from the inside to the outside and the pressure limit must at all times be based on analysis of the most critical criterion.

Finally, the composite curves for the heatup rate data and the cooldown rate data are adjusted for possible errors in the pressure and temperature sensing instruments by the values indicated on the respective curves.

The pressurizer operates in a temperature range where there is no reason for concern of non-ductile failure. However, operation limits are provided to assure compatibility of operation with the fatigue analys is performed in accordance with the ASME Code requirements.

The OPERABILITY of two PORVs or an RCS vent opening of greater than ( ) square inches ensures that the RCS will be protected from pressure transients which could exceed the limits of Appendix G to 10 CFR part 50 when one or more of the RCS cold legs are less than or equal to $(275)^{\circ} \mathrm{F}$. Either PORV has adequate relieving capability to protect the RCS from overpressurization when the transient is limited to either (1) the start of an idle RCP with the secondary water temperature of the steam generator less than or equal to ()$^{\circ} \mathrm{F}$ above the RCS cold leg temperatures or (2) the start of a HPSI pump and its injection into a water solid RCS. 


\section{3/4.4.10 STRUCTURAL INTEGRITY}

The inservice inspection and testing programs for ASME Code Class 1, 2 and 3 components ensure that the structural integrity and operational readiness of these components will be maintained at an acceptable level throughout the life of the plant. These programs are in accordance with Section XI of the ASME Boiler and Pressure Vessel Code and applicable Addenda as required by 10 CFR Part $50.55 \mathrm{a}(\mathrm{g})$ except where specific written relief has been granted by the Commission pursuant to 10 CFR Part $50.55 \mathrm{a}$ (g) (6) (i).

Components of the reactor coolant system were designed to provide access to permit inservice inspections in accordance with Section XI of the ASME Boiler and Pressure Vessel Code, Edition and Addenda through 


\section{3/4.5 EMERGENCY CORE COOLING SYSTEMS}

BASES

\section{3/4.5.1 ACCUMULATORS}

The OPERABILITY of each RCS accumulator ensures that a sufficient volume of borated water will be immediately forced into the reactor core through each of the cold legs in the event the RCS pressure falls below the pressure of the accumulators. This initial surge of water into the core provides the initial cooling mechanism during large RCS pipe ruptures.

The limits on accumulator volume, boron concentration and pressure ensure that the assumptions used for accumulator injection in the safety analysis are met.

The accumulator power operated isolation valves are considered to be "operating bypasses" in the context of IEEE Std. 279-1971, which requires that bypasses of a protective function be removed automatically whenever permissive conditions are not met. In addition, as these accumulator isolation valves fail to meet single failure criteria, removal of power to the valves is required.

The limits for operation with an accumulator inoperable for any reason except an isolation valve closed minimizes the time exposure of the plant to a LOCA event occurring concurrent with failure of an additional accumulator which may result in unacceptable peak cladding temperatures. If a closed isolation valve cannot be immediately opened, the full capability of one accumulator is not available and prompt action is required to place the reactor in a mode where this capability is not required.

\section{$3 / 4.5 .2$ and $3 / 4.5 .3$ ECCS SUBSYSTEMS}

The OPERABILITY of two independent ECCS subsystems ensures that sufficient emergency core cooling capability will be available in the event of a LOCA assuming the loss of one subsystem through any single failure consideration. Either subsystem operating in conjunction with the accumulators is capable of supplying sufficient core cooling to limit the peak cladding temperatures within acceptable limits for all postulated break sizes ranging from the double ended break of the largest RCS cold leg pipe downward. In addition, each ECCS subsystem provides long term core cooling capability in the recirculation mode during the accident recovery period.

With the RCS temperature below $350^{\circ} \mathrm{F}$, one OPERABLE ECCS subsystem is acceptable without single failure consideration on the basis of the stable reactivity condition of the reactor and the limited core cooling requirements. 
The limitation for a maximum of one centrifugal charging pump to be OPERABLE and the Surveillance Requirement to verify all charging pumps and safety injection pumps except the required OPERABLE charging pump to be inoperable below $(275)^{\circ} \mathrm{F}$ provides assurance that a mass addition pressure transient can be relieved by the operation of a single PORV.

The Surveillance Requirements provided to ensure OPERABILITY of each component ensures that at a minimum, the assumptions used in the safety analyses are met and that subsystem OPERABILITY is maintained. Surveillance requirements for throttle valve position stops and flow balance testing provide assurance that proper ECCS flows will be maintained in the event of a LOCA. Maintenance of proper flow resistance and pressure drop in the piping system to each injection point is necessary to: (1) prevent total pump flow from exceeding runout conditions when the system is in its minimum resistance configuration, (2) provide the proper flow split between injection points in accordance with the assumptions used in the ECCS-LOCA analyses, and (3) provide an acceptable level of total ECCS flow to all injection points equal to or above that assumed in the ECCS-LOCA analyses.

\section{3/4.5.4 BORON INJECTION SYSTEM}

The OPERABILITY of the boron injection system as part of the ECCS ensures that sufficient negative reactivity is injected into the core to counteract any positive increase in reactivity caused by RCS system cooldown. RCS cooldown can be caused by inadvertent depressurization, a loss-of-coolant accident or a steam line rupture.

The limits on injection tank minimum contained volume and boron concentration ensure that the assumptions used in the steam line break analysis are met. The contained water volume limit includes an allowance for water not usable because of tank discharge line location or other physical characteristics.

The OPERABILITY of the redundant heat tracing channels associated with the boron injection system ensure that the solubility of the boron solution will be maintained above the solubility limit of $135^{\circ} \mathrm{F}$ at $22,500 \mathrm{ppm}$ boron.

\section{3/4.5.5 REFUELING WATER STORAGE TANK (RWST)}

The OPERABILITY of the RWST as part of the ECCS ensures that a sufficient supply of borated water is available for injection by the ECCS in the event of a LOCA. The limits on RWST minimum volume and boron concentration ensure that 1) sufficient water is available within containment to permit recirculation cooling flow to the core, and 2) the reactor will remain subcritical in the cold condition following mixing of the RWST and the RCS water volumes with all 


\section{BASES}

control rods inserted except for the most reactive control assembly. These assumptions are consistent with the LOCA analyses.

The contained water volume limit includes an allowance for water not usable because of tank discharge line location or other physical characteristics.

The limits on contained water volume and boron concentration of the RWST also ensure a pH value of between (8.5) and (11.0) for the solution recirculated within containment after a LOCA. This $\mathrm{pH}$ band minimizes the evolution of iodine and minimizes the effect of chloride and caustic stress corrosion on mechanical systems and components. 
-

-

• 


\section{BASES}

FOR

SECTION 3/4.6A

CONTAINMENT SYSTEMS SPECIFICATIONS

FOR

WESTINGHOUSE

ATMOSPHERIC TYPE CONTAINMENT 


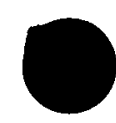

-

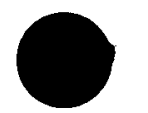




\section{$3 / 4.6$ CONTAINMENT SYSTEMS}

BASES

\section{3/4.6.1 PRIMARY CONTAINMENT}

\section{3/4.6.1.1 CONTAINMENT INTEGRITY}

Primary CONTAINMENT INTEGRITY ensures that the release of radioactive materials from the containment atmosphere will be restricted to those leakage paths and associated leak rates assumed in the accident analyses. This restriction, in conjunction with the leakage rate limitation, will limit the site boundary radiation doses to within the limits of 10 CFR 100 during accident conditions.

\section{3/4.6.1.2 CONTAINMENT LEAKAGE}

The limitations on containment leakage rates ensure that the total containment leakage volume will not exceed the value assumed in the accident analyses at the peak accident pressure, $\mathrm{Pa}$. As an added conservatism, the measured overall integrated leakage rate is further limited to less than or equal to $0.75 \mathrm{~L}_{\text {a }}$ or $0.75 \mathrm{~L}_{t}$, as applicable, during performance of the periodic test to account ${ }^{a}$ for possible degradation of the containment leakage barriers between leakage tests.

The surveillance testing for measuring leakage rates are consistent with the requirements of Appendix "J" of 10 CFR 50.

\section{3/4.6.1.3 CONTAINMENT AIR LOCKS}

The limitations on closure and leak rate for the containment air locks are required to meet the restrictions on CONTAINMENT INTEGRITY and containment leak rate. Surveillance testing of the air lock seals provide assurance that the overall air lock leakage will not become excessive due to seal damage during the intervals between air lock leakage tests.

\section{3/4.6.1.4 CONTAINMENT ISOLATION VALVE AND CHANNEL WELD PRESSURIZATION SYSTEMS (OPTIONAL)}

The OPERABILITY of the isolation valve and containment channel weld pressurization systems is required to meet the restrictions on overall containment leak rate assumed in the accident analyses. The surveillance Requirements for determing OPERABILITY are consistent with Appendix " $J$ " of 10 CFR 50. 
CONTAINMENT SYSTEMS

BASES

3/4.6.1.5 INTERNAL PRESSURE

The limitations on containment internal pressure ensure that 1 ) the containment structure is prevented from exceeding its design negative pressure differential with respect to the outside atmosphere of (3.0) psig and 2) the containment peak pressure does not exceed the design pressure of (54) psig during (LOCA or steam line break conditions).

The maximum peak pressure expected to be obtained from a (LOCA or steam line break) event is (45) psig. The limit of (3) psig for initial positive containment pressure will limit the total pressure to (48) psig which is less than design pressure and is consistent with the accident analyses.

\section{3/4.6.1.6 AIR TEMPERATURE}

The limitations on containment average air temperature ensure that the overall containment average air temperature does not exceed the initial temperature condition assumed in the accident analysis for a (LOCA or steam line break accident).

\section{3/4.6.1.7 CONTAINMENT STRUCTURAL INTEGRITY}

(Prestressed concrete containment with ungrouted tendons.)

This limitation ensures that the structural integrity of the containment will be maintained comparable to the original design standards for the life of the facility. Structural integrity is required to ensure that the containment will withstand the maximum pressure of (48) psig in the event of a (LOCA or steam line break accident). The measurement of containment tendon lift off force, the tensile tests of the tendon wires or strands, the visual examination of tendons, anchorages and exposed interior and exterior surfaces of the containment, and the Type A leakage test are sufficient to demonstrate this capability. (The tendon wire or strand samples will also be subjected to stress cycling tests and to accelerated corrosion tests to simulate the tendon's operating conditions and environment.)

The surveillance requirements for demonstrating the containment's structural integrity are in compliance with the recommendations of Regulatory Guide 1.35 "Inservice Surveillance of Ungrouted Tendons in Prestressed Concrete Containment Structures", January 1976.

(Reinforced concrete containment.)

This limitation ensures that the structural integrity of the containment will be maintained comparable to the original design standards for the life of the facility. Structural integrity is required to ensure that the containment 
will withstand the maximum pressure of (48) psig in the event of a (LOCA or steam line break accident). A visual inspection in conjunction with the Type A leakage tests is sufficient to demonstrate this capability.

\section{3/4.6.1.8 CONTAINMENT VENTILATION SYSTEM}

The containment purge supply and exhaust isolation valves are required to be closed during plant operation since these valves have not been demonstrated capable of closing during a (LOCA or steam line break accident). Maintaining these valves closed during plant operations ensures that excessive quantities of radioactive materials will not be released via the containment purge system.

\section{3/4.6.2 DEPRESSURIZATION AND COOLING SYSTEMS}

\section{3/4.6.2.1 CONTAINMENT SPRAY SYSTEM}

The OPERABILITY of the containment spray system ensures that containment depressurization and cooling capability will be available in the event of a (LOCA or steam line break). The pressure reduction and resultant lower containment leakage rate are consistent with the assumptions used in the accident analyses.

(Credit taken for iodine removal)

The containment spray system and the containment cooling system are redundant to each other in providing post accident cooling of the containment atmosphere. However, the containment spray system also provides a mechanism for removing iodine from the containment atmosphere and therefore the time requirements for restoring an inoperable spray system to OPERABLE status have been maintained consistent with that assigned other inoperable ESF equipment.

(No credit taken for iodine removal)

The containment spray system and the containment cooling system are redundant to each other in providing post accident cooling of the containment atmosphere. Since no credit has been taken for iodine removal by the containment spray system, the allowable out of service time requirements for the containment spray system and containment cooling system have been interrelated and adjusted to reflect this additional redundancy in cooling capability.

\section{3/4.6.2.2 SPRAY ADDITIVE SYSTEM (OPTIONAL)}

The OPERABILITY of the spray additive system ensures that sufficient $\mathrm{NaOH}$ is added to the containment spray in the event of a LOCA. The limits on $\mathrm{NaOH}$ volume and concentration ensure a $\mathrm{pH}$ value of between $(8.5)$ and $(11.0)$ for the 
solution recirculated within containment after a LOCA. This pH band minimizes the evolution of iodine and minimizes the effect of chloride and caustic stress corrosion on mechanical systems and components. The contained water volume limit includes an allowance for water not usable because of tank discharge line location or other physical characteristics. These assumptions are consistent with the iodine removal efficiency assumed in the accident analyses.

\section{3/4.6.2.3 CONTAINMENT COOLING SYSTEM (OPTIONAL)}

The OPERABILITY of the containment cooling system ensures that 1) the containment air temperature will be maintained within limits during normal operation, and 2) adequate heat removal capacity is available when operated in conjunction with the containment spray systems during post-LOCA conditions.

(Credit taken for iodine removal by spray systems)

The containment cooling system and the containment spray system are redundant to each other in providing post accident cooling of the containment atmosphere. As a result of this redundancy in cooling capability, the allowable out of service time requirements for the containment cooling system have been appropriately adjusted. However, the allowable out of service time requirements for the containment spray system have been maintained consistent with that assigned other inoperable ESF equipment since the containment spray system also provides a mechanism for removing iodine from the containment atmosphere.

(No credit taken for iodine removal by spray systems)

The containment cooling system and the containment spray system are redundant to each other in providing post accident cooling of the containment atmosphere. Since no credit has been taken for iodine removal by the containment spray system, the allowable out of service time requirements for the containment cooling system and containment spray system have been interrelated and adjusted to reflect this additional redundancy in cooling capacity.

\section{3/4.6.3 IODINE CLEANUP SYSTEM (OPTIONAL)}

The OPERABILITY of the containment iodine filter trains ensures that sufficient iodine removal capability will be available in the event of a LOCA. The reduction in containment iodine inventory reduces the resulting site boundary radiation doses associated with containment leakage. The operation of this system and resultant jodine removal capacity are consistent with the assumptions used in the LOCA analyses. 


\section{$3 / 4.6 .4$ CONTAINMENT ISOLATION VALVES}

The OPERABILITY of the containment isolation valves ensures that the containment atmosphere will be isolated from the outside environment in the event of a release of radioactive material to the containment atmosphere or pressurization of the containment. Containment isolation within the time limits specified ensures that the release of radioactive material to the environment will be consistent with the assumptions used in the analyses for a LOCA.

\section{3/4.6.5 COMBUSTIBLE GAS CONTROL}

The OPERABILITY of the equipment and systems required for the detection and control of hydrogen gas ensures that this equipment will be available to maintain the hydrogen concentration within containment below its flammable limit during post-LOCA conditions. Either recombiner unit (or the purge system) is capable of controlling the expected hydrogen generation associated with 1) zirconium-water reactions, 2) radiolytic decomposition of water and 3 ) corrosion of metals within containment. These hydrogen control systems are consistent with the recommendations of Regulatory Guide 1.7, "Control of Combustible Gas Concentrations in Containment Following a LOCA," March 1971.

The hydrogen mixing systems are provided to ensure adequate mixing of the containment atmosphere following a LOCA. This mixing action will prevent localized accumulations of hydrogen from exceeding the flammable limit.

\section{3/4.6.6 PENETRATION ROOM EXHAUST AIR FILTRATION SYSTEM (OPTIONAL)}

The OPERABILITY of the penetration room exhaust system ensures that radioactive materials leaking from the containment atmosphere through containment penetrations following a LOCA are filtered and adsorbed prior to reaching the environment. The operation of this system and the resultant effect on offsite dosage calculations was assumed in the LOCA analyses.

\section{3/4.6.7 VACUUM RELIEF VALVES (OPTIONAL)}

The OPERABILITY of the primary containment to atmosphere vacuum relief valves ensures that the containment internal pressure does not become more negative than _ psig. This condition is necessary to prevent exceeding the containment design limit for internal vacuum of psig. 
0

○

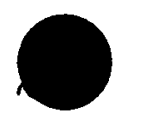




\section{BASES}

FOR

SECTION $3 / 4.6 B$

CONTAINMENT SYSTEMS SPECIFICATIONS

FOR

WESTINGHOUSE

ICE CONDENSER TYPE CONTAINMENTS 
-
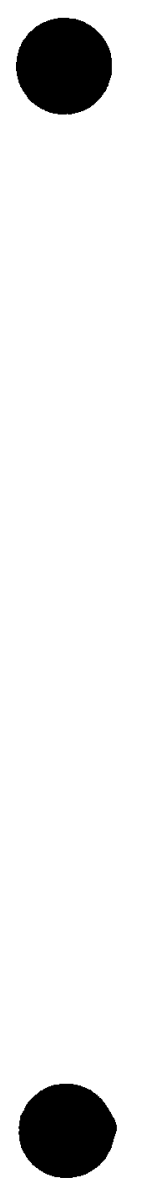
3/4.6 CONTAINMENT SYSTEMS

BASES

\section{3/4.6.1 PRIMARY CONTAINMENT}

\section{3/4.6.1.1 CONTAINMENT INTEGRITY}

Primary CONTAINMENT INTEGRITY ensures that the release of radioactive materials from the containment atmosphere will be restricted to those leakage paths and associated leak rates assumed in the accident analyses. This restriction, in conjunction with the leakage rate limitation, will limit the site boundary radiation doses to within the limits of 10 CFR 100 during accident conditions.

\section{3/4.6.1.2 CONTAINMENT LEAKAGE}

The limitations on containment leakage rates ensure that the total containment leakage volume will not exceed the value assumed in the accident analyses at the peak accident pressure, $P_{2}$. As an added conservatism, the measured overall integrated leakage rate is further limited to less than or equal to $0.75 \mathrm{~L}_{\text {or }} 0.75 \mathrm{~L}_{t}$, as applicable, during performance of the periodic tests to account for possible degradation of the containment leakage barriers between leakage tests.

The surveillance testing for measuring leakage rates are consistent with the requirements of Appendix " $\mathrm{J}$ " of 10 CFR 50.

\section{3/4.6.1.3 CONTAINMENT AIR LOCKS}

The limitations on closure and leak rate for the containment air locks are required to meet the restrictions on CONTAINMENT INTEGRITY and containment leak rate. Surveillance testing of the air lock seals provide assurance that the overall air lock leakage will not become excessive due to seal damage during the intervals between air lock leakage tests.

\section{3/4.6.1.4 CONTAINMENT ISOLATION VALVE AND CHANNEL WELD PRESSURIZATION} SYSTEMS (OPTIONAL)

The OPERABILITY of the isolation valve and containment channel weld pressurization systems is required to meet the restrictions on overall containment leak rate assumed in the accident analyses. The Surveillance Requirements for determining OPERABILITY are consistent with Appendix " $J$ " of 10 CFR 50. 


\section{3/4.6.1.5 INTERNAL PRESSURE}

The limitations on containment internal pressure ensure that 1) the containment structure is prevented from exceeding its design negative pressure differential with respect to the outside atmosphere of (3.0) psig and 2) the containment peak pressure does not exceed the design pressure of (15) psig during ( $L O C A$ or steam line break) conditions.

The maximum peak pressure expected to be obtained from a (LOCA or steam line break) event is (11) psig. The limit of (2) psig for initial positive containment pressure will limit the total pressure to (13) psig which is less than the design pressure and is consistent with the accident analyses.

\section{3/4.6.1.6 AIR TEMPERATURE}

The limitations on containment average air temperature ensure that 1) the containment air mass is limited to an initial mass sufficiently low to prevent exceeding the design pressure during (LOCA or steam line break) conditions and 2) the ambient air temperature does not exceed that temperature allowable for the continuous duty rating specified for equipment and instrumentation located within containment.

The containment pressure transient is sensitive to the initially contained air mass during a (LOCA or steam line break). The contained air mass increases with decreasing temperature. The lower temperature limit of ()$^{\circ} \mathrm{F}$ will limit the peak pressure to (11) psig which is less than the containment design pressure of (15) psig. The upper temperature limit influences the peak accident temperature slightly during a LOCA or steam line break; however, this limit is based primarily upon equipment protection and anticipated operating conditions. Both the upper and lower temperature limits are consistent with the parameters used in the accident analyses.

\section{3/4.6.1.7 CONTAINMENT VESSEL STRUCTURAL INTEGRITY}

This limitation ensures that the structural integrity of the containment steel vessel will be maintained comparable to the original design standards for the life of the facility. Structural integrity is required to ensure that the vessel will withstand the maximum pressure of (15) psig in the event of a (LOCA or steam line break). A visual inspection in conjunction with Type $A$ leakage tests is sufficient to demonstrate this capability.

\section{3/4.6.1.8 SHIELD BUILDING STRUCTURAL INTEGRITY}

This limitation ensures that the structural integrity of the containment shield building will be maintained comparable to the original design standards 
for the life of the facility. Structural integrity is required to provide 1) protection for the steel vessel from external missiles, 2) radiation shielding in the event of a LOCA, and 3) an annulus surrounding the steel vessel that can be maintained at a negative pressure during accident conditions. A visual inspection is sufficient to demonstrate this capability.

\section{3/4.6.1.9 AIR CLEANUP SYSTEM}

The OPERAEILITY of the shield building air cleanup system ensures that during LOCA conditions, containment vessel leakage into the annulus will be filtered through the HEPA filters and charcoal adsorber trains prior to discharge to the atmosphere. This requirement is necessary to meet the assumptions used in the accident analyses and limit the site boundary radiation doses to within the limits of 10 CFR 100 during LOCA conditions.

\section{3/4.6.1.10 CONTAINMENT VENTILATION SYSTEM}

The containment purge supply and exhaust isolation valves are required to be closed during plant operation since these valves have not been demonstrated capable of closing during a LOCA. Maintaining these valves closed during plant operations ensures that excessive quantities of radioactive materials will not be released via the containment purge system.

\section{3/4.6.2 DEPRESSURIZATION AND COOLING SYSTEMS}

\section{3/4.6.2.1 CONTAINMENT SPRAY SYSTEM}

The OPERABILITY of the containment spray system ensures that containment depressurization and cooling capability will be available in the event of a LOCA. The pressure reduction and resultant lower containment leakage rate are consistent with the assumptions used in the accident analyses.

(Credit taken for iodine removal)

The containment spray system and the containment cooling system are redundant to each other in providing post accident cooling of the containment atmosphere. However, the containment spray system also provides a mechanism for removing iodine from the containment atmosphere and therefore the time requirements for restoring an inoperable spray system to OPERABLE status have been maintained consistent with those assigned other inoperable ESF equipment. 
(No credit taken for iodine removal)

The containment spray system and the containment cooling system are redundant to each other in providing post accident cooling of the containment atmosphere. Since no credit has been taken for iodine removal by the containment spray system, the allowable out of service time requirements for the containment spray system and containment cooling system have been interrelated and adjusted to reflect this additional redundancy in cooling capability.

\section{3/4.6.2.2 SPRAY ADDITIVE SYSTEM (OPTIONAL)}

The OPERABILITY of the spray additive system ensures that sufficient $\mathrm{NaOH}$ is added to the containment spray in the event of a LOCA. The limits on $\mathrm{NaOH}$ volume and concentration ensure a $\mathrm{pH}$ value of between (8.5) and (11.0) for the solution recirculated within containment after a LOCA. This $\mathrm{pH}$ band minimizes the evolution of iodine and minimizes the effect of chloride and caustic stress corrosion on mechanical systems and components. These assumptions are consistent with the iodine removal efficiency assumed in the accident analyses.

The contained water volume limit includes an allowance for water not usable because of tank discharge location or other physical characteristics.

\section{3/4.6.2.3 CONTAINMENT COOLING SYSTEM (OPTIONAL)}

The OPERABILITY of the containment cooling system ensures that 1) the containment air temperature will be maintained within limits during normal operation, and 2) adequate heat removal capacity is available when operated in conjunction with the containment spray systems during post-LOCA conditions.

(Credit taken for iodine removal by spray systems)

The containment cooling system and the containment spray system are redundant to each other in providing post accident cooling of the containment atmosphere. As a result of this redundancy in cooling capability, the allowable out of service time requirements for the containment cooling system have been appropriately adjusted. However, the allowable out of service time requirements for the containment spray system have been maintained consistent with that assigned other inoperable ESF equipment since the containment spray system also provides a mechanism for removing iodine from the containment atmosphere.

(No credit taken for iodine removal by spray systems)

The containment cooling system and the containment spray system are redundant to each other in providing post accident cooling of the containment 
CONTAINMENT SYSTEMS

BASES

atmosphere. Since no credit has been taken for iodine removal by the containment spray system, the allowable out of service time requirements for the containment cooling system and containment spray system have been interrelated and adjusted to reflect this additional redundancy in cooling capacity.

\section{3/4.6.3 IODINE CLEANUP SYSTEM (OPTIONAL)}

The OPERABILITY of the containment iodine filter trains ensures that sufficient iodine removal capability will be available in the event of a LOCA. The reduction in containment iodine inventory reduces the resulting site boundary radiation doses associated with containment leakage. The operation of this system and resultant iodine removal capacity are consistent with the assumptions used in the LOCA analyses.

\section{$3 / 4.6 .4$ CONTAINMENT ISOLATION VALVES}

The OPERABILITY of the containment isolation valves ensures that the containment atmosphere will be isolated from the outside environment in the event of a release of radioactive material to the containment atmosphere or pressurization of the containment. Containment isolation within the time limits specified ensures that the release of radioactive material to the environment will be consistent with the assumptions used in the analyses for a LOCA.

\section{3/4.6.5 COMBUSTIBLE GAS CONTROL}

The OPERABILITY of the equipment and systems required for the detection and control of hydrogen gas ensures that this equipment will be available to maintain the hydrogen concentration within containment below its flammable limit during post-LOCA conditions, Either recombiner unit (or the purge system) is capable of controlling the expected hydrogen generation associated with 1) zirconium-water reactions, 2) radiolytic decomposition of water and 3 ) corrosion of metals within containment. These hydrogen control systems are consistent with the recommendations of Regulatory Guide 1.7, "Control of Combustible Gas Concentrations in Containment Following a LOCA", March 1971.

The hydrogen mixing systems are provided to ensure adequate mixing of the containment atmosphere following a LOCA. This mixing action will prevent localized accumulations of hydrogen from exceeding the flammable limit.

\section{3/4.6.6 PENETRATION ROOM EXHAUST AIR FILTRATION SYSTEM (OPTIONAL)}

The OPERABILITY of the penetration room exhaust system ensures that radioactive materials leaking from the containment atmosphere through containment penetrations following a LOCA are filtered prior to reaching the environment. The operation of this system and the resultant effect on offsite dosage calculations was assumed in the LOCA analyses.
W-ICE CONDENSER
B $3 / 46-5 B$ 


\section{3/4.6.7 ICE CONDENSER}

The requirements associated with each of the components of the ice condenser ensure that the overall system will be available to provide sufficient pressure suppression capability to limit the containment peak pressure transient to less than psig during LOCA conditions.

\section{3/4.6.7.1 ICE BED}

The OPERABILITY of the ice bed ensures that the required ice inventory will 1) be distributed evenly through the containment bays, 2) contain sufficient boron to preclude dilution of the containment sump following the LOCA and 3) contain sufficient heat removal capability to condense the reactor system volume released during a LOCA. These conditions are consistent with the assumptions used in the accident analyses.

The minimum weight figure of pounds of ice per basket contains a $10 \%$ conservative allowance for ice loss through sublimation which is a factor of 10 higher than assumed for the ice condenser design. In the event that observed sublimation rates are equal to or lower than design predictions after three years of operation, the minimum ice baskets weight may be adjusted downward. In addition, the number of ice baskets required to be weighted each 18 months may be reduced after 3 years of operation if such a reduction is supported by observed sublimation data.

\section{3/4.6.7.2 ICE BED TEMPERATURE MONITORING SYSTEM}

The OPERABILITY of the ice bed temperature monitoring system ensures that the capability is available for monitoring the ice temperature. In the event the monitoring system is inoperable, the ACTION requirements provide assurance that the ice bed heat removal capacity will be retained within the specified time limits.

\section{3/4.6.7.3 ICE CONDENSER DOORS}

The OPERABILITY of the ice condenser doors and the requirement that they be maintained closed ensures 1 ) that the reactor coolant system fluid released during a LOCA will be diverted through the ice condenser bays for heat removal and 3 ) that excessive sublimation of the ice bed will not occur because of warm air intrusion. 


\section{3/4.6.7.4 INLET DOOR POSITION MONITORING SYSTEM}

The OPERABILITY of the inlet door position monitoring system ensures that the capability is available for monitoring the individual inlet door position. In the event the monitoring system is inoperable, the ACTION requirements provide assurance that the ice bed heat removal capacity will be retained within the specified time limits.

\section{3/4.6.7.5 DIVIDER BARRIER PERSONNEL ACCESS DOORS AND EQUIPMENT HATCHES}

The requirements for the divider barrier personnel access doors and equipment hatches being closed and OPERABLE ensure that a minimum bypass steam flow will occur from the lower to the upper containment compartments during a LOCA. This condition ensures a diversion of the steam through the ice condenser bays that is consistent with the LOCA analyses.

\section{3/4.6.7.6 CONTAINMENT AIR RECIRCULATION SYSTEMS}

The OPERABILITY of the containment air recirculation systems ensures that following a LOCA 1) the containment atmosphere is circulated for cooling by the spray system and 2) the accumulation of hydrogen in localized portions of the containment structure is minimized.

\section{3/4.6.7.7 and 3/4.6.7.8 FLOOR AND REFUELING CANAL DRAINS}

The OPERABILITY of the ice condenser floor and refueling canal drains ensures that following a LOCA, the water from the melted ice and containment spray system has access for drainage back to the containment lower compartment and subsequently to the sump. This condition ensures the availability of the water for long term cooling of the reactor during the post accident phase.

\section{3/4.6.7.9 DIVIDER BARRIER SEAL}

The requirement for the divider barrier seal to be OPERABLE ensures that a minimum bypass steam flow will occur from the lower to the upper containment compartments during a LOCA. This condition ensures a diversion of steam through the ice condenser bays that is consistent with the LOCA analyses.

\section{3/4.6.8 VACUUM RELIEF VALVES (OPTIONAL)}

The OPERABILITY of the primary containment to atmosphere vacuum relief valves ensures that the containment internal pressure does not become more negative than psia. This condition is necessary to prevent exceeding the containment design limit for internal vacuum of psia.
W-ICE CONDENSER
B 3/4 6-7B 
○

-

• 


\title{
BASES
}

FOR

\author{
SECTION $3 / 4.6 C$ \\ CONTAINMENT SYSTEMS SPECIFICATIONS \\ FOR \\ WESTINGHOUSE \\ SUBATMOSPHERIC TYPE CONTAINMENTS
}


-

-

• 
$3 / 4.6$ CONTAINMENT SYSTEMS

BASES

\section{3/4.6.1 PRIMARY CONTAINMENT}

\section{3/4.6.1.1 CONTAINMENT INTEGRITY}

Primary CONTAINMENT INTEGRITY ensures that the release of radioactive materials from the containment atmosphere will be restricted to those leakage paths and associated leak rates assumed in the accident analyses. This restriction, in conjunction with the leakage rate limitation, will limit the site boundary radiation doses to within the limits of 10 CFR 100 during accident conditions.

\section{3/4.6.1.2 CONTAINMENT LEAKAGE}

The limitations on containment leakage rates ensure that the total containment leakage volume will not exceed the value assumed in the accident analyses at the peak accident pressure, $P_{\text {. }}$. As an added conservatism, the measured overall integrated leakage rate is further limited to less than or equal to $0.75 \mathrm{~L}$ or $0.75 \mathrm{~L}_{t}$, as applicable, during performance of the periodic test to account for possible degradation of the containment leakage barriers between leakage tests.

The surveillance testing for measuring leakage rates are consistent with the requirements of Appendix "J" of 10 CFR 50.

\section{3/4.6.1.3 CONTAINMENT AIR LOCKS}

The limitations on closure and leak rate for the containment air locks are required to meet the restrictions on CONTAINMENT INTEGRITY and containment leak rate. Surveillance testing of the air lock seals provides assurance that the overall air lock leakage will not become excessive due to seal damage during the intervals between air lock leakage tests.

\section{3/4.6.1.4 CONTAINMENT ISOLATION VALVE AND CHANNEL WELD PRESSURIZATION SYSTEMS (OPTIONAL)}

The OPERABILITY of the isolation valve and containment channel weld pressurization systems is required to meet the restrictions on overall containment leak rate assumed in the accident analyses. The Surveillance Requirements for determining OPERABILITY are consistent with Appendix "J" of 10 CFR 50. 
The limitations on containment internal pressure and average air temperature as a function of RWST and service water temperature ensure that 1) the containment structure is prevented from exceeding its design negative pressure of (8) psia, 3) the containment peak pressure does not exceed the design pressure of (45) psig during (LOCA or steam line break) conditions, and 3 ) the containment pressure is returned to subatmospheric conditions following a (LOCA or steam line break).

The containment internal pressure and temperature limits shown as a function of RWST and service water temperature describe the operational envelope that will 1) limit the containment peak pressure to less than its design value of (45) psig and 3 ) ensure the containment internal pressure returns subatmospheric within (40) minutes following a LOCA.

The limits on the parameters of Figures (3.6-1 and 3.6-2) are consistent with the assumptions of the accident analyses.

\section{3/4.6.1.7 CONTAINMENT STRUCTURAL INTEGRITY}

(Prestressed concrete containment with ungrouted tendons.)

This limitation ensures that the structural integrity of the containment vessel will be maintained comparable to the original design standards for the life of the facility. Structural integrity is required to ensure that the vessel will withstand the maximum pressure of (40) psig in the event of a (LOCA or steam line break accident). The measurement of containment tendon lift off force, the tensile tests of the tendon wires or strands, the visual examination of tendons, anchorages and exposed interior and exterior surfaces of the containment, and the Type A leakage tests are sufficient to demonstrate this capability. (The tendon wire or strand samples will also be subjected to stress cycling tests and to accelerated corrosion tests to simulate the tendon's operating conditions and environment.)

The surveillance requirements for demonstrating the containment's structural integrity are in compliance with the recommendations of Regulatory Guide 1.35 "Inservice Surveillance of Ungrouted Tendons in Prestressed Concrete Containment Structures", January 1976.

(Reinforced concrete containment.)

This limitation ensures that the structural integrity of the containment will be maintained comparable to the original design standards for the life of the facility. Structural integrity is required to ensure that the containment will withstand the maximum pressure of (48) psig in the event of a (LOCA or steam line break accident). A visual inspection in conjunction with the Type A leakage tests is sufficient to demonstrate this capability. 


\section{3/4.5.1.8 CONTAINMENT VENTILATION SYSTEM}

The containment purge supply and exhaust isolation valves are required to be closed during plant operation since these valves have not been demonstrated capable of closing during a LOCA. Maintaining these valves closed during plant operations ensures that excessive quantities of radioactive materials will not be released via to containment purge system

\section{3/4.6.2 DEPRESSURIZATION AND COOLING SYSTEMS}

\section{3/4.6.2.1 and 3/4.6.2.2 CONTAINMENT QUENCH AND RECIRCULATION SPRAY SYSTEMS}

The OPERABLILITY of the containment spray systems ensures that containment depressurization and subsequent return to subatmospheric pressure will occur in the event of a LOCA. The pressure reduction and resultant termination of containment leakage are consistent with the assumptions used in the accident analyses.

\section{3/4.6.2.3 SPRAY ADDITIVE SYSTEM (OPTIONAL)}

The OPERABILITY of the spray additive system ensures that sufficient $\mathrm{NaOH}$ is added to the containment spray in the event of a LOCA. The limits on $\mathrm{NaOH}$ volume and concentration ensure a pH value of between (8.5) and (11.0) for the solution recirculated within containment after a LOCA. This pH band minimizes the evolution of iodine and minimizes the effect of chloride and caustic stress corrosion on mechanical systems and components. The contained water volume limit includes an allowance for water not usable because of tank discharge line location or other physical characteristics. These assumptions are consistent with the iodine removal efficiency assumed in the accident analyses.

\section{3/4.6.3 CONTAINMENT ISOLATION VALVES}

The OPERABILITY of the containment isolation vaives ensures that the containment atmosphere will be isolated from the outside environment in the event of a release of radioactive material to the containment atmosphere or pressurization of the containment. Containment isolation within the time limits specified ensures that the release of radioactive material to the environment will be consistent with the assumptions used in the analyses for a LOCA. 


\section{3/4.6.4 COMBUSTIBLE GAS CONTROL}

The OPERABILITY of the equipment and systems required for the detection and control of hydrogen gas ensures that this equipment will be available to maintain the hydrogen concentration within containment below its flammable limit during post-LOCA conditions. Either recombiner unit (or the purge system) is capable of controlling the expected hydrogen generation associated with 1) zirconium-water reactions, 2) radiolytic decomposition of water 3 ) corrosion of metals within containment. These hydrogen control systems are consistent with the recommendations of Regulatory Guide 1.7, "Control of Combustible Gas Concentrations in Containment Following a LOCA", March 1971.

The hydrogen mixing systems are provided to ensure adequate mixing of the containment atmosphere following a LOCA. This mixing action will prevent localized accumulations of hydrogen from exceeding the flammable limit.

\section{3/4.6.5 SUBATMOSPHERIC PRESSURE CONTROL SYSTEM}

\section{3/4.6.5.1 STEAM JET AIR EJECTOR}

The closure of the manual isolation valves in the suction of the steam jet air ejector ensures that 1) the containment internal pressure may be maintained within its operation limits by the mechanical vacuum pumps and 2) the containment atmosphere is isolated from the outside environment in the event of a LOCA. These valves are required to be closed for containment isolation.

\section{3/4.6.5.2 MECHANICAL VACUUM PUMPS}

The OPERABILITY of the mechanical vacuum pumps ensures that 1) the containment internal pressure is maintained within limits during normal operation and 2) the containment pressure is maintained in a subatmospheric condition on a long term basis following a LOCA.

The operation of these pumps provide sufficient exhaust capacity to accommodate the internal pressure fluctuations associated with containment inleakage and anticipated atmospheric pressure and temperature changes.

\section{3/4.6.6 VACUUM RELIEF VALVES (OPTIONAL)}

The OPERABILITY of the primary containment vacuum relief valves ensures that the internal pressure does not become more negative than (_) psia. This capability is necessary to prevent exceeding the containment design limit for internal pressure of (8.0) psia. 


\section{BASES}

FOR

SECTION 3/4.6D

CONTAINMENT SYSTEMS SPECIFICATIONS

FOR

WESTINGHOUSE

DUAL TYPE CONTAINMENTS 
-

○

• 
$3 / 4.6$ CONTAINMENT SYSTEMS

BASES

3/4.6.1 PRIMARY CONTAINMENT

\section{3/4.6.1.1 CONTAINMENT INTEGRITY}

Primary CONTAINMENT INTEGRITY ensures that the release of radioactive materials from the containment atmosphere will be restricted to those leakage paths and associated leak rates assumed in the accident analyses. This restriction, in conjunction with the leakage rate limitation, will limit the site boundary radiation doses to within the limits of 10 CFR 100 during accident conditions.

\section{3/4.6.1.2 CONTAINMENT LEAKAGE}

The limitations on containment leakage rates ensure that the total containment leakage volume will not exceed the value assumed in the accident analyses at the peak accident pressure, $\mathrm{P}_{\mathrm{a}}$. As an added conservatism, the measured overall integrated leakage rate is further limited to less than or equal to $0.75 \mathrm{~L}_{a}$ or $0.75 \mathrm{~L}_{t}$, as applicable, during performance of the periodic tests to account for possible degradation of the containment leakage barriers between leakage tests.

The surveillance testing for measuring leakage rates are consistent with the requirements of Appendix "J" of 10 CFR 50.

\section{3/4.6.1.3 CONTAINMENT AIR LOCKS}

The limitations on closure and leak rate for the containment air locks are required to meet the restrictions on CONTAINMENT INTEGRITY and containment leak rate. Surveillance testing of the air lock seals provide assurance that the overall air lock leakage will not become excessive due to seal damage during the intervals between air lock leakage tests. 
The OPERABILITY of the isolation valve and containment channel weld pressurization systems is required to meet the restrictions on overall containment leak rate assumed in the accident analyses. The Surveillance Requirements for determing OPERABILITY are consistent with Appendix " $J "$ of 10 CFR 50 .

\section{3/4.6.1.5 INTERNAL PRESSURE}

The limitations on containment internal pressure ensure that 1) the containment structure is prevented from exceeding its design negative pressure differential with respect to the annulus atmosphere of (1.0) psi and 2) the containment peak pressure does not exceed the design pressure of (40) psig during (LOCA or steam line break) conditions.

The maximum peak pressure expected to be obtained from a (LOCA or steam line break) event is (35) psig. The limit of (2) psig for initial positive containment pressure will limit the total pressure to (37) psig which is less than the design pressure and is consistent with the accident analyses.

\section{3/4.6.1.6 AIR TEMPERATURE}

The limitation in containment average air temperature ensures that the containment peak air temperature does not exceed the design temperature of ( ) ${ }^{\circ} \mathrm{F}$ during (LOCA or steam line break) conditions and is consistent with the accident analyses.

\section{3/4.6.1.7 CONTAINMENT VESSEL STRUCTURAL INTEGRITY}

This limitation ensures that the structural integrity of the containment steel vessel will be maintained comparable to the original design standards for the life of the facility. Structural integrity if required to ensure that the vessel will withstand the maximum pressure of (40) psig in the event of a (LOCA or steam line break accident). A visual inspection in conjunction with Type $A$ leakage tests is sufficient to demonstrate this capability.

\section{3/4.6.1.8 CONTAINMENT VENTILATION SYSTEM}

The containment purge supply and exhaust isolation valves are required to be closed during plant operation since these valves have not been demonstrated capable of closing during a (LOCA or steam line break). Maintaining these valves closed during plant operations ensures that excessive quantities of radioactive materials will not be released via the containment purge system. 
BASES

\section{3/4.6.2 DEPRESSURIZATION AND COOLING SYSTEMS}

\section{3/4.6.2.1 CONTAINMENT SPRAY SYSTEM}

The OPERABILITY of the containment spray system ensures that containment depressurization and cooling capability will be available in the event of a LOCA. The pressure reduction and resultant lower containment leakage rate are consistent with the assumptions used in the accident analyses.

(Credit taken for iodine removal)

The containment spray system and the containment cooling system are redundant to each other in providing post accident cooling of the containment atmosphere. However, the containment spray system also provides a mechanism for removing iodine from the containment atmosphere and therefore the time requirements for restoring an inoperable spray system to OPERABLE status have been maintained consistent with those assigned other inoperable ESF equipment.

(No credit taken for iodine removal)

The containment spray system and the containment cooling system are redundant to each other in providing post accident cooling of the containment atmosphere. Since no credit has been taken for iodine removal by the containment spray system, the allowable out of service time requirements for the containment spray system and containment cooling system have been interrelated and adjusted to reflect this additional redundancy in cooling capability.

\section{3/4.6.2.2 SPRAY ADDITIVE SYSTEM (OPTIONAL)}

The OPERABILITY of the spray additive system ensures that sufficient $\mathrm{NaOH}$ is added to the containment spray in the event of a LOCA. The limits on $\mathrm{NaOH}$ volume and concentration ensure a pH value of between (8.5) and (11.0) for the solution recirculated within containment after a LOCA. This pH band minimizes the evolution of iodine and minimizes the effect of chloride and caustic stress corrosion on mechanical systems and components. The contained water volume limit includes an allowance for water not usable because of tank discharge line location or other physical characteristics. These assumptions are consistent with the iodine removal efficiency assumed in the accident analyses. 
CONTAINMENT SYSTEMS

BASES

\section{3/4.6.2.3 CONTAINMENT COOLING SYSTEM (OPTIONAL)}

The OPERABILITY of the containment cooling system ensures that 1) the containment air temperature will be maintained within limits during normal operation, and 2) adequate heat removal capacity is available when operated in conjunction with the containment spray systems during post-LOCA conditions.

(Credit taken for iodine removal by spray systems)

The containment cooling system and containment spray system are redundant to each other in providing post accident cooling of the containment atmosphere. As a result of this redundancy in cooling capability, the allowable out of service time requirements for the containment cooling system have been appropriately adjusted. However, the allowable out of service time requirements for the containment spray system have been maintained consistent with that assigned other inoperable ESF equipment since the containment spray system also provides a mechanism for removing iodine from the containment atmosphere.

(No credit taken for iodine removal by spray systems)

The containment cooling system and the containment spray system are redundant to each other in providing post accident cooling of the containment atmosphere. Since no credit has been taken for iodine removal by the containment spray system, the allowable out of service time requirements for the containment spray system, and containment spray system have been interrelated and adjusted to reflect this additional redundancy in cooling capacity.

\section{3/4.6.3 IODINE REMOVAL SYSTEM (OPTIONAL)}

The OPERABILITY of the containment iodine filter trains ensures that sufficient iodine removal capability will be available in the event of a LOCA. The reduction in containment iodine inventory reduces the resulting site boundary radiation doses associated with containment leakage. The operation of this system and resultant iodine removal capacity are consistent with the assumptions used in the LOCA analyses.

\section{$3 / 4.6 .4$ CONTAINMENT ISOLATION VALVES}

The OPERABILITY of the containment isolation valves ensures that the containment atmosphere will be isolated from the outside environment in the event of a release of radioactive material to the containment atmosphere or pressurization of the containment. Containment isolation within the time limits specified ensures that the release of radioactive material to the environment will be consistent with the assumptions used in the analyses for a LOCA. 


\section{3/4.6.5 COMBUSTIBLE GAS CONTROL}

The OPERABILITY of the equipment and systems required for the detection and control of hydrogen gas ensures that this equipment will be available to maintain the hydrogen concentration within containment below its flammable limit during post-LOCA conditions. Either recombiner unit (or the purge system) is capable of controlling the expected hydrogen generation associated with 1) zirconium-water reactions, 3) radiolytic decomposition of water and 3 ) corrosion of metals within containment. These hydrogen control systems are consistent with the recommendations of Regulatory Guide 1.7, "Control of Combustible Gas Concentrations in Containment Following a LOCA", March 1971.

The hydrogen mixing systems are provided to ensure adequate mixing of the containment atmosphere following a LOCA. This mixing action will prevent localized accumulations of hydrogen from exceeding the flammable limit.

\section{3/4.6.6 PENETRATION ROOM EXHAUST AIR FILTRATION SYSTEM (OPTIONAL)}

The OPERABILITY of the penetration room exhaust system ensures that radioactive materials leaking from the containment atmosphere through containment penetrations following a LOCA are filtered prior to reaching the environment. The operation of this system and the resultant effect on offsite dosage calculations was assumed in the LOCA analyses.

\section{3/4.6.7 VACUUM RELIEF VALVES (OPTIONAL)}

The OPERABILITY of the primary containment to atmosphere vacuum relief valves ensures that the containment internal pressure differential does not become more negative than ( ) psi. This condition is necessary to prevent exceeding the containment design limit for internal pressure differential of (1.0) psi.

\section{$3 / 4.6 .8$ SECONDARY CONTAINMENT}

\section{3/4.6.8.1 VENTILATION SYSTEM}

The OPERABILITY of the shield building ventilation systems ensures that containment vessel leakage occuring during LOCA conditions into the annulus will be filtered through the HEPA filters and charcoal adsorber trains prior to discharge to the atmosphere. This requirement is necessary to meet the assumptions used in the accident analyses and limit the site boundary radiation doses to within the limits of 10 CFR 100 during LOCA conditions. 


\section{3/4.6.8.2 CONTAINMENT INTEGRITY}

Secondary CONTAINMENT INTEGRITY ensures that the release of radioactive materials from the primary containment atmosphere will be restricted to those leakage paths and associated leak rates assumed in the accident analyses.

This restriction, in conjunction with operation of the secondary containment ventilation system, will limit the site boundary radiation doses to within the limits of 10 CFR 100 during accident conditions.

\section{3/4.6.8.3 SHIELD BUILDING STRUCTURAL INTEGRITY}

This limitation ensures that the structural integrity of the containment shield building will be maintained comparable to the original design standards for the life of the facility. Structural integrity is required to provide 1) protection for the steel vessel from external missiles, 2) radiation shielding in the event of a LOCA, and 3) an annulus surrounding the steel vessel that can be maintained at a negative pressure during accident conditions. A visual inspection is sufficient to demonstrate this capability. 
$3 / 4.7$ PLANT SYSTEMS

BASES

\section{3/4.7.1 TURBINE CYCLE}

\section{$3 / 4.7 .1 .1$ SAFETY VALVES}

The OPERABILITY of the main steam line code safety valves ensures that the secondary system pressure will be limited to within $110 \%$ (1100 psig) of its design pressure of (1000) psig during the most severe anticipated system operational transient. The maximum relieving capacity is associated with a turbine trip from 100\% RATED THERMAL POWER coincident with an assumed loss of condenser heat sink (i.e., no steam bypass to the condenser).

The specified valve lift settings and relieving capacities are in accordance with the requirements of Section III of the ASME Boiler and Pressure Code, 1971 Edition. The total relieving capacity for all valves on all of the steam lines is () lbs/hr which is () percent of the total secondary steam flow of () $1 \mathrm{bs} / \mathrm{hr}$ at $100 \%$ RATED THERMAL POWER. A minimum of 2 OPERABLE safety valves per steam generator ensures that sufficient relieving capacity is available for the allowable THERMAL POWER restriction in Table 3. 7-2.

STARTUP and/Or POWER OPERATION is allowable with safety valves inoperable within the limitations of the ACTION requirements on the basis of the reduction in secondary system steam flow and THERMAL POWER required by the reduced reactor trip settings of the Power Range Neutron Flux channels. The reactor trip setpoint reductions are derived on the following bases:

For $\mathrm{N}$ loop operation

$$
S P=\frac{(X)-(Y)(V)}{X} \times(109)
$$

For $\mathrm{N}-1$ loop operation

$$
S P=\frac{(X)-(Y)(U)}{X} \times(76)
$$

Where:

$$
\begin{aligned}
S P= & \text { Reduced reactor trip setpoint in percent of RATED THERMAL POWER } \\
V= & \text { Maximum number of inoperable safety valves per steam line } \\
U= & \begin{array}{l}
\text { Maximum number of inoperable safety valves per operating } \\
\text { steam line }
\end{array}
\end{aligned}
$$




$$
\begin{aligned}
(109)= & \begin{array}{l}
\text { Power Range Neutron Flux-High Trip Setpoint for }(\mathrm{N}) \text { loop } \\
\text { operation }
\end{array} \\
(76)= & \begin{array}{l}
\text { Maximum percent of RATED THERMAL POWER permissible by } \\
\text { P-8 Setpoint for }(N-1) \text { loop operation. }
\end{array} \\
X= & \begin{array}{l}
\text { Total relieving capacity of all safety valves per steam } \\
\text { line in lbs/hour }
\end{array} \\
Y= & \begin{array}{l}
\text { Maximum relieving capacity of any one safety valve in } \\
\text { lbs/hour }
\end{array}
\end{aligned}
$$

\section{3/4.7.1.2 AUXILIARY FEEDWATER SYSTEM}

The OPERABILITY of the auxiliary feedwater system ensures that the Reactor Coolant System can be cooled down to less than $(350)^{\circ} \mathrm{F}$ from normal operating conditions in the event of a total loss of off-site power.

Each electric driven auxiliary feedwater pump is capable of delivering a total feedwater flow of (350) gpm at a pressure of (1133) psig to the entrance of the steam generators. The steam driven auxiliary feedwater pump is capable of delivering a total feedwater flow of (700) gpm at a pressure of (1133) psig to the entrance of the steam generators. This capacity is sufficient to ensure that adequate feedwater flow is available to remove decay heat and reduce the Reactor Coolant System temperature to less than $(350)^{\circ} \mathrm{F}$ when the Residual Heat Removal System may be placed into operation.

\section{$3 / 4.7 .1 .3^{\circ}$ CONDENSATE STORAGE TANK}

The OPERABILITY of the condensate storage tank with the minimum water volume ensures that sufficient water is available to maintain the RCS at HOT STANDBY conditions for ( ) hours with steam discharge to the atmosphere concurrent with total loss of off-site power. The contained water volume limit includes an allowance for water not usable because of tank discharge line location or other physical characteristics.

\section{3/4.7.1.4 ACTIVITY}

The limitations on secondary system specific activity ensure that the resultant off-site radiation dose will be 1 imited to a small fraction of 10 CFR Part 100 limits in the event of a steam line rupture. This dose also includes the effects of a coincident $1.0 \mathrm{GPM}$ primary to secondary tube leak in the steam generator of the affected steam line. These values are consistent with the assumptions used in the accident analyses. 
PLANT SYSTEMS

BASES

\section{3/4.7.1.5 MAIN STEAM LINE ISOLATION VALVES}

The OPERABILITY of the main steam line isolation valves ensures that no more than one steam generator will blowdown in the event of a steam line rupture. This restriction is required to 1) minimize the positive reactivity effects of the Reactor Coolant System cooldown associated with the blowdown, and 2) limit the pressure rise within containment in the event the steam line rupture occurs within containment. The OPERABILITY of the main steam isolation valves within the closure times of the surveillance requirements are consistent with the assumptions used in the accident analyses.

\section{3/4.7.2 STEAM GENERATOR PRESSURE/TEMPERATURE LIMITATION}

The limitation on steam generator pressure and temperature ensures that the pressure induced stresses in the steam generators do not exceed the maximum allowable fracture toughness stress limits. The limitations of $(70)^{\circ} \mathrm{F}$ and (200) psig are based on a steam generator RT $T_{N D T}$ of ()$^{\circ} \mathrm{F}$ and are sufficient to prevent brittle fracture.

\section{3/4.7.3 COMPONENT COOLING WATER SYSTEM}

The OPERABILITY of the component cooling water system ensures that sufficient cooling capacity is available for continued operation of safety related equipment during normal and accident conditions. The redundant cooling capacity of this system, assuming a single failure, is consistent with the assumptions used in the accident analyses.

\section{3/4.7.4 SERVICE WATER SYSTEM}

The OPERABILITY of the service water system ensures that sufficient cooling capacity is available for continued operation of safety related equipment during normal and accident conditions. The redundant cooling capacity of this system, assuming a single failure, is consistent with the assumptions used in the accident conditions within acceptable limits.

\section{3/4.7.5 ULTIMATE HEAT SINK (OPTIONAL)}

The limitations on the ultimate heat sink level and temperature ensure that sufficient cooling capacity is available to either 1) provide normal cooldown of the facility, or 2) to mitigate the effects of accident conditions within acceptable limits. 
PLANT SYSTEMS

BASES

ULTIMATE HEAT SINK (Continued)

The limitations on minimum water level and maximum temperature are based on providing a 30 day cooling water supply to safety related equipment without exceeding their design basis temperature and is consistent with the recommendations of Regulatory Guide 1.27, "Ultimate Heat Sink for Nuclear Plants", March 1974.

\section{3/4.7.6 FLOOD PROTECTION (OPTIONAL)}

The limitation on flood protection ensures that facility protective actions will be taken (and operation will be terminated) in the event of flood conditions. The limit of elevation ( ) Mean Sea Level is based on the maximum elevation at which facility flood control measures provide protection to safety related equipment.

\section{$3 / 4.7 .7$ CONTROL ROOM VENTILATION SYSTEM}

The OPERABILITY of the control room ventilation system ensures that 1) the ambient air temperature does not exceed the allowable temperature for continuous duty rating for the equipment and instrumentation cooled by this system and 2) the control room will remain habitable for operations personnel during and following all credible accident conditions. The OPERABILITY of this system in conjunction with control room design provisions is based on limiting the radiation exposure to personnel occupying the control room to 5 rem or less whole body, or its equivalent. This limitation is consistent with the requirements of General Design Criteria 19 of Appendix "A", 10 CFR 50.

\section{3/4.7.8 ECCS PUMP ROOM EXHAUST AIR FILTRATION SYSTEM}

The OPERABILITY of the ECCS pump room exhaust air filtration system ensures that radioactive materials leaking from the ECCS equipment within the pump room following a LOCA are filtered prior to reaching the environment. The operation of this system and the resultant effect on offsite dosage calculations was assumed in the accident analyses.

\section{3/4.7.9 HYDRAULIC SNUBBERS}

The hydraulic snubbers are required OPERABLE to ensure that the structural integrity of the reactor coolant system and all other safety related systems is maintained during and following a seismic or other event initiating dynamic loads. The only snubbers excluded from this inspection program are those installed on nonsafety related systems and then only if their failure or 
PLANT SYSTEMS

BASES

HYDRAULIC SNUBBERS (Continued)

failure of the system on which they are installed, would have no adverse effect on any safety related system.

The inspection frequency applicable to snubbers containing seals fabricated from materials which have been demonstrated compatible with their operating environment is based upon maintaining a constant level of snubber protection. Therefore, the required inspection interval varies inversely with the observed snubber failures. The number of inoperable snubbers found during an inspection of these snubbers determines the time interval for the next required inspection of these snubbers. Inspections performed before that interval has elapsed may be used as a new reference point to determine the next inspection. However, the results of such early inspections performed before the original required time interval has elapsed (nominal time less 25\%) may not be used to lengthen the required inspection interval. Any inspection whose results require a shorter inspection interval will override the previous schedule.

To provide further assurance of snubber reliability, a representative sample of the installed snubbers will be functionally tested during plant shutdowns at 18 month intervals. These tests will include stroking of the snubbers to verify proper piston movement, lock-up and bleed. Observed failures of these sample snubbers will require functional testing of additional units. To minimize personnel exposures, snubbers installed in areas which have high radiation fields during shutdown or in especially difficult to remove locations may be exempted from these functional testing requirements provided the OPERABILITY of these snubbers was demonstrated during functional testing at either the completion of their fabrication or at a subsequent date.

\section{3/4.7.10 SEALED SOURCE CONTAMINATION}

The limitations on removable contamination for sources requiring leak testing, including alpha emitters, is based on 10 CFR 70.39(c) limits for plutonium. This limitation will ensure that leakage from byproduct, source, and special nuclear material sources will not exceed allowable intake values. Sealed sources are classified into three groups according to their use, with surveillance requirements commensurate with the probability of damage to a source in that group. Those sources which are frequently handled are required to be tested more often than those which are not. Sealed sources which are continuously enclosed within a shielded mechanism (i.e. sealed sources within radiation monitoring or boron measuring devices) are considered to be stored and need not be tested unless they are removed from the shielded mechanism. 
PLANT SYSTEMS

BASES

\section{3/4.7.11 FIRE SUPPRESSION SYSTEMS}

The OPERABILITY of the fire suppression systems ensures that adequate fire suppression capability is available to confine and extinquish fires occuring in any portion of the facility where safety related equipment is located. The fire suppression system consists of the water system, spray and/or sprinklers, $\mathrm{CO}_{2}$, Halon, fire hose stations, and yard fire hydrants. The collective capabifity of the fire suppression systems is adequate to minimize potential damage to safety related equipment and is a major element in the facility fire protection program.

In the event that portions of the fire suppression systems are inoperable, alternate backup fire fighting equipment is required to be made available in the affected areas until the inoperable equipment is restored to service.

In the event the fire suppression water system becomes inoperable, immediate corrective measures must be taken since this system provides the major fire suppression capability of the plant. The requirement for a twenty-four hour report to the Commission provides for prompt evaluation of the acceptability of the corrective measures to provide adequate fire suppression capability for the continued protection of the nuclear plant.

\section{3/4.7.12 FIRE BARRIER PENETRATIONS}

The functional integrity of the fire barrier penetrations ensures that fires will be confined or adequately retarded from spreading to adjacent portions of the facility. This design feature minimizes the possibility of a single fire rapidly involving several areas of the facility prior to detection and extinguishment. The fire barrier penetrations are a passive element in the facility fire protection program and are subject to periodic inspections.

Fire barrier penetrations, including cable penetration barriers, fire doors and dampers are considered functional when the visually observed condition is the same as the as-designed condition. For those fire barrier penetrations that are not in the as-designed condition, an evaluation shall be performed to show that the modification has not degraded the fire rating of the fire barrier penetration.

During periods of time when a barrier is not functional, either, 1) a continuous fire watch is required to be maintained in the vicinity of the affected barrier, or 2) the fire detectors on at least one side of the affected barrier must be verified OPERABLE and a hourly fire watch patrol established, until the barrier is restored to functional status. 


\section{PLANT SYSTEMS}

\section{BASES}

\section{3/4.7.13 AREA TEMPERATURE MONITORING}

The area temperature limitations ensure that safety related equipment will not be subjected to temperatures in excess of their environmental qualification temperatures. Exposure to excessive temperatures may degrade equipment and can cause a loss of its OPERABILITY. The temperature limits include an allowance for instrument error of ()$^{\circ} \mathrm{F}$. 
-

-

• 
3/4.8 ELECTRICAL POWER SYSTEMS

BASES

\section{3/4.8.1 AND 3/4.8.2 A.C. SOURCES AND ONSITE POWER DISTRIBUTION SYSTEMS}

The OPERABILITY of the A.C. and D.C power sources and associated distribution systems during operation ensures that sufficient power will be available to supply the safety related equipment required for 1) the safe shutdown of the facility and 2) the mitigation and control of accident conditions within the facility. The minimum specified independent and redundant A.C. and D.C. power sources and distribution systems satisfy the requirements of General Design Criterion 17 of Appendix "A" to 10 CFR 50.

The ACTION requirements specified for the levels of degradation of the power sources provide restriction upon continued facility operation commensurate with the level of degradation. The OPERABILITY of the power sources are consistent with the initial condition assumptions of the safety analyses and are based upon maintaining at least one redundant set of onsite A.C. and D.C. power sources and associated distribution systems OPERABLE during accident conditions coincident with an assumed loss of offsite power and single failure of the other onsite A.C. source.

The OPERABILITY of the minimum specified A.C. and D.C. power sources and associated distribution systems during shutdown and refueling ensures that 1) the facility can be maintained in the shutdown or refueling condition for extended time periods and 2) sufficient instrumentation and control capability is available for monitoring and maintaining the unit status.

- The Surveillance Requirements for demonstrating the OPERABILITY of the diesel generators are in accordance with the recommendations of Regulatory Guides 1.9 "Selection of Diesel Generator Set Capacity for Standby Power Supplies", March 10, 1971, and 1.108 "Periodic Testing of Diesel Generator Units Used as Onsite Electric Power Systems at Nuclear Power Plants," Revision 1, August 1977.

The Surveillance Requirement for demonstrating the OPERABILITY of the Station batteries are in accordance with the recommendations of Regulatory Guide 1.129 "Maintenance Testing and Replacement of Large Lead Storage Batteries for Nuclear Power Plants," February 1978.

\section{3/4.8.3 ELECTRICAL EQUIPMENT PROTECTIVE DEVICES}

Containment electrical penetrations and penetration conductors are protected by either deenergizing circuits not required during reactor operation or by demonstrating the OPERABILITY of primary and backup overcurrent protection circuit breakers during periodic surveillance. 
The surveillance requirements applicable to lower voltage circuit breakers and fuses provides assurance of breaker and fuse reliability by testing at least one representative sample of each manufacturers brand of circuit breaker and/or fuse. Each manufacturer's molded case and metal case circuit breakers and/or fuses are grouped into representative samples which are then tested on a rotating basis to ensure that all breakers and/or fuses are tested. If a wide variety exists within any manufacturer's brand of circuit breakers and/or fuses, it is necessary to divide that manufacturer's breakers and/or fuses into groups and treat each group as a separate type of breaker or fuses for surveillance purposes.

The OPERABILITY of the motor operated valves thermal overload protection and/or bypass devices ensures that these devices will not prevent safety related valves from performing their function. The Surveillance Requirements for demonstrating the OPERABILITY of these devices are in accordance with Regulatory Guide 1.106 "Thermal Overload Protection for Electric Motors on Motor Operated Valves", Revision 1, March 1977. 
3/4.9 REFUELING OPERATIONS

BASES

\section{3/4.9.1 BORON CONCENTRATION}

The limitations on reactivity conditions during REFUELING ensure that: 1) the reactor will remain subcritical during CORE ALTERATIONS, and 2) a uniform boron concentration is maintained for reactivity control in the water volume having direct access to the reactor vessel. These limitations are consistent with the initial conditions assumed for the boron dilution incident in the accident analyses.

\section{3/4.9.2 INSTRUMENTATION}

The OPERABILITY of the source range neutron flux monitors ensures that redundant monitoring capability is available to detect changes in the reactivity condition of the core.

\section{3/4.9.3 DECAY TIME}

The minimum requirement for reactor subcriticality prior to movement of irradiated fuel assemblies in the reactor pressure vessel ensures that sufficient time has elapsed to allow the radioactive decay of the short lived fission products. This decay time is consistent with the assumptions used in the accident analyses.

\section{3/4.9.4 CONTAINMENT BUILDING PENETRATIONS}

The requirements on containment building penetration closure and OPERABILITY ensure that a release of radioactive material within containment will be restricted from leakage to the environment. The OPERABILITY and closure restrictions are sufficient to restrict radioactive material release from a fuel element rupture based upon the lack of containment pressurization potential while in the REFUELING MODE.

\section{3/4.9.5 COMMUNICATIONS}

The requirement for communications capability ensures that refueling station personnel can be promptly informed of significant changes in the facility status or core reactivity conditions during CORE ALTERATIONS.

\section{3/4.9.6 MANIPULATOR CRANE OPERABILITY}

The OPERABILITY requirements for the manipulator cranes ensure that:

1) manipulator cranes will be used for movement of drive rods and fuel assemblies, 2) each crane has sufficient load capacity to lift a drive rod or fuel assembly, W-STS

B 3/4 9-1 
REFUELING OPERATIONS

BASES

MANIPULATOR CRANE OPERABILITY (Continued)

assembly, and 3) the core internals and pressure vessel are protected from excessive lifting force in the event they are inadvertently engaged during lifting operations.

\section{3/4.9.7 CRANE TRAVEL - SPENT FUEL STORAGE BUILDING}

The restriction on movement of loads in excess of the nominal weight of a fuel and control rod assembly and associated handling tool over other fuel assemblies in the storage pool ensures that in the event this load is dropped 1) the activity release will be limited to that contained in a single fuel assembly, and 2) any possible distortion of fuel in the storage rocks will not result in a critical array. This assumption is consistent with the activity release assumed in the accident analyses.

\section{3/4.9.8 COOLANT CIRCULATION}

The requirement that at least one residual heat removal loop be in operation ensures that 1) sufficient cooling capacity is available to remove decay heat and maintain the water in the reactor pressure vessel below $140^{\circ} \mathrm{F}$ as required during the REFUELING MODE, and 2) sufficient coolant circulation is maintained thru the reactor core to minimize the effects of a boron dilution incident and prevent boron stratification.

\section{3/4.9.9 CONTAINMENT PURGE AND EXHAUST ISOLATION SYSTEM}

The OPERABILITY of this system ensures that the containment vent and purge penetrations will be automatically isolated upon detection of high radiation levels within the containment. The OPERABILITY of this system is required to restrict the release of radioactive material from the containment atmosphere to the environment.

\section{3/4.9.10 and 3/4.9.11 WATER LEVEL - REACTOR VESSEL AND STORAGE POOL}

The restrictions on minimum water level ensure that sufficient water depth is available to remove $99 \%$ of the assumed $10 \%$ jodine gap activity released from the rupture of an irradiated fuel assembly. The minimum water depth is consistent with the assumptions of the accident analysis.

\section{3/4.9.12 STORAGE POOL VENTILATION SYSTEM}

The limitations on the storage pool ventilation system ensure that all radioactive material released from an irradiated fuel assembly will be filtered through the HEPA filters and charcoal adsorber prior to discharge to the atmosphere. The OPERABILITY of this system and the resulting iodine removal capacity are consistent with the assumptions of the accident analyses. W-STS

B $3 / 4$ 9-2 
$\underline{3 / 4.10 \quad \text { SPECIAL TEST EXCEPTIONS }}$

BASES

3/4.10.1 SHUTDOWN MARGIN

This special test exception provides that a minimum amount of control rod worth is immediately available for reactivity control when tests are performed for control rod worth measurement. This special test exception is required to permit the periodic verification of the actual versus predicted core reactivity condition occuring as a result of fuel burnup or fuel cycling operations.

\section{3/4.10.2 GROUP HEIGHT, INSERTION, AND POWER DISTRIBUTION LIMITS}

This special test exception permits individual control rods to be positioned outside of their normal group heights and insertion limits during the performance of such PHYSICS TESTS as those required to 1) measure control rod worth and 2) determine the reactor stability index and damping factor under xenon oscillation conditions.

\section{$3 / 4.10 .3$ PHYSICS TESTS}

This special test exception permits PHYSICS TESTS to be performed at less than or equal to $5 \%$ of RATED THERMAL POWER and is required to verify the fundamental nuclear characteristics of the reactor core and related instrumentation.

\section{3/4.10.4 REACTOR COOLANT LOOPS}

This special test exception permits reactor criticality under no flow conditions and is required to perform certain startup and PHYSICS TESTS while at low THERMAL POWER levels.

\section{3/4.10.5 POSITION INDICATION SYSTEM-SHUTDOWN}

This special test exception permits the position indication systems to be inoperable during rod drop time measurements. The exception is required since the data necessary to determine the rod drop time is derived from the induced voltage in the position indicator coils as the rod is dropped. This induced voltage is small compared to the normal voltage and, therefore, can not be observed if the position indication systems remain OPERABLE. 
-

-

○ 
SECTION 5.0

DESIGN FEATURES 
-

○

• 


\section{$5.1 \quad$ SITE}

\section{EXCLUSION AREA}

5.1.1 The exclusion area shall be as shown in Figure (5.1-1).

\section{LOW POPULATION ZONE}

5.1.2 The low population zone shall be as shown in Figure (5.1-2).

\subsection{CONTAINMENT}

\section{CONFIGURATION}

5.2.1 The reactor containment building is a steel lined, reinforced concrete building of cylindrical shape, with a dome roof and having the following design features:

a. Nominal inside diameter $=$ feet.

b. Nominal inside height $=$ feet.

c. Minimum thickness of concrete walls = feet.

d. Minimum thickness of concrete roof $=$ feet.

e. Minimum thickness of concrete floor pad $=$ feet.

f. Nominal thickness of steel liner $=$ inches.

g. Net free volume $=$ cubic feet.

\section{DESIGN PRESSURE AND TEMPERATURE}

5.2.2 The reactor containment building is designed and shall be maintained for a maximum internal pressure of psig and a temperature of ${ }^{\circ} \mathrm{F}$. 
This figure shall consist of a map of the site area and provide at a minimum, the information described in Section (2.1.2) of the FSAR and meteorological tower location.

\section{EXCLUSION AREA}

\section{FIGURE $5.1-1$}


This figure shall consist of a map of the site area showing the Low Population Zone boundary. Features such as towns, roads and recreational areas shall be indicated in sufficient detail to allow identification of significant shifts in population distribution within the LPZ.

LOW POPULATION ZONE

FIGURE $5.1-2$ 
5.3 REACTOR CORE

FUEL ASSEMBLIES

5.3.1 The reactor core shall contain fuel assemblies with each fuel assembly containing fuel rods clad with (Zircaloy -4). Each fuel rod

shall have a nomina active fuel length of inches and contain a maximum total weight of grams uranium. The initia 1 core loading shall have a maximum enrichment of weight percent U-235. Reload fuel shall be similar in physical design to the initial core loading and shall have a maximum enrichment of weight percent $\mathrm{U}-235$.

\section{CONTROL ROD ASSEMBLIES}

5.3.2 The reactor core shall contain full length and part length control rod assemblies. The full length control rod assembTies shall contain a nominal 142 inches of absorber material. The part length control rod assemblies shall contain a nominal 36 inches of absorber material at their lower ends. The nominal values of absorber material shall be 80 percent silver, 15 percent indium and 5 percent cadmium. All control rods shall be clad with stainless steel tubing. The balance of the void length in the part length rods shall contain aluminum oxide.

\subsection{REACTOR COOLANT SYSTEM}

DESIGN PRESSURE AND TEMPERATURE

5.4.1 The reactor coolant system is designed and shall be maintained:

a. In accordance with the code requirements specified in Section (5.2) of the FSAR, with allowance for normal degradation pursuant to the applicable Surveillance Requirements,

b. For a pressure of _ psig, and

c. For a temperature of $\_{ }^{\circ} \mathrm{F}$, except for the pressurizer which is

VOLUME

5.4.2 The total water and steam volume of the reactor coolant system is \pm cubic feet at a nominal $\mathrm{T}_{\text {avg }}$ of $(525)^{\circ} \mathrm{F}$.

\subsection{METEOROLOGICAL TOWER LOCATION}

5.5.1 The meteorological tower shall be located as shown on Figure (5.1-1). 


\subsection{FUEL STORAGE}

\section{CRITICALITY - SPENT FUEL}

5.6.1.1 The spent fuel storage racks are designed and shall be maintained with:

a. A $k_{\text {eff }}$ equivalent to less than 0.95 when flooded with unborated water, which includes a conservative allowance of (2.6\%) delta k/k for uncertainties as described in Section (4.3) of the FSAR.

b. A nominal (21) inch center-to-center distance between fuel assemblies placed in the storage racks.

5.6.1.2 The $k_{\text {eff }}$ for new fuel for the first core loading stored dry in the spent fuel storage racks shall not exceed $(0.98)$ when aqueous foam moderation is assumed.

\section{DRAINAGE}

5.6.2 The spent fuel storage pool is designed and shall be maintained to prevent inadvertent draining of the pool below elevation

\section{CAPACITY}

5.6.3 The spent fuel storage pool is designed and shall be maintained with a storage capacity limited to no more than fuel assemblies.

\subsection{COMPONENT CYCLIC OR TRANSIENT LIMIT}

5.7.1 The components identified in Table 5.7-1 are designed and shall be maintained within the cyclic or transient limits of Table 5.7-1. 


\section{COMPONENT CYCLIC OR TRANSIENT LIMITS}

COMPONENT

Reactor Coolant System

ón

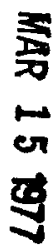

\section{CYCLIC OR}

TRANSIENT LIMIT

(250) heatup cycles at $<100^{\circ} \mathrm{F} / \mathrm{hr}$ and (250) cooldown cyclēs at $<100^{\circ} \mathrm{F} / \mathrm{hr}$

(250) pressurizer cooldown cycles at $\leq 200^{\circ} \mathrm{F} / \mathrm{hr}$

(100) loss of load cycles, without immediate turbine or reactor trip.

(50) cycles of loss of offsite A.C. electrical power.

(100) cycles of loss of flow in one reactor coolant loop.

(500) reactor trip cycles.

(10) inadvertent auxiliary spray actuation cycles.
DESIGN CYCLE

OR TRANSIENT

Heatup cycle - $\mathrm{T}_{\text {avg }}$ from $\leq 200^{\circ} \mathrm{F}$

to $>550^{\circ} \mathrm{F}$

Coōidown cycle - $\mathrm{T}_{\text {avg from }}$

$\geq 550^{\circ} \mathrm{F}$ to $\leq 200^{\circ} \mathrm{F}$.

Pressurizer cooldown cycle temperatures from $\geq 650^{\circ} \mathrm{F}$ to $\leq 200^{\circ} \mathrm{F}$.

$>15 \%$ of RATED THERMAL POWER to $\overline{0} \%$ of RATED THERMAL POWER.

Loss of offsite A.C. electrical ESF Electrical System.

Loss of only one reactor coolant pump.

$100 \%$ to $0 \%$ of RATED THERMAL POWER.

Spray water temperature differential $>320^{\circ} \mathrm{F}$. 
SECTION 6.0

ADMINISTRATIVE CONTROLS 
-

-

• 


\subsection{RESPONSIBILITY}

6.1.1 The (Plant Superintendent) shall be responsible for overallunit operation and shall delegate in writing the succession to this responsibility during his absence.

\subsection{ORGANIZATION}

\section{OFFSITE}

6.2.1 The offsite organization for unit management and technical support shall be as shown on Figure 6.2-1.

\section{UNIT STAFF}

6.2.2 The Unit organization shall be as shown on Figure 6.2-2 and:

a. Each on duty shift shall be composed of at least the minimum shift crew composition shown in Table 6.2-1.

b. At least one licensed Operator shall be in the control room when fuel is in the reactor.

c. At least two licensed Operators shall be present in the control room during reactor start-up, scheduled reactor shutdown and during recovery from reactor trips.

d. An individual qualified in radiation protection procedures shall be on site when fuel is in the reactor.

e. All CORE ALTERATIONS shall be directly supervised by either a licensed Senior Reactor Operator or Senior Reactor Operator Limited to Fuel Handling who has no other concurrent responsibilities during this operation.

f. A site Fire Brigade of at least 5 members shall be maintained onsite at all times\#. The Fire Brigade shall not include (3) members of the minimum shift crew necessary for safe shutdown of the unit and any personnel required for other essential functions during a fire emergency.

\footnotetext{
\#Fire Brigade composition may be less than the minimum requirements for a period of time not be exceed 2 hours in order to accommodate unexpected absence of Fire Brigade members provided immediate action is taken to restore the Fire Brigade to within the minimum requirements.
} 
This figure shall show the organizational structure and lines of responsibility for the offsite groups that provide technical and management support for the unit. The organizational arrangement for performance and monitoring Quality Assurance activities should also be indicated.

Figure 6.2-1

OFFSITE ORGANIZATION 
This figure shall show the organizational structure and lines of responsibility for the unit staff.

Positions to be staffed by licensed personnel should be indicated.

Figure 6.2-2

UNIT ORGANIZATION 
TABLE 6.2-1

MINIMUM SHIFT CREW COMPOSITION\#

\begin{tabular}{|l|c|c|}
\hline \multirow{2}{*}{$\begin{array}{l}\text { LICENSE } \\
\text { CATEGORY }\end{array}$} & \multicolumn{2}{|c|}{ APPLICABLE MODES } \\
\cline { 2 - 3 } & $1,2,3 \& 4$ & $5 \& 6$ \\
\hline SOL & 1 & $1^{*}$ \\
\hline OL & 2 & 1 \\
\hline Non-Licensed & 2 & 1 \\
\hline
\end{tabular}

* Does not include the licensed Senior Reactor Operator or Senior Reactor Operator Limited to Fuel Handling, supervising CORE ALTERATIONS.

\# Shift crew composition may be less than the minimum requirements for a period of time not to exceed 2 hours in order to accommodate unexpected absence of on duty shift crew members provided immediate action is taken to restore the shift crew composition to within the minimum requirements of Table $6.2-1$. 


\subsection{UNIT STAFF QUALIFICATIONS}

Minimum qualifications for members of the unit staff may be specified by use of an overall qualification statement referencing ANSI N18.1-1971 orr alternately by specifying individual position qualifications. Generally, the first method is preferable; however, the second method is adaptable to those unit staffs requiring special qualification statements because of a unique organizational structure.

6.3.1 Each member of the unit staff shall meet or exceed the minimum qualifications of ANSI N18.1-1971 for comparable positions, except for the (Radiation Protection Manager) who shall meet or exceed the qualifications of Regulatory Guide 1.8, September 1975.

\subsection{TRAINING}

6.4.1 A retraining and replacement training program for the unit staff shall be maintained under the direction of the (position title) and shall meet or exceed the requirements and recommendations of Section 5.5 of ANSI N18.1-1971 and Appendix "A" of 10 CFR Part 55.

6.4.2 A training program for the Fire Brigade shall be maintained under the direction of the (position title) and shall meet or exceed the requirements of Section 27 of the NFPA Code-1975, except for Fire Brigade training sessions which shall be held at least once per 92 days.

\subsection{REVIEW AND AUDIT}

The method by which independent review and audit of facility operations is accomplished may take one of several forms. The licensee may either assign this function to an organizational unit separate and independent from the group having responsibility for unit operation or may utilize a standing committee composed of individuals from within and outside the licensee's organization.

Irrespective of the method used, the licensee shall specify the details of each functional element provided for the independent review and audit process as illustrated in the following example specifications.

\subsubsection{UNIT REVIEW GROUP (URG)}

\section{FUNCTION}

6.5.1.1 The (Unit Review Group) shall function to advise the (Plant Superintendent) on all matters related to nuclear safety. 


\section{COMPOSITION}

\subsubsection{The (Unit Review Group) shall be composed of the:}

$\begin{array}{ll}\text { Chairman: } & \text { (Plant Superintendent) } \\ \text { Member: } & \text { (Operations Supervisor) } \\ \text { Member: } & \text { (Technical Supervisor) } \\ \text { Member: } & \text { (Maintenance Supervisor) } \\ \text { Member: } & \text { (Plant Instrument and Control Engineer) } \\ \text { Member: } & \text { (Plant Nuclear Engineer) } \\ \text { Member: } & \text { (Health Physicist) }\end{array}$

\section{ALTERNATES}

6.5.1.3 All alternate members shall be appointed in writing by the (URG) Chairman to serve on a temporary basis; however, no more than two alternates shall participate as voting members in (URG) activities at any one time.

\section{MEETING FREQUENCY}

6.5.1.4 The (URG) shall meet at least once per calendar month and as convened by the (URG) Chairman or his designated alternate.

\section{QUORUM}

6.5.1.5 The minimum quorum of the (URG) necessary for the performance of the (URG) responsibility and authority provisions of these technical specifications shall consist of the Chairman or his designated alternate and four members including alternates.

\section{RESPONSIBILITIES}

6.5.1.6 The (Unit Review Group) shall be responsible for:

a. Review of 1) all procedures required by Specification 6.8 and changes thereto, 2) any other proposed procedures or changes thereto as determined by the (Plant Superintendent) to affect nuclear safety.

b. Review of all proposed tests and experiments that affect nuclear safety.

c. Review of all proposed changes to Appendix "A" Technical Specifications.

d. Review of all proposed changes or modifications to unit systems or equipment that affect nuclear safety. 
e. Investigation of all violations of the Technical Specifications including the preparation and forwarding of reports covering evaluation and recommendations to prevent recurrence to the (Superintendent of Power Plants) and to the (Company Nuclear Review and Audit Group).

f. Review of events requiring 24 hour written notification to the Commission.

g. Review of unit operations to detect potential nuclear safety hazards.

h. Performance of special reviews, investigations or analyses and reports thereon as requested by the ( $P$ lant Superintendent) or the (Com,lany Nuclear Review and Audit Group).

i. Review of the Security Plan and implementing procedures and shall submit recommended changes to the (Company Nuclear Review and Audit Group).

j. Review of the Emergency Plan and implementing procedures and shall submit recommended changes to the (Company Nuclear Review and Audit Group).

\section{AUTHORITY}

6.5.1.7 The (Unit Review Group) shal1:

a. Recommend in writing to the (Plant Superintendent) approval or disapproval of items considered under 6.5.1.6(a) through (d) above.

b. Render determinations in writing with regard to whether or not each item considered under 6.5.1.6(a) through (e) above constitutes an unreviewed safety question.

c. Provide written notification within 24 hours to the (Superintendent of Power Plants) and the (Company Nuclear Review and Audit Group) of disagreement between the (URG) and the (Plant Superintendent); however, the (Plant Superintendent) shall have responsibility for resolution of such disagreements pursuant to 6.1.1 above.

$\underline{\text { RECORDS }}$

6.5.1.8 The (Unit Review Group) shall maintain written minutes of each (URG) meeting that, at a minimum, document the results of all (URG) activities performed under the responsibility and authority provisions of these technical specifications. Copies shall be provided to the (Superintendent of Power Plants) and the (Company Nuclear Review and Audit Group). 


\subsubsection{COMPANY NUCLEAR REVIEW AND AUDIT GROUP (CNRAG)}

\section{FUNCTION}

6.5.2.1 The (Company Nuclear Review and Audit Group) shal1 function to provide independent review and audit of designated activities in the areas of:
a. nuclear power plant operations
b. nuclear engineering
c. chemistry and radiochemistry
d. metallurgy
e. instrumentation and control
f. radiological safety
g. mechanical and electrical engineering
h. quality assurance practices
i. (other appropriate fields associated with the unique characteristics of the nuclear power plant)

\section{COMPOSITION}

6.5.2.2 The (CNRAG) shall be composed of the:

$\begin{array}{ll}\text { Director: } & \text { (Position Title) } \\ \text { Member: } & \text { (Position Title) } \\ \text { Member: } & \text { (Position Title) } \\ \text { Member: } & \text { (Position Title) } \\ \text { Member: } & \text { (Position Title) }\end{array}$

\section{ALTERNATES}

6.5.2.3 All alternate members shall be appointed in writing by the (CNRAG) Director to serve on a temporary basis; however, no more than two alternates shall participate as voting members in (CNRAG) activities at any one time.

\section{CONSULTANTS}

6.5.2.4 Consultants shall be utilized as determined by the (CNRAG) Director to provide expert advice to the (CNRAG). 


\section{MEETING FREQUENCY}

6.5.2.5 The (CNRAG) shall meet at least once per calendar quarter during the initial year of unit operation following fuel loading and at least once per six months thereafter.

\section{QUORUM}

6.5.2.6 The minimum quorum of the (CNRAG) necessary for the performance of the (CNRAG) review and audit functions of these technical specifications shall consist of the Director or his designated alternate and (at least 4 CNRAG) members including alternates. No more than a minority of the quorum shall have line responsibility for operation of the unit.

\section{REVIEW}

\subsubsection{The (CNRAG) shall review:}

a. The safety evaluations for 1) changes to procedures, equipment or systems and 2) tests or experiments completed under the provision of Section 50.59, $10 \mathrm{CFR}$, to verify that such actions did not constitute an unreviewed safety question.

b. Proposed changes to procedures, equipment or systems which involve an unreviewed safety question as defined in Section 50.59, 10 CFR.

c. Proposed tests or experiments which involve an unreviewed safety question as defined in Section 50.59, 10 CFR.

d. Proposed changes to Technical Specifications or this Operating License.

e. Violations of codes, regulations, orders, Technical Specifications, license requirements, or of internal procedures or instructions having nuclear safety significance.

f. Significant operating abnormalities or deviations from normal and expected performance of unit equipment that affect nuclear safety.

g. Events requiring 24 hour written notification to the Commission.

h. All recognized indications of an unanticipated deficiency in some aspect of design or operation of structures, systems, or components that could affect nuclear safety.

i. Reports and meetings minutes of the (Unit Review Group). 
AUDITS

6.5.2.8 Audits of unit activities shall be performed under the cognizance of the (CNRAG). These audits shall encompass:

a. The conformance of unit operation to provisions contained within the Technical Specifications and applicable license conditions at least once per 12 months.

b. The performance, training and qualifications of the entire unit staff at least once per 12 months.

c. The results of actions taken to correct deficiencies occurring in unit equipment, structures, systems or method of operation that affect nuclear safety at least once per 6 months.

d. The performance of activities required by the Operational Quality Assurance Program to meet the criteria of Appendix "B", 10 CFR 50, at least once per 24 months.

e. The Emergency Plan and implementing procedures at least once per 24 months.

f. The Security Plan and implementing procedures at least once per 24 months.

g. Any other area of unit operation considered appropriate by the (CNRAG) or the (Vice President Operations).

h. The Fire Protection Program and implementing procedures at least once per 24 months.

i. An independent fire protection and loss prevention inspection and audit shall be performed annually utilizing either qualified offsite licensee personnel or an outside fire protection firm.

j. An inspection and audit of the fire protection and loss prevention program sha 11 be performed, by an outside qualified fire consultant at intervals no greater than 3 years.

\section{AUTHORITY}

6.5.2.9 The (CNRAG) shall report to and advise the (Vice President Operations) on those areas of responsibility specified in Sections 6.5.2.7 and 6.5.2.8. 


\section{$\underline{\text { RECORDS }}$}

6.5.2.10 Records of (CNRAG) activities shall be prepared, approved and distributed as indicated below:

a. Minutes of each (CNRAG) meeting shall be prepared, approved and forwarded to the (Vice President-Operations) within 14 days following each meeting.

b. Reports of reviews encompassed by Section 6.5.2.7 above, shall be prepared, approved and forwarded to the (Vice President-Operations) within 14 days following completion of the review.

c. Audit reports encompassed by Section 6.5.2.8 above, shall be forwarded to the (Vice President-Operations) and to the management positions responsible for the areas audited within 30 days after completion of the audit by the auditing organization.

\subsection{REPORTABLE OCCURPEENCE ACTION}

6.6.1 The following actions shall be taken for REPORTABLE OCCURRENCES:

a. The Commission shall be notified and/or a report submitted pursuant to the requirements of Specification 6.9 .

b. Each REPORTABLE OCCURRENCE requiring 24 hour notification to the Commission shall be reviewed by the (URG) and submitted to the (CNRAG) and the (Superintendent of Power Plants).

\subsection{SAFETY LIMIT VIOLATION}

6.7.1 The following actions shall be taken in the event a Safety Limit is violated:

a. The unit shall be placed in at least HOT STANDBY within one hour.

b. The Safety Limit violation shall be reported to the Commission, the (Superintendent of Power Plants) and to the (CNRAG) within 24 hours.

c. A Safety Limit Violation Report shall be prepared. The report shall be reviewed by the (URG). This report shall describe (1) applicable circumstances preceding the violation, (2) effects of the violation upon facility components, systems or structures, and (3) corrective action taken to prevent recurrence.

d. The Safety Limit Violation Report shall be submitted to the Commission, the (CNRAG) and the (Superintendent of Power Plants) within 14 days of the violation. 


\subsection{PROCEDURES}

6.8.1 Written procedures shall be established, implemented and maintained covering the activities referenced below:
a. The applicable procedures recommended in Appendix "A" of Regulatory Guide 1.33, Revision 2, February 1978.
b. Refueling operations.
c. Surveillance and test activities of safety related equipment.
d. Security Plan implementation.
e. Emergency Plan implementation.
f. Fire Protection Program implementation.

6.8.2 Each procedure of 6.8.1 above, and changes thereto, shall be reviewed by the (URG) and approved by the (Plant Superintendent) prior to implementation and reviewed periodically as set forth in administrative procedures.

\subsubsection{Temporary changes to procedures of 6.8 .1 above may be made provided:}

a. The intent of the original procedure is not altered.

b. The change is approved by two members of the plant management staff, at least one of whom holds a Senior Reactor Operator's License on the unit affected.

c. The change is documented, reviewed by the (URG) and approved by the (Plant Superintendent) within 14 days of implementation.

\subsection{REPORTING REQUIREMENTS}

\section{ROUTINE REPORTS AND REPORTABLE OCCURRENCES}

6.9.1 In addition to the applicable reporting requirements of Title 10 , Code of Federal Regulations, the following reports shall be submitted to the Director of the Regional Office of Inspection and Enforcement unless otherwise noted.

\section{STARTUP REPORT}

6.9.1.1 A summary report of plant startup and power escalation testing shall be submitted following (1) receipt of an operating license, (2) amendment to the license involving a planned increase in power level, (3) installation of fuel that has a different design or has been manufactured by a different fuel supplier, and (4) modifications that may have significantly altered the nuclear, thermal, or hydraulic performance of the plant. 
6.9.1.2 The startup report shall address each of the tests identified in the FSAR and shall include a description of the measured values of the operating conditions or characteristics obtained during the test program and a comparison of these values with design predictions and specifications. Any corrective actions that were required to obtain satisfactory operation shall also be described. Any additional specific details required in license conditions based on other commitments shall be included in this report.

6.9.1.3 Startup reports shall be submitted within (1) 90 days following completion of the startup test program, (2) 90 days following resumption or commencement of commercial power operation, or (3) 9 months following initial criticality, whichever is earliest. If the Startup Report does not cover all three events (i.e., initial criticality, completion of startup test program, and resumption or commencement of commercial operation) supplementary reports shall be submitted at least every three months until all three events have been completed.

\section{ANNUAL REPORTS-1/}

6.9.1.4 Annual reports covering the activities of the unit as described below for the previous calendar year shall be submitted prior to March 1 of each year. The initial report shall be submitted prior to March 1 of the year following initial criticality.

6.9.1.5 Reports required on an annual basis shall include:

a. A tabulation on an annual basis of the number of station, utility, and other personnel (including contractors) receiving exposures greater than $100 \mathrm{mrem} / \mathrm{yr}$ and their associated manrem exposure according to work and job functions, $2 /$ e.g., reactor operations and surveillance, inservice inspection, routine maintenance, special maintenance (describe maintenance), waste processing, and refueling. The dose assignments to various duty functions may be estimated based on pocket dosimeter, TLD, or film badge measurements. Small exposures totalling less than 20 percent of the individual total dose need not be accounted for. In the aggregate, at least 80 percent of the total whole body dose received from external sources should be assigned to specific major work functions.

I/A single submittal may be made for a multiple unit station. The submittal should combine those sections that are common to all units at the station.

2/This tabulation supplements the requirements of $\$ 20.407$ of 10 CFR Part 20 . 
b. The results of the core barrel movement monitoring activities performed during the report period. (CE units only).

c. (Any other unit unique reports required on an annual basis.)

\section{MONTHLY OPERATING REPORT}

6.9.1.6 Routine reports of operating statistics and shutdown experience shall be submitted on a monthly basis to the Director, Office of Management and Program Analysis, U.S. Nuclear Regulatory Commission, Washington, D.C. 20555, with a copy to the Regional Office of Inspection and Enforcement, no later than the 15th of each month following the calendar month covered by the report.

\section{REPORTABLE OCCURRENCES}

6.9.1.7 The REPORTABLE OCCURRENCES of Specifications 6.9.1.8 and 6.9.1.9 below, including corrective actions and measures to prevent recurrence, shall be reported to the NRC. Supplemental reports may be required to fully describe final resolution of occurrence. In case of corrected or supplemental reports, a licensee event report shall be completed and reference shall be made to the original report date.

\section{PROMPT NOTIFICATION WITH WRITTEN FOLLOWUP}

6.9.1.8 The types of events listed below shall be reported within 24 hours by telephone and confirmed by telegraph, mailgram, or facsimile transmission to the Director of the Regional Office, or his designate no later than the first working day following the event, with a written followup report within 14 days. The written followup report shall include, as a minimum, a completed copy of a licensee event report form. Information provided on the licensee event report form shall be supplemented, as needed, by additional narrative material to provide complete explanation of the circumstances surrounding the event.

a. Failure of the reactor protection system or other systems subject to limiting safety system settings to initiate the required protective function by the time a monitored parameter reaches the setpoint specified as the limiting safety system setting in the technical specifications or failure to complete the required protective function.

b. Operation of the unit or affected systems when any parameter or operation subject to a limiting condition for operation is less conservative than the least conservative aspect of the limiting condition for operation established in the technical specifications.

c. Abnormal degradation discovered in fuel cladding, reactor coolant pressure boundary, or primary containment. 
d. Reactivity anomalies involving disagreement with the predicted value of reactivity balance under steady state conditions during power operation greater than or equal to $1 \% \Delta \mathrm{k} / \mathrm{k}$; a calculated reactivity balance indicating a SHUTDOWN MARGIN less conservative than specified in the technical specifications; short-term reactivity increases that correspond to a reactor period of less than 5 seconds or, if subcritical, an unplanned reactivity insertion of more than $0.5 \%$ $\Delta \mathrm{k} / \mathrm{k}$; or occurrence of any unplanned criticality.

e. Failure or malfunction of one or more components which prevents or could prevent, by itself, the fulfillment of the functional requirements of system(s) used to cope with accidents analyzed in the SAR.

f. Personnel error or procedural inadequacy which prevents or could prevent, by itself, the fulfillment of the functional requirements of systems required to cope with accidents analyzed in the SAR.

g. Conditions arising from natural or man-made events that, as a direct result of the event require unit shutdown, operation of safety systems, or other protective measures required by technical specifications.

h. Errors discovered in the transient or accident analyses or in the methods used for such analyses as described in the safety analysis report or in the bases for the technical specifications that have or could have permitted reactor operation in a manner less conservative than assumed in the analyses.

i. Performance of structures, systems, or components that requires remedial action or corrective measures to prevent operation in a manner less conservative than assumed in the accident analyses in the safety analysis report or technical specifications bases; or discovery during unit life of conditions not specifically considered in the safety analysis report or technical specifications that require remedial action or corrective measures to prevent the existence or development of an unsafe condition.

\section{THIRTY DAY WRITTEN REPORTS}

6.9.1.9 The types of events listed below shall be the subject of written reports to the Director of the Regional Office within thirty days of occurrence of the event. The written report shall include, as a minimum, a completed copy of a licensee event report form. Information provided on the licensee event report form shall be supplemented, as needed, by additional narrative material to provide complete explanation of the circumstances surrounding the event. 
a. Reactor protection system or engineered safety feature instrument settings which are found to be less conservative than those established by the technical specifications but which do not prevent the fulfillment of the functional requirements of affected systems.

b. Conditions leading to operation in a degraded mode permitted by a limiting condition for operation or plant shutdown required by a limiting condition for operation.

c. Observed inadequacies in the implementation of administrative or procedural controls which threaten to cause reduction of degree of redundancy provided in reactor protection systems or engineered safety feature systems.

d. Abnormal degradation of systems other than those specified in 6.9.1.8. c above designed to contain radioactive material resulting from the fission process.

SPECIAL REPORTS

Special reports may be required covering inspections, test and maintenance activities. These special reports are determined on an individual basis for each unit and their preparation and submittal are designated in the Technical Specifications.

6.9.2 Special reports shall be submitted to the Director of the Office of Inspection and Enforcement Regional office within the time period specified for each report.

\subsection{RECORD RETENTION}

In addition to the applicable record retention requirements of Title 10 , Code of Federal Regulations, the following records shall be retained for at least the minimum period indicated.

6.10.1 The following records shall be retained for at least five years:

a. Records and logs of unit operation covering time interval at each power level.

b. Records and logs of principal maintenance activities, inspections, repair and replacement of principal items of equipment related to nuclear safety.

c. A11 REPORTABLE OCCURRENCES submitted to the Commission. 
d. Records of surveillance activities, inspections and calibrations required by these Technical Specifications.

e. Records of changes made to the procedures required by Specification 6.8.1.

f. Records of radioactive shipments.

g. Records of sealed source and fission detector leak tests and results.

h. Records of annual physical inventory of all sealed source material of record.

6.10.2 The following records shall be retained for the duration of the Unit Operating License:

a. Records and drawing changes reflecting unit design modifications made to systems and equipment described in the Final Safety Analysis Report.

b. Records of new and irradiated fuel inventory, fuel transfers and assembly burnup histories.

c. Records of radiation exposure for all individuals entering radiation control areas.

d. Records of gaseous and liquid radioactive material released to the environs.

e. Records of transient or operational cycles for those unit components identified in Table 5.7-1.

f. Records of reactor tests and experiments.

g. Records of training and qualification for current members of the unit staff.

h. Records of in-service inspections performed pursuant to these Technical Specifications.

i. Records of Quality Assurance activities required by the QA Manual.

j. Records of reviews performed for changes made to procedures or equipment or reviews of tests and experiments pursuant to 10 CFR 50.59 .

k. Records of meetings of the (URG) and the (CNRAG). 


\subsection{RADIATION PROTECTION PROGRAM}

Procedures for personnel radiation protection shall be prepared consistent with the requirements of 10 CFR Part 20 and shall be approved, maintained and adhered to for all operations involving personnel radiation exposure.

\subsection{HIGH RADIATION AREA (OPTIONAL)}

6.12.1 In 1ieu of the "control device" or "alarm signal" required by paragraph 20.203(c)(2) of 10 CFR 20, each high radiation area in which the intensity of radiation is greater than $100 \mathrm{mrem} / \mathrm{hr}$ but 1 ess than $1000 \mathrm{mrem} / \mathrm{hr}$ shall be barricaded and conspicuously posted as a high radiation area and entrance thereto shall be controlled by requiring issuance of a Radiation Work Permit*. Any individual or group of individuals permitted to enter such areas shall be provided with or accompanied by one or more of the following:

a. A radiation monitoring device which continuously indicates the radiation dose rate in the area.

b. A radiation monitoring device which continuously integrates the radiation dose rate in the area and alarms when a preset integrated dose is received. Entry into such areas with this monitoring device may be made after the dose rate level in the area has been established and personnel have been made knowledgeable of them.

c. An individual qualified in radiation protection procedures who is equipped with a radiation dose rate monitoring device. This individual shall be responsible for providing positive control over the activities within the area and shall perform periodic radiation surveillance at the frequency specified by the facility Health Physicist in the Radiation Work Permit.

6.12.2 The requirements of 6.12 .1 , above, shall also apply to each high radiation area in which the intensity of radiation is greater than 1000 $\mathrm{mrem} / \mathrm{hr}$. In addition, locked doors shall be provided to prevent unauthorized entry into such areas and the keys shall be maintained under the administrative control of the Shift Foreman on duty and/or the Plant Health Physicist.

*Health Physics personnel or personnel escorted by Health Physics personnel shall be exempt from the RWP issuance requirement during the performance of their assigned radiation protection duties, provided they comply with approved radiation protection procedures for entry into high radiation areas. 
UNITEO STATES

NUCLEAR REGULATORY COMMISSION WASHINGTON, D. C. 20555

$$
\begin{aligned}
& \text { POSTAGE AND FEESPAID } \\
& \text { S. NUCLEAR REGULATORY } \\
& \text { COMMISSION }
\end{aligned}
$$

